\title{
Lead Research and Development Activity for DOE's High Temperature, Low Relative Humidity Membrane Program (Topic 2)
}

DOE Award Number --- DE-FG36-06G016028

Principal Investigator: James Fenton University of Central Florida/Florida Solar Energy Center

Co-PIs

Darlene Slattery (Project Manager)

University of Central Florida/Florida Solar Energy Center

321-638-1449, dkslatt@fsec.ucf.edu

\author{
Nahid Mohajeri \\ University of Central Florida/Florida Solar Energy Center
}

Project Time Period: April 1, 2006 to May 31, 2012

FSEC-CR-1940-13 


\section{Executive Summary}

The Department of Energy's High Temperature, Low Relative Humidity Membrane Program was begun in 2006 with the Florida Solar Energy Center (FSEC) as the lead organization. During the first three years of the program, FSEC was tasked with developing non-Nafion ${ }^{\circledR}$ proton exchange membranes with improved conductivity for fuel cells. Additionally, FSEC was responsible for developing protocols for the measurement of in-plane conductivity, providing conductivity measurements for the other funded teams, developing a method for through-plane conductivity and organizing and holding semiannual meetings of the High Temperature Membrane Working Group (HTMWG).

The FSEC membrane research focused on the development of supported poly[perfluorosulfonic acid] (PFSA) - Teflon membranes and a hydrocarbon membrane, sulfonated poly(ether ether ketone). The fourth generation of the PFSA membrane (designated FSEC-4) came close to, but did not meet, the Go/No-Go milestone of 0.1 $\mathrm{S} / \mathrm{cm}$ at $50 \%$ relative humidity at $120^{\circ} \mathrm{C}$.

In-plane conductivity of membranes provided by the funded teams was measured and reported to the teams and DOE. Late in the third year of the program, DOE used this data and other factors to decide upon the teams to continue in the program. The teams that continued provided promising membranes to FSEC for development of membrane electrode assemblies (MEAs) that could be tested in an operating fuel cell. FSEC worked closely with each team to provide customized support. A logic flow chart was developed and discussed before MEA fabrication or any testing began.

Of the five teams supported, by the end of the project, membranes from two of the teams were easily manufactured into MEAs and successfully characterized for performance. One of these teams exceeded performance targets, while the other requires further optimization. An additional team developed a membrane that shows great promise for significantly reducing membrane costs and increasing membrane lifetime. 


\section{TABLE OF CONTENTS}

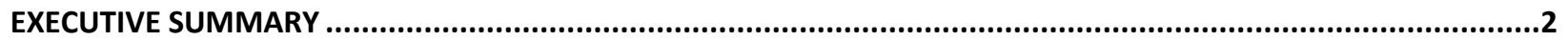

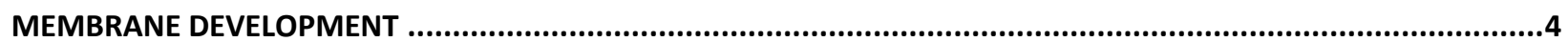

TASK 1: NON-NAFION ${ }^{\circledR}$ BASED PFSAS-PHOSPHOTUNGSTIC ACID COMPOSITE MEMBRANE AND MEA FABRICATION ........................

TASK 2. SPEKK AND/OR SPEEK-PHOSPHOTUNGSTIC ACID COMPOSITE MEMBRANE AND MEA FABRICATION..............................13

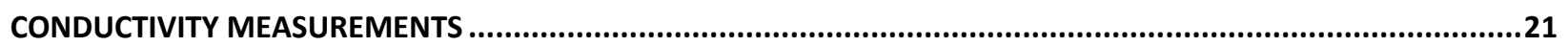

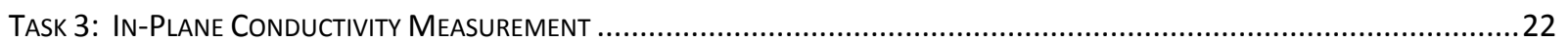

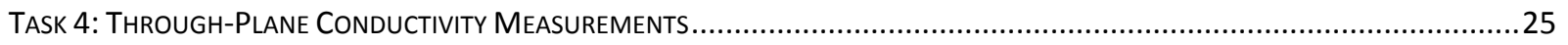

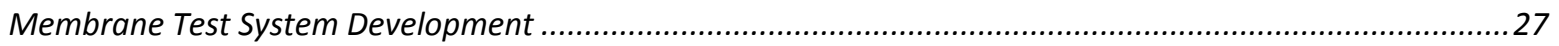

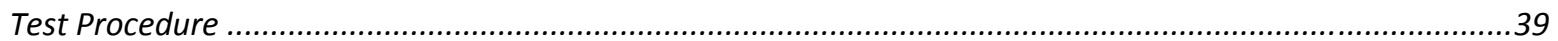

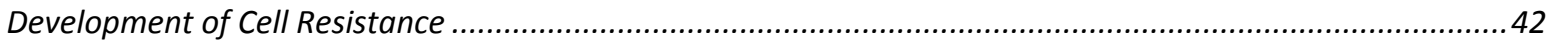

Procedure for Determination of the Sample Effective Cross-sectional Area ...................................................43

COMPARISON OF CONDUCTIVITY TESTING, IN-PLANE VERSUS THROUGH-PLANE .................................................................45

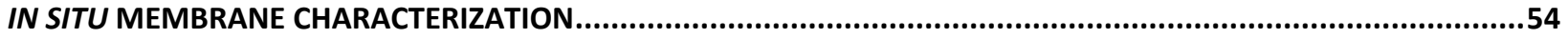

Task 5. Characterize Performance of Membrane Electrode Assemblies ..............................................................54

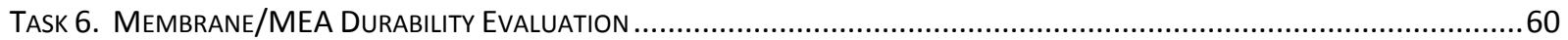

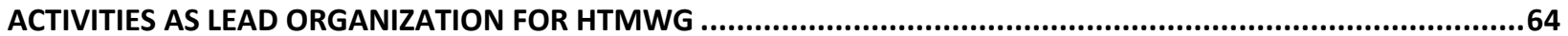

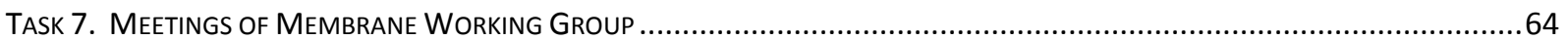

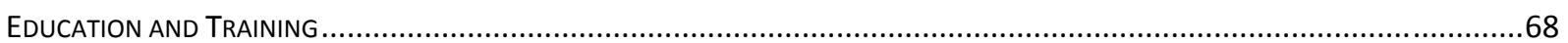

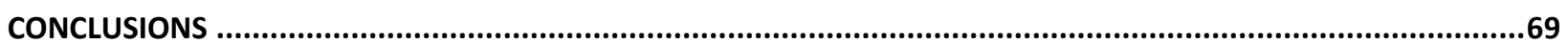

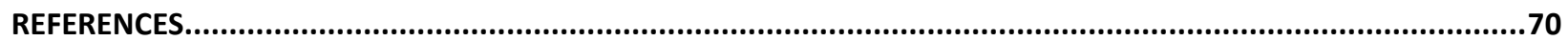

APPENDIX I: PROCEDURE FOR PERFORMING IN-PLANE MEMBRANE CONDUCTIVITY TESTING .......................... I-1

APPENDIX II: THROUGH-PLANE CONDUCTIVITY PROTOCOL .........................................................................

APPENDIX III: FSEC'S PROCEDURES FOR PERFORMING PEM SINGLE CELL TESTING......................................... III-0 


\section{Membrane Development}

The FOA required the Topic 2 awardee to have a membrane development program, as well as being responsible for the conductivity measurements and the fabrication and testing of membrane electrode assemblies (MEAs) using the Topic 1 winners' membranes. The Florida Solar Energy Center (FSEC) program concentrated on developing both non-Nafion based poly[perfluorosulfonic acids] (PFSAs) - Teflon membranes and sulfonated poly(ether ether ketone) and sulfonated poly(ether ketone ketone) membranes. The results from this membrane development work are discussed below in Tasks 1 and 2.

\section{Task 1: Non-Nafion® based PFSAs-Phosphotungstic Acid composite Membrane and MEA Fabrication}

A primary objective of Task 1 of the program was to fabricate composite membranes with properties superior to Nafion ${ }^{\circledR}$ based PFSA-Teflon ${ }^{\mathrm{TM}}$ membranes, building upon work established by the PI at the University of Connecticut. The membranes, which had been developed at the University of Connecticut in the Pl's lab before his move to the Florida Solar Energy Center (FSEC), were Nafion ${ }^{\circledR}$-based, containing a stabilized phosphotungstic acid, cast on Tetratex membrane (a.k.a. NTPA membrane and FSEC1 membrane). Their reproducibility at FSEC was confirmed before modifications were begun. This membrane had previously demonstrated good and stable conductivity in a 1000 hour test at a cell temperature of $100{ }^{\circ} \mathrm{C}$ while operating at $25 \%$ relative humidity. From the beginning of this program, it was clear that the humidity of Florida played a major role on quality of the cast membrane. Figure 1shows two membranes cast at two different relative humidities $(\mathrm{RH})$. In Figure 1A, the membrane was cast at $20 \% \mathrm{RH}$ and is transparent, while the membrane in Figure $1 \mathrm{~B}$ is opaque and was cast at $75 \%$ $\mathrm{RH}$.
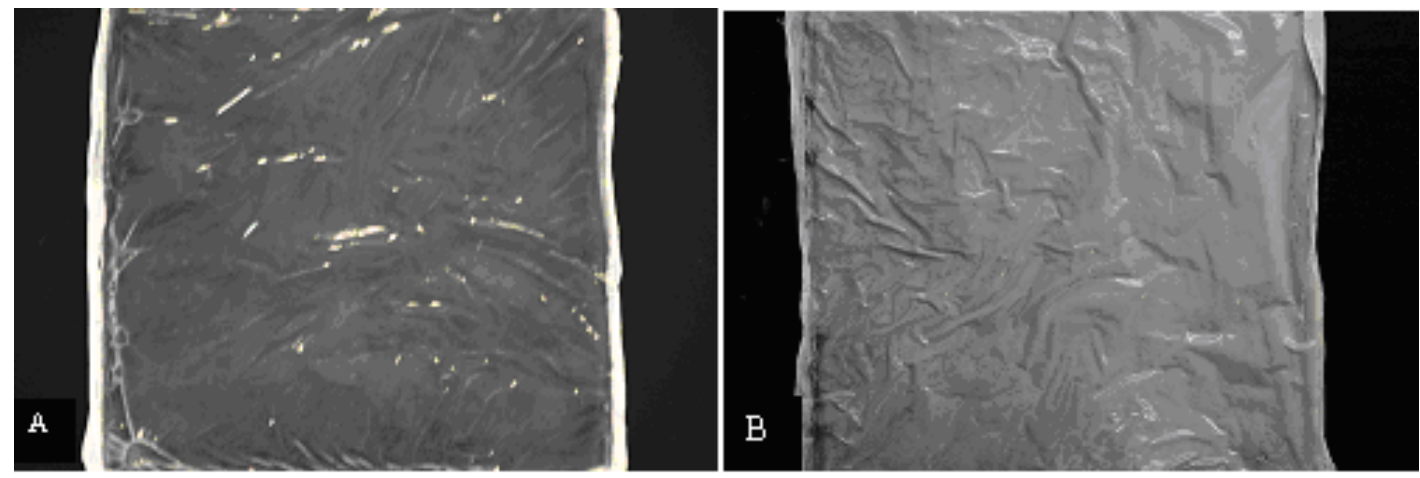

Figure 1. NTPA membrane cast at (A) $20 \% \mathrm{RH}$, (B) $75 \% \mathrm{RH}$

While the differences in conductivity between membranes cast at varying humidities had not been established, it was known that those that are transparent have good and reproducible characteristics. Because of the high Florida humidity, a dry box was fabricated for use in membrane preparation and all membranes were prepared under this controlled atmosphere with a $24-28 \%$ relative humidity. These membranes were, 
in fact, transparent. To determine if the membranes cast under low $\mathrm{RH}$ were better than the translucent ones, a series of experiments were run. Membranes were cast both inside and out of the dry box and then subjected to scanning electron microscopy (SEM), X-ray diffraction (XRD) and conductivity testing.

XRD was performed to observe changes in crystalline nature of the host Nafion ${ }^{\circledR}$ matrix due to changes in RH during cast process. Nafion ${ }^{\circledR}$ has a characteristic peak of $17^{\circ} 2 \theta$, largely attributed to the PTFE-like backbone. Nafion ${ }^{\circledR}$ has a largely amorphous nature while PTA is highly crystalline characterized by high activity peaks in the range of 5- 60 ${ }^{\circ} 2 \theta$, with peaks at 25 and $35^{\circ} 2 \theta$. As shown in Figure 2, the composite membrane nature turns more crystalline and it loses the characteristic $17^{\circ} 2 \Theta$ peak as casting relative humidity decreases. The XRD pattern for membranes cast at $60 \% \mathrm{RH}$ represents little PTA incorporation and a high Nafion ${ }^{\circledR}$ peak at $17^{\circ} 2 \theta$ whereas the membrane cast at $50 \% \mathrm{RH}$ has a lower $17^{\circ} 2 \Theta$ peak and matches well with XRD pattern for PTA. $6 \mathrm{H}_{2} \mathrm{O}$. Membranes cast at $40 \% \mathrm{RH}$ matched well with the PTA pattern with no water. Also the Full Width Half Maximum value for the $60 \% \mathrm{RH}$ membrane was $0.523^{\circ}$, for the $50 \% \mathrm{RH}$ membrane the value was $0.905^{\circ}$, and for the $40 \% \mathrm{RH}$ membrane, the value was $2.901^{\circ}$ (Figure 3 ). Hence the crystallinity of the membrane increases on reducing the casting relative humidity.

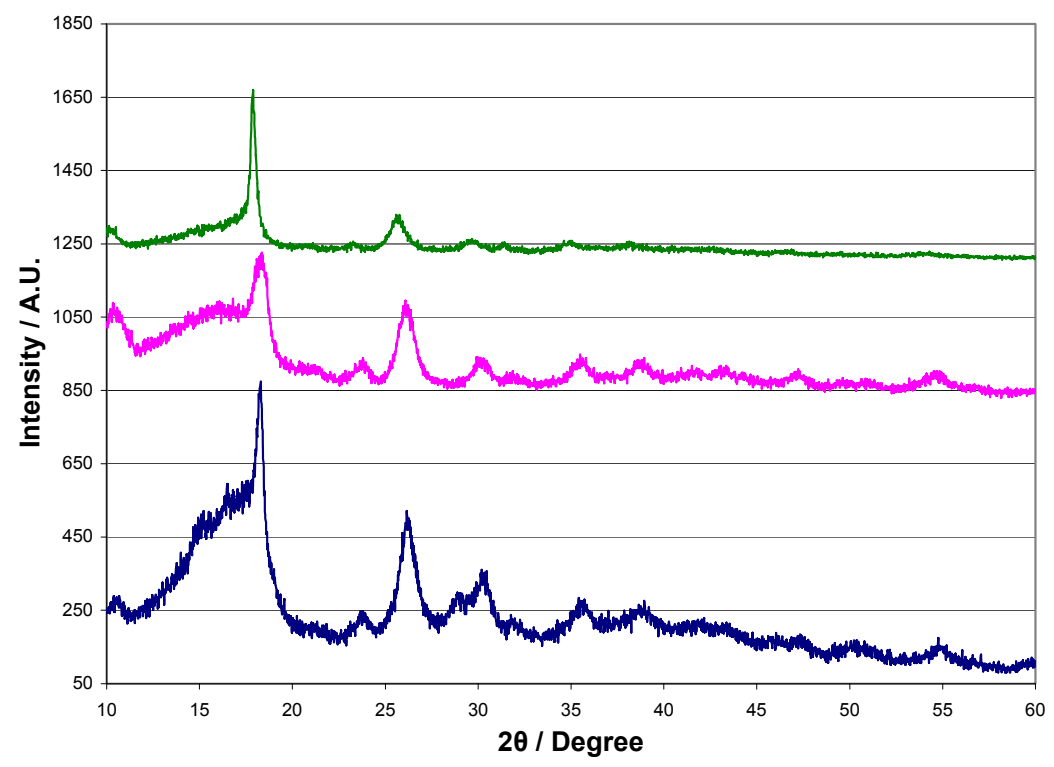

Figure 2. XRD pattern of NTPAs with $15 \%$ PTA at different relative humidity. The peak at $17^{\circ} 2 \theta$ is a characteristic of pure Nafion ${ }^{\circledR}$. Peak at $35^{\circ} 2 \theta$ is a characteristic PTA peak. As seen, Nafion ${ }^{\circledR}$ nature decreases steadily on increasing the PTA loading and the PTA peak becomes prominent. 


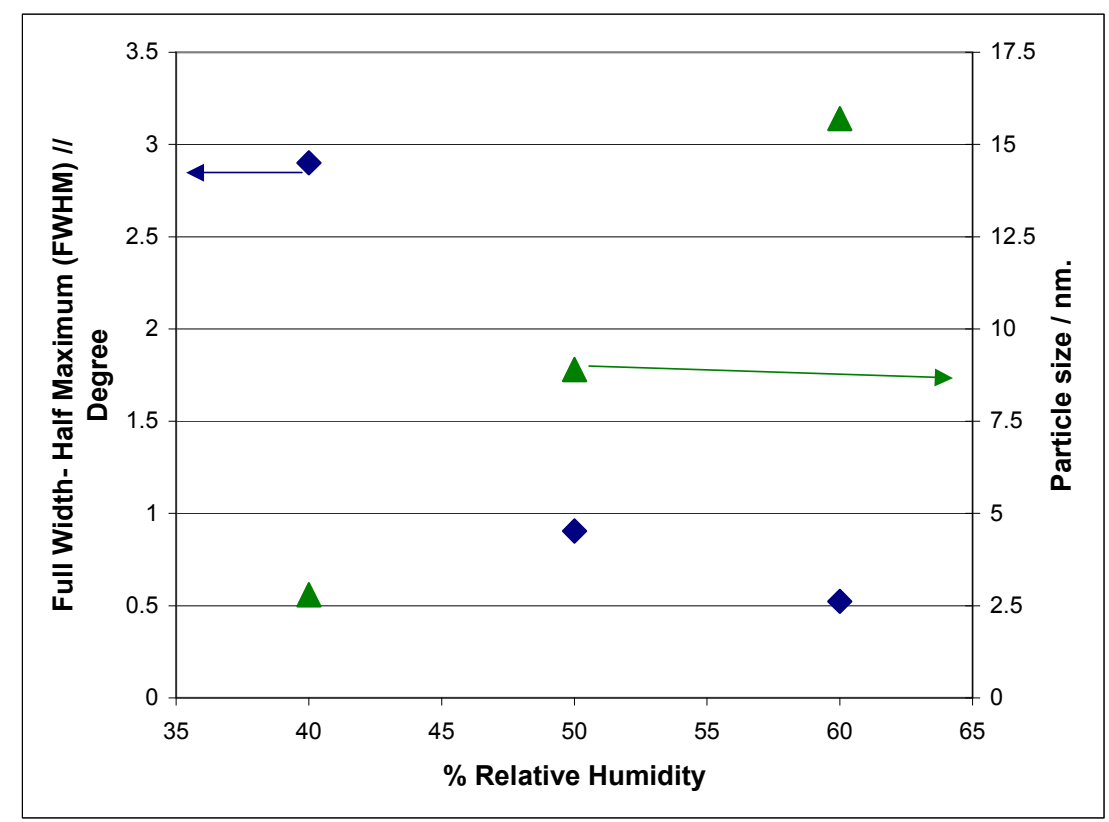

Figure 3. Full Width Half Maximum and particle size variation with increasing relative humidity while casting the membrane as measured by the $17^{\circ} 2 \theta$ peak. The particles coalesce together on increasing the relative humidity and the membranes have lower crystallinity.

To determine if there was also an influence on membrane function, conductivity tests were run on both membranes. As can be seen by the plots in Figure 4, the membrane cast at low $\mathrm{RH}$ showed an increased conductivity at $80^{\circ} \mathrm{C}$ and a humidity of less than $80 \%$.

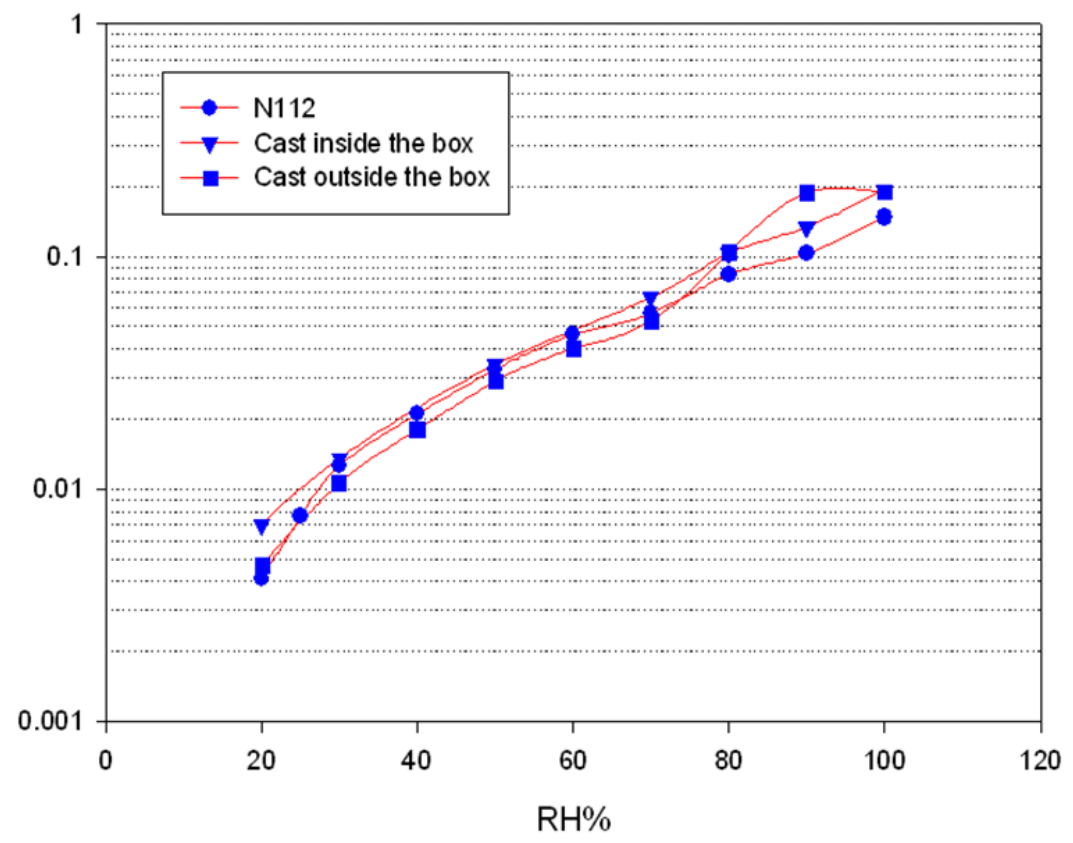

Figure 4. Conductivity of membranes cast at low and high RH 
After confirming the ability to cast 1100 equivalent weight (EW) ionomers, the procedure was modified to cast lower EW materials in order to increase the proton conductivity. The membranes containing the $1100 \mathrm{EW}$ ionomer and made using the procedure developed at UConn were named FSEC-1. Any variation from this procedure required that the resulting membranes be given a new designation. The table below describes these subsequent membranes and the following paragraphs describe their development.

\begin{tabular}{|l|l|l|}
\hline \multicolumn{1}{|c|}{ Membrane Designation } & \multicolumn{1}{|c|}{ lonomer } & \multicolumn{1}{c|}{ Comments } \\
\hline FSEC- 1 & $1100 \mathrm{EW}$ & UConn Technology \\
\hline FSEC-2 & $950 \mathrm{EW}$ & Cast with DMF \\
\hline FSEC- 3 & $750 \mathrm{EW}$ & $\begin{array}{l}\text { Cs treated before } \\
\text { catalyst application }\end{array}$ \\
\hline FSEC-3 & a & Cast with DMSO \\
\hline FSEC- 4 & $750 \mathrm{EW}$ & $\begin{array}{l}\text { See task } 2 \\
\text { sulfonated poly(ether ether } \\
\text { ketone) }\end{array}$ \\
\hline
\end{tabular}

${ }^{a}$ To prevent sulfonate group decomposition during the following thermal treatment (hotpressing), the membranes were ion-exchanged with $\mathrm{Cs}^{+}$by immersion in $0.05 \mathrm{M}$ cesium carbonate solution. Hot-pressing allows polymer chains to move and align themselves into an optimal structure.

Initial attempts to cast FSEC- 2 membranes resulted in membranes that did not have the integrity to survive the required handling of the multi-step, membrane casting procedure. Modifications that were made included changing the ratio of ethanol and dimethylformamide (DMF) in the casting solution. Additionally, the first side of the membrane was cured at $100-150^{\circ} \mathrm{C}$ before casting the other side. This helped with the membrane's mechanical strength during the casting process and with solubility.

Thermal Gravimetric Analysis (TGA) of the 950EW composite membrane showed a similar two-step degradation process compared to $1100 \mathrm{EW}$ composite membranes, Figure 5. However, the onset of the second degradation for the 950EW membrane had shifted to a lower temperature $\left(\sim 370^{\circ} \mathrm{C}\right)$ compared to $1100 \mathrm{EW}$ membrane at approximately $410^{\circ} \mathrm{C}$. 


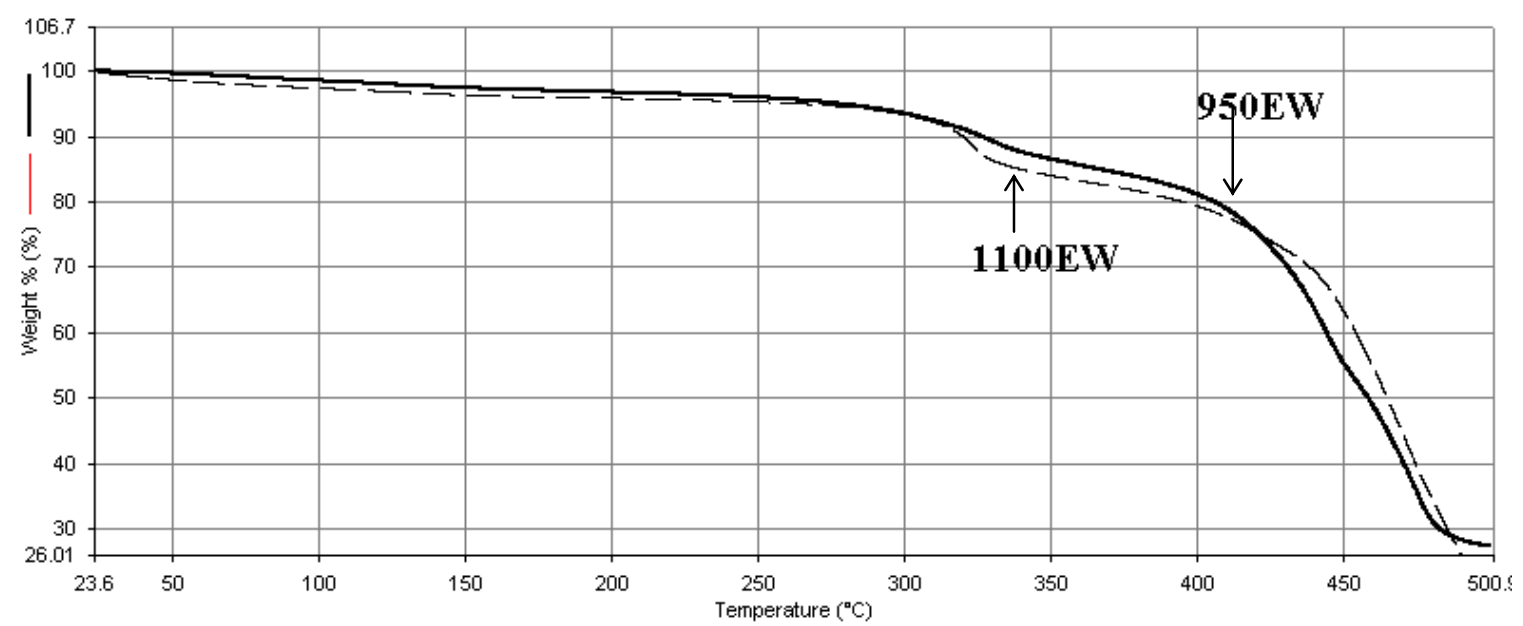

Figure 5. TGA Analysis of Composite Membranes

After experimenting with a 950EW ionomer, membranes were fabricated using a $750 \mathrm{EW}$ ionomer and designated FSEC- 3. The standard procedure for the fabrication of the catalyst coated membranes (CCMs) called for them to be cesium treated before being hot pressed. The $\mathrm{Cs}$ treatment converts the ionomer from the acid form to the salt form, making it more stable to the subsequent hot pressing. The hot pressing encourages more intimate contact between the catalyst layer and the membrane and increases the crystallinity within the membrane, leading to greater durability.

After the hot pressing, the CCM is converted back to the acid form by treatment overnight in an acid solution. During the fabrication of the FSEC-3 CCMs, it was observed that there was a loss of catalyst during the processing.

Repetition of the process resulted in the same loss of catalyst. To examine the loss of catalyst from the electrode during processing, a batch of $750 \mathrm{EW}$ ionomer (at $25 \mathrm{wt} \%$ ) ink was prepared and sprayed onto an FSEC-3 membrane (Brother) and Nafion ${ }^{\circledR} 112$ membrane (Sister). After processing, the FSEC-3 CCM had more holes and more scuff marks than the Nafion ${ }^{\circledR} 112$ CCM, although both showed signs of damage. It appeared that the membrane plays a role in how much damage the electrodes receive.

The loss of catalyst had likely been occurring to some extent for all CCMs, due mainly to the need for tweezers to hold the CCM submerged in the solutions. Exactly why damage appeared to be increased for the 750EW membranes and electrode was unknown. Perhaps decreasing equivalent weight increases agglomeration of the ionomer, so less ionomer covers each catalyst particle. Or perhaps the increased exchange capacity leads to increased cesium uptake, which may then alter the structure of the ionomer in the electrode. In any event, the $750 \mathrm{EW}$ electrodes were more fragile and required gentler handling. It is possible that the electrode structure was destroyed during the $\mathrm{Cs}+/$ heat treatment $/ \mathrm{H}+$ steps. To verify this, a modified procedure was defined to prevent the catalyst layer from experiencing these steps. Before applying the catalyst ink, the FSEC-3 membrane was treated with $0.1 \mathrm{~N} \mathrm{Cs}_{2} \mathrm{CO}_{3}$ solution, hotpressed and protonated. Subsequently, the catalyst ink was applied on the treated membrane. The CCM made in this way was identified as FSEC-3*. There was a 
considerable improvement in cell performance for FSEC- $3^{*}$ at all three conditions. At $120{ }^{\circ} \mathrm{C}, 35 \% \mathrm{RH}$, and $400 \mathrm{~mA} / \mathrm{cm}^{2}$, there was a performance increase of $200 \mathrm{mV}$ compared to that of FSEC-3. Since the cell was assembled without hot pressing the electrodes, there was concern that the durability of the membrane/electrode interface was impaired.

As work proceeded, questions arose as to the advantage of using PTA in the membranes. Tests at UConn had suggested that PTA increased conductivity. However, this needed to be confirmed and the optimal level of PTA ascertained. Membranes of varying PTA concentration were prepared and tested. The results, Figure 6, indicated that at $80^{\circ} \mathrm{C}$, the FSEC-3 membrane was more conductive than an NRE 212 membrane but that, within the range of concentration tested, the PTA concentration was not important. Furthermore, at $120^{\circ} \mathrm{C}$, the membrane with $25 \%$ PTA decreased in conductivity to roughly the level of the NRE 212.

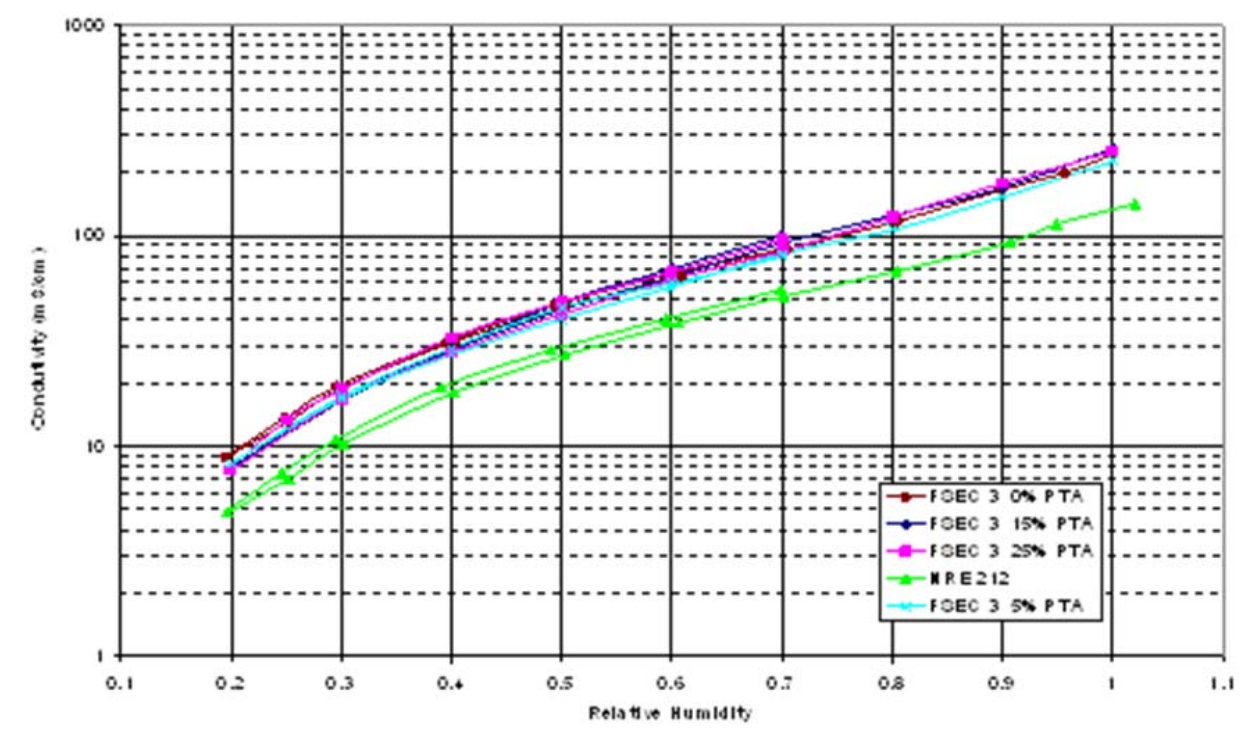

Figure 6. Conductivity measurements of 750 EW PFSA composite membranes with $0,5,15$, and $25 \%$ PTA compared to NRE 212 at $80^{\circ} \mathrm{C}$ 


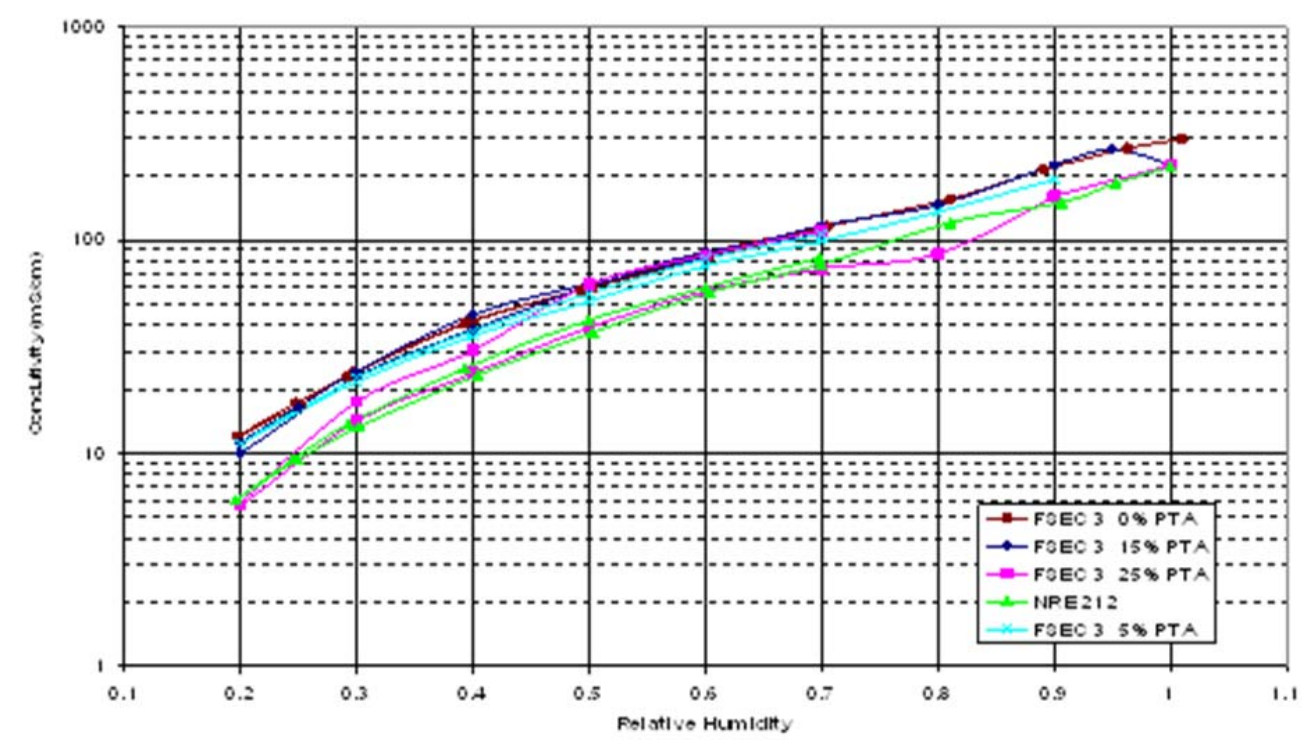

Figure 7. Conductivity measurements of 750 EW PFSA composite membranes with $0,5,15$, and $25 \%$ PTA compared to NRE 212 at $120^{\circ} \mathrm{C}$

To determine if these results were due to the in-plane analysis, which looks more at the surface of the material while the PTA is more in the bulk, samples of FSEC-1 (containing $1100 \mathrm{EW}$ ionomer) with varying PTA content were sent to Scribner for through-plane analysis (through-plane vs. in-plane conductivity will be discussed in detail in the section on Tasks 3 and 4, below). As can be seen in Figure 8 below, at each temperature, the membrane formulated to contain 25\% PTA resulted in lower conductivity than the sample fabricated without PTA. The difference is more pronounced at lower RH. This data supported previous research in the FSEC lab. However, the PTA was determined to have an effect on cell performance and durability. With increasing PTA concentration, MEAs showed that the amounts of crossover and OCV losses decrease. Additionally, the fluoride emission rate decreases with increasing PTA loading. 


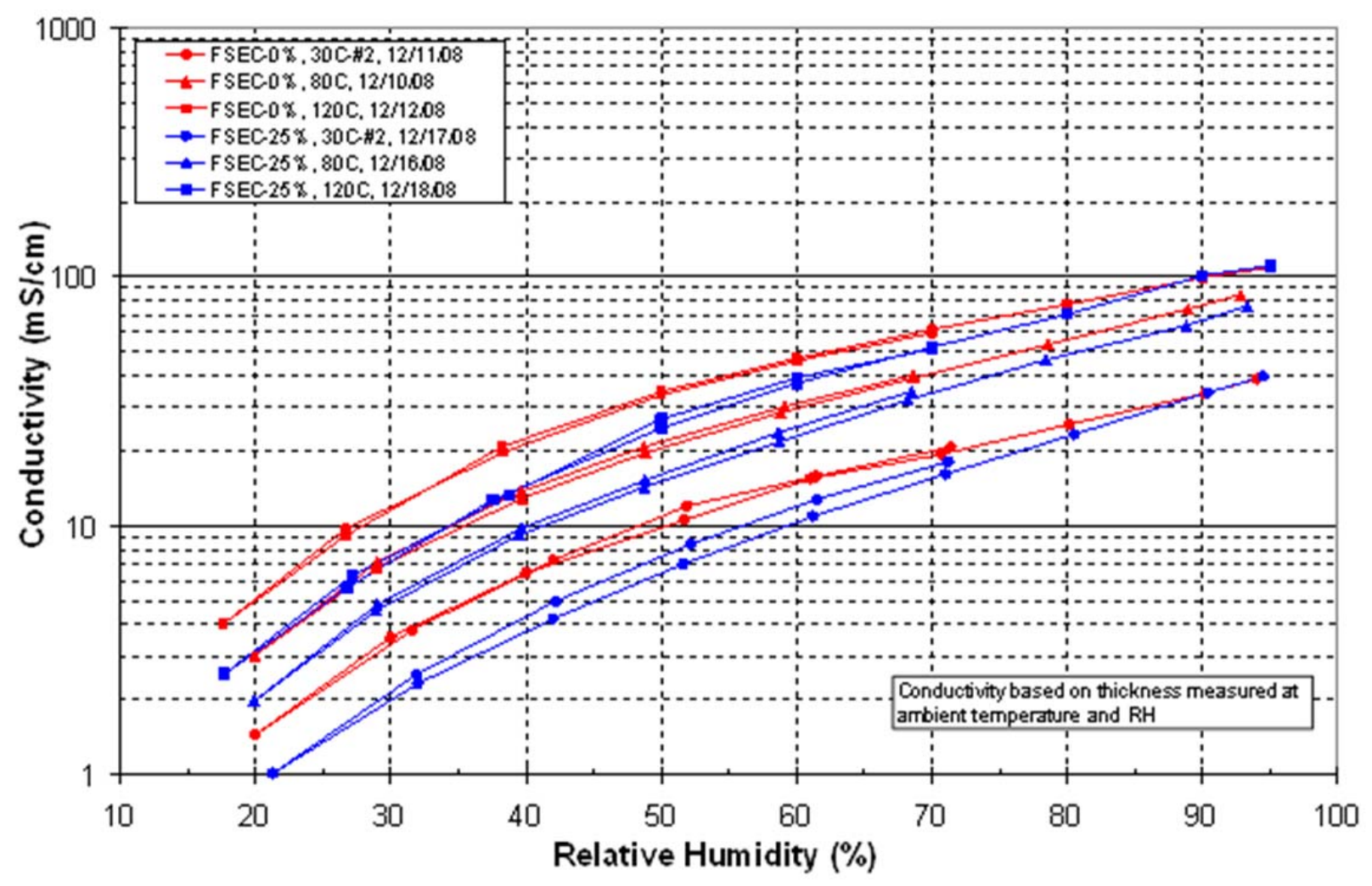

Figure 8. Through-Plane Conductivity of FSEC-1 with and Without PTA

Over the course of the membrane development, conductivity experiments indicated that conductivity could be correlated to the solvent used in the casting process. To determine the cause of this effect, additional experiments were conducted. Low equivalent weight perfluorosulfonic acid membranes were cast from polymer solutions made using combinations of different solvents such as, ethanol (EtOH), DMF, dimethylsulfoxide (DMSO), and water.

The solutions were analyzed using Dynamic Light Scattering (DLS) to determine ionomer particle sizes that vary due to different solvent-solute interactions. Furthermore, the solid membrane morphology was investigated by means of SmallAngle X-ray Scattering (SAXS). The effects of ionomer morphology and particle sizes on membrane's proton conductivity were studied.

It was found that there is a correlation between the arrangements of the polymer strands in solution to the resultant membrane morphology, which in turn has a large effect on its proton conductivity. Hence, the choice of solvent for the casting of membranes is of great importance.

The FSEC-3 membrane casting procedure was modified to take advantage of these results and fabricated with DMSO, rather than DMF. This membrane became the FSEC-4 membrane. Preliminary results on the conductivity indicated that FSEC-4 
would meet the Go/No-Go target. Unfortunately, those results could not be reproduced by BekkTech, who was responsible for the official measurements on conductivity.

It was hypothesized that the presence of the high boiling point solvents during hot pressing would prevent collapse of the hydrophilic domains because, unlike water, they would remain in the membranes even at temperatures above $100{ }^{\circ} \mathrm{C}$. To avoid conductivity losses due to hot pressing, proton exchange membranes were immersed in high-boiling solvents prior to hot pressing.

Two types of membranes, FSEC-1 (contains $1100 \mathrm{EW}$ ionomer) and FSEC-3 (contains $750 \mathrm{EW}$ ionomer), were hot pressed in the presence of high boiling point solvents. All membranes were Cs-treated overnight, soaked in water and then in DMF or $85 \%$ $\mathrm{H}_{3} \mathrm{PO}_{4}$. After processing, the in plane conductivity of each membrane was measured at 80 and $120^{\circ} \mathrm{C}$ and from 20 to $100 \% \mathrm{RH}$. The effects of saturating the membranes with phosphoric acid and DMF during hot pressing on membrane conductivity at $120{ }^{\circ} \mathrm{C}$ and 20 to $90 \%$ RH are plotted in Figure 9 and Figure 10, respectively. In both cases, using high-boiling point solvents significantly improved the conductivity of the membranes. For example, at $120{ }^{\circ} \mathrm{C}$ and $50 \% \mathrm{RH}$, the conductivities of FSEC-1 and FSEC-3 were both improved $20 \%$ through the use of phosphoric acid, while the conductivity of FSEC-1 was improved $30 \%$ through the use of DMF. Similar results were observed at $80^{\circ} \mathrm{C}$.

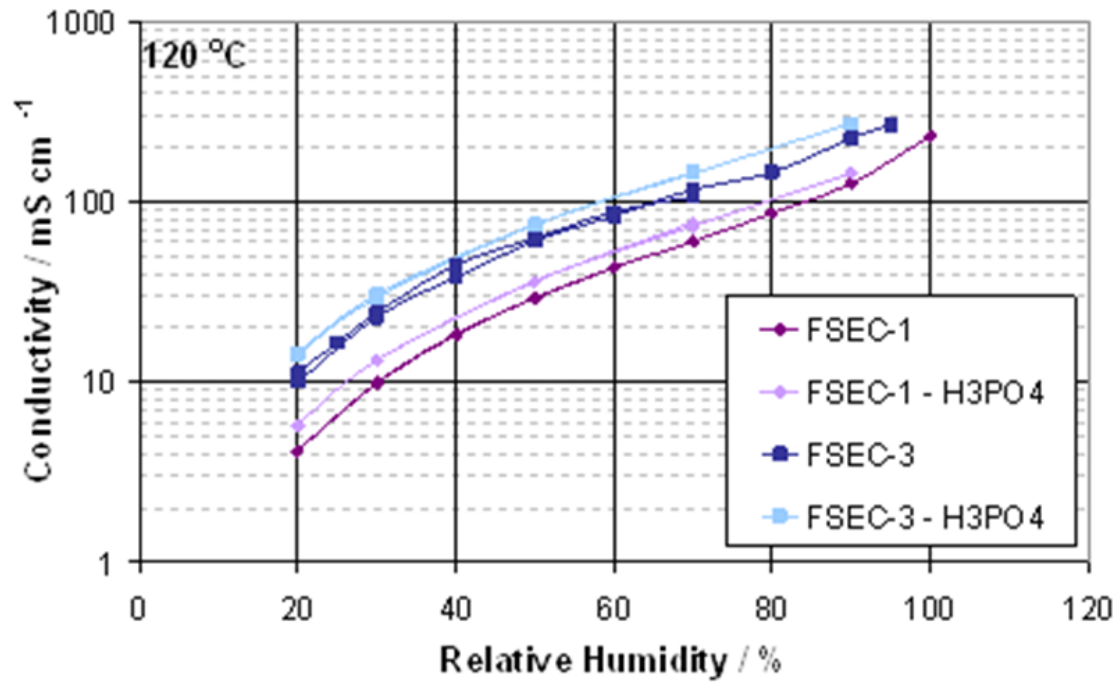

Figure 9. Membrane conductivity at $120{ }^{\circ} \mathrm{C}$ and from 20 to $100 \%$ RH using phosphoric acidsaturated membranes during hot pressing 


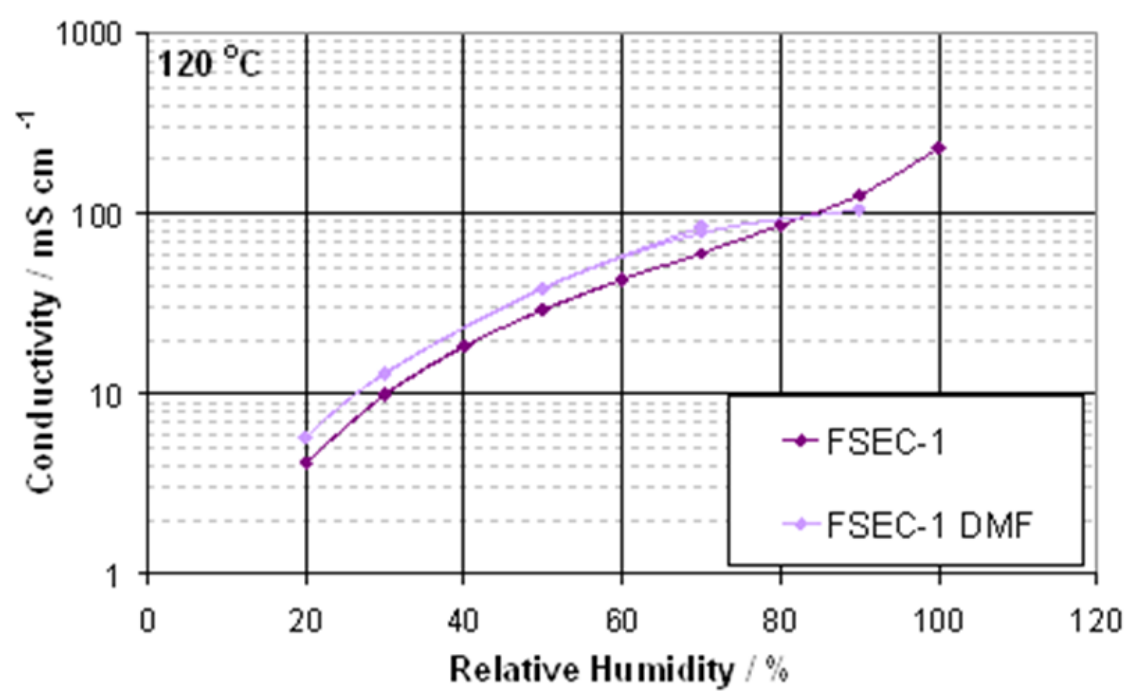

Figure 10. Membrane conductivity at $120{ }^{\circ} \mathrm{C}$ and from 20 to $100 \%$ RH using DMF saturated membranes during hot pressing.

\section{Task 2. SPEKK and/or SPEEK-Phosphotungstic Acid Composite Membrane and MEA Fabrication}

The objective of Task 2 was the preparation of cross-linked SPEEK, sulfonated poly(ether ether ketone) membranes. Sulfonated hydrocarbons are a low cost alternative to perfluorosulfonic acid membranes such as Nafion ${ }^{\circledR}$ for polymer electrolyte fuel cell. SPEEK was synthesized at three levels of sulfonation: $26 \%, 60 \%$, and $85 \%$, where the percent refers to the proportion of monomer units that contain sulfonic acid groups. Level of sulfonation was determined by titrimetric analysis. A higher level of sulfonation is desirable from the conductivity standpoint but can result in increased solubility and swelling, and, therefore, is not suitable for fuel cell membrane formation. The lowest sulfonation level is soluble in pure DMF, and represents virtually the lowest level obtainable without the polymer becoming intractable. The $60 \%$ sulfonation is soluble in hot DMF, and can tolerate a reasonable proportion of ethanol. The final level, $85 \%$, contains many acidic protons, but is also water soluble.

Water-soluble SPEEK was successfully rendered insoluble via crosslinking chemistry, without substantially increasing the equivalent weight (i.e., without tying up or otherwise removing sulfonic acid groups). Friedel-Crafts cross-linking of high sulfonation PEEK polymers was accomplished using 1,4-benzenedimethanol (BDM) following reported procedures for polymers with aromatic backbones similar to PEEK. ${ }^{1,2}$. Cross-linking utilizing high temperatures $\left(>150{ }^{\circ} \mathrm{C}\right)$ for cross-linking of polymers with aromatic backbone may produce polymer chains with increased chemical, thermal and mechanical properties. It was hypothesized that condensation of the hydroxyl groups on BDM, with the aromatic protons on the SPEEK polymer backbone would form characteristically strong covalent bonds; especially with highly conjugated systems ${ }^{2}$. The synthetic mechanism assumed for cross-linking is shown in Figure 11. To effectively initiate the solid state reaction it was necessary to heat the SPEEK/BDM/ZnCl 2 to $200{ }^{\circ} \mathrm{C}$ for $15 \mathrm{~min}$. To obtain maximum yield, a large excess of 
$\mathrm{ZnCl}_{2}$ was added to provide an excess of Friedel-Crafts active catalytic sites.
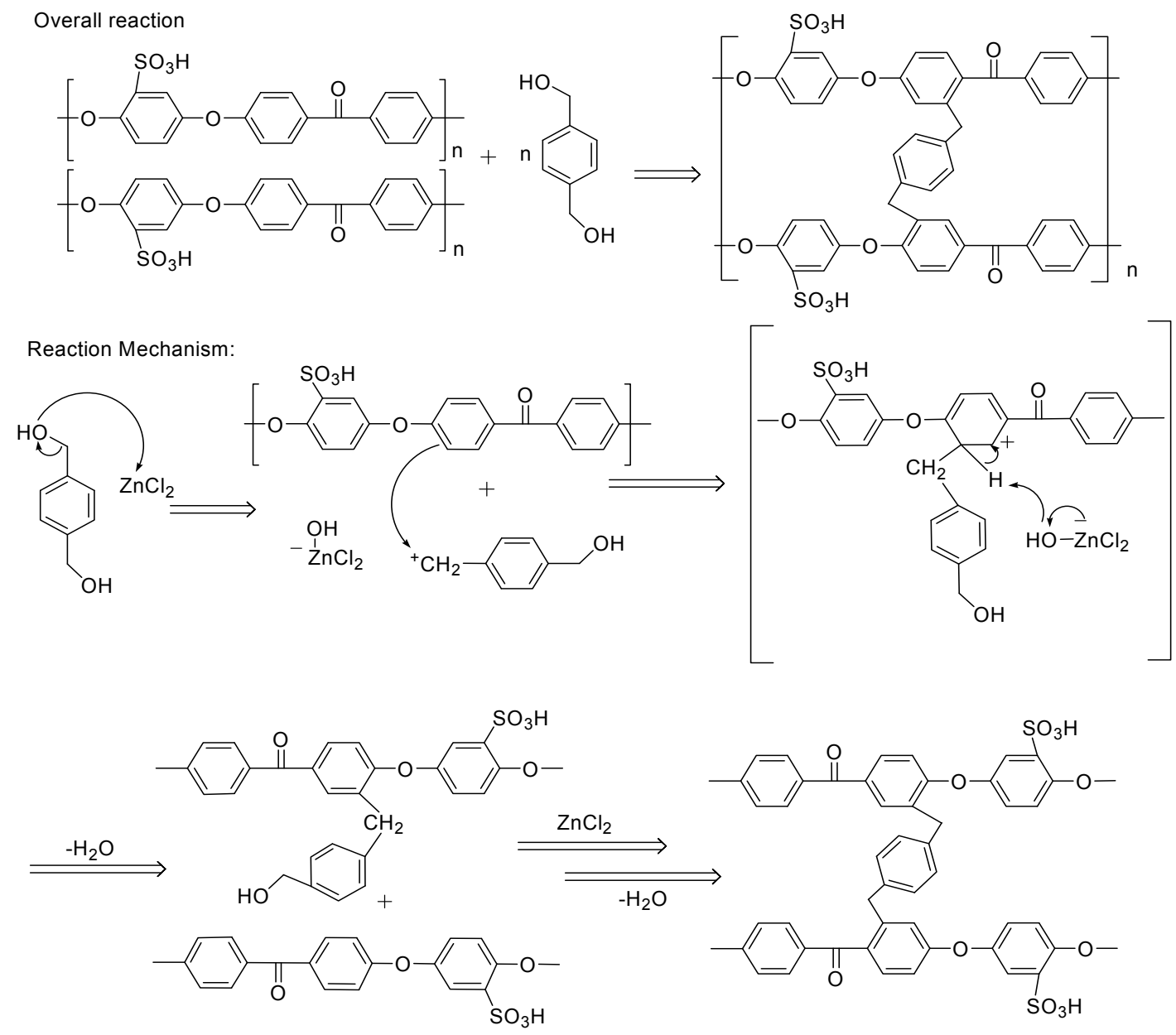

Figure 11 Mechanism of $\mathrm{ZnCl}_{2}$ catalyzed cross-linking of SPEEK

A comparison of IEC determinations for SPEEK-96 (SPEEK with 96\% degree of sulfonation) and cross-linked products containing various BDM amounts are listed in Table 1 . The relatively small decrease in IEC was concluded to be due to a FriedelCrafts mechanism on the SPEEK aromatic chain and not sulfonate-ester cross-linkage formation. The increase in mass by adding the BDM to SPEEK is expected to decrease the IEC, i.e. a lower sulfonic acid group per unit mass ratio. 
Table 1. Water uptake of cross-linked and a non-cross-linked SPEEK-96 membranes

\begin{tabular}{cccccc}
\hline Sample & IEC (meq/g) & $25^{\circ} \mathrm{C} \mathrm{WU} \%$ & $\begin{array}{c}800^{\circ} \mathrm{C} \text { WU } \\
\%\end{array}$ & $100{ }^{\circ} \mathrm{C} \mathrm{WU} \%$ & $\lambda_{\max }$ \\
\hline SPEEK-96 & 2.62 & $700^{\mathrm{a}}$ & $\infty$ & $\infty$ & 148 \\
X-6-SPEEK-96 & 2.56 & 550 & 640 & 638 & 138 \\
X-12-SPEEK-96 & 2.53 & 179 & 228 & 214 & 47 \\
X-24-SPEEK-96 & 2.40 & 69 & 99 & 96 & 22 \\
\hline
\end{tabular}

${ }^{a}$ Used to calculate $\lambda_{\max }$ for highly swollen SPEEK-96 membrane

SPEEK-96 polymers cross-linked with 6 wt\% or less BDM (X-6-SPEEK-96) had low levels of cross-linking and demonstrated high swelling in water and poor mechanical properties in comparison with the X-12-SPEEK-96 and X-24-SPEEK-96 membranes. Notwithstanding, the X-6-SPEEK-96 polymer was characterized given its low degree of cross-linking.

The solubility of the cross-linked polymer was investigated using some common solvents: acetone, DMF, DMAc, and water. SPEEK-96 dissolved readily in room temperature and $60{ }^{\circ} \mathrm{C}$ DMF and DMAc, and boiling water; with the polymer showing high swelling in room temperature water. X-6-SPEEK-96 swelled heavily in boiling DMF, DMAc and water, with a simultaneous reduction in mechanical strength. This was conclusive evidence for low levels of cross-linking in the X-6-SPEEK-96 polymer. The SPEEK-96 membranes cross-linked with $12 \%$ or $24 \%$ BDM had higher levels of crosslinkages and showed no loss of weight or mechanical stability while boiling in any of the listed solvents. Heating these membranes in concentrated sulfuric acid caused negligible change in the polymers mass and physical appearance. Membranes exhibiting properties such as these are known to be good candidates for hydrogen PEM fuel cell applications ${ }^{3,4}$.

In-plane conductivity of SPEEK-96, X-12-SPEEK-96 and X-24-SPEEK-96 membrane was evaluated using the four-probe conductivity technique. The results are shown in Figure 12. 


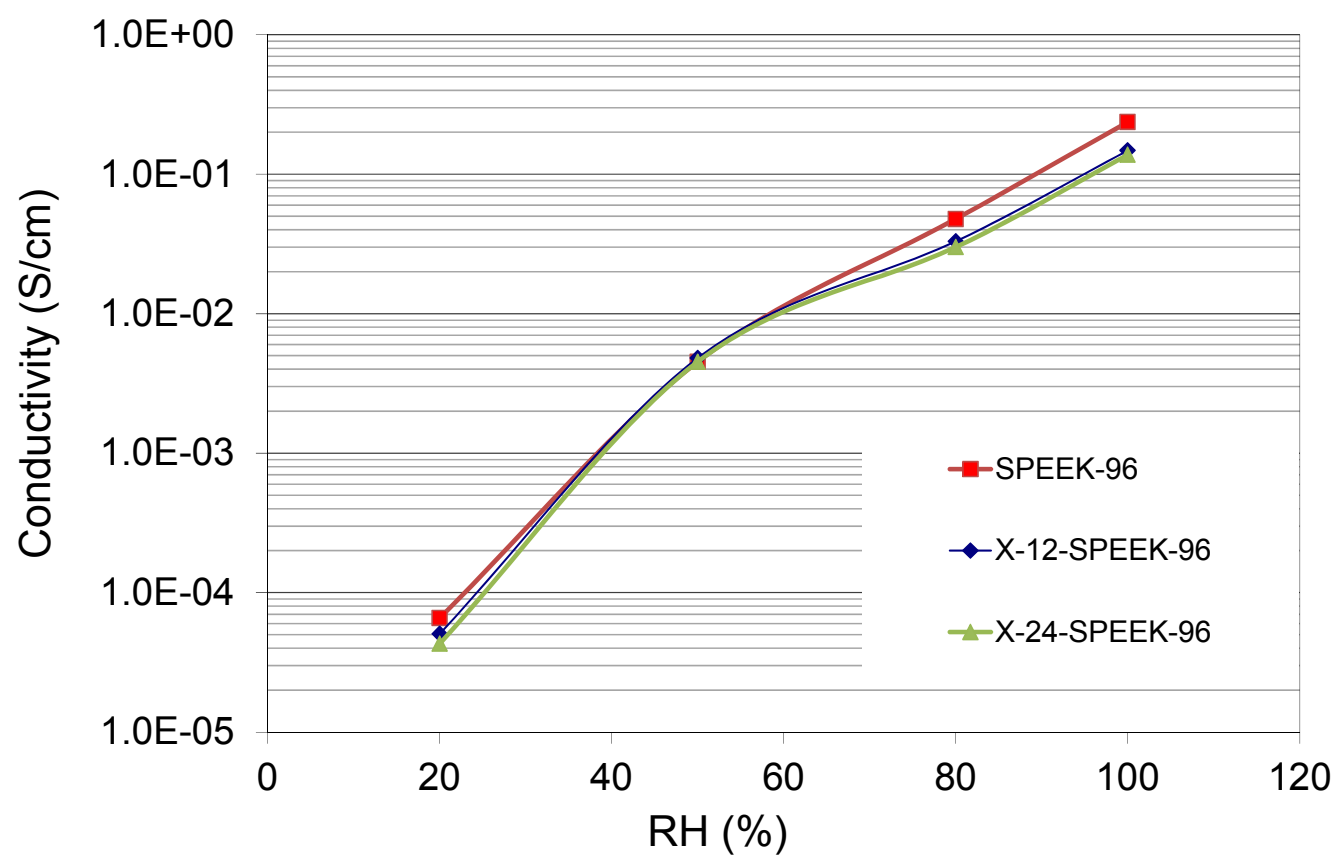

Figure 12. In-plane conductivity of SPEEK-96, X-12-SPEEK- 96 , and X-24SPEEK-96 at $80^{\circ} \mathrm{C}$

The proton conductivities of the three materials are quite similar over the sequence of relative humidities tested: $80,50,20,50,80$ and 100\%. The SPEEK-96 membrane showed conductivity values slightly greater than that of its cross-linked counterpart. This can be correlated to the lower EW of the former compared with the latter. At $100 \% \mathrm{RH}$, proton conductivity was at $0.2,0.15$ and $0.14 \mathrm{~S} / \mathrm{cm}$ for SPEEK-96, X-12-SPEEK-96 and X-24-SPEEK-96, respectively. Below the saturation point, the SPEEK-96 and crosslinked SPEEK-96 samples showed similar order of magnitude decreases in proton conductivity. The significant loss in conductivity at low RHs for all hydrocarbon membranes is purely dependent on the amount of water beyond the primary and secondary hydration spheres ${ }^{5}$. The effect of the cross-linker in this case is two-fold: it forms cross-links to stabilize the polymer against dissolution, but also increases the hydrophobic nonproton-conductive domain.

The mechanical and chemical stability of the cross-linked SPEEK-96 membranes were found to be satisfactory for manufacturing catalyst coated membranes (CCMs). As such, these membranes were easily sprayed with $\mathrm{Pt} / \mathrm{C}$ electrocatalyst, Nafion ${ }^{\circledR}$-based ink to give uniform electrode surfaces. The cross-linked SPEEK-96 CCMs were tested under fuel cell operating conditions, and their worthiness as a replacement candidate for Nafion ${ }^{\circledR}$ was evaluated ${ }^{6}$. Figure 13 shows the polarization curves taken for X-12-SPEEK96 and X-24-SPEEK-96 CCMs performed under air and then oxygen atmospheres at cell temperature $\left({ }^{\circ} \mathrm{C}\right.$ )/anode temperature $\left({ }^{\circ} \mathrm{C}\right) /$ cathode temperature $\left({ }^{\circ} \mathrm{C}\right) 80 / 80 / 73$. The membranes performed essentially the same on the respective oxidants until about 800 $\mathrm{mA} / \mathrm{cm}^{2}$. 


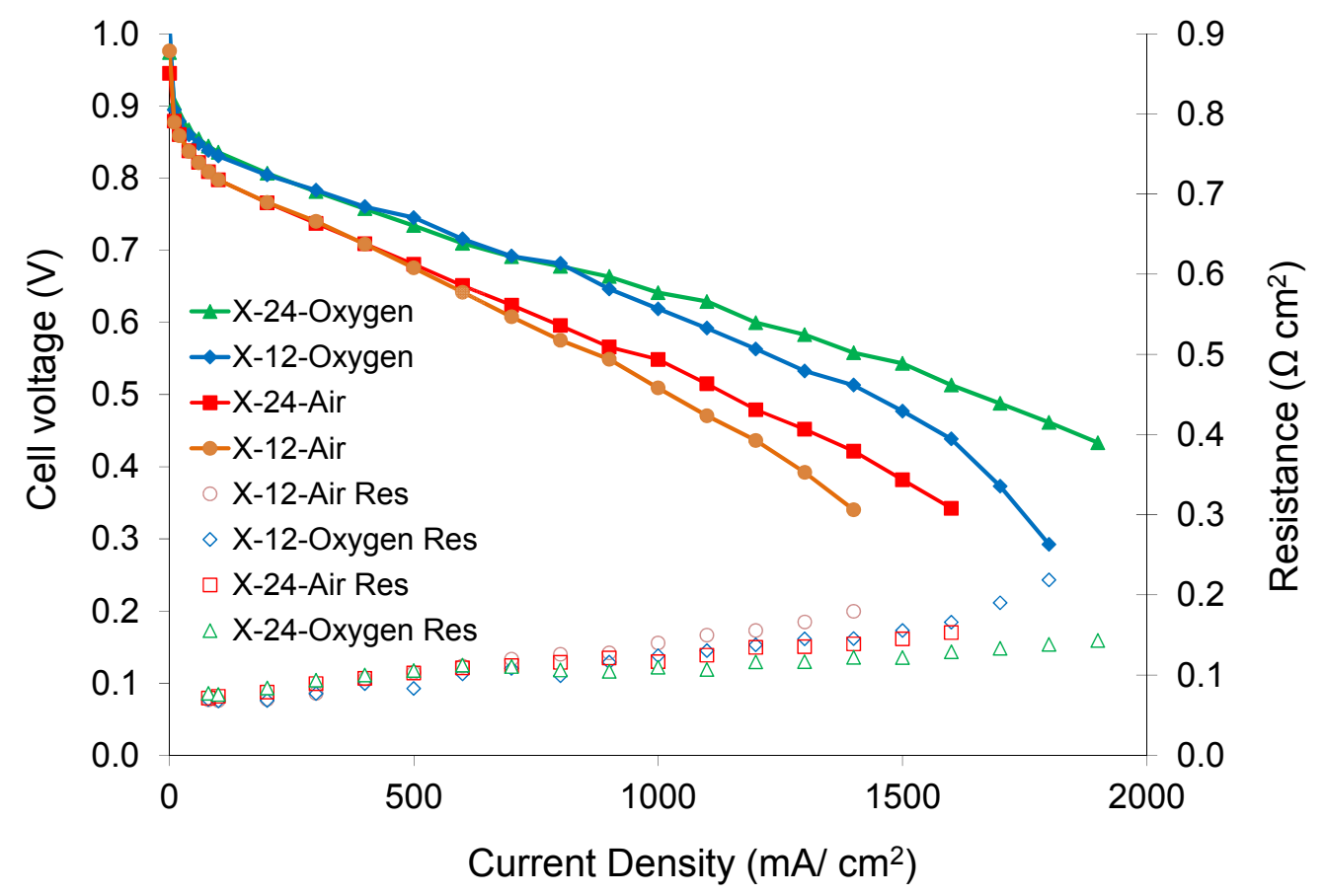

Figure 13. The polarization curves taken for X-12-SPEEK-96 and X-24-SPEEK-96 CCMs performed under air and then oxygen atmospheres at $80 / 80 / 73$

Above this current density, the X-24-SPEEK-96 exhibited higher voltage than the X-12SPEEK-96. This difference in the effective resistance at higher current density may be due to better transport of water in the X-24-SPEEK-96 membrane. Cell resistance is known to be a function of both the back transport of water to the anode and electroosmotic drag transporting water towards the cathode ${ }^{7,8}$. At 100/90/90 (Figure 14), the higher temperature and lower relative humidity conditions caused the resistance of both cells to double compared to performance taken at 80/80/73 (Figure 13), over all current densities tested. These conditions, however, were better suited for the X-12-SPEEK-96 membrane, the performance of which was slightly better on oxygen, but notably superior on air in comparison to the X-24-SPEEK-96 membrane. At these current densities, the ohmic membrane resistance causes decreased cell performance. The $X-$ 24-SPEEK-96 PEM does not bind waters of hydration as well as the X-12-SPEEK-96 membrane; evidence for this was recorded in Table 1. This phenomenon follows from decreased membrane conductivity as a function of lower relative humidity. It follows that proton diffusion will be increased many orders of magnitude through a conducting medium in a fully hydrated state ${ }^{9}$. High levels of swelling as a result of the hydration can lead to structural changes, such as bond breaking, and finally degradation [9]. SPEEK polymer allows strong proton conduction and very low permeability to fuels when compared to Nafion. These are essential membrane properties for high efficiency and long term cell durability ${ }^{10}$. 


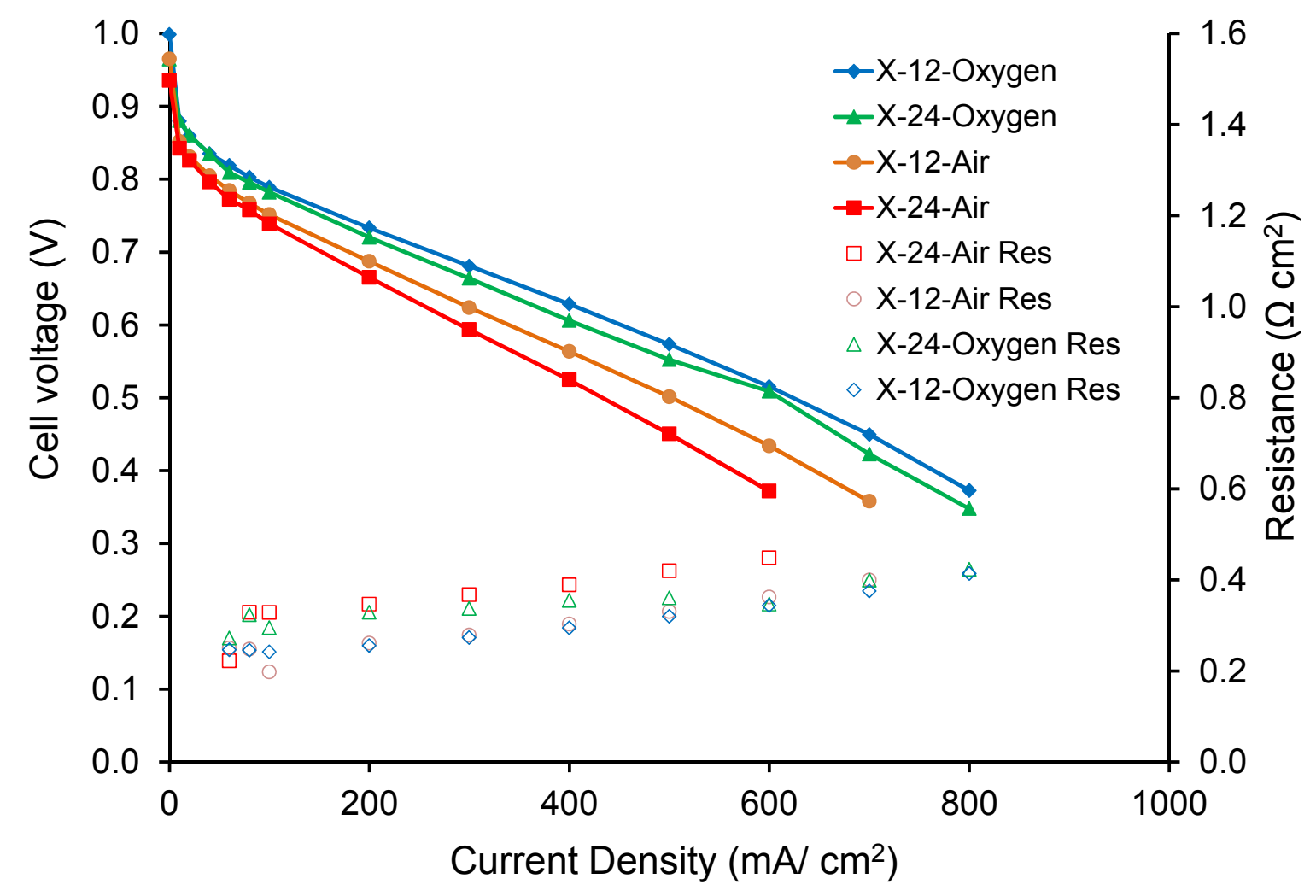

Figure 14. The polarization curves taken for X-12-SPEEK-96 and X-24-SPEEK-96 CCMs performed under air and then oxygen atmospheres at 100/90/90

Figure 15 shows IR-free cell voltages obtained by the current interrupt method for Nafion 211, X-12-SPEEK-96 and X-24-SPEEK-96 at 80/80/73 testing condition. The cross-linked SPEEK-96 membranes had comparable performance to Nafion 211 MEA with similar electrocatalyst loading.

Before and after conducting each performance experiment, LSV was used to determine fuel cross-over currents. Tests for cross-over currents before the performance tests at 80/80/73 and 100/90/90 showed negligible hydrogen gas cross-over. Figure 16 illustrates the results of a LSV experiment on an X-24-SPEEK-96 CCM. The change in cross-over of hydrogen gas before and after testing was deemed negligible. The LSV had a limiting current comparable with Nafion 211 membranes. This means that the flux of hydrogen gas from anode to cathode compartment is low. Thus, while free-radical driven decomposition of SPEEK CCMs has been noted by others, there were no durability issues encountered in the performance of our testing protocols ${ }^{11}$. 


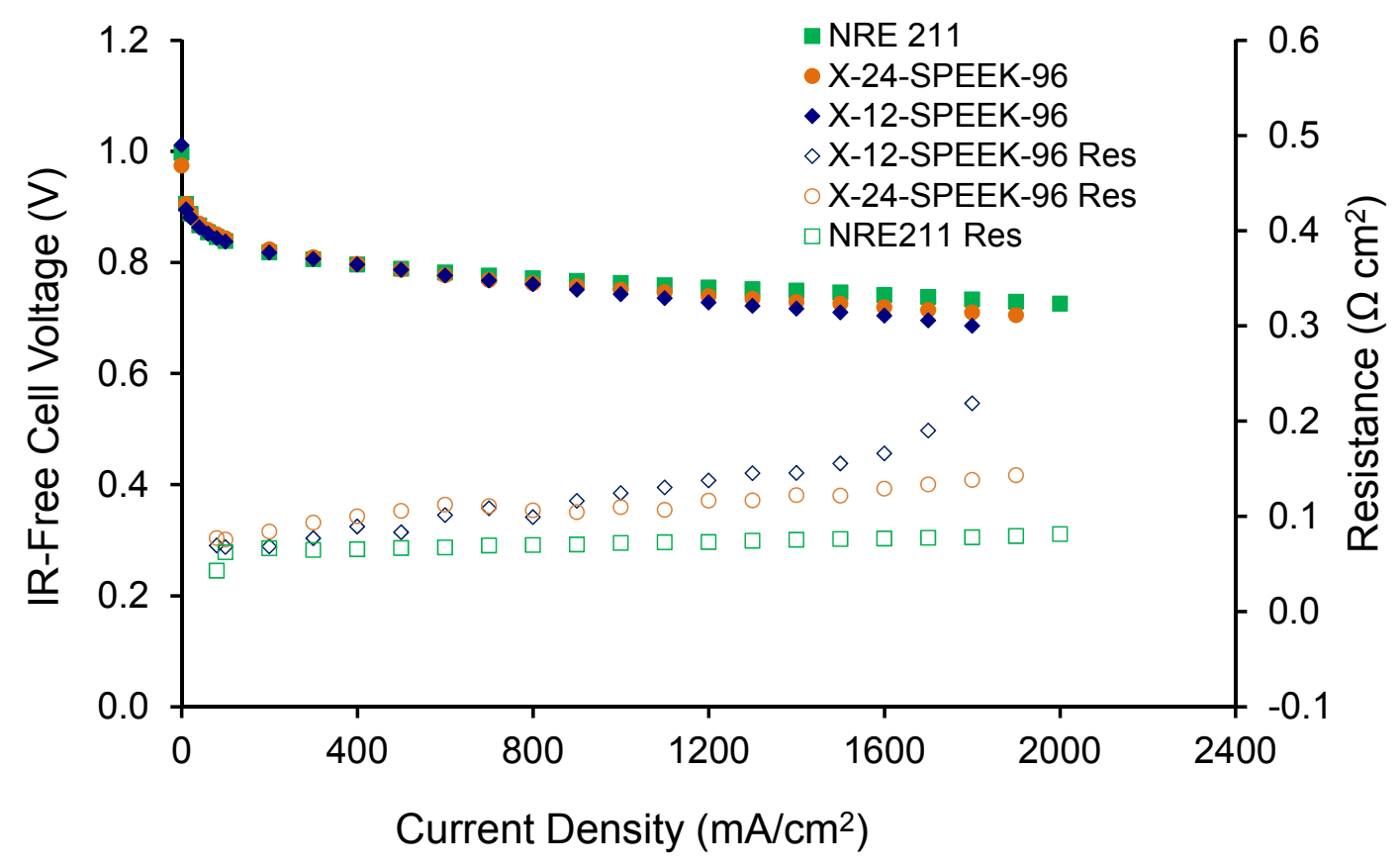

Figure 15. IR-free cell voltages obtained by the current interrupt method for Nafion 211, X-12SPEEK-96 and X-24-SPEEK-96 at 80/80/73 testing condition

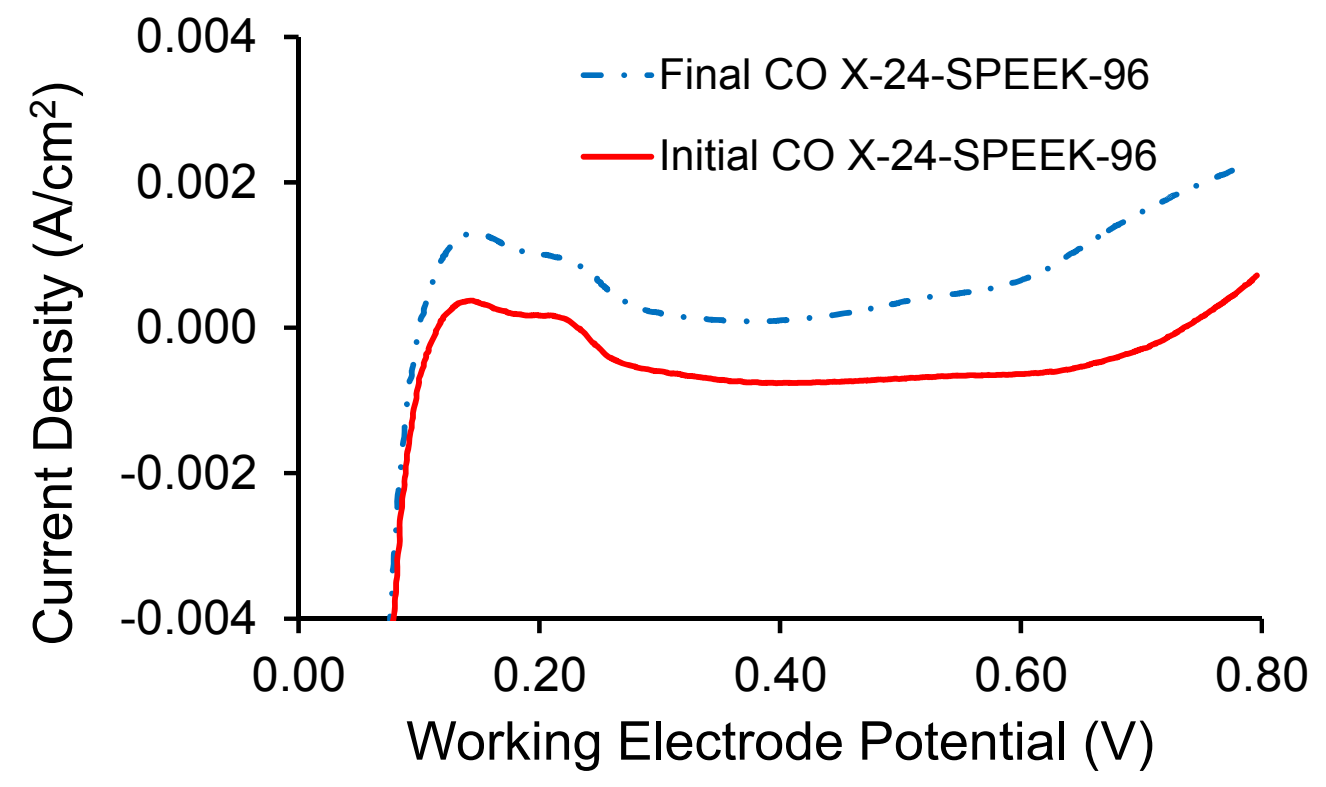

Figure 16 Hydrogen cross-over measured by linear sweep voltammetry of X-24-SPEEK-96 membranes before and after performance testing at 80 and $100 \circ \mathrm{C}$

In a parallel work, the effects of of heteropolyacid phosphotungstic acid, $\mathrm{H}_{3} \mathrm{PW}_{12} \mathrm{O}_{40}$ (PTA), and its cesium salt, $\mathrm{Cs}_{2.5} \mathrm{PW}_{12} \mathrm{O}_{40}\left(\mathrm{PTA} / \mathrm{Cs}^{+}\right)$, on the proton conductivity of SPEEK membranes was studied. Various concentrations of PTA were added to SPEEK solution to achieve $0,5,15,30$, or $40 \mathrm{wt} \%$ solid acid content. The PTA was 
stabilized by conducting a cesium exchange using $\mathrm{Cs}_{2} \mathrm{CO}_{3}$.

ATR-FTIR spectra (Figure 17) of SPEEK and SPEEK composite samples shows that the percent transmittance of PTA stretches decreased with increasing solid acid content. These tungsten-oxygen stretches were still present in the membrane spectrum after cesium treatment (Figure 17f). The disappearance of PTA stretching bands from the FTIR surface measurements of the composite polymer occurred after the $0.1 \mathrm{M}$ $\mathrm{H}_{2} \mathrm{SO}_{4}$ acid/DI water treatment of the polymer (Figure $17 \mathrm{~g}$ ). This acid treatment should effectively exchange any $\mathrm{Cs}^{+}$cations attached to the sulfonic acid groups of the polymer. Therefore, it can be stated that the sulfuric acid treatment causes leaching of the cesium-stabilized PTA from the surface of SPEEK composite membranes. This phenomenon was also observed for membranes with 5,15 , and $30 \%$ PTA/Cs ${ }^{+}$.

Loss of stabilized PTA from the membranes was also reflected in membranes' proton conductivity measurements. Figure 18 shows the four-probe-measured conductivity of stabilized SPEEK/PTA composites containing 0, 5, 15, 30, and 40\% PTA by weight, represented as S- 0, S-5, S-15, S-30, and S-40, respectively. The conductivity for the stabilized membranes gave nearly identical results.

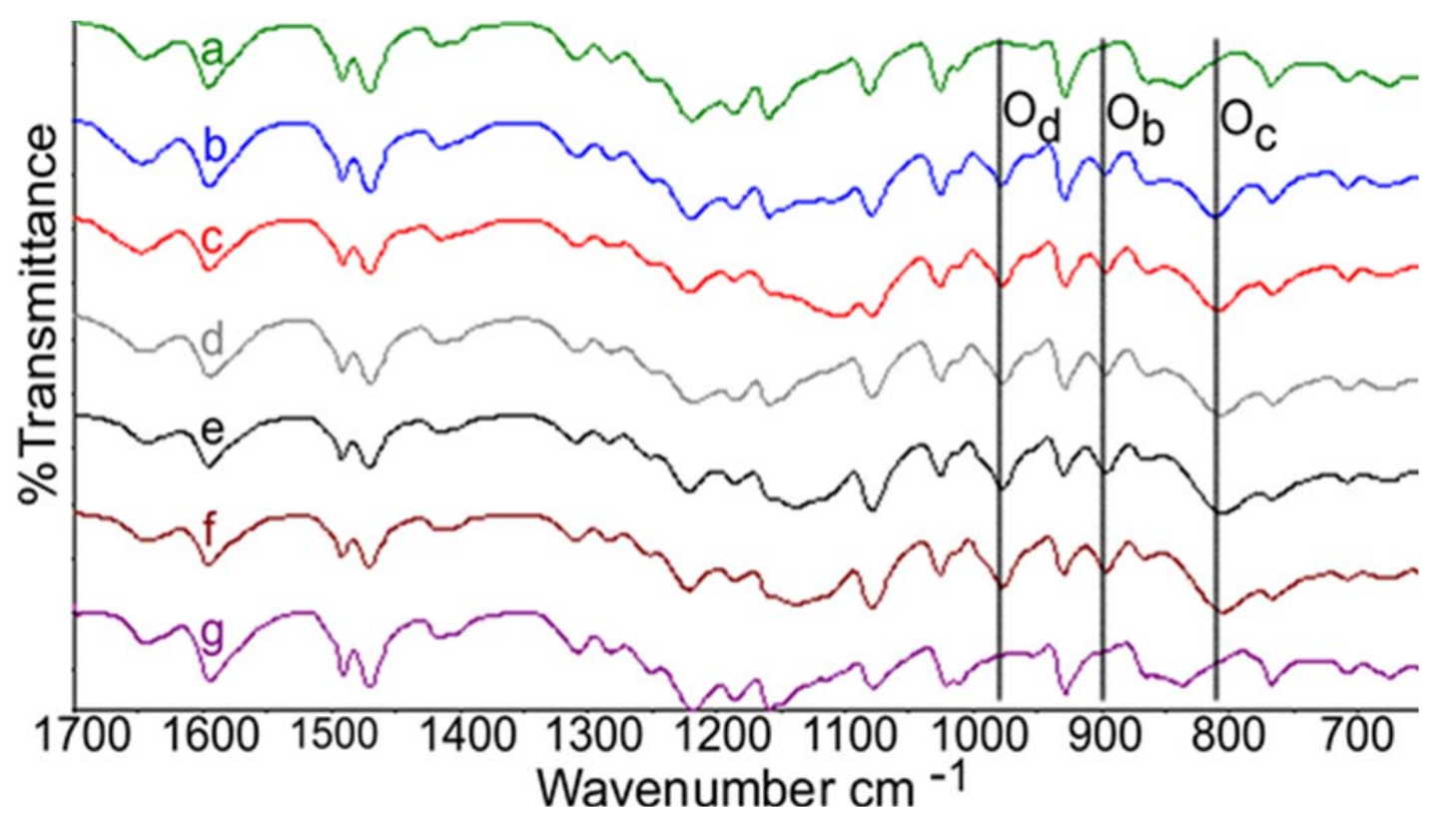

Figure 17. ATR- FTIR of sulfonated PEEK/PTA composite membranes non-stabilized: a) S-0, b) S5 , c) $\mathrm{S}-15$, d) $\mathrm{S}-30$, e) $\mathrm{S}-40$, and stabilized: f) $\mathrm{S}-40 / \mathrm{Cs}^{+}$, and g) $\mathrm{S}-40 / \mathrm{Cs}^{+} / \mathrm{H}^{+}$showing an increase in percent transmittance of PTA stretches for the W-O terminal double bonds $\left(O_{d}\right)$ at $980 \mathrm{~cm}^{-1}, W-O$ $W$ inter-linking bridges between corner sharing octahedra $\left(O_{b}\right)$ at $910 \mathrm{~cm}^{-1}$, and W-O-W intra bridges between edge sharing octahedral $\left(O_{c}\right)$ at $810 \mathrm{~cm}^{-1}$

It was concluded that the addition of stabilized PTA to SPEEK membranes does not have any significant ability to bind or uptake waters of hydration to facilitate proton conductivity. 


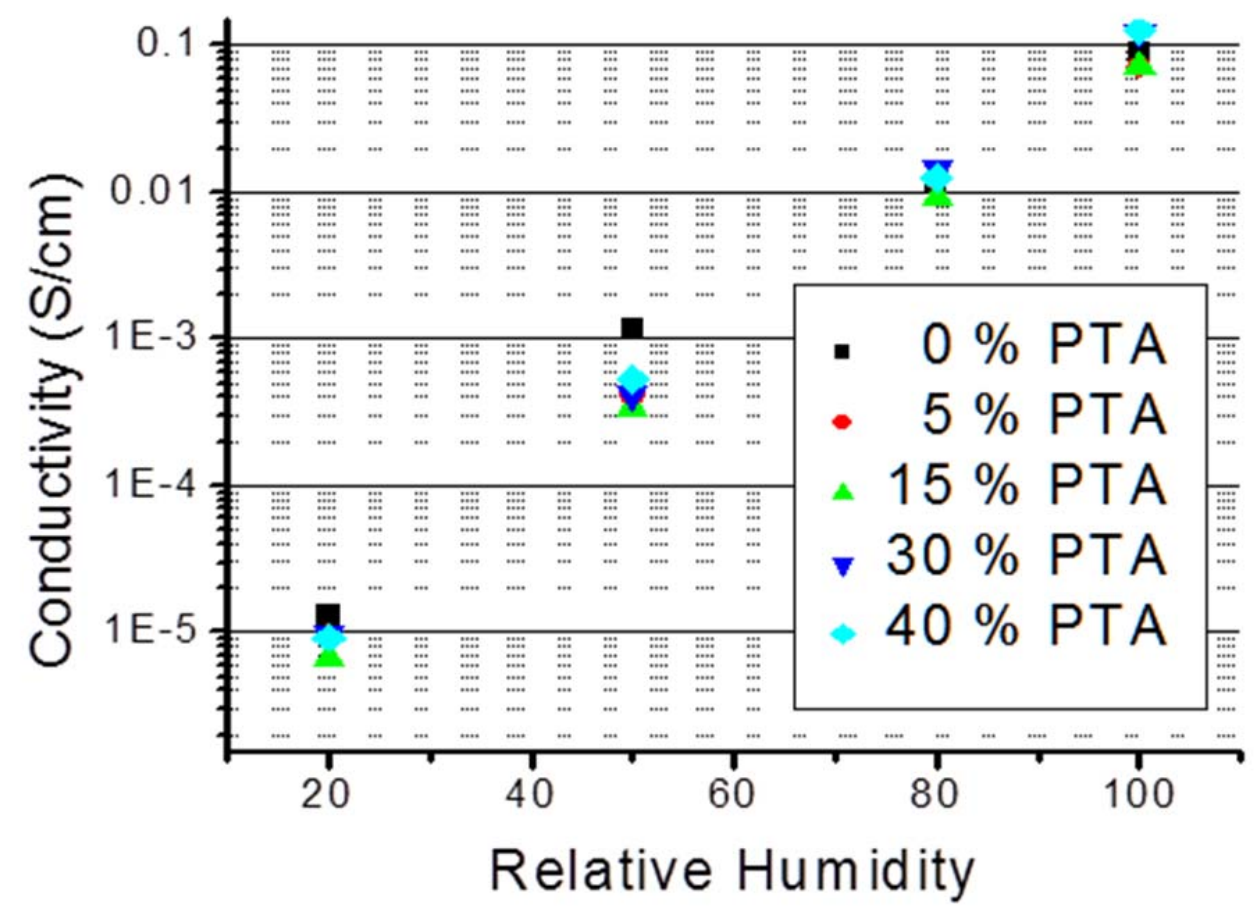

Figure 18 Conductivity measurements of stabilized SPEEK/PTA composite membranes: S$0 / \mathrm{Cs}^{+} / \mathrm{H}^{+}, \mathrm{S}-15 / \mathrm{Cs}^{+} / \mathrm{H}^{+}, \mathrm{S}-30 / \mathrm{Cs}^{+} / \mathrm{H}^{+}$, and S-40/Cs ${ }^{+} / \mathrm{H}^{+}$

\section{Conductivity Measurements}

As briefly introduced in the first task, conductivity measurements can be made through the membrane or across the membrane, Figure 19. Through-thickness membrane resistance (or conductance) is a key property of interest for fuel cells but is traditionally measured with catalyzed membrane (MEA) in 2-probe configuration (i.e., a single-cell fuel cell). This leads to problems because of inconsistency in the MEA assembly (catalyst distribution, materials used, etc.). There are also contact resistance issues. Higher or lower conductivity results will be achieved based on how the MEA is assembled. These variables must be quantified and backed-out when using throughplane resistance calculations to arrive at membrane conductivity. One must also account for contact resistance between the diffusion media \& the catalyst layer. However, in a fuel cell, the protons are conducted through-plane, making such an exsitu measurement important for understanding the in-situ performance. 


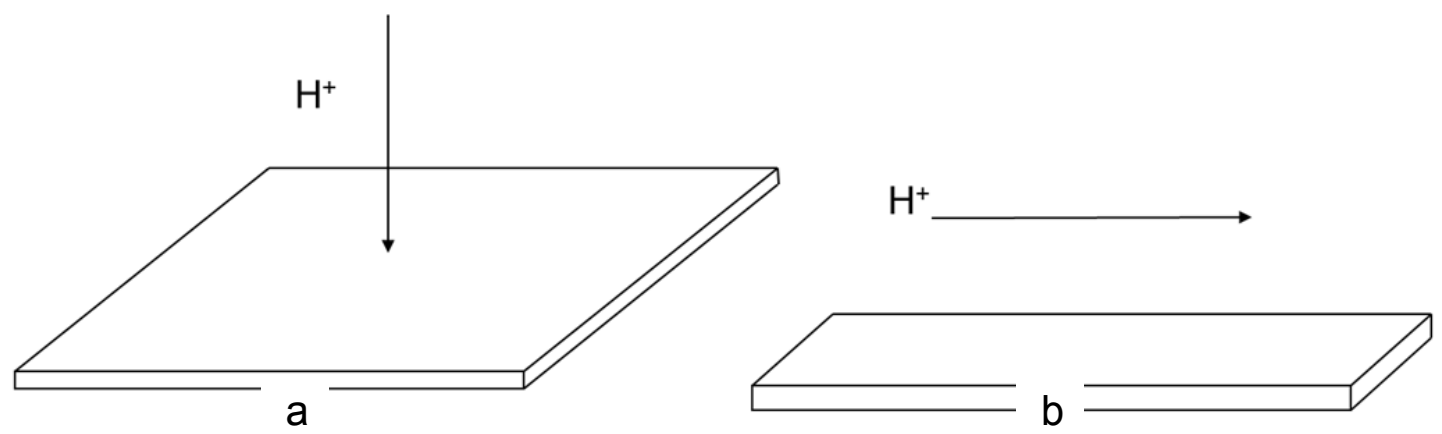

Figure 19. (a) Through-Plane: Ionic conductivity is measured through the membrane; (b) In-Plane: lonic conductivity is measured across the membrane

For in-plane measurements, the pure membrane sample is assembled into the Conductivity Cell. This approach eliminates the following variables:

- Inconsistency in the MEA assembly - The membrane sample is not assembled into an MEA

- Contact resistance issues - True 4-electrode measurement eliminates contact resistance issues.

- Bonding Technique issues- True 4-electrode measurement eliminates catalystmembrane interface issues

- Voltages measured are due to moving charge only

In-plane conductivity measurements make for an easier measurement (versus throughplane) and the results demonstrate the character of the polymer. It is a reliable and reproducible screening tool that eliminates other fuel cell performance factors. It is faster to equilibrate due to no catalyst layer or GDL and less skill and equipment are required than in making and testing a good MEA.

For this program, initial measurements were to be made using the in-plane method for the advantages mentioned above. Simultaneously, a new method for through-plane measurements was to be developed. Conductivity measurements were the subject of Tasks 3 and 4 as described in the following sections.

\section{Task 3: In-Plane Conductivity Measurement}

The goal of the High Temperature Membrane program was the development of membranes that met the DOE targets for conductivity. Therefore, measurement of the conductivity of membranes produced under the contract was to be accomplished using a standard procedure developed by FSEC subcontractor, BekkTech Corp. Conductivity testing for the Milestones was conducted by BekkTech and reported to the individual teams and to FSEC Program Management for presentation and review with DOE. The protocol for in-plane conductivity testing can be seen in Appendix I.

A number of issues were raised early in the program with regard to the accuracy and reproducibility of conductivity measurements. The concerns and the suggested solutions were:

1. Reproducibility and repeatability of the length measurement 
a. Develop more rigid supports of the platinum wires in the conductivity cell

b. Modify the conductivity cell so that lifting the platinum wires is not necessary when assembling a sample into the conductivity cell

2. Reproducibility of the thickness measurement

a. Research the effect of the measurement tool on the sample.

b. Research the accuracy of measurement tools available

c. Determine the best tool to accurately measure the sample thickness.

3. Reproducibility of the width measurement

a. Develop a tool that cuts reproducibly

b. Determine the accuracy of the width measurements

The first concern was addressed by redesigning the conductivity cell so that the platinum wires would be better secured with the membrane running over the top of the wire. To address the second concern, potential distortion of membrane samples in the measurement process was calculated to determine if the gauge compresses and distorts the thickness measurement. Calculations indicated that this measurement tool did not measurably affect the thickness measurement. After additional research on the tools available for thickness measurements, the best tool was determined to be the Mitutoyo part 547-400 used by DuPont.

A special tool was developed for cutting the samples to address the third concern of cutting reproducibly. With regard to accuracy, BekkTech's Loupe with 6x magnification and $0.2 \mathrm{~mm}$ gradients provided the ability to read within $0.1 \mathrm{~mm}$, an error of about $3 \%$ on the width. This was determined to be an acceptable variance.

A similar device at McMaster Carr having a magnification of $11 \mathrm{x}$ and a reticule that has $0.1 \mathrm{~mm}$ gradients was also identified (part numbers $1502 \mathrm{~T} 3$ and 1060T22 and part number 1502T6).

An additional concern was related to the effects of the direction in which a sample is cut. For example, will the results be different if a sample is cut parallel to the edge of the Nafion sheet or perpendicular to the edge (see Figure 20)?

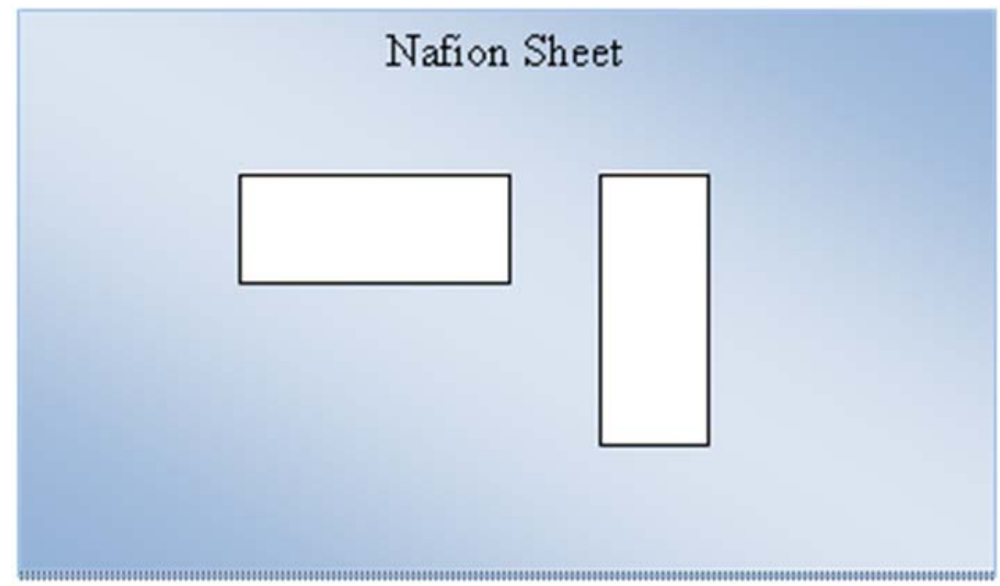

Figure 20. Directions in which sample could be cut with respect to edge of Nafion 
Tests indicated that the direction of the cut may affect the results of the conductivity tests, Figure 21. Therefore, it was important to be consistent when cutting samples to ensure that each sample was cut the same direction relative to the edge.

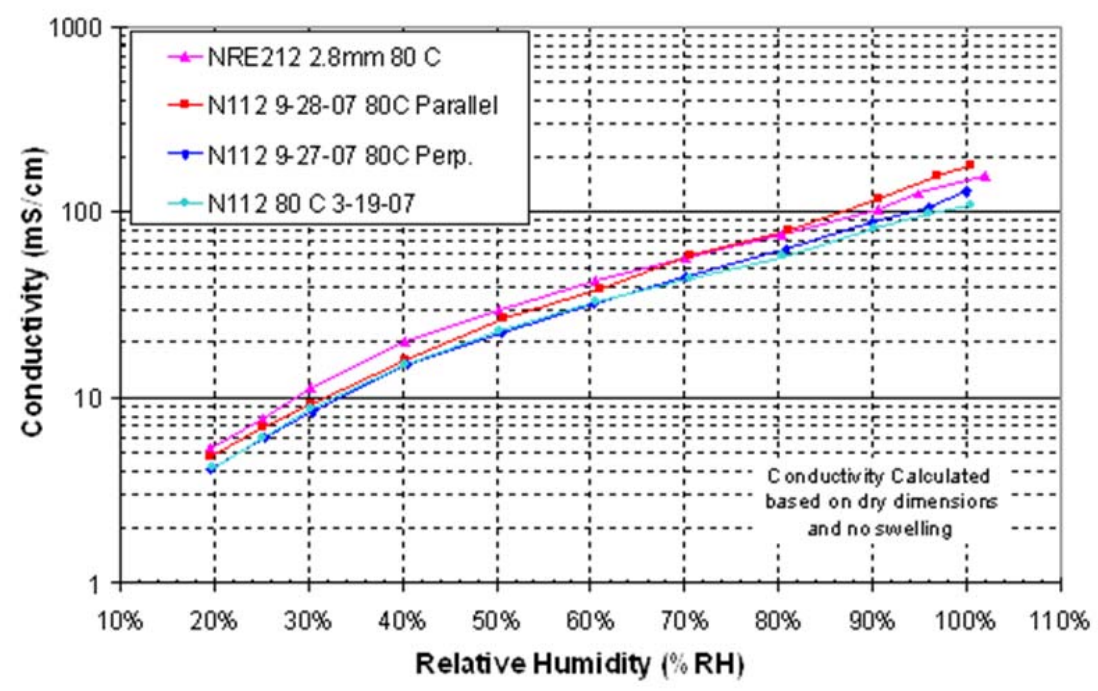

Figure 21. Comparision of conductivity for samples cut perpendicular and parallel to edge

To verify the repeatability of conductivity measurements, a series of standard membranes were tested according to the protocol that had been developed. When test results showed variances, the potential causes of the variance were investigated and the necessary adjustments made. The samples tested included N112, NRE212, NRE211, N117, N1035, and N1135. Testing conditions were:

- Each sample was heated to its operating temperature $\left(30^{\circ} \mathrm{C}, 80^{\circ} \mathrm{C}\right.$ or $\left.120^{\circ} \mathrm{C}\right)$

- Pressure: $100 \mathrm{kPa}$ at $30^{\circ} \mathrm{C}$ and $80{ }^{\circ} \mathrm{C} ; 230 \mathrm{kPa}$ at $120^{\circ} \mathrm{C}$

- Sample was held at $70 \% \mathrm{RH}$ for two hours

- RH was decreased to $20 \%$ in $10 \%$ increments (i.e. $70 \%, 60 \%, 50 \%$, etc), held at each $\mathrm{RH}$ for 15 minutes

- At $20 \% \mathrm{RH}, \mathrm{RH}$ begins increasing to $100 \%$ in $10 \%$ increments (i.e. $30 \%, 40 \%$, $50 \%$, etc), held at each $\mathrm{RH}$ for 15 minutes

- A scanning DC sweep was performed from +0.1 Volts to -0.1 Volts

An examples of the results obtained on different days are shown in Figure 22 and Figure 23, below. 


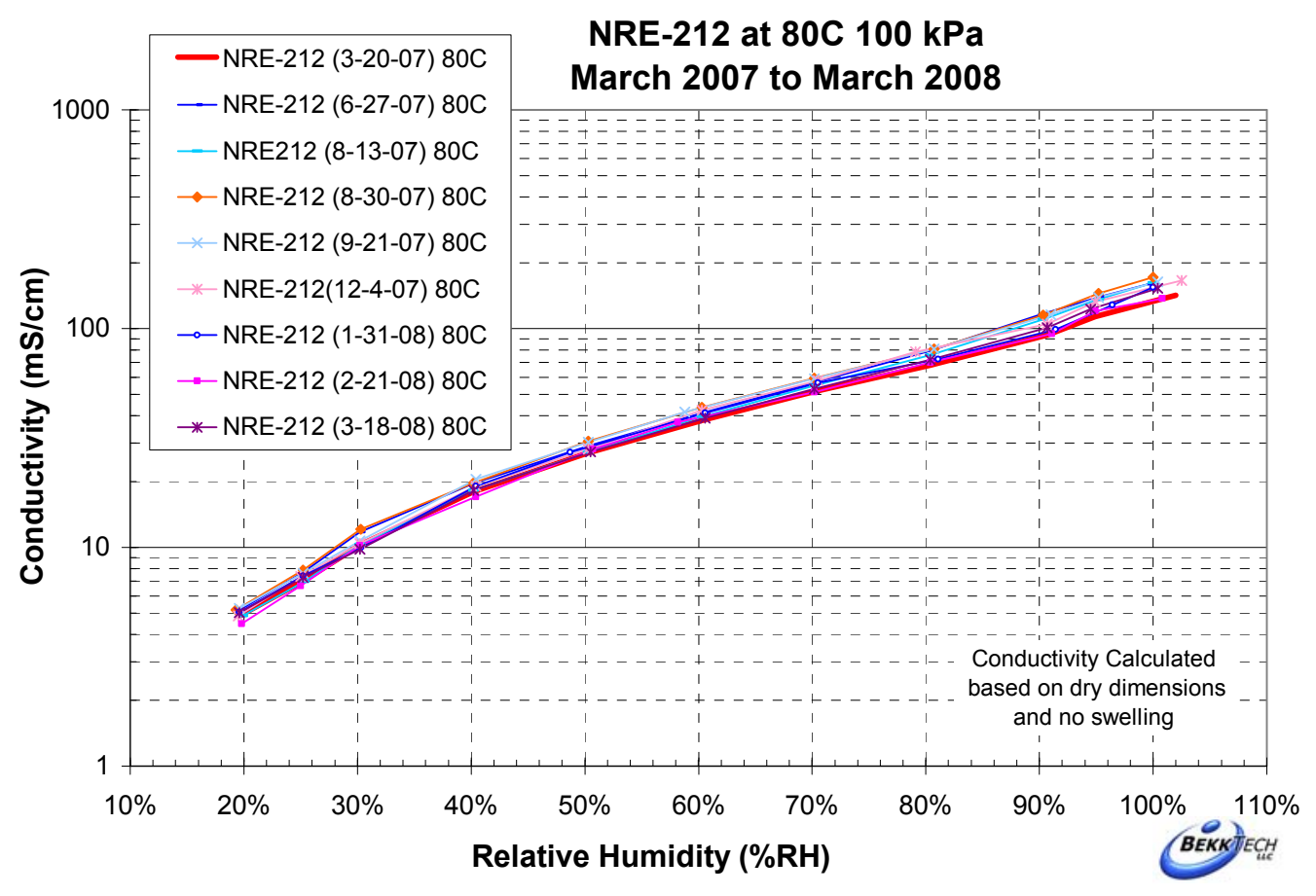

Figure 22. Conductivity of Nafion samples tested on various days at $80^{\circ} \mathrm{C}$ and $100 \mathrm{kPa}$

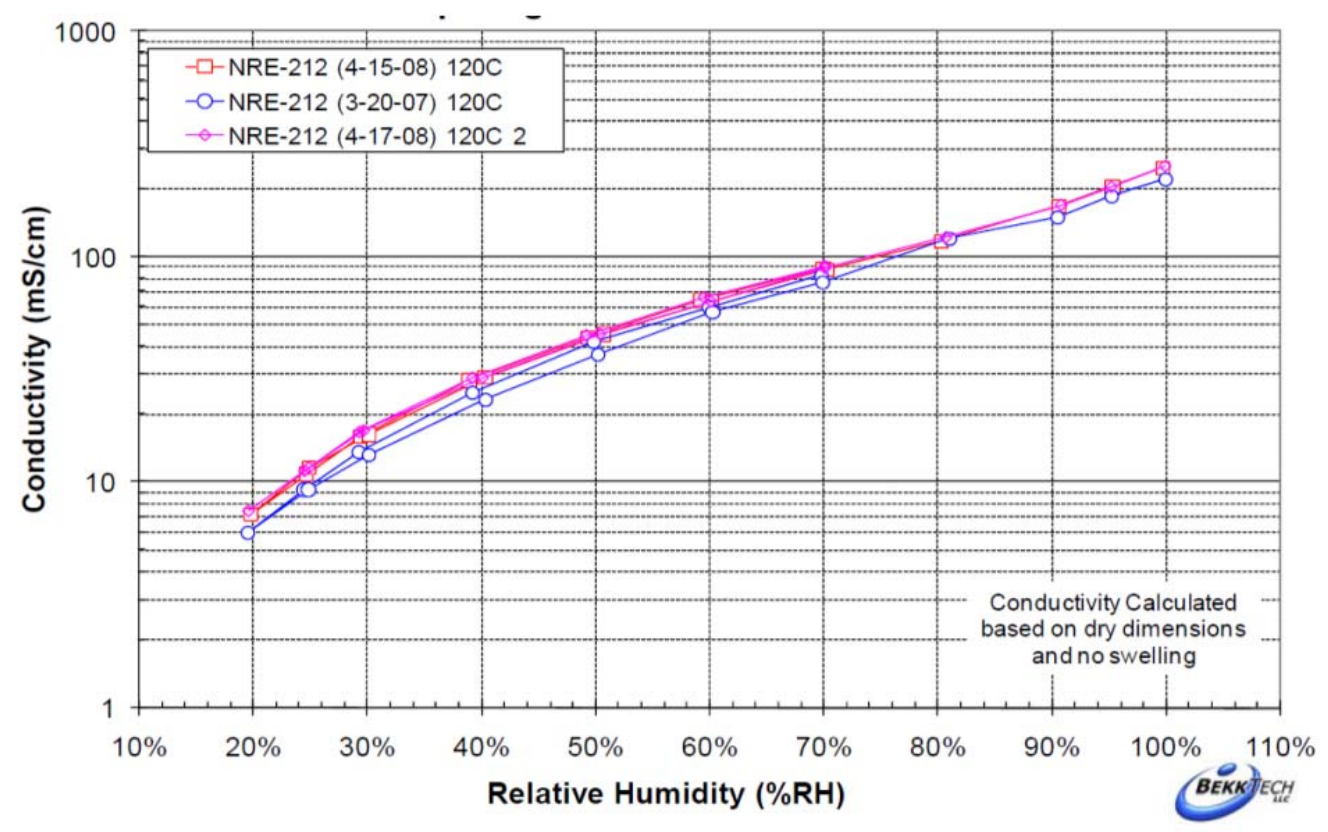

Figure 23. Conductivity of Nafion samples tested on three days at $120^{\circ} \mathrm{C}$ and $100 \mathrm{kPa}$

Task 4: Through-Plane Conductivity Measurements

This section describes the conceptual design of the through-plane measurement system, followed chronologically by the engineering design, evaluation and evolution of the test system hardware, including the major components such as the electrodes and 
environmental control system, as well as the software. A detailed description of the final test procedure can be found in Appendix II.

Scribner, sub-contractor to FSEC, was tasked with developing a test system and procedure to measure the through-plane resistance and conductivity of polymer electrolyte membranes (PEMs).

Specifically, the objective was to determine the through-thickness area specific resistance $\left(A S R\right.$ in $\left.\Omega-\mathrm{cm}^{2}\right)$ and conductivity $(\sigma$ in $S / \mathrm{cm})$ of commercially available PEMs as well as materials developed by Topic 2 project participants.

ASR and conductivity are determined by measuring the through-thickness resistance of the membrane sample. As illustrated in Figure 24, the through-thickness conductivity $\left(\sigma_{\perp}\right)$ is determined from the resistance $\left(R_{\perp}\right.$ in $\Omega$ ), the thickness of the membrane ( $L$ in $\mathrm{cm})$ and the cross-sectional area through which the current passes $\left(A\right.$ in $\left.\mathrm{cm}^{2}\right)$,

$$
\sigma_{\perp}=\frac{L}{R_{\perp} \cdot A}=\frac{I}{V} \frac{L}{A}
$$

The area specific resistance $\left(A S R\right.$ in $\left.\Omega-\mathrm{cm}^{2}\right)$ is the product of the through-plane resistance and the effective area,

$$
A S R=R_{\perp} \cdot A
$$

The requirements of such a membrane test system included the ability to accurately measure this material property over a range of temperature, humidity and absolute pressure conditions,

- $30^{\circ} \mathrm{C}$ to $120^{\circ} \mathrm{C}$

- $20 \%$ to $95 \% \mathrm{RH}$

- $100 \mathrm{kPa}_{\mathrm{a}}$ to $230 \mathrm{kPa}_{\mathrm{a}}$

Furthermore, to be useful as a research and development (R\&D) tool for membrane analysis, the test system should use bare membranes. That is, accurate measurement of the through-thickness resistance and conductivity should not require the use of a catalyzed membrane. The requirement to use a catalyzed membrane significantly increases the time, cost and complexity of the evaluation process, which is undesirable for developmental membranes for which electrode/bulk membrane interfacial chemistry and processing parameters are unknown. In addition, ideally, the measured resistance would not include confounding non-membrane resistances, such as those due to contacts and electrical leads. This requirement necessitates a four-electrode technique such as is commonly used for in-plane membrane resistance/conductivity measurement. 


\section{Membrane Test System Development}

\section{Membrane Test System Description}

The main components of the MTS hardware set-up are shown in Figure 25:

i. Wet-dry mixed gas handling system temperature controlled humidifier tank; two $500 \mathrm{sccm}$ full-scale $\mathrm{H}_{2}$ mass flow controllers; heated gas transfer line and gas mixing zone; water and multi-gas $\left(\mathrm{H}_{2}, \mathrm{~N}_{2}\right)$ inlets; and electronics for control and communications with MTS control hardware. A fan-cooled radiator, stainless steel collection tank and back pressure regulator are used when operating the humidifier and cell at high temperatures (> $100{ }^{\circ} \mathrm{C}$ ). Selected points within the gas humidification and transfer system are instrumented with thermocouples for temperature profile monitoring.

ii. Test chamber and cell head - insulated,

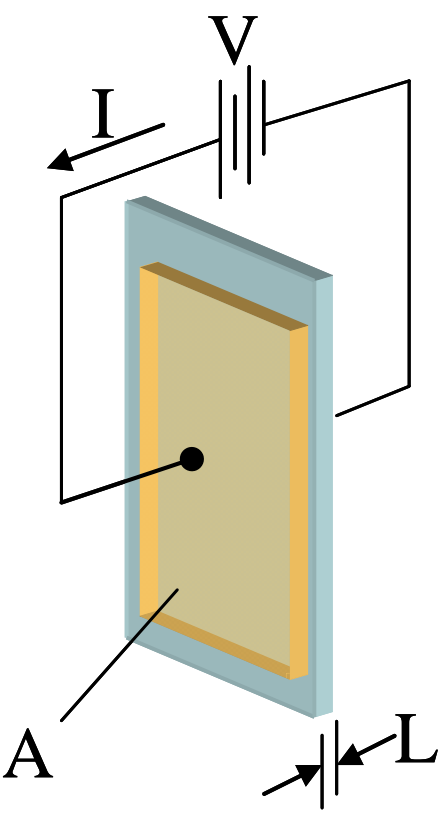

Figure 24. Illustration of throughthickness resistance and conductivity measurement principle. temperature-controlled aluminum housing with gas inlet and outlet; Vaisala gas dew point (DP) and temperature sensors; and cell head with integrated electrodes/specimen holder, specimen clamping mechanism, and thermocouples for in-situ gas and specimen temperature monitoring.

iii. MTS control and DAQ hardware - host computer-controlled electronics for gas flow rate and temperature control and data acquisition (DAQ); four temperature controllers, communications with PC, alarm inputs $\left(\mathrm{H}_{2}\right.$ sensor, low water level, loss of inlet gas pressure).

iv. Frequency Response Analyzer - Solartron Analytical 1260 Impedance Analyzer for 4-terminal impedance spectroscopy measurement.

v. Host computer (not shown) - proprietary MTS software for experiment set-up and control (humidifier and cell temperature, gas flow rate and wet-to-dry ratio, etc.); ZPlot $\AA /$ CorrWare ${ }^{\circ}$ for impedance/DC electrochemical measurements.

First and second generation prototypes of the membrane test system are shown in Figure 26 and Figure 29, respectively. 


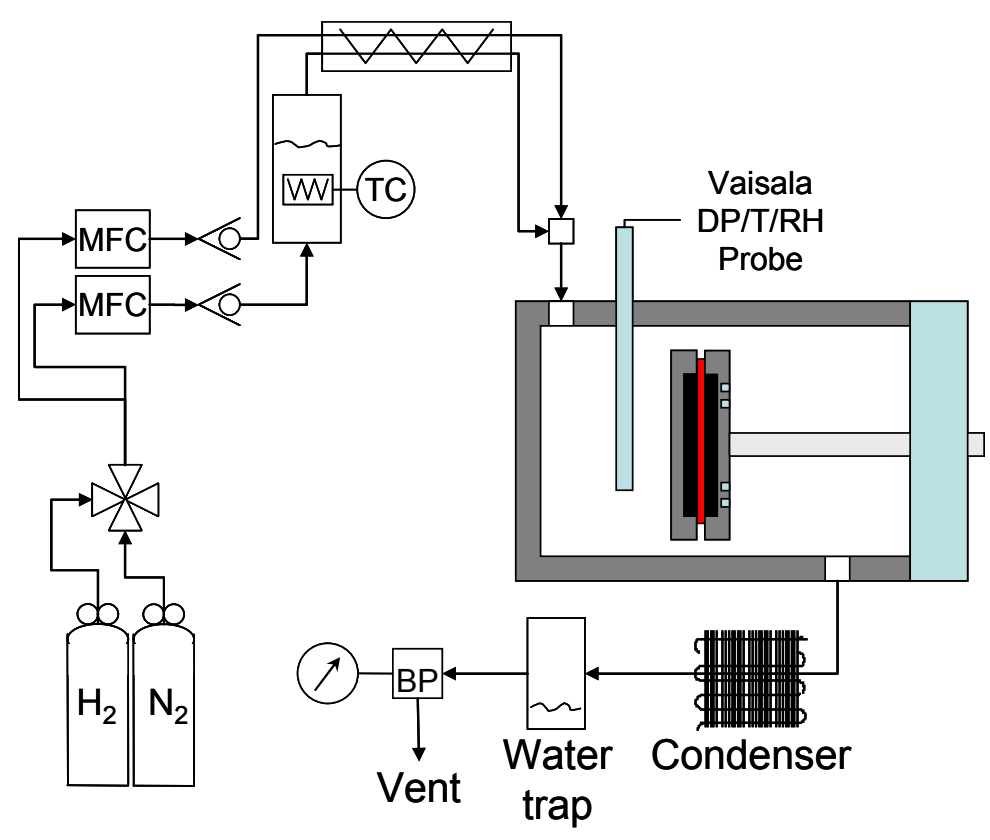

Figure 25. Schematic of the major hardware components of the Membrane Test System, excluding the control electronics, DAQ system and analytical instrumentation.

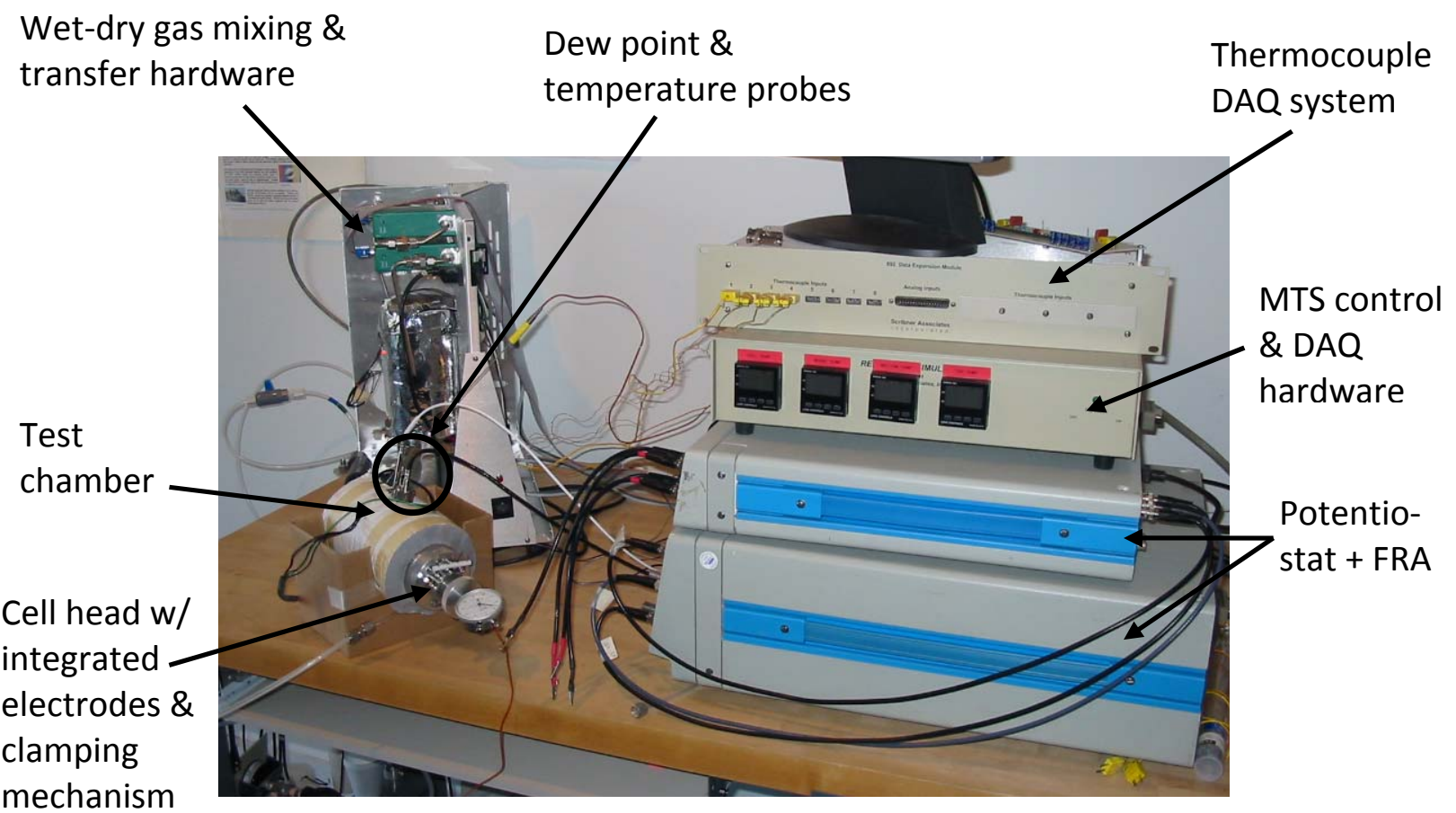

Figure 26. Initial development unit used for proof-of-concept testing, verification of the wet-dry gas mixing humidification scheme and preliminary control board and firmware. 
Operation at temperatures at or above $100{ }^{\circ} \mathrm{C}$ requires that the system be operated at pressures above ambient, e.g., $230 \mathrm{kPa}_{\mathrm{a}}$ is the current recommended operating pressure for conductivity measurements at $120{ }^{\circ} \mathrm{C}$. Pressurized operation poses significant safety hazards because unintended loss of pressure due to failure of a gas transfer line, fitting or seal results in explosive release of superheated steam. A further hazard is the potential release of hydrogen in the event of a pressure loss.

Because of the safety issues involved with pressurized operation at elevated temperatures, the MTS gas handling system includes the following features,

- All gas handling components that must operate at elevated temperature are made from stainless steel with the exception of a $0.5 \mathrm{~m}$ section of stainless steel braid reinforced flexible line that connects the exit of the MTS test chamber to a force-air radiator. (The pressure rating of the braid-reinforced plastic line is $1500 \mathrm{psi}$ at $150^{\circ} \mathrm{C}$, which far exceeds the operating condition).

- The back pressure regulator used to control the system pressure has a maximum operating temperature of $\sim 60{ }^{\circ} \mathrm{C}$. Therefore, the gas must be cooled to at least that temperature prior to reaching the regulator. This is achieved with a $1000 \mathrm{~W}$ forced-air radiator. Tests confirm that the temperature of the gas exiting the radiator is near ambient.

- A stainless steel water collection vessel.

- Alarm outputs that when triggered cause the set-points of all temperature controllers to be set to ambient $\left(20^{\circ} \mathrm{C}\right)$. The alarm is triggered in the event of,

o Detection of a combustible gas $\left(\mathrm{H}_{2}\right)$ via an integrated combustion sensor,

o Low water level condition in the humidifier tank via an internal float switch, or

o Loss of inlet gas pressure.

\section{Environmental Control System - Temperature, $\mathrm{RH}$ and Pressure}

During the development process, modifications to the wet-dry gas handling system were made with the objective of improving the accuracy and stability of the gas $\mathrm{RH}$ over the required temperature, dew point and pressure operation. In particular, we did extensive testing and analysis of the system for accurate, reproducible and stable high $\mathrm{RH}$ (> $90 \%$ ). $\mathrm{RH}$ control at values greater than $90 \%$ is a challenge because of increased likelihood of condensation within the cell chamber and the humidity-dependence of the gas temperature.

Evaluation of the first generation of the prototype MTS indicated stable and repeatable control of the gas and membrane specimen temperature and relative humidity $(\mathrm{RH})$ to better than $\pm 0.5{ }^{\circ} \mathrm{C}$ and $\pm 2 \% \mathrm{RH}$ for $\mathrm{RH}$ between $20 \%$ and $90 \%$, respectively, at $80{ }^{\circ} \mathrm{C}$.

Figure 27 shows the measured specimen and gas temperature, dew point and calculated $\mathrm{RH}$ during a typical $\mathrm{RH}$-step cycle. The nominal $\mathrm{RH}$ sequence was $80 \%$ to $20 \%$ to $100 \%$ to $80 \% \mathrm{RH}$ at $10 \%$ intervals. Each step consists of a 15 min membrane pre-conditioning period followed by a $3.5 \mathrm{~min}$ impedance measurement. Table 2 
summarizes the environment data - temperature, dew point and $\mathrm{RH}$ - for the stepseries shown in Figure 27.

Figure 28 demonstrates the $\mathrm{RH}$ performance of the first generation of the prototype MTS. For the range $20 \%$ to $90 \%$, the $\mathrm{RH}$ can generally be controlled absolutely to within $\pm 2 \%$ and the temperature of the electrode to within $\pm 0.3{ }^{\circ} \mathrm{C}$. Figure 27 and Figure 28 demonstrate the difficulty in developing high $\mathrm{RH}(>90 \%)$ in a controlled manner.

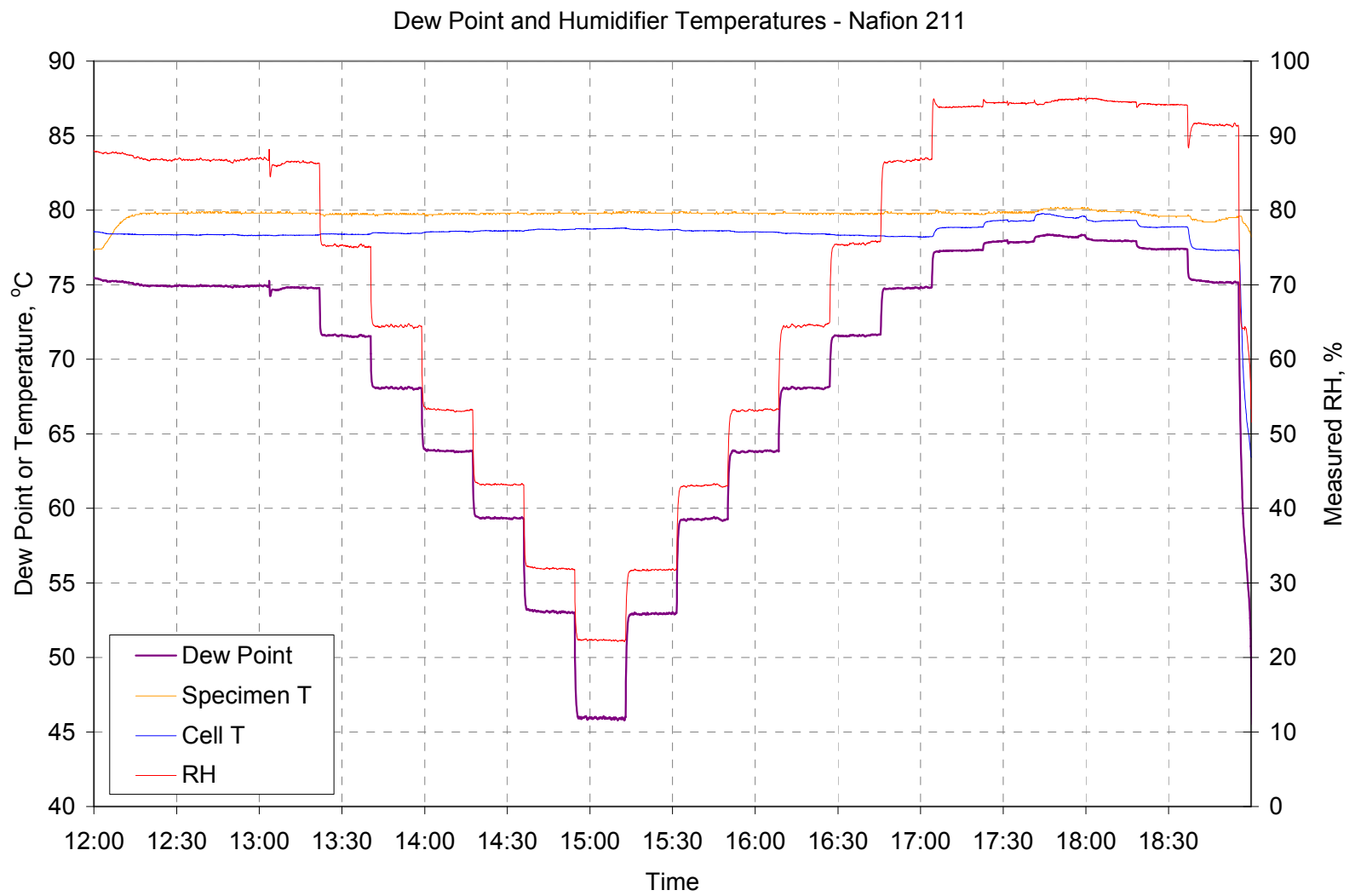

Figure 27. Specimen temperature, and gas temperature, dew point and RH during RH-step cycle. Nominal Sequence: $80 \%$ to $20 \%$ to $100 \%$ to $80 \%$ RH. Note that controlled RH $>90 \%$ is not currently possible with the wet-dry gas handling system. The duration of each step is approximately 18.5 min: 15 min pre-conditioning period followed by 3.5 min resistance measurement. 
Table 2. Summary of RH step cycle. Values are the average over the last $3 \mathrm{~min}$ of each step interval.

\begin{tabular}{|c|c|c|c|c|c|c|c|}
\hline \multirow{2}{*}{$\#$} & \multirow{2}{*}{ \% } & Nominal & \multicolumn{2}{|c|}{ Cell Gas (Vaisala) } & \multicolumn{2}{c|}{ Specimen } \\
\cline { 5 - 8 } & $\mathbf{W e t}$ & $\mathbf{R H}, \%$ & $\mathbf{R H}, \%$ & $\mathbf{D P},{ }^{\circ} \mathbf{C}$ & $\mathbf{T}_{\text {Gas }}{ }^{\circ} \mathbf{C}$ & $\mathbf{T},{ }^{\circ} \mathbf{C}$ & $\mathbf{R H}, \%$ \\
\hline 1 & 68 & 80 & 86.4 & 74.8 & 78.3 & 79.8 & 81.4 \\
\hline 2 & 55 & 70 & 75.3 & 71.6 & 78.4 & 79.7 & 71.2 \\
\hline 3 & 44 & 60 & 64.3 & 68.0 & 78.5 & 79.7 & 61.1 \\
\hline 4 & 34 & 50 & 53.1 & 63.8 & 78.6 & 79.8 & 50.5 \\
\hline 5 & 26 & 40 & 43.2 & 59.3 & 78.6 & 79.8 & 41.1 \\
\hline 6 & 18 & 30 & 31.9 & 53.0 & 78.7 & 79.8 & 30.5 \\
\hline 7 & 12 & 20 & 22.3 & 45.9 & 78.8 & 79.8 & 21.3 \\
\hline 8 & 18 & 30 & 31.8 & 52.9 & 78.7 & 79.8 & 30.4 \\
\hline 9 & 26 & 40 & 43.0 & 59.3 & 78.6 & 79.8 & 41.0 \\
\hline 10 & 34 & 50 & 53.2 & 63.8 & 78.5 & 79.8 & 50.6 \\
\hline 11 & 44 & 60 & 64.4 & 68.0 & 78.4 & 79.8 & 60.9 \\
\hline 12 & 55 & 70 & 75.8 & 71.6 & 78.3 & 79.8 & 71.3 \\
\hline 13 & 68 & 80 & 86.9 & 74.8 & 78.2 & 79.8 & 81.5 \\
\hline 14 & 83 & 90 & 93.9 & 77.3 & 78.8 & 79.8 & 90.5 \\
\hline 15 & 91 & 95 & 94.3 & 77.9 & 79.3 & 79.9 & 92.2 \\
\hline 16 & 100 & 100 & 94.9 & 78.2 & 79.5 & 80.1 & 92.7 \\
\hline 17 & 91 & 95 & 94.5 & 77.9 & 79.3 & 79.9 & 92.3 \\
\hline 18 & 83 & 90 & 94.1 & 77.4 & 78.9 & 79.6 & 91.4 \\
\hline 19 & 68 & 80 & 91.3 & 75.1 & 77.3 & 79.5 & 83.5 \\
\hline
\end{tabular}



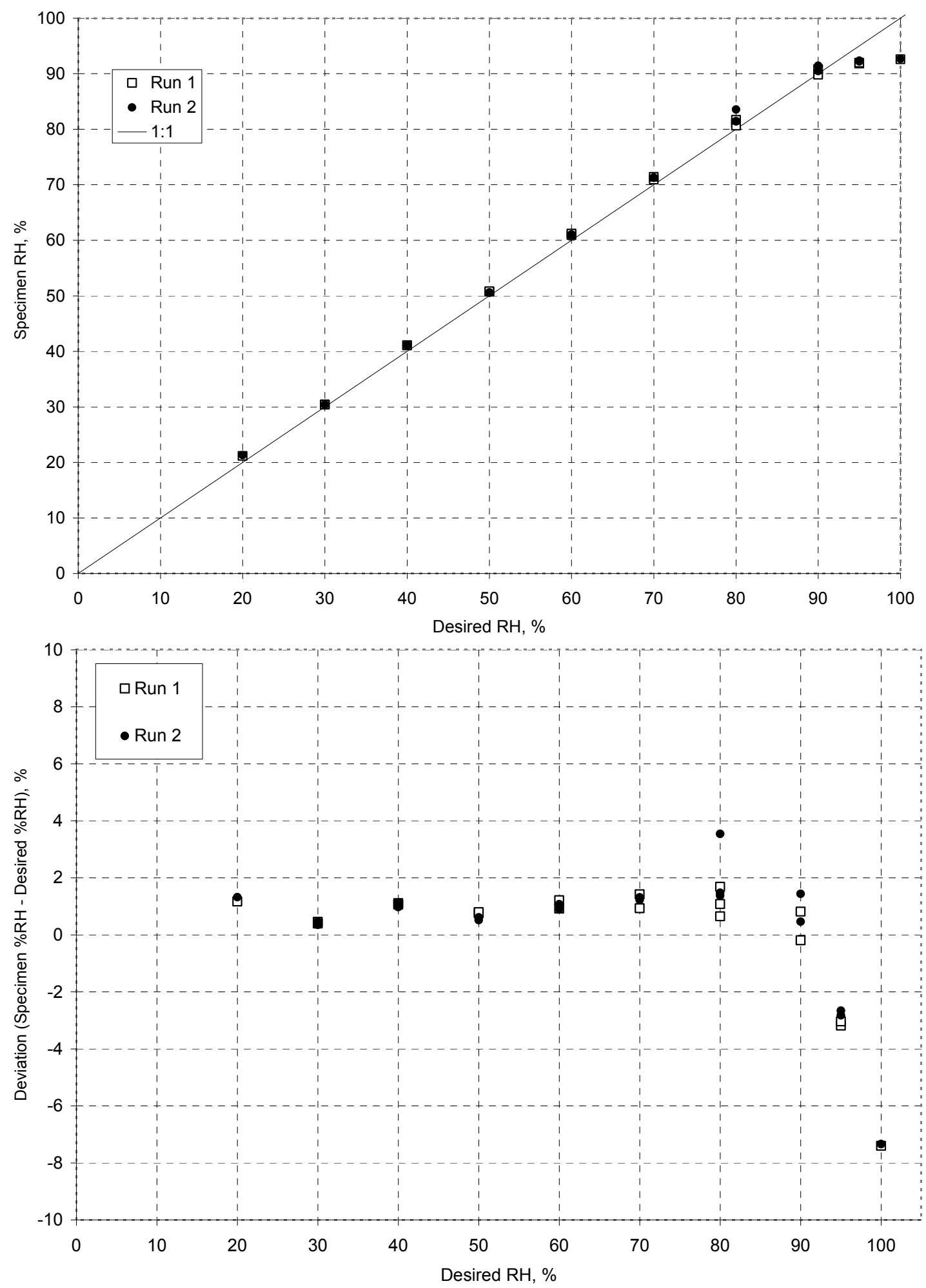

Figure 28. RH performance of wet-dry mixing gas handling system at $80^{\circ} \mathrm{C}$. Top: Specimen RH vs. desired RH. Bottom: Absolute deviation of specimen RH from the desired RH. 
It is not feasible to obtain and control a $100 \% \mathrm{RH}$ environment because by definition this is an unstable operating condition: either the humidity level is less than saturated $(\mathrm{RH}<$ $100 \%$ ) or it exceeds saturation and liquid water is developed within the test chamber and/or on the specimen. The current MTS is capable of producing stable RH to $95 \%$. For this reason, future membrane conductivity testing will be performed up to a maximum of $95 \% \mathrm{RH}$.

\section{2-D potential distribution modeling}

As alluded to earlier, measurement of small resistances are preferably performed with a four-electrode configuration in order to eliminate contact and lead resistance contributions inherent in a two-electrode approach. Scribner developed and evaluated multiple electrode configurations via computational modeling and experimental work.

Scribner contracted with a consultant to perform 2-D steady-state modeling of the potential distribution within thin electrolytes (i.e., ionically conductive membranes) in order ascertain the feasibility of various four-electrode configurations.

The modeling was performed using a commercial finite element modeling software package (FEMLab) as well as a finite difference-based method using code developed by the consultant. The advantage of the finite difference approach is that a finer mesh size can be employed which provides higher spatial resolution of the potential distribution. The potential distribution profiles generated by both modeling approaches were identical for two test cases (a constant current and a constant voltage case) and so further modeling employed the finite difference-based method.

Two distinct electrode configurations were considered. Potential distribution modeling results of the first design revealed that it would not be suitable for accurate throughplane membrane conductivity measurement if manufacture of the electrode was restricted to traditional machining methods. Micromachining and/or lithographic techniques would be required, both of which are prohibitively costly.

Model results supported an alternate concept developed by Scribner for an electrode configuration that would enable true four-probe through thickness conductivity measurement of thin solid electrolytes. The modeling results confirmed that the electrode concept would be effective for a wide range of membrane conductivity $\left(<10^{-3}\right.$ to $0.1 \mathrm{~S} / \mathrm{cm})$ and membrane thickness $(10 \mu \mathrm{m}$ to $500 \mu \mathrm{m})$. Furthermore, it has the advantage of being robust from the stand-point of fabrication tolerance requirements (i.e., extremely strict dimensional and machining tolerances are not required).

Based on the encouraging electrolyte potential distribution model results, we fabricated and evaluated the novel electrodes for the membrane conductivity measurements.

Year 2 focused on continued development of the MTS hardware and system characterization. The $2^{\text {nd }}$ generation prototype is shown in Figure 29. 
Development and Evaluation of MTS Hardware.

1. Installed new wet and dry gas mass flow controllers (MKS) and confirmed performance over full operating range with a digital mass flow meter (Alicat Scientific).

2. Developed optimum MTS temperature operating set-points and evaluated the dew point (DP) and relatively humidity $(\mathrm{RH})$ as a function of the fraction of wet gas using the Vaisala DP probe and cell gas temperature.

3. Anodized test chamber, electrode holder and compression head.

4. Reconfigured dry and wet heated transfer gas lines.

5. Added case-fan for low temperature $\left(30^{\circ} \mathrm{C}\right)$ testing.

6. Developed auto-water feed capability via HPLC pump for continuous $120{ }^{\circ} \mathrm{C}$ operation.

7. Dew point (DP) probe testing,

- Factory calibration of DP probe.

- Checked factory calibration in-house with saturated salts at $~ 11 \%$, $50 \%$ and $75 \% \mathrm{RH}$.

- Evaluated DP probe performance with different probe heat settings.

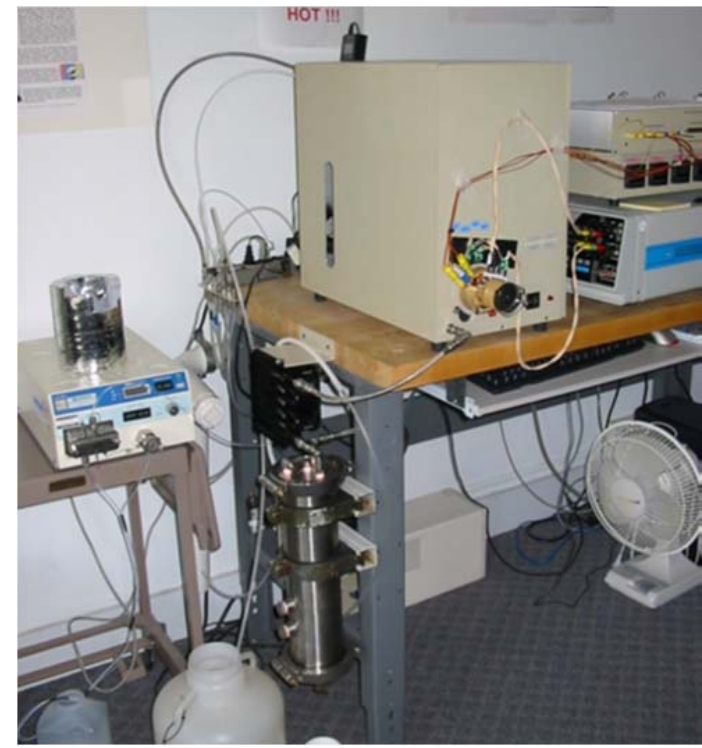

Figure 29. Second generation prototype of the through-plane membrane resistance measurement system where the cell chamber is incorporated into the rest of the instrument. Note the multiple thermocouples for temperature measurement at various locations and the external radiator.

Performed water balance analysis for dew point / $\mathrm{RH}$ verification at $120^{\circ} \mathrm{C}, 230 \mathrm{kPa}$.

A water mass balance analysis was performed to evaluate the accuracy of the Vaisala DP probe and to characterize the performance of the humidification system at $120^{\circ} \mathrm{C}$, $230 \mathrm{kPa}$. Verification of the humidifier performance and/or probe DP data is particularly important at $120^{\circ} \mathrm{C}$ where the predicted DP / RH deviate from the DP reported by the probe and because the probe is only rated for measurement of $\mathrm{DP}<100^{\circ} \mathrm{C}$. At $120^{\circ} \mathrm{C}$, a DP of $100{ }^{\circ} \mathrm{C}$ corresponds to only $\sim 35 \% \mathrm{RH}$ and therefore another means was 
required to verify the performance of the gas humidification system at higher humidity levels at this temperature.

Briefly, the procedure consisted of measuring the amount of water consumed from the humidifier tank and measuring the amount of water collected in the condensation tank over a known duration. The analysis also accounted for the amount of water in the postcondenser exist gas, which was assumed to be saturated in water vapor at $25^{\circ} \mathrm{C}, 100$ $\mathrm{kPa}$. The amount of water consumed and collected was used to back-calculate the timeaveraged $\mathrm{RH}$ and dew point of the gas during the test. This was done for five different $\%$ wet settings.

Replicate measurements were performed for four \% wet set points $(3,12,50$ and $100 \%)$ and one measurement at $35 \%$ wet. The test duration was such that the amount of water collected / consumed was at least three times greater than the accuracy with which the amount of water collected / consumed could be determined.

The results are presented in Table 3 and Figure 30.

The results indicate that the actual $\mathrm{RH}$, based on the water balance results, was very close to the predicted or theoretical $\mathrm{RH}$, which was based on the percent wet setting and known saturated water vapor - temperature - pressure relationships. At \% wet settings $>12 \%$, the actual DP was within $+/-1{ }^{\circ} \mathrm{C}$ of the theoretical DP. For the $12 \%$ wet condition, the actual DP was also close to the theoretical DP, although the discrepancy was as much as $4{ }^{\circ} \mathrm{C}$. These results indicate that for $\%$ wet setting $>10 \%$, the humidification system performs nearly ideally and that using theoretical wet-dry ratio settings results in actual DP and RH conditions very close to predicted.

Near-ideal performance of the MTS humidification system did not hold true for the $3 \%$ wet setting. As indicated in Table 3 , we predict a DP $=73.8^{\circ} \mathrm{C}$. However, for this $\%$ wet setting, the Vaisala probe reported DP $=57.5^{\circ} \mathrm{C}$ and the water balance indicated that the actual DP was $60.8+/-1.4^{\circ} \mathrm{C}$ (range $59.4-62.4^{\circ} \mathrm{C}$ ). This is a significant deviation from the predicted value.

Figure 30 reveals that $\mathrm{RH}$ is a strong function of and is very sensitive to changes in \% wet for the small \% wet region (lower left portion of graph). That is, small errors in the flow rate of gas through the humidifier or in the humidifiers performance will result in large deviation in the actual $\mathrm{RH}$ from the theoretical $\mathrm{RH}$. Sub-ideal performance of the humidification system at low $\%$ wet settings can be compensated for by using greater than theoretical \% wet settings.

Two key conclusions from the water mass balance tests at $120^{\circ} \mathrm{C}$ are:

1. The Vaisala probe is accurate for $\mathrm{DP}<100^{\circ} \mathrm{C}$.

2. The MTS humidification system performs nearly ideally for $\%$ wet settings greater than about $10 \%$ but deviates to lower-than-expected humidity levels for \%wet settings less than this amount. 
MTS Percent Wet vs. RH based on Water Balance at $120^{\circ} \mathrm{C}, 230 \mathrm{kPa}$

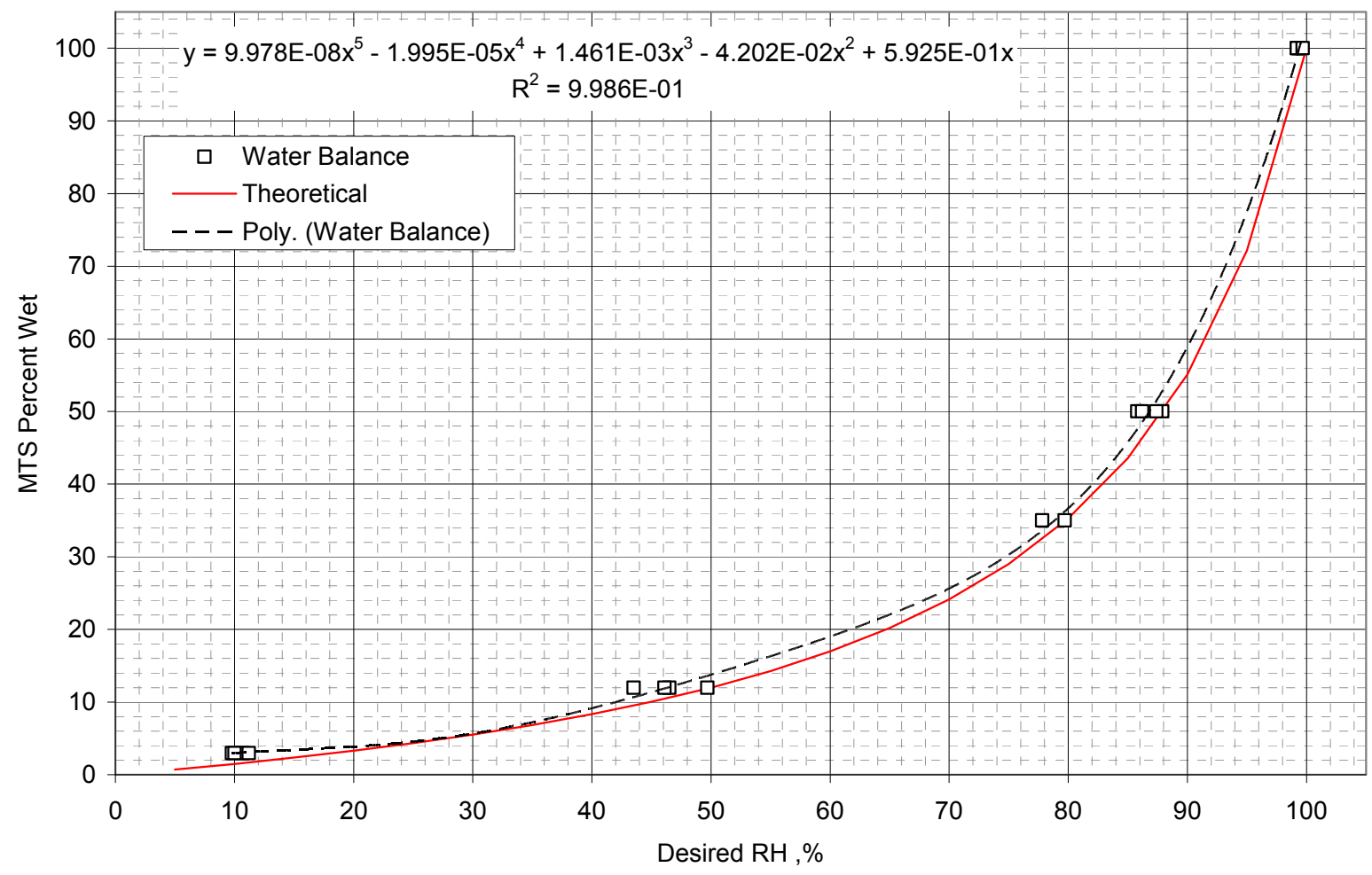

Figure 30. Comparison of the actual RH as determined by water balance vs. the MTS percent wet setting. 
Table 3. Results of water balance analysis for determination of the dew point (DP) and RH at $120^{\circ} \mathrm{C}, 230 \mathrm{kPa}$.

\begin{tabular}{|c|c|c|c|c|c|c|c|c|c|c|c|c|}
\hline \multirow[b]{3}{*}{$\begin{array}{c}\text { Test } \\
\#\end{array}$} & \multirow[b]{3}{*}{$\begin{array}{c}\text { MTS } \\
\% \text { Wet }\end{array}$} & \multirow[b]{3}{*}{\begin{tabular}{|c} 
Theoretical \\
DP, ${ }^{\circ} \mathrm{C}$
\end{tabular}} & \multirow[b]{3}{*}{$\begin{array}{l}\text { Vaisala } \\
\mathrm{DP},{ }^{\circ} \mathrm{C}\end{array}$} & \multirow[b]{3}{*}{$\begin{array}{l}\text { Time, } \\
\text { min }\end{array}$} & \multicolumn{8}{|c|}{ Water Balance } \\
\hline & & & & & \multicolumn{4}{|c|}{ Actual Consumption } & \multicolumn{4}{|c|}{ Actual Collection (adjusted for loss to exit) } \\
\hline & & & & & $\mathrm{mL}$ & $\mathrm{mL} / \mathrm{min}$ & $\begin{array}{l}\text { Actual } \\
\mathrm{RH}, \%\end{array}$ & $\begin{array}{l}\text { Actual } \\
\mathrm{DP},{ }^{\circ} \mathrm{C}\end{array}$ & $\mathrm{mL}$ & $\mathrm{mL} / \mathrm{min}$ & $\begin{array}{l}\text { Actual } \\
\mathrm{RH}, \%\end{array}$ & $\begin{array}{c}\text { Actual DP, } \\
{ }^{\circ} \mathrm{C}\end{array}$ \\
\hline 10 & 3 & 73.8 & 57.5 & 1104.5 & 40.73 & 0.037 & 9.8 & 59.4 & 42.23 & 0.038 & 10.0 & 59.9 \\
\hline 11 & 3 & 73.8 & 58.5 & 497.5 & 20.39 & 0.041 & 10.7 & 61.4 & 21.58 & 0.043 & 11.2 & 62.4 \\
\hline 4 & 12 & 99.4 & 96.5 & 182.5 & 49.03 & 0.269 & 46.5 & 97.4 & 55.03 & 0.302 & 49.7 & 99.3 \\
\hline 5 & 12 & 99.4 & 95.5 & 180.5 & 47.78 & 0.265 & 46.1 & 97.1 & 43.52 & 0.241 & 43.5 & 95.5 \\
\hline 3 & 35 & 113.0 & 115.7 & 90.5 & 80.45 & 0.889 & 79.7 & 113.0 & 74.35 & 0.822 & 77.8 & 112.2 \\
\hline 8 & 50 & 116.0 & 121.0 & 63.0 & 79.93 & 1.269 & 87.9 & 116.0 & 72.55 & 1.152 & 85.8 & 115.2 \\
\hline 9 & 50 & 116.0 & 121.0 & 64.0 & 79.33 & 1.240 & 87.4 & 115.8 & 74.8 & 1.169 & 86.2 & 115.7 \\
\hline 6 & 100 & 120.0 & -- & 34.0 & 81.53 & 2.398 & 99.2 & 119.7 & 81.51 & 2.397 & 99.2 & 119.7 \\
\hline 7 & 100 & 120.0 & -- & 33.5 & 81.96 & 2.447 & 99.4 & 119.8 & 83.38 & 2.489 & 99.7 & 119.9 \\
\hline
\end{tabular}


Developed method and performed process control study of the dimensions of disposable porous electrode material used in through-thickness conductivity test.

The through-plane membrane conductivity tester uses a porous, compressible electrode material, e.g., E-TEK's ELAT ${ }^{\circledR}$ gas diffusion electrode (GDE) media. Each test requires a pair of the GDE of the appropriate dimensions. Because the effective cross-sectional area is defined in part by the GDE width, the reproducibility of the dimensions of the GDE material is of interest.

A die was used to cut 85 samples of GDE. The length and width of the GDE were optically measured using a stage micrometer (KR-812, Klarmann Rulings, Inc.). The micrometer had a resolution of $0.02 \mathrm{~mm}(20 \mu \mathrm{m}, 0.8 \mathrm{mil})$. The focus here is on the analysis of width as opposed to the length of the GDE piece.

Table 4 and Table 5 summarize the results of the process control study for die cutting of the disposable GDE layer.

Within-sample variation in width was examined by making five measurements along the length of a GDE. This was repeated for five different samples of GDE (labeled A - E). These results along with measurements of the die width are summarized in Table 4. The statistical parameters (mean, etc.) for the GDE were comparable to that of the die, indicating that the cut pieces of GDE are no less uniform than the variation in die dimensions. The widths of the GDE samples closely match those of the cutting die.

Table 5 summarizes the results of dimension measurements performed on 85 pieces of GDE. Here, only a single length and width measurement were made per sample. Again the focus is on the results of the width measurements. As with the results presented in Table 2, the distribution in width dimension is narrow. The tight distribution is exemplified by the fact that the standard deviation $(0.017 \mathrm{~mm})$ is small relative to the mean $(5.01 \mathrm{~mm})$, which corresponds to a relative standard deviation (RSD) ${ }^{1}$ of only 0.3 $\%$. (RSD on the length was also $0.3 \%$ ). RSD is an indication of how tight or broad a distribution is.

The key conclusion of this study is that die cut samples are uniform in dimension and reproducible from sample-to-sample.

\footnotetext{
${ }^{1} \mathrm{RSD}=$ standard deviation $/$ mean $\times 100 \%$
} 
Table 4. Multiple width measurements long GDE pieces cut with the die. 5 samples (A-E); 5 measurements / sample.

\begin{tabular}{|l|ccccc|c|}
\hline \multirow{2}{*}{ Measurement } & \multicolumn{5}{|c|}{ Width, mm } & \multirow{2}{*}{ Die Width, } \\
\cline { 2 - 6 } & A & B & C & D & E & \\
\hline \multicolumn{1}{|c|}{$\mathbf{1}$} & 4.96 & 4.98 & 4.98 & 4.98 & 4.96 & 4.98 \\
$\mathbf{2}$ & 5.00 & 5.02 & 5.02 & 5.00 & 5.00 & 5.00 \\
$\mathbf{3}$ & 5.02 & 5.02 & 5.02 & 5.02 & 5.02 & 5.02 \\
$\mathbf{4}$ & 5.02 & 5.02 & 5.02 & 5.00 & 5.02 & 5.00 \\
$\mathbf{5}$ & 5.02 & 5.00 & 5.00 & 4.98 & 5.00 & 4.96 \\
\hline Mean, $\mathbf{~ m m}$ & 5.00 & 5.01 & 5.01 & 5.00 & 5.00 & 4.99 \\
Std. Dev., $\mathbf{m m}$ & 0.03 & 0.02 & 0.02 & 0.02 & 0.02 & 0.02 \\
Max., $\mathbf{~ m m}$ & 5.02 & 5.02 & 5.02 & 5.02 & 5.02 & 5.02 \\
Min., $\mathbf{m m}$ & 4.96 & 4.98 & 4.98 & 4.98 & 4.96 & 4.96 \\
Range, $\mathbf{~ m m}$ & 0.06 & 0.04 & 0.04 & 0.04 & 0.06 & 0.06 \\
\hline
\end{tabular}

Table 5. Results of GDE process control study. No. samples $=85,1$ measurement I sample.

\begin{tabular}{|lccc|}
\hline & $\begin{array}{c}\text { Length, } \\
\mathbf{m m}\end{array}$ & $\begin{array}{c}\text { Width, } \\
\mathbf{~ m m}\end{array}$ & $\begin{array}{c}\text { Area } \mathbf{( L = 1} \mathbf{~ c m}), \\
\mathbf{c m}^{\mathbf{2}}\end{array}$ \\
\hline $\begin{array}{l}\text { Mean, } \mathbf{m m} \\
\text { Std Dev., }\end{array}$ & 17.98 & 5.01 & 0.501 \\
mm & 0.052 & 0.017 & 0.002 \\
Max., $\mathbf{m m}$ & 18.04 & 5.04 & 0.504 \\
Min., $\mathbf{m m}$ & 17.70 & 4.96 & 0.496 \\
Range., $\mathbf{m m}$ & 0.34 & 0.08 & 0.008 \\
\hline
\end{tabular}

With the majority of the hardware system development completed in the first two program years, Year 3 focused on the measurement or test procedure.

\section{Test Procedure}

Experimental work during Year 3 focused on development of the test procedure for accurate through-thickness membrane conductivity measurement. This included attempts to identify the source of the lower conductivity observed during the initial $30^{\circ} \mathrm{C}$ - $\mathrm{RH}$ cycle series in comparison to the $30^{\circ} \mathrm{C}-\mathrm{RH}$ series performed after testing at 80 ${ }^{\circ} \mathrm{C}$ and $120{ }^{\circ} \mathrm{C}$. Recall that the procedure calls for conducting the $\mathrm{RH}$ cycle at the following temperatures: $30^{\circ} \mathrm{C}(\# 1) \rightarrow 80^{\circ} \mathrm{C} \rightarrow 30^{\circ} \mathrm{C}(\# 2) \rightarrow 120^{\circ} \mathrm{C} \rightarrow 30^{\circ} \mathrm{C}(\# 3)$.

Based on discussion with DuPont, it was hypothesized that because the as-received Nafion membrane is in a very dry condition (essentially dehydrated) and stored at ambient conditions, that the membrane is not hydrated at $30^{\circ} \mathrm{C}$ to the same degree that it does when subsequently exposed to the humid environment at elevated temperature, e.g., $80^{\circ} \mathrm{C}$ and $120^{\circ} \mathrm{C}$. That is, after exposure to the $80^{\circ} \mathrm{C}$ or $120^{\circ} \mathrm{C}$ condition, the 
membrane maintains higher water content when subsequently tested at $30{ }^{\circ} \mathrm{C}$ (\#2 and \#3) than when tested for the first time at $30{ }^{\circ} \mathrm{C}$. The higher water content in the membrane during the $2^{\text {nd }}$ and $3^{\text {rd }} \mathrm{RH}$ cycles conducted at $30{ }^{\circ} \mathrm{C}$ results in high conductivity observed for those tests than the initial test performed at the same temperature.

To test this hypothesis, samples of Nafion were boiled for 30 minutes in high-purity water prior to immediately assembling the membrane into the MTS test fixture and testing according the standard protocol. This was performed for NRE-211, NRE-212 and Nafion 115. The results are shown in Figure 31 through Figure 33. Note that here the conductivity is shown during the increasing $\mathrm{RH}$ portion of the $\mathrm{RH}$ cycle test (from $20 \%$ to $95 \% \mathrm{RH}$ ). This was done for clarity of presentation of the data.

Unfortunately, the results were inconclusive. For the NRE-212 sample (Figure 31) an effect of boiling the sample prior to testing was not apparent at low RH. However, at higher $\mathrm{RH}$, the observed conductivity approached that normally observed only after exposing the membrane to $80^{\circ} \mathrm{C}$. That is, for a boiled NRE-212 membrane at $30^{\circ} \mathrm{C}$, the initial conductivity was considerably less than after exposure to $80^{\circ} \mathrm{C}$ at low $\mathrm{RH}$ but not at high $\mathrm{RH}$.

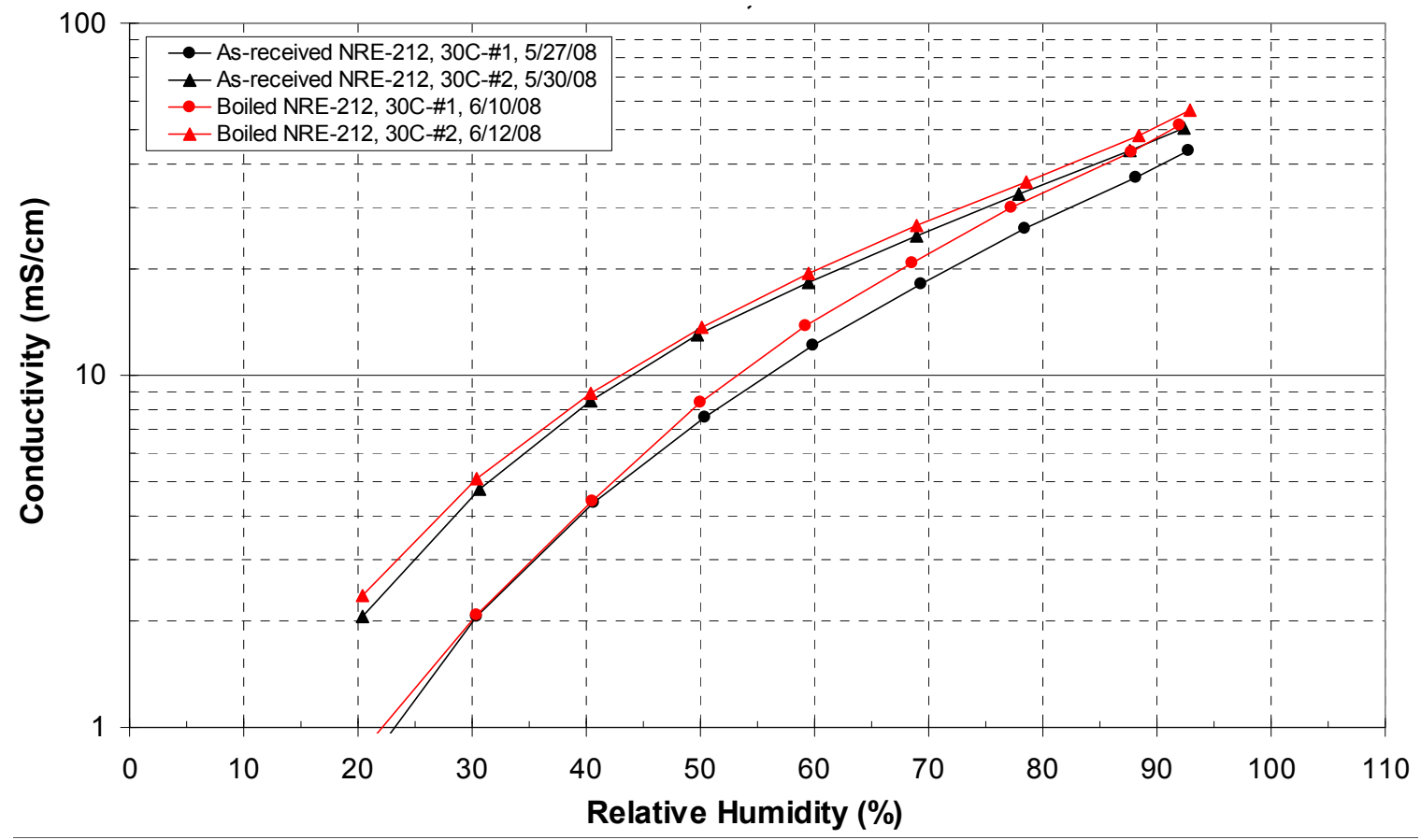

Figure 31. Conductivity of as-received (black) and pre-boiled (red) Nafion NRE-212 at $30^{\circ} \mathrm{C}$ before $(\# 1, O)$ and after $(\# 2, \Delta)$ testing at $80^{\circ} \mathrm{C}$ (not shown). For the initial test at $30^{\circ} \mathrm{C}$, boiling did not affect the conductivity test at low humidity but did result in an increased conductivity at high $\mathrm{RH}$, i.e., the conductivity was the same as the post $-80^{\circ} \mathrm{C}$ test $\left(30^{\circ} \mathrm{C}-\# 2\right)$.

Similar to the results with NRE-212, the boiled NRE-211 sample (Figure 32) exhibited some improvement in the initial $30{ }^{\circ} \mathrm{C}$ conductivity in that it was greater than the initial 
conductivity of as-received samples but that the conductivity was less than when tested after elevated temperature exposure. As with the NRE-212 sample, the initial $30{ }^{\circ} \mathrm{C}$ conductivity of the boiled membrane was similar to that of the as-received membrane at low $\mathrm{RH}$ but had higher conductivity at higher $\mathrm{RH}$, approaching that of a sample tested after the $80^{\circ} \mathrm{C}$ exposure.

Finally, as shown in Figure 33, the boiled N115 sample exhibited similar conductivity initially as when tested after the $80^{\circ} \mathrm{C}$. In addition, the initial conductivity at $30^{\circ} \mathrm{C}$ for the boiled sample was considerably higher than the initial $30{ }^{\circ} \mathrm{C}$ conductivity of the asreceived material.

The conductivity data for a boiled sample of NRE-212, shown in Figure 32, indicates that the pre-hydration did not alter the $\mathrm{RH}$-dependent conductivity. That is, the response of the membrane to $\mathrm{RH}$ changes was the same for the boiled sample as for the asreceived sample. In addition, there was no observable effect of boiling on measured conductivity at either $80^{\circ} \mathrm{C}$ or at $30^{\circ} \mathrm{C}$ after higher temperature test.

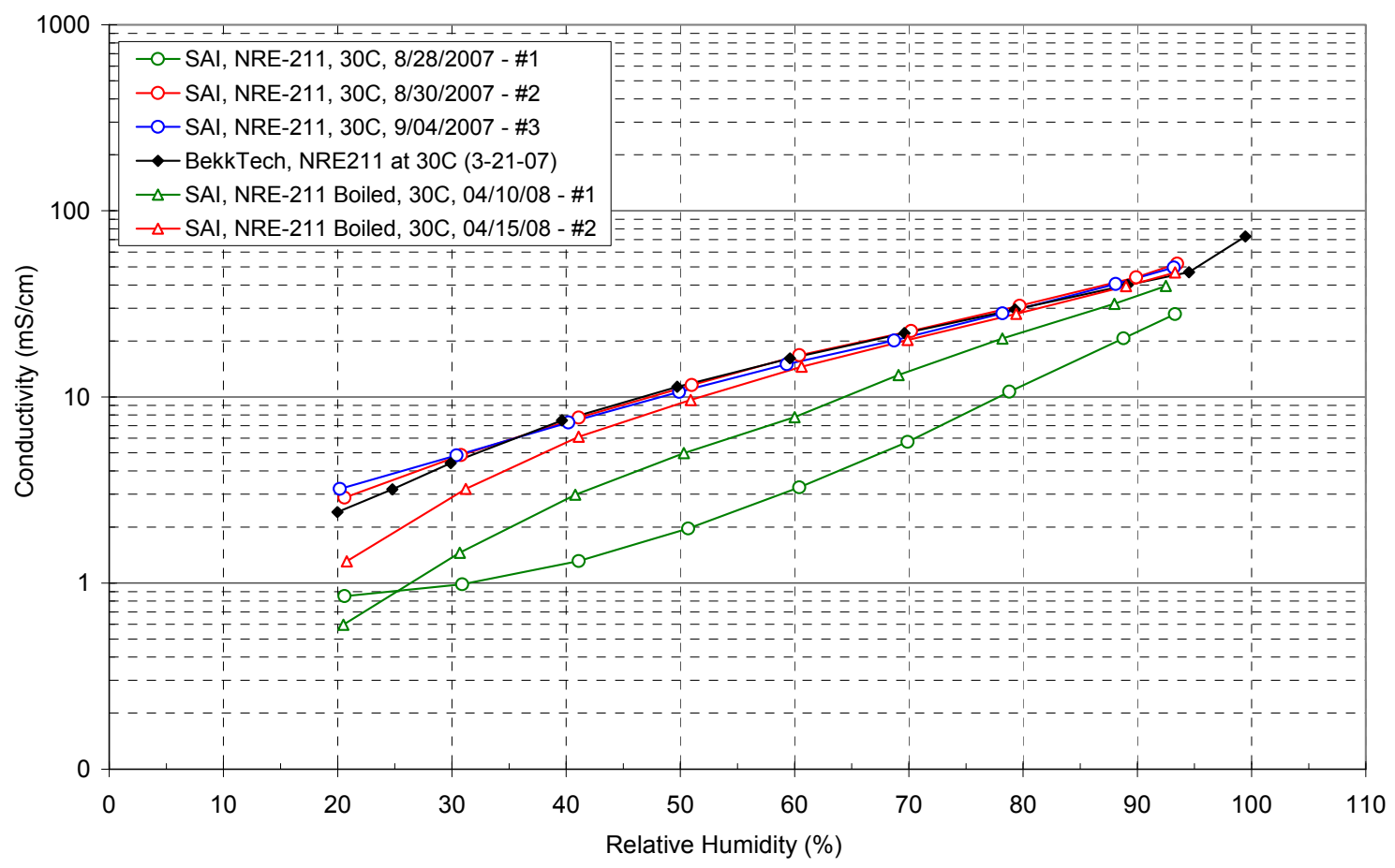

Figure 32. Conductivity of as-received $(O)$ and boiled $(\Delta)$ Nafion NRE-211 at $30^{\circ} \mathrm{C}$ before (\#1) and after testing at $80^{\circ} \mathrm{C}(\# 2)$ and $120^{\circ} \mathrm{C}(\# 3)$. The boiled sample exhibited greater conductivity for the initial $30^{\circ} \mathrm{C}(\# 1)$ trial when compared to the as-received sample but lower conductivity then when tested post $80^{\circ} \mathrm{C}$ and $120^{\circ} \mathrm{C}$ exposure (\#2 and \#3, respectively). After exposure to elevated temperature, the measured conductivity was the same for the as-received and pre-boiled membrane.

It is unclear why boiling the membrane would impact the conductivity at high $\mathrm{RH}$ but not (or less so) at low $\mathrm{RH}$ during the initial testing at $30{ }^{\circ} \mathrm{C}$. The somewhat contradictory 
results on the effect of pre-hydrating the Nafion make drawing conclusions from this study problematic. The results suggest that a low water content of the membrane during the initial testing at $30^{\circ} \mathrm{C}$ is not the sole source of the initial low conductivity. Additional experiments to identify more conclusively the source of the low conductivity observed during the initial low temperatures $\mathrm{RH}$ cycle would need to be conducted.

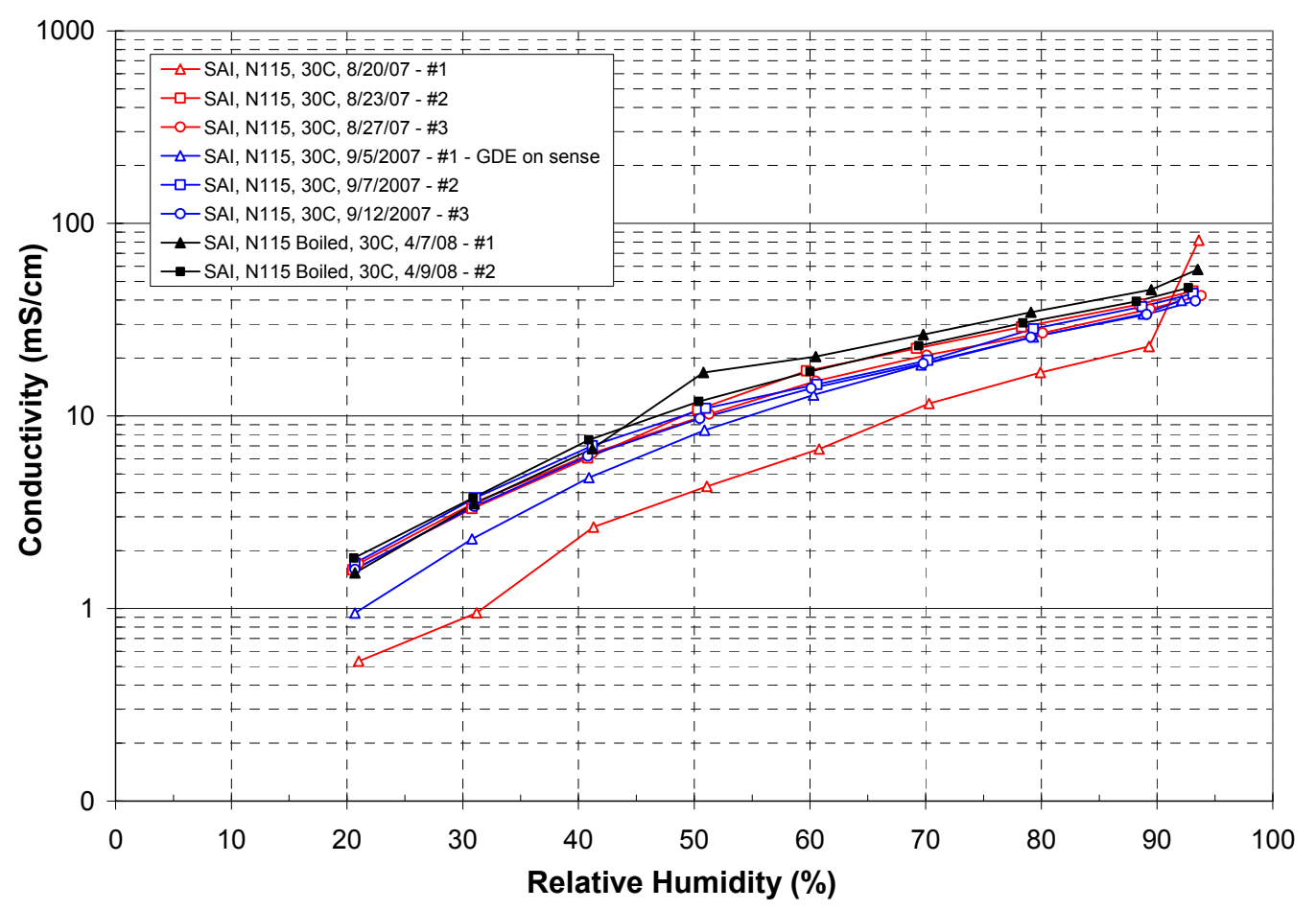

Figure 33. Conductivity of as-received (red and blue) and boiled (black) Nafion 115 at $30^{\circ} \mathrm{C}$ before (\#1) and after testing at $80^{\circ} \mathrm{C}(\# 2)$ and $120^{\circ} \mathrm{C}(\# 3)$. The pre-boiled sample exhibited conductivity for the initial $30^{\circ} \mathrm{C}(\# 1)$ run similar to that when tested post $80^{\circ} \mathrm{C}$ and $120^{\circ} \mathrm{C}$ exposure (\#2 and \#3, respectively). This contrasted to the samples which were tested in the as-received condition for which the conductivity during the initial $30^{\circ} \mathrm{C}$ run was lower than in subsequent runs. After the elevated temperature, all of the samples exhibited similar conductivity.

\section{Development of Cell Resistance}

This work focused on determining the cell area specific resistance ASR $\left(R_{\text {cell }}, \Omega-\mathrm{cm}^{2}\right)$ for each test condition (temperature and $\mathrm{RH}$ ) used in the protocol. Because $R_{\text {cell }}$ may include a component that is a function of temperature and humidity, it should be determined for each condition, i.e., $R_{\text {cell }}(\mathrm{T}, \mathrm{RH})$.

Once $R_{\text {cell }}(T, R H)$ is known, determination of the sample resistance, $R_{\text {sample }}(T, R H)$ and conductivity, $\sigma_{\text {sample }}(T, R H)$ for each test condition follows:

$$
\begin{aligned}
& R_{\text {sample }}(T, R H)=R_{H F}(T, R H)-R_{\text {cell }}(T, R H) \\
& \sigma_{\text {sample }}(T, R H)=\frac{l}{R_{\text {sample }}(T, R H)}
\end{aligned}
$$


where $I$ is the thickness of the membrane and $R_{H F}$ is the high frequency intercept determined from the impedance measurement.

The test matrix consists of three (3) samples of each of the following membranes:

Nafion 111

Nafion 112

Nafion 1135

Nafion 115

Nafion 117

Initially, triplicate measurements for each membrane will be used to develop a statistical-based evaluation of $R_{\text {cell }}(T, R H)$. Additional replicates will be tested as necessary

Assumptions in the analysis are:

The intrinsic conductivity of Nafion is independent of thickness

At a given test condition ( $T, R H), R_{\text {cell }}$ is constant from test sample to test sample

$R_{\text {cell }}(T, R H)$ is independent of sample type and can be applied to non-Nafion membranes.

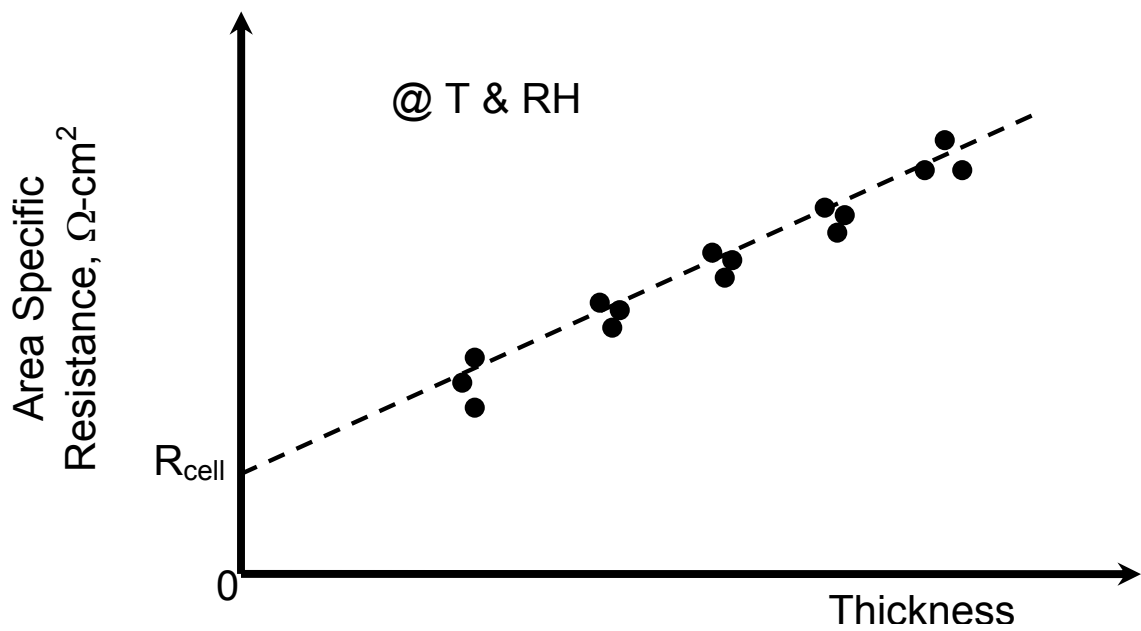

Figure 34. Illustration of the concept behind the resistance vs. membrane thickness study for determination of $\mathbf{R}_{\text {cell }}(T, R H)$.

\section{Procedure for Determination of the Sample Effective Cross-sectional Area}

Data analysis has assumed that the effective-cross sectional area for the throughthickness membrane resistance and conductivity measurement were based on the nominal design values $\left(0.5 \mathrm{~cm}^{2}\right)$. Development of a method to determine the effective area based on image analysis of photographs of the post-test sample was begun. 
Year 4 focused on continued development of the measurement procedure, determination of the cell resistance $R_{\text {cell }}$ and testing of HTM Program Topic 2 member samples. In all cases, written reports and data were submitted to FSEC-UCF.

\begin{tabular}{lcl}
\hline Designation & No. samples tested & Status \\
\hline A1-FESC1 & 3 & Report and data provided 4/1/2010 \\
B1-FSEC4 & 2 & Report and data provided 4/6/2010 \\
D1-FSEC12 & 1 & Report and data provided 4/8/2010 \\
D4-FSEC17 & 1 & Report and data provided 5/7/2010 \\
CCM 022610 Low & 1 & Report and data provided 5/19/2010 \\
CCM 022610 Mid & 1 & Report and data provided 5/19/2010 \\
U Arizona-\#1 & 1 & Report and data provided 7/23/2010 \\
D1-FSEC-12 & 1 & Report and data provided 4/13/2010 \\
D4-FSEC-17 & 1 & Report and data provided 5/07/2010
\end{tabular}

For the following samples, Scribner performed in-plane and through-plane evaluation.

\begin{tabular}{|c|c|c|c|}
\hline$\underline{\text { Membrane ID }}$ & Testing & Temperature, ${ }^{\circ} \mathrm{C}$ & $\underline{\text { Report Date }}$ \\
\hline B9-FSEC-30 & $\mathrm{TP}$ & $30,80,120$ & $4 / 26 / 2011$ \\
\hline A5-FSEC-21 & IP, TP & $30,80,120$ & 9/1/2011 \\
\hline B7-FSEC-22 & IP, TP & $30,80,120$ & 9/1/2011 \\
\hline B10-FSEC-31 & IP, TP & $30,80,120$ & 9/1/2011 \\
\hline
\end{tabular}

D8-FSEC-25

Found to be too brittle to successfully test. Attempts to treat the provided material to make it less brittle so that it could be loaded in the in-plane and through-plane test fixtures were not successful.

$\begin{array}{llll}\text { D11-FSEC-40 } & \text { IP, TP } & \text { 30, 80, } 120 & 3 / 5 / 2012 \\ \text { Vanderbilt } & & & 1 / 31 / 2012 \\ \text { 092211-\#1-M2 } & \text { TP } & 120 & \\ \text { 092211-\#2-M4 } & \text { IP } & 120 & \\ \text { 030311-M4-\#1 } & \text { IP } & 120 & \\ \text { 030311-M4-\#2 } & \text { TP } & 120 & \\ \text { 030311-M3-\#1 } & \text { IP } & 120 & \\ \text { 030311-M3-\#2 } & \text { TP } & 120 & \end{array}$




\section{Comparison of conductivity testing, in-plane versus through-plane}

Four samples of as-received commercially-available Nafion ${ }^{\circledR}$ (DuPont) were tested using in-plane and through-plane conductivity testing. The test protocols used for the two measurement methods had similarities and differences as discussed below.

\section{Samples Tested}

Table 6 shows the samples that were tested for in-plane and/or through-plane conductivity.

Table 6. Summary of Nafion ${ }^{\circledR}$ membranes tested for in-plane and/or throughplane conductivity.

\begin{tabular}{|l|l|l|}
\hline Sample & $\begin{array}{l}\text { BekkTech In-Plane } \\
\text { Jan \& Feb 2007 }\end{array}$ & $\begin{array}{l}\text { Scribner Through- } \\
\text { Plane } \\
\text { Aug \& Sep 2007 }\end{array}$ \\
\hline NRE-211 & X & X \\
\hline NRE-212 & X & X \\
\hline NE1035 & X & \\
\hline NE1135 & X & X \\
\hline N117 & X & X \\
\hline N115 & & X \\
\hline
\end{tabular}

The conductivity of Nafion $\AA$ samples tested for both in-plane conductivity by BekkTech, LLC (BekkTech) and for through-plane conductivity by Scribner Associates, Inc. (SAl) are available for comparison:

- NRE-211

- NRE-212

- NE-1135

- $\mathrm{N}-117$

\section{Test Protocol Similarities:}

The relative humidity $(\mathrm{RH})$ set for each data point was the same and held for the same duration (15 minutes at each $\mathrm{RH}$ prior to the membrane resistance measurement). All in-plane and through-plane $30{ }^{\circ} \mathrm{C}$ and $80^{\circ} \mathrm{C}$ tests were conducted at $100 \mathrm{kPa}$ absolute pressure and $120^{\circ} \mathrm{C}$ tests were performed at $230 \mathrm{kPa}$ absolute pressure.

\section{Test Protocol Differences:}

The order of tests and data presentation was different for the two methods. For each of the graphs presented below, test parameters differed as indicated in Table 7.

Table 7. Summary of the comparison of in-plane and through-plane conductivity of Nafion $\otimes$ samples.

\begin{tabular}{|l|l|l|}
\hline Parameter & In-Plane & Thru-Plane \\
\hline Test Sequence & $30^{\circ} \mathrm{C}$ to $80^{\circ} \mathrm{C}$ to $120^{\circ} \mathrm{C}$ & $30^{\circ} \mathrm{C}$ to $80^{\circ} \mathrm{C}$ to $30^{\circ} \mathrm{C}$ \\
\hline
\end{tabular}




\begin{tabular}{|l|l|l|}
\hline & to $120^{\circ} \mathrm{C}$ to $30^{\circ} \mathrm{C}$ \\
\hline Test Continuity & $\begin{array}{l}\text { Continuous test over } \\
\text { approximately 24 hours }\end{array}$ & $\begin{array}{l}\text { Shut-Down after each } \\
\text { temperature over } \\
\text { approximately } 5 \text { days }\end{array}$ \\
\hline $\begin{array}{l}\text { \# of Samples Used in } \\
\text { Data Presented }\end{array}$ & One & Two to five samples \\
\hline
\end{tabular}

\section{Summary Comparison of the Data Presented:}

Results of the in-plane and through-plane conductivity tests as function of membrane type, temperature and $\mathrm{RH}$ are qualitatively presented in Table 8.

Table 8. Summary of the comparison of in-plane and through-plane conductivity of Nafion ${ }^{\circledR}$ samples.

\begin{tabular}{|l|l|l|l|l|}
\hline \multirow{2}{*}{ Sample } & $\begin{array}{l}\text { Temp } \\
\left({ }^{\circ} \mathbf{C}\right)\end{array}$ & $\begin{array}{l}\text { Absolute } \\
\text { Conductivity } \\
\text { Values }\end{array}$ & Slope & $\begin{array}{l}\text { Overall Character } \\
\text { of Sample }\end{array}$ \\
\hline \multirow{2}{*}{$\begin{array}{l}\text { NRE- } \\
211\end{array}$} & 30 & Very Similar & Similar & Very Similar \\
\cline { 2 - 5 } & 80 & Similar & Similar & Similar \\
\cline { 2 - 5 } $\begin{array}{l}\text { NRE- } \\
212\end{array}$ & 120 & In-Plane is Higher & Similar & Similar \\
\cline { 2 - 5 } & 80 & Very Similar & Very Similar & Very Similar \\
\cline { 2 - 5 } NE- & 120 & In-Plane is Higher & Similar & Very Similar \\
\cline { 2 - 5 } & 30 & In-Plane is Lower & Up-sweeps Differ & $\begin{array}{l}\text { In-Plane Curve is } \\
\text { Unusual }\end{array}$ \\
\cline { 2 - 5 } & 80 & $\begin{array}{l}\text { In-Plane is Much } \\
\text { Lower }\end{array}$ & Similar & Similar \\
\cline { 2 - 5 } & 120 & $\begin{array}{l}\text { In-Plane is Much } \\
\text { Lower }\end{array}$ & Similar & Similar \\
\hline \multirow{3}{*}{ N-117 } & 30 & Similar & Similar & Similar \\
\cline { 2 - 5 } & 80 & In-Plane is Lower & Similar & Similar \\
\cline { 2 - 5 } & 120 & $\begin{array}{l}\text { In-Plane is Slightly } \\
\text { Lower }\end{array}$ & Similar & Similar \\
\hline
\end{tabular}

\section{Discussion of results}

In general the thinner, dispersion-cast membranes, NRE-211 and NRE-212, had higher in-plane conductivity results at higher temperatures. The thicker, extruded membranes, $\mathrm{NE}-1135$ and $\mathrm{N}-117$, exhibited higher through-plane conductivity results at higher temperatures. 
Despite the forgoing remarks, it should be noted that in general there was quite strong similarity in the results for the two methods. The similarity in results across sample types and conditions is perhaps surprising given the historical tendency for significant differences in reported conductivities for Nafion ${ }^{\circledR}$. Demonstration of the significant variability in reported conductivity of Nafion ${ }^{\circledR} 117$ at $30{ }^{\circ} \mathrm{C}$ is shown in Figure 27.

Should one expect systematic differences in the in-plane and through-thickness conductivity of Nafion ${ }^{\circledR}$ membranes? As of yet there is no consensus among the community as to whether the conductivity of Nafion ${ }^{\circledR}$ is anisotropic.

Gardner and coworkers ${ }^{12}$ reported that the conductivity of Nafion ${ }^{\circledR} 117$ is anisotropic after finding that in-plane conductivity was more than 3-times greater than the throughthickness conductivity. Ma et. al. ${ }^{13}$ also reported that the in-plane conductivity of Nafion $®$ was $2.5 x$ to 5 -times greater in comparison to the through-plane conductivity. The authors note, however, that the anisotropy was the result of the through-plane samples being subjected to extreme hot pressing conditions (up to $1,200 \mathrm{~kg} / \mathrm{cm}^{2}$ or 17,000 psi at $150{ }^{\circ} \mathrm{C}$ ) resulting in a microstructural modification to the test sample. In fact, Ma et. al. ${ }^{13}$ note that for samples not subjected to the compressive load, the conductivity was essentially the same in both orientations.

Reports of the anisotropy of Nafion $\circledast$ conductivity have been disputed by a number of studies. For example, Fedkiw et. al. ${ }^{14}$ reported that in-plane and through thickness conductivity of Nafion ${ }^{\circledR} 112$ and 117 were essentially the same $(140 \mathrm{mS} / \mathrm{cm}$, water immersed, $65^{\circ} \mathrm{C}$ ).

Silva et. al. ${ }^{15}$ thoroughly investigated the orientation-dependence of Nafion $\circledast$ membrane conductivity and concluded that its conductivity is the same in the through-thickness and in-plane orientations. Silva et. al. concluded that Nafion ${ }^{\circledR}$ membranes exhibit isotropic behavior: the in-plane and through-thickness conductivity was the same when the hydration level (water content of the membrane) was the same.

In a careful analysis of published literature, Silva and coworkers ${ }^{15}$ noted that much of the discrepancy surrounding reports of the conductivity of Nafion $®$ may be attributed some or a combination of the following: (i) differences in handling and/or treatment of samples prior to testing, (ii) differences in measurement method, including 2- and 4teminal, and DC or AC impedance measurement approaches, which require different data treatment, (iii) different experimental procedures and conditions including equilibration time, exposure conditions such as immersed in water vs. water vapor saturated gas exposure, etc.

\section{Graphical Comparisons}

Following are the graphical comparisons of through- and in - plane conductivity for the various standard membranes at 30,80 , and $100^{\circ} \mathrm{C}$. 


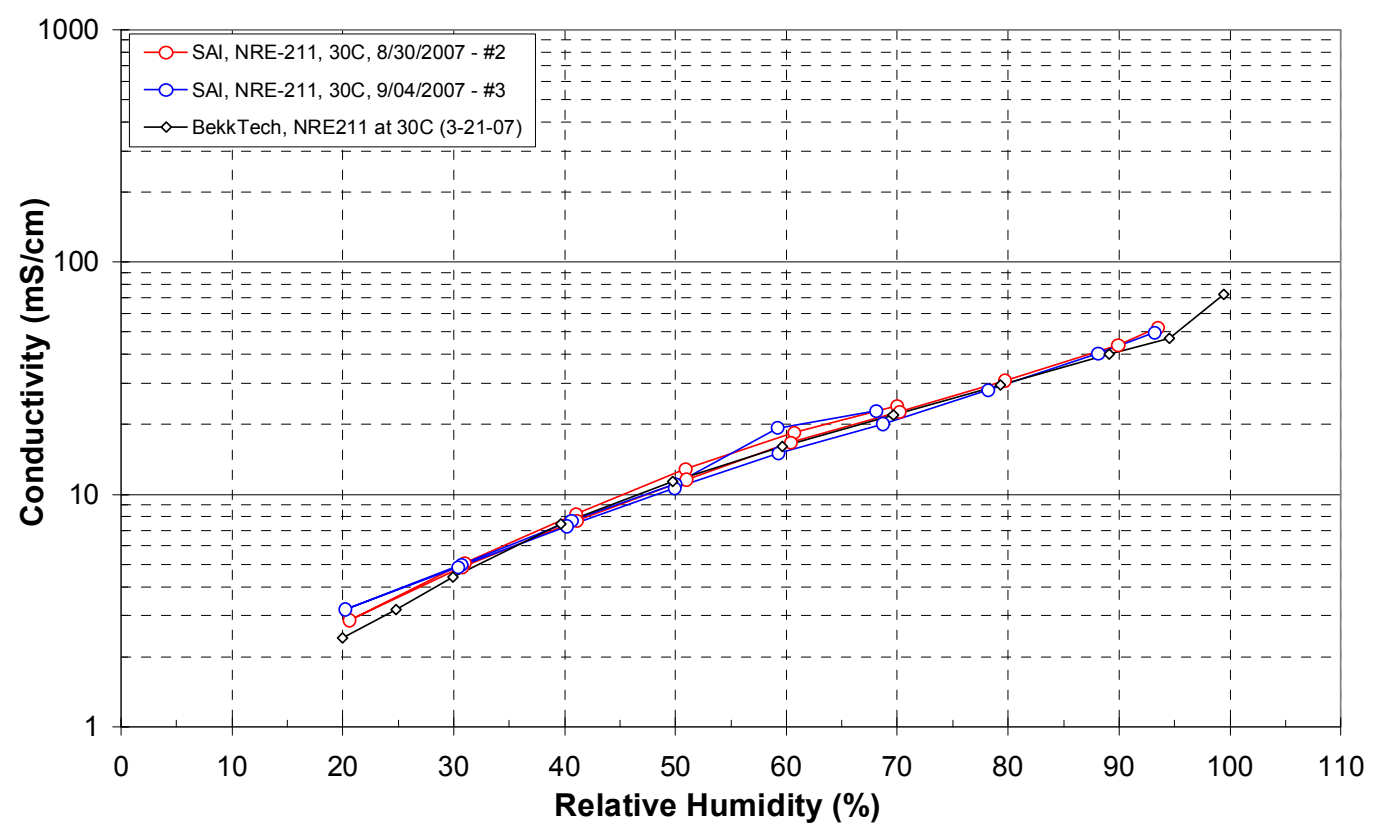

Figure 35. Comparison of in-plane and through-plane conductivity for NRE-211 at $30^{\circ} \mathrm{C}$.

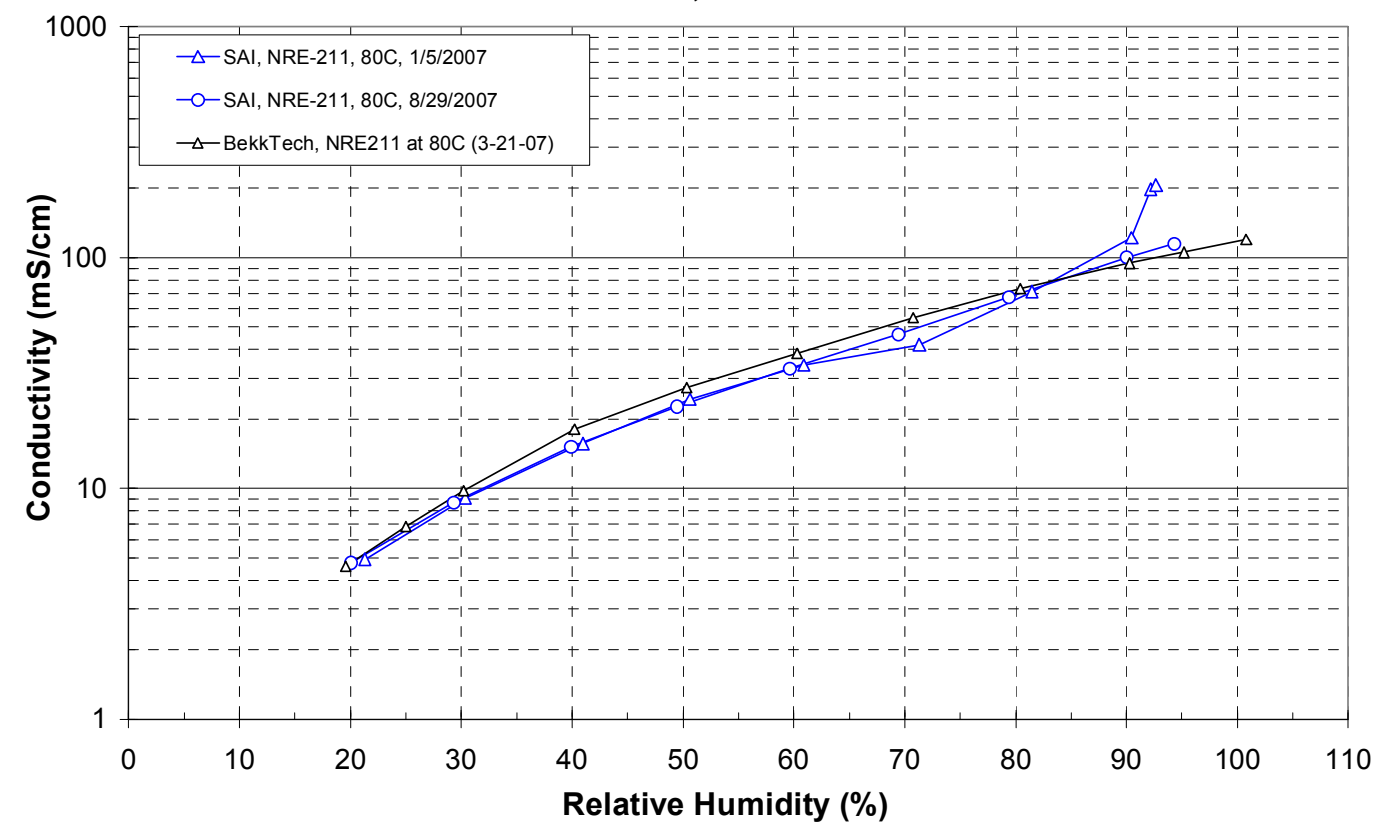

Figure 36. Comparison of in-plane and through-plane conductivity for NRE-211 at $80^{\circ} \mathrm{C}$. 


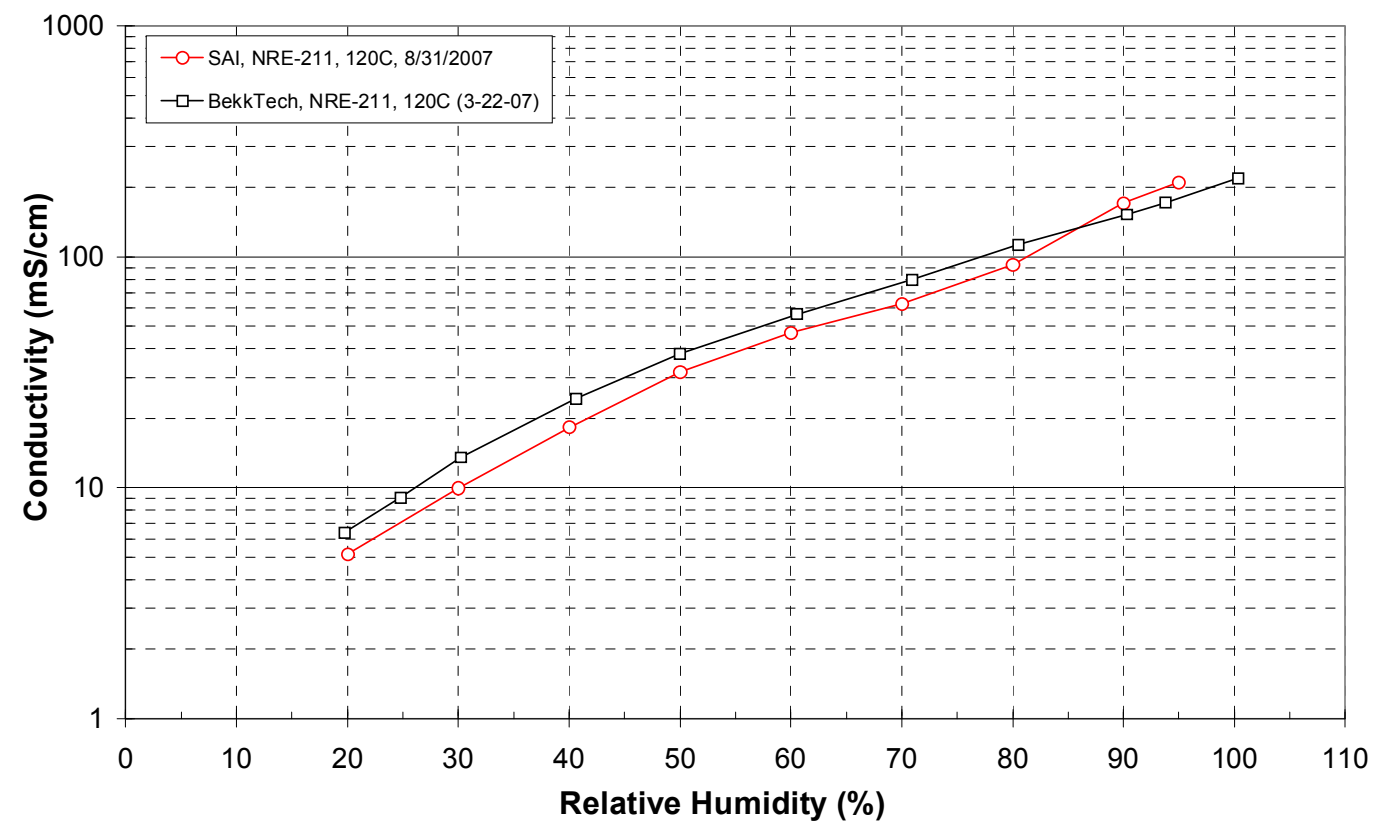

Figure 37. Comparison of in-plane and through-plane conductivity for NRE-211 at $120^{\circ} \mathrm{C}$.

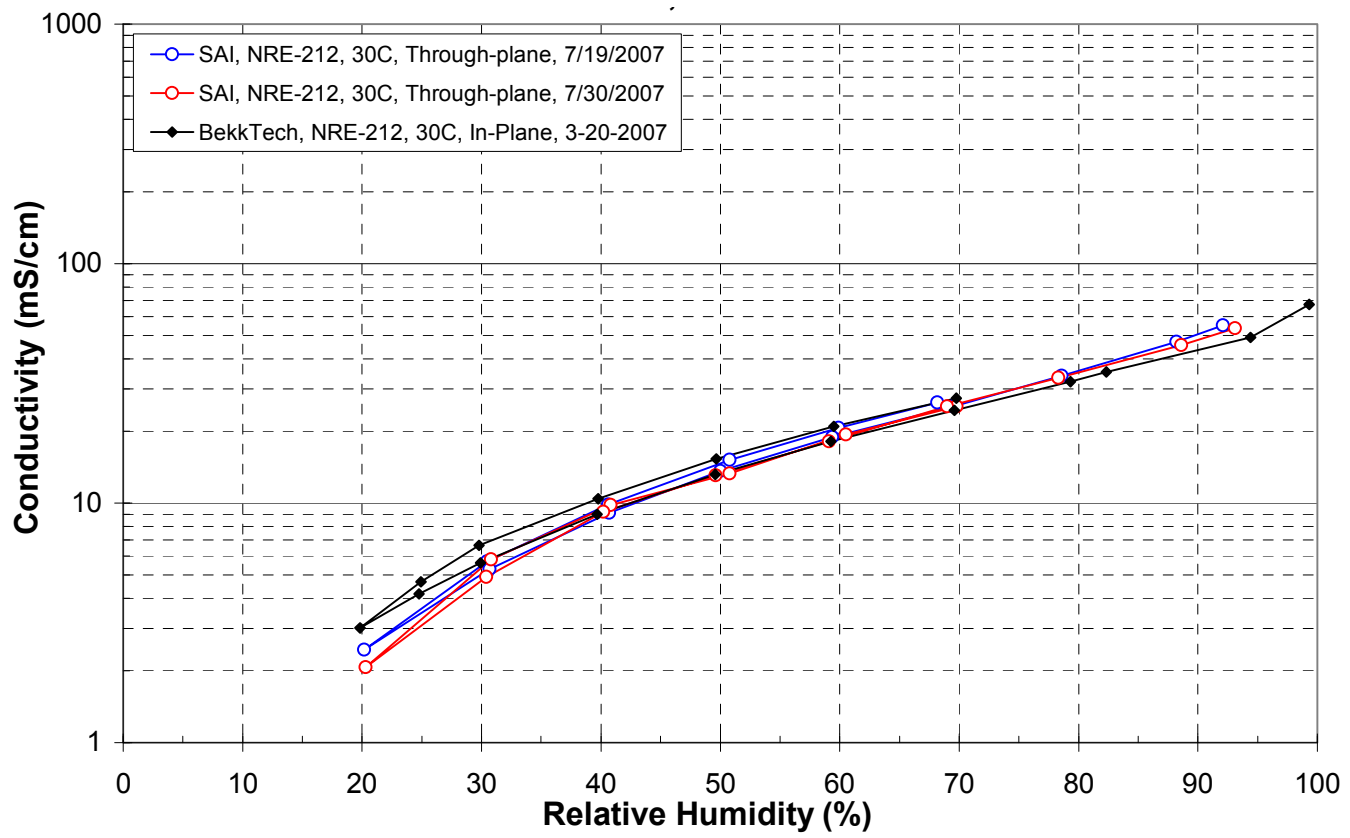

Figure 38. Comparison of in-plane and through-plane conductivity for NRE-212 at $30^{\circ} \mathrm{C}$. 


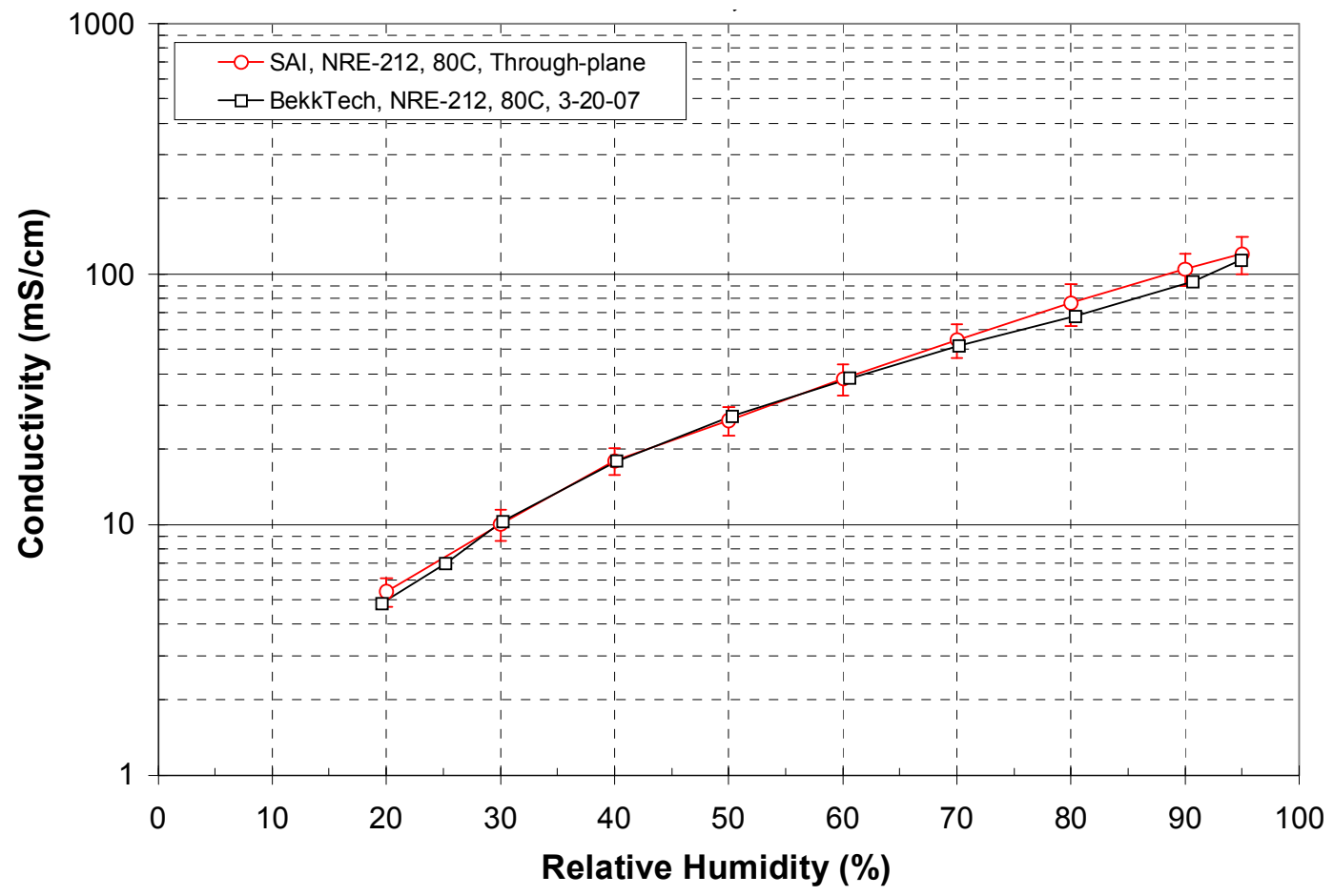

Figure 39. Comparison of in-plane and through-plane conductivity for NRE-212 at $80^{\circ} \mathrm{C}$

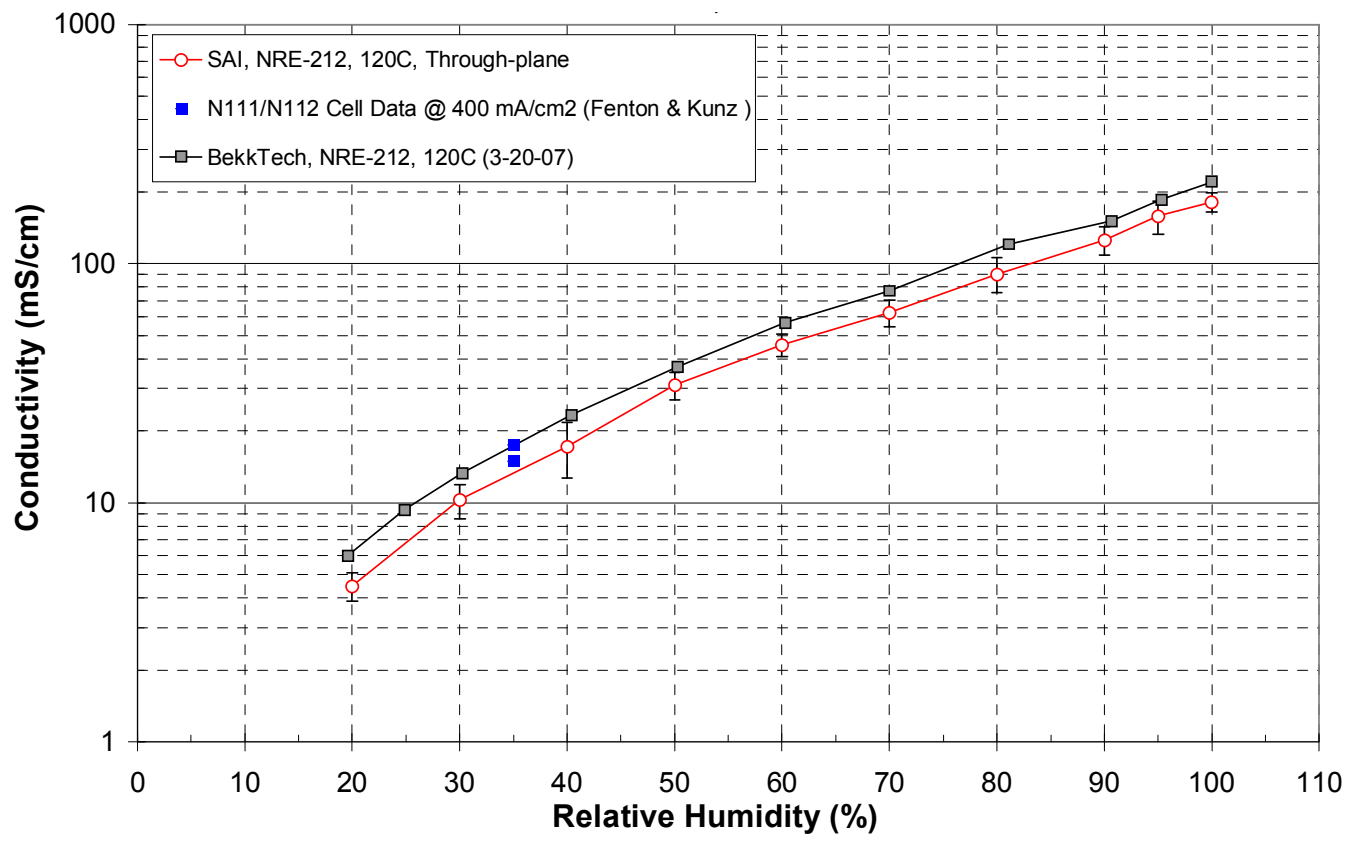

Figure 40. Comparison of in-plane and through-plane conductivity for NRE-212 at $120^{\circ} \mathrm{C}$ 


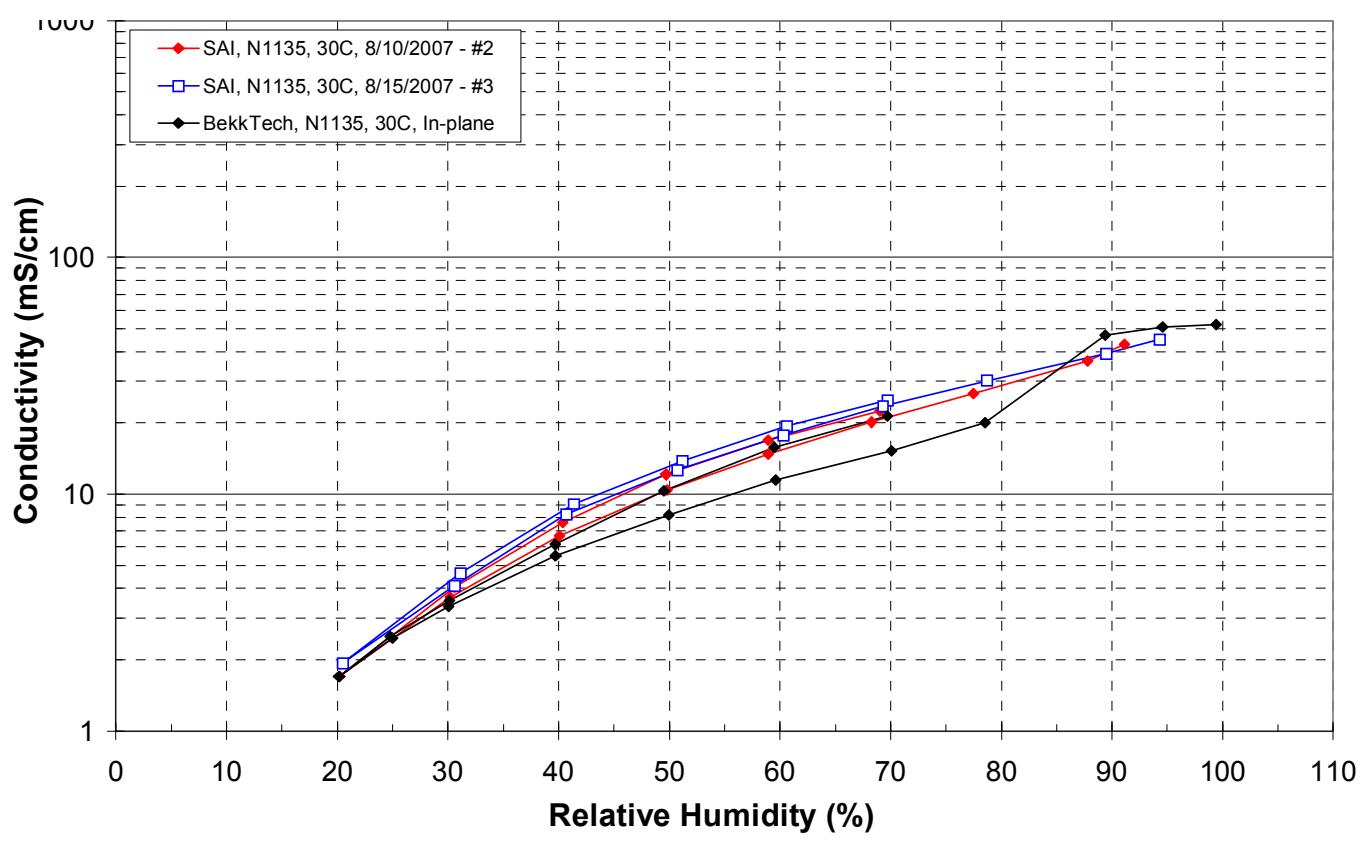

Figure 41. Comparison of in-plane and through-plane conductivity for NE-1135 at $30^{\circ} \mathrm{C}$.

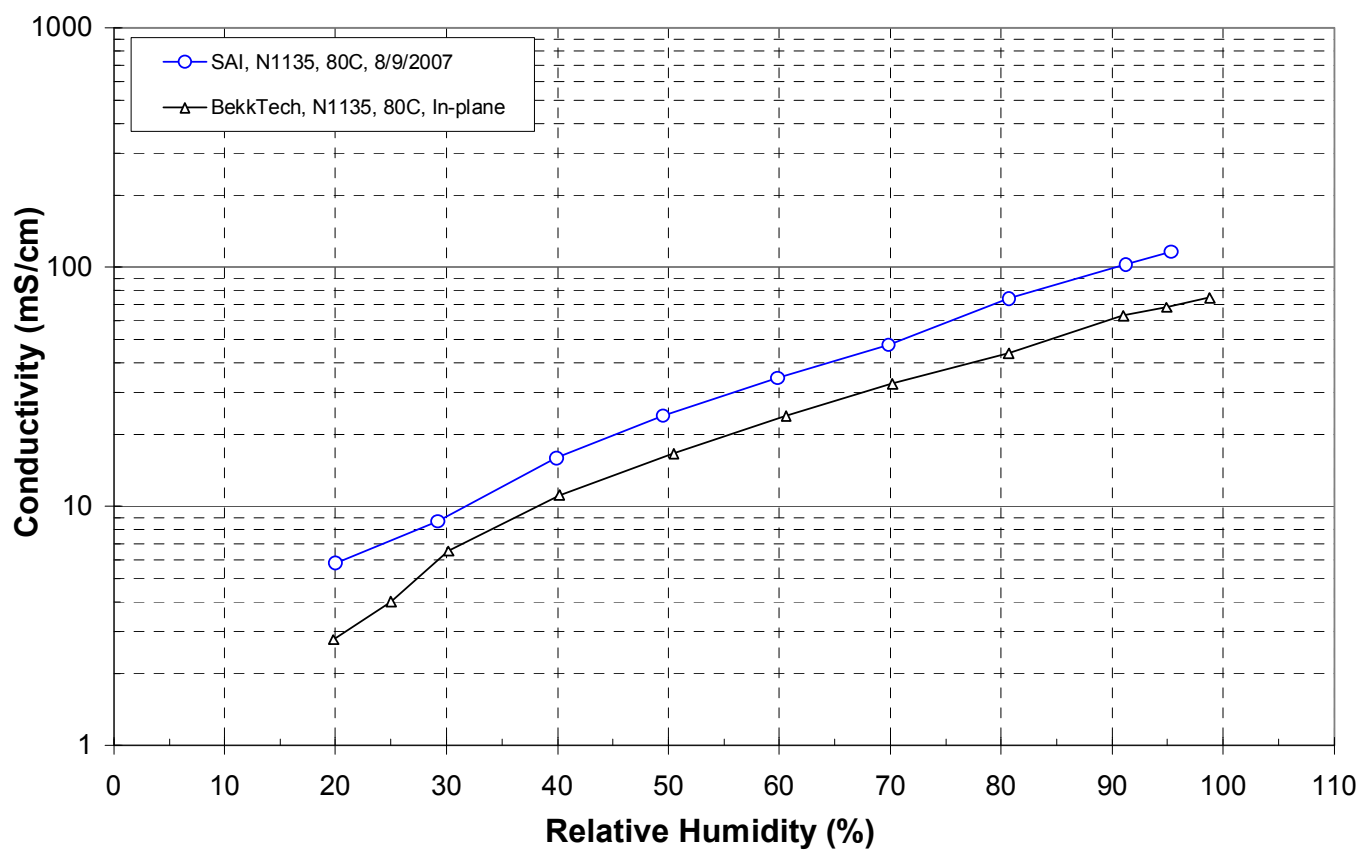

Figure 42. Comparison of in-plane and through-plane conductivity for NE-1135 at $80^{\circ} \mathrm{C}$. 


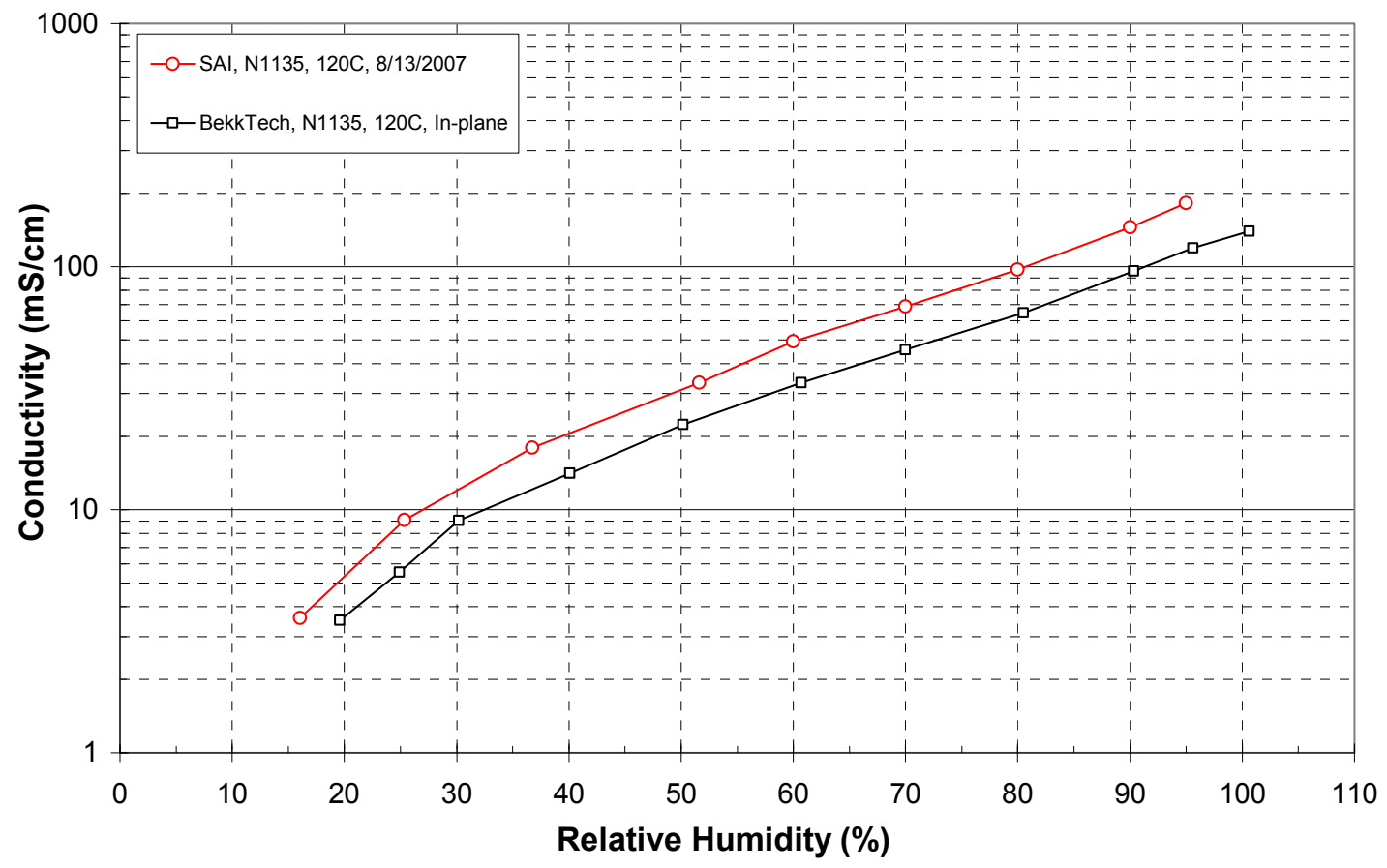

Figure 43. Comparison of in-plane and through-plane conductivity for NE-1135 at $120^{\circ} \mathrm{C}$.

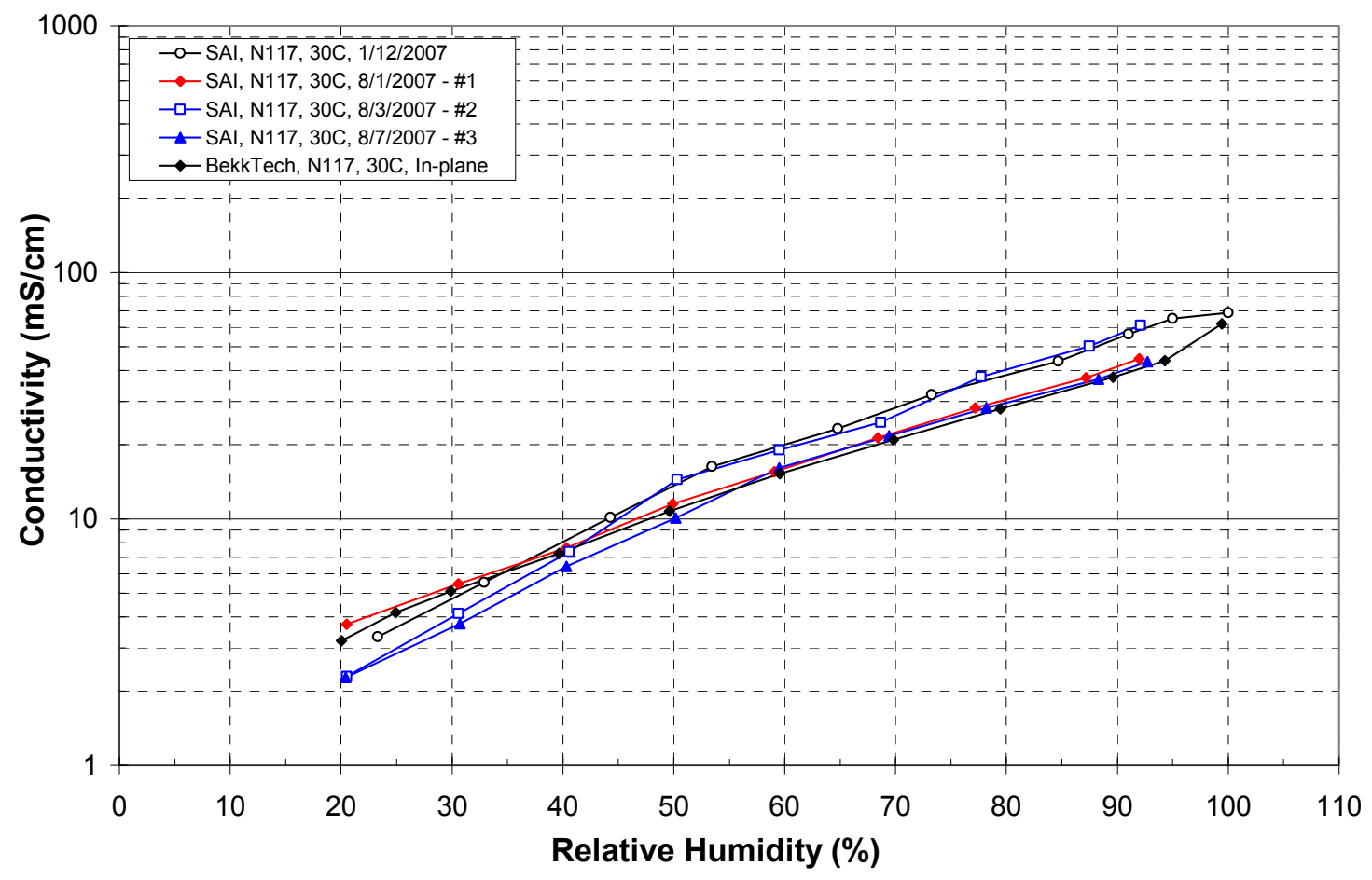

Figure 44. Comparison of in-plane and through-plane conductivity for NE-117 at $30^{\circ} \mathrm{C}$. 


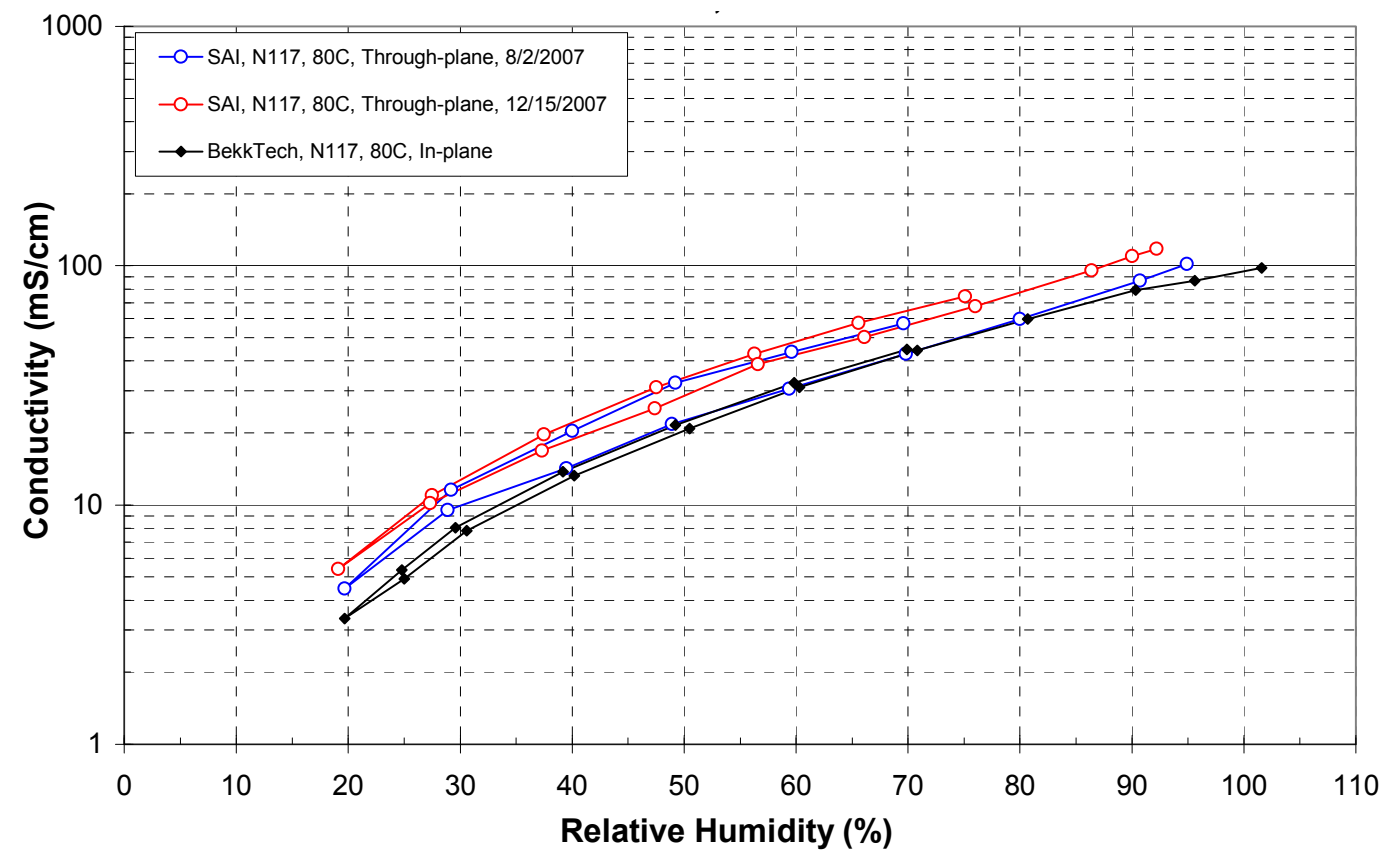

Figure 45. Comparison of in-plane and through-plane conductivity for NE-117 at $80^{\circ} \mathrm{C}$.

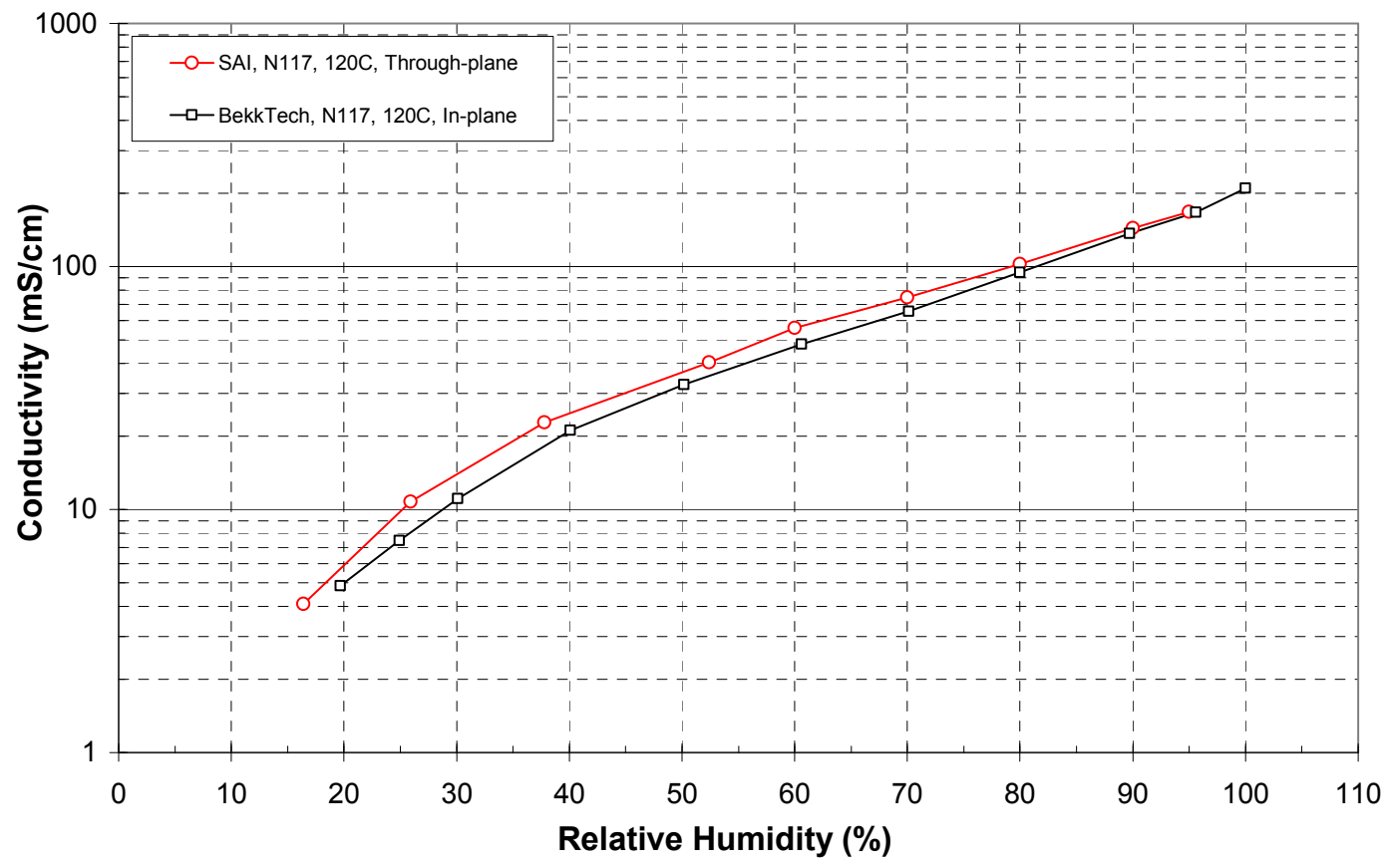

Figure 46. Comparison of in-plane and through-plane conductivity for NE-117 at $120^{\circ} \mathrm{C}$. 


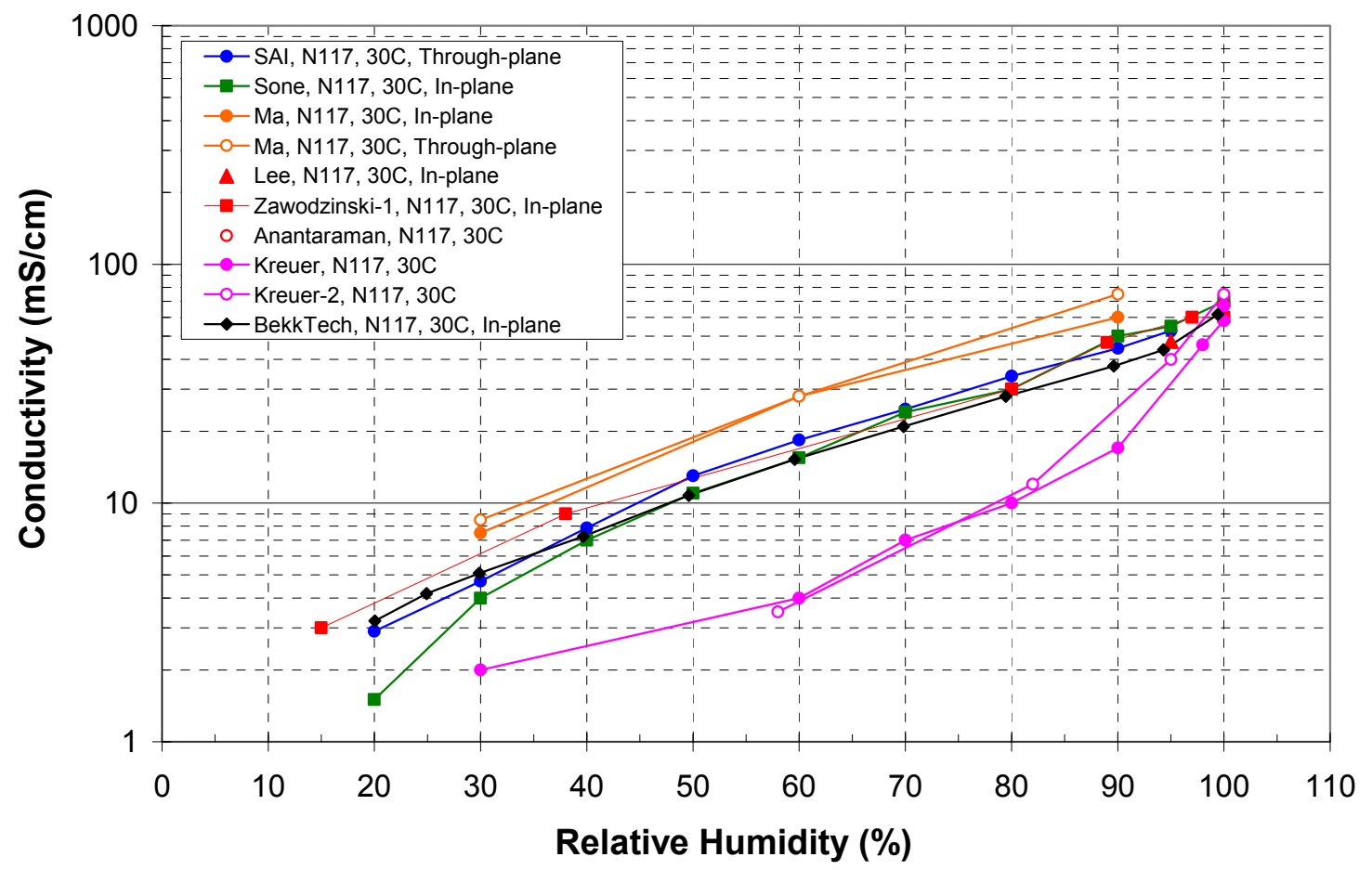

Figure 47. Reported Nafion $® 117$ conductivities at $30^{\circ} \mathrm{C}$ vary by nearly an order of magnitude at some RH conditions. Data at $100 \%$ RH are for water vapor saturated conditions.

\section{In situ Membrane Characterization}

\section{Task 5. Characterize Performance of Membrane Electrode Assemblies}

To reduce membrane/electrode interface resistances, the decision was made to prepare catalyst coated membranes (CCMs) and to couple these with a gas diffusion layer (GDL). While it would have been easier to apply a generic gas diffusion electrode (GDE) to a membrane, it was felt that the added effort would provide better performance for the resulting membrane electrode assemblies.

The FSEC protocol for preparing CCMs calls for the application of the catalyst to the membrane via spraying. Membrane electrode assembly (MEA) fabrication equipment, using automated $X, Y$ slides (Velmex Inc.) and catalyst spray gun, was setup in the glove box. Figure 48 shows the schematic of the spray system setup. All the components were mounted on a platform. There are a number of process variables, such as spray gun settings, $\mathrm{N}_{2}$ carrier gas pressure, $\mathrm{X}, \mathrm{Y}$ slide speed, spray pattern, and membrane drying temperature, which can influence the MEA performance and reproducibility. Trials were run to establish a standard procedure by fixing all the above variables. A standard procedure to obtain a desired catalyst loading at a fixed number of spray passes was established by adjusting the operating variables like spray pressure, spray gun opening and slide speed. The catalyst loading was calculated from the amount of catalyst ink sprayed, spray area, and the known weight of catalyst in the ink. The $X$ and $Y$ slides were programmed to obtain the desired spray pattern and speed. 
Because of overspray, the above calculations are an approximation only. The actual amount of catalyst loading was determined experimentally by the weight change of the individual CCMs before and after spraying.

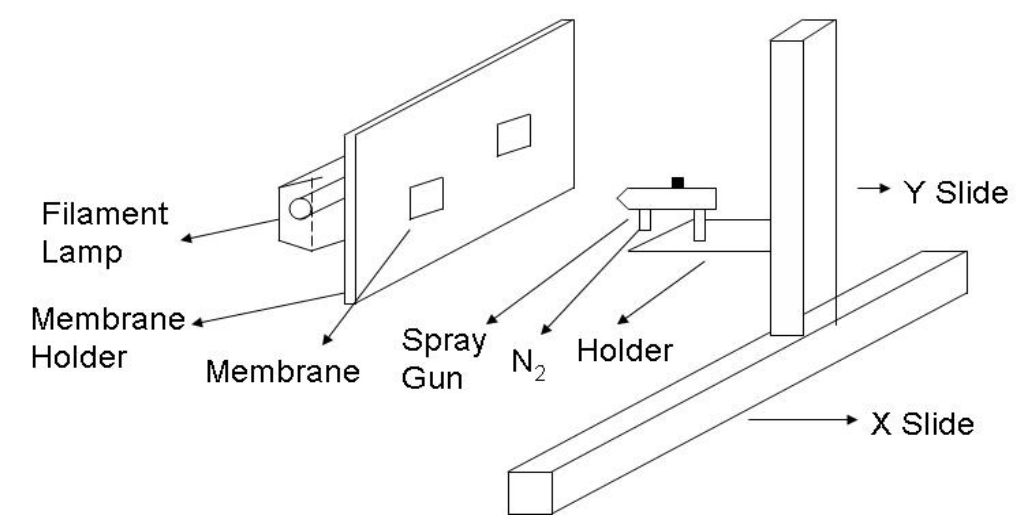

Figure 48. XY Catalyst Spray System Schematic

A study on the effects of spray parameters on fuel cell performance was published. ${ }^{16}$ Figure 49 shows the effect of the spray gun parameters on fuel cell performance. For this test, three different spray patterns were used: coarse, fine, and mist. The "coarse" spray pattern was a narrower and focused stream, while the "fine" and "mist" patterns resulted in broader, more diffuse streams. The results indicate that the "coarse" spray pattern resulted in greater diffusion losses than the "mist", which is likely due to decreased oxygen transport within the electrode.

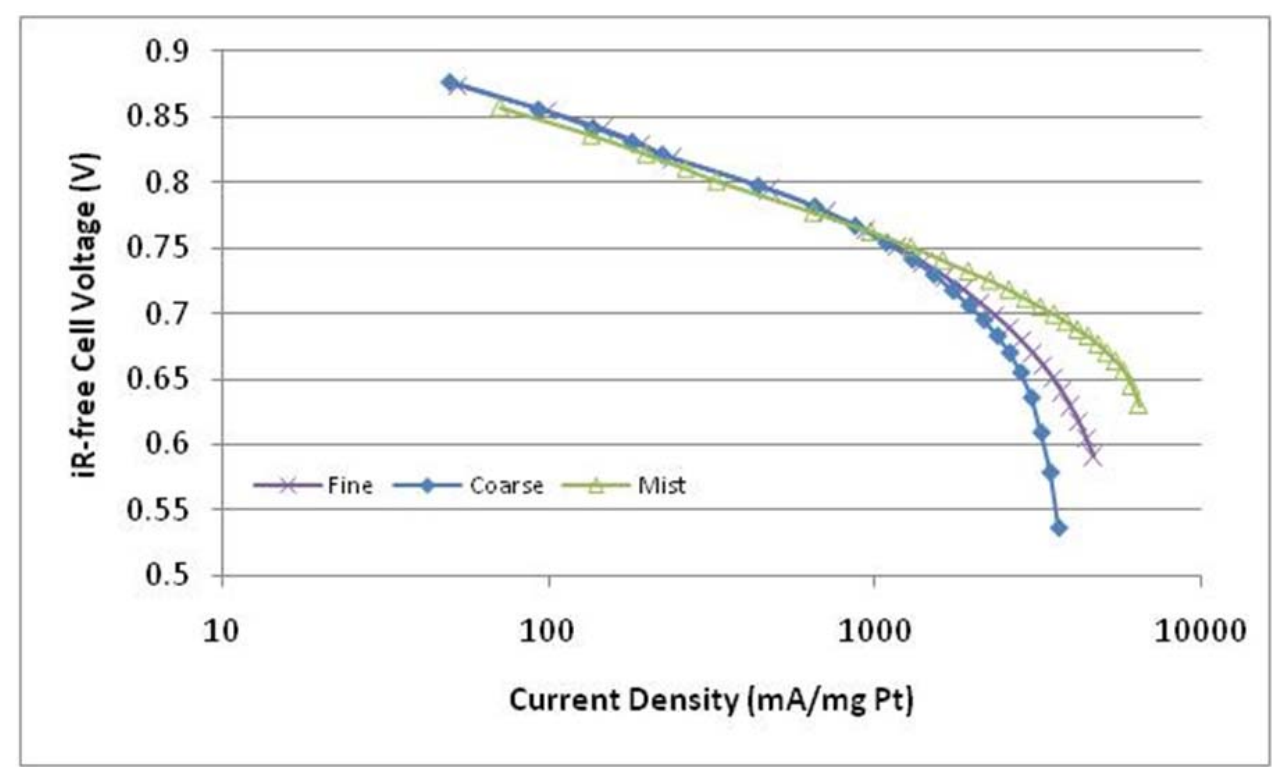

Figure 49. Effect of spray pattern on fuel cell performance. Conditions: $\mathrm{H}_{2} / \mathrm{air}, 80^{\circ} \mathrm{C} / 100 \% \mathrm{RH}$, ambient pressure ${ }^{17}$

The effect of spray parameters on the electrode surface is shown in Figure 50. Clearly, the "mist" pattern resulted in larger particles forming on the surface, while the "coarse" pattern resulted in a more planar electrode. The presence of the large particles in the 
"mist" spray indicates that mass transport within this electrode would be enhanced due to larger gaps within the electrode structure. This improved mass transport explains why the "mist" pattern resulted in higher performance than the "coarse" pattern.

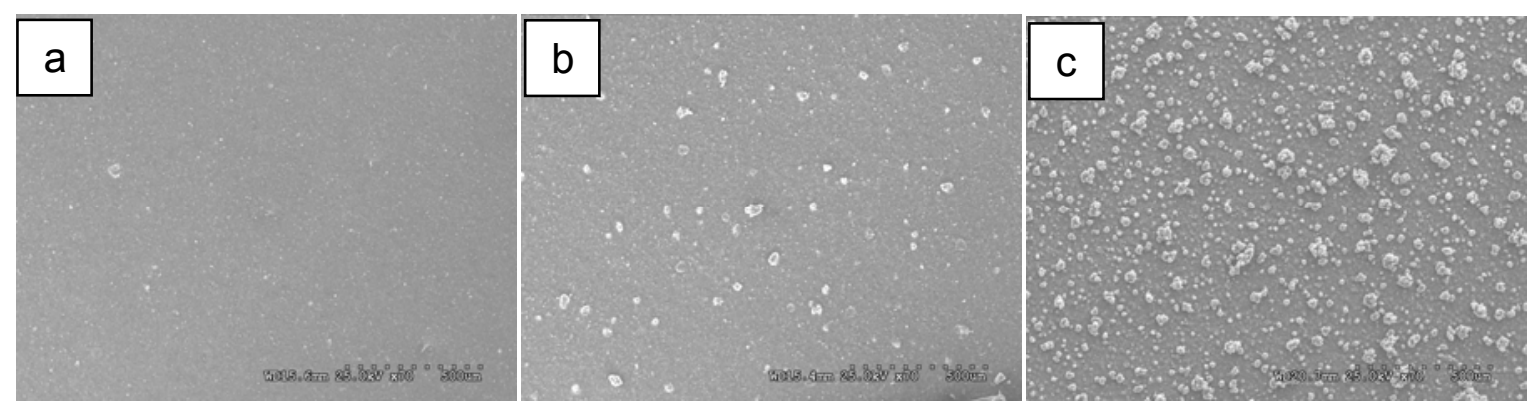

Figure 50. SEM images of the electrode surfaces for a) coarse, b) fine, and c) mist spray patterns. $^{17}$

After the Go/No-Go point in the program, efforts were refocused on the preparation and testing of membrane electrode assemblies. By this point, a number of MEAs had been prepared and tested but all of the membranes used were either standard Nafion ${ }^{\circledR}$ membranes or membranes prepared as a part of the FSEC membrane fabrication program. It was understood that the membranes to be supplied by the remaining teams would potentially be very different and would require existing procedures to be modified.

After discussions with $\mathrm{DOE}$, it was decided that the catalyst to be used for the team member CCMs would be Tanaka Pt-Co on carbon. Previous FSEC studies had used Tanaka Pt on carbon so experiments were conducted to determine any necessary changes to the catalyst ink formulation. An additional change in procedure was the ionomer used in the ink. While this was to be individualized in collaboration with the membrane provider, the standard was an 825 equivalent weight PFSA ionomer supplied by $3 \mathrm{M}$. Based on previous work with $\mathrm{Pt}-\mathrm{Co} / \mathrm{C}$ catalyst and lower equivalent weight ionomers, it was decided that the ionomer loading for the standard FSEC electrode for the team member samples would be $28 \%$.

The continuing team members (Case Western, Vanderbilt, Arizona State University, Colorado School of Mines, Giner, and Fuel Cell Energies) were contacted during the Annual Merit Review Meeting and a discussion initiated regarding the fabrication of the MEAs. In order to better support the HTM team members and accommodate their requests for deviations from standard FSEC procedures, a process of communication with the teams was established. A logic flow chart, Figure 51, was formulated and supplied to each team for discussion. The flow chart clarified the steps that would be used for processing and analysis of the membranes and served as a starting point for discussions. 


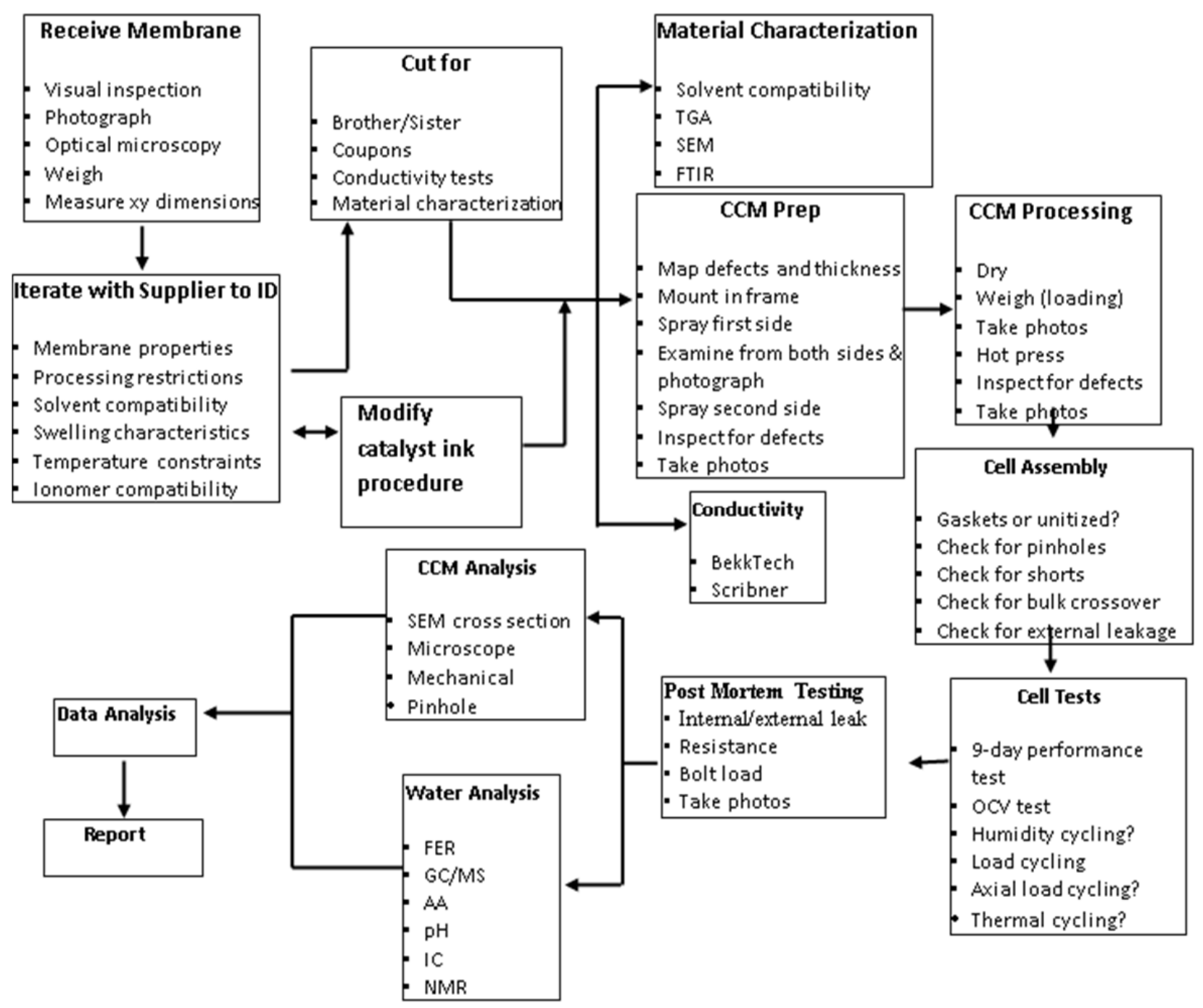

Figure 51. Logic flow chart for MEA fabrication and analysis

Each membrane that was received from a Team was assigned a tracking number and photographed. In some cases, the supplier provided information regarding potential incompatibilities with our processing steps or requested modifications to our procedure. In other cases, requests were made to modify the electrode. As a result of these interactions, it was possible to provide individualized support.

A procedure for the standard 11-day test was prepared and a copy of that procedure can be seen in Appendix C. The purpose of this testing was to assess the relative merits of the candidate membranes that were submitted by the team members. These tests were conducted at operating conditions that are of interest to the DOE. The goal was to show the current capability of these membranes compared to the program requirements, without significantly degrading the membranes. To the extent that all membranes were tested to the same protocol, the results provide a fair and accurate evaluation of the performance capabilities of each configuration. Any variance from this standard was documented and reported in the subsequent report to the membrane supplier. Briefly, the MEAs were evaluated through performance testing at 
$80{ }^{\circ} \mathrm{C} / 100 \% \mathrm{RH}$ (at ambient and 0.5 atm backpressure), $95{ }^{\circ} \mathrm{C} / 83 \% \mathrm{RH} 0.5 \mathrm{~atm}$ backpressure, and $120^{\circ} \mathrm{C} / 35 \% \mathrm{RH} 0.5$ atm backpressure, followed by a stability test for 64 hours at $95{ }^{\circ} \mathrm{C} / 83 \% \mathrm{RH}, 400 \mathrm{~mA} / \mathrm{cm}^{2}$. Throughout the performance tests, hydrogen crossover, electrical resistance and electrochemically active area were determined through linear sweep voltammetry, potential hold and cyclic voltammetry, respectively. Typical performance curves at each of the temperature/humidity/pressure conditions under $\mathrm{H}_{2} /$ air are plotted in Figure 52. In this plot, it is clear that increasing the pressure from ambient to $7 \mathrm{psig}$ ( $0.5 \mathrm{~atm}$ backpressure) improves performance at $80{ }^{\circ} \mathrm{C} / 100 \%$ $\mathrm{RH}$. When the temperature is increased to $95^{\circ} \mathrm{C}$ and the relative humidity is reduced to $83 \% \mathrm{RH}$, the performance is very similar to that observed at $80^{\circ} \mathrm{C} / 100 \% \mathrm{RH} / 7 \mathrm{psig}$. However, when cell temperature is further increased to $120^{\circ} \mathrm{C}$ and relative humidity is decreased to $35 \% \mathrm{RH}$, the performance decreases significantly.

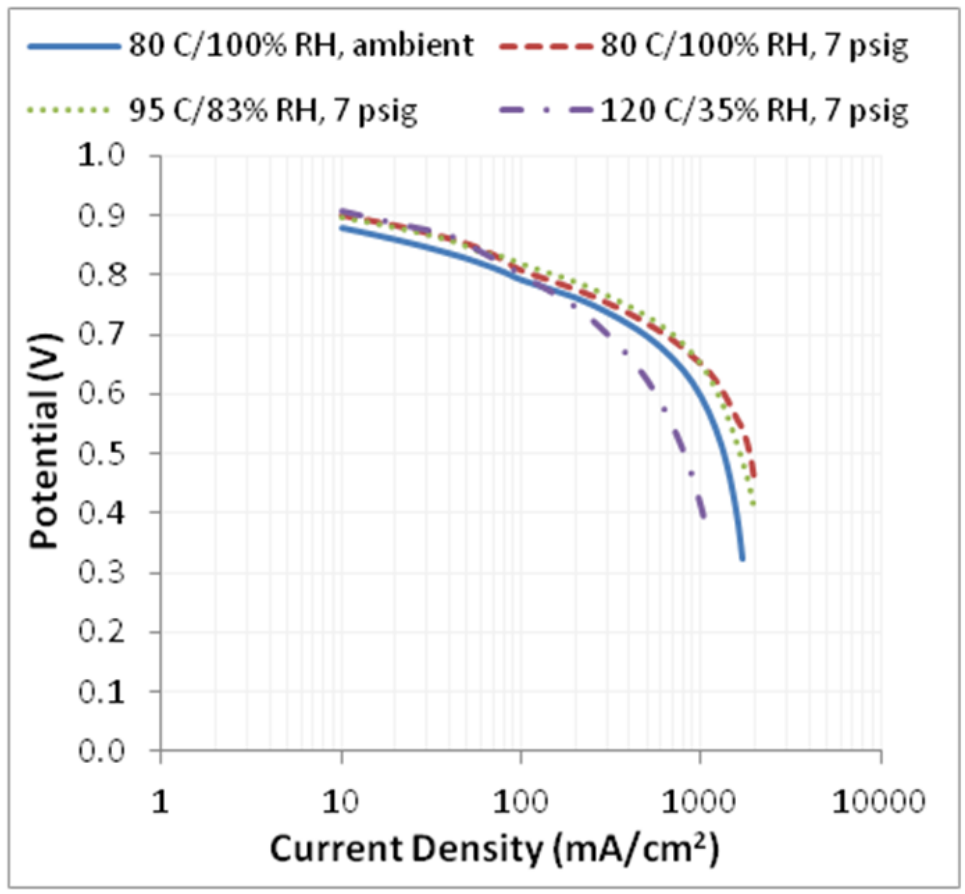

Figure 52. Typical performance curves at each temperature/humidity/pressure condition during the 11-day test under $\mathrm{H}_{2}$ /air

Following performance testing, the data was analyzed to determine several sources of polarization, with the intent to identify how membrane and electrode selection impacted performance (e.g. how did electrode diffusion characteristics change when a nonNafion $\circledast$ membrane is employed with a standard electrode?). A typical performance curve corrected for several sources of polarization at $95{ }^{\circ} \mathrm{C} / 83 \% \mathrm{RH} / 7 \mathrm{psig}$ is plotted in Figure 53. In this plot, Vcell is the raw data obtained from the test under hydrogen/air; ViR corr is the potential after correcting for cell resistance, which is usually attributed to membrane resistance; Velec corr is the potential after correcting for electrode resistance; Vconc corr is the potential after correcting for concentration overpotential; 
Vact corr is the potential after correcting for activation losses; and Vtheor is the theoretical potential at these conditions. From this analysis, it becomes clear that the electrode ohmic resistance becomes significant around $300 \mathrm{~mA} / \mathrm{cm}^{2}$, and that diffusion resistance is significant only above $1000 \mathrm{~mA} / \mathrm{cm}^{2}$. This type of analysis can then be repeated at each cell operating condition to evaluate how the cell performance is impacted by temperature and relative humidity.

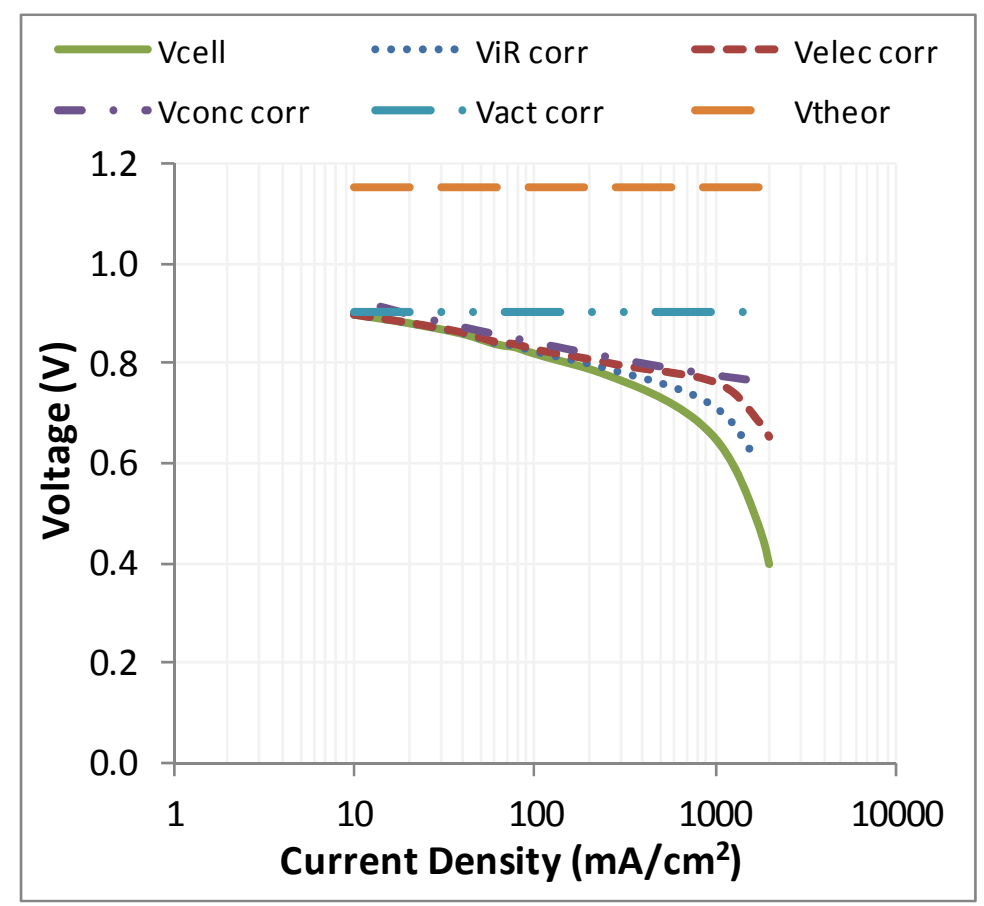

Figure 53. Typical cell performance at $95 \mathrm{C} / 83 \% \mathrm{RH} / 7$ psig with corrections for sources of polarization

During testing of team member membranes, a few LSV tests revealed "negative" crossover. During these instances (as shown in Figure 54) the current at $0.4 \mathrm{~V}$ is negative, indicative of a reduction reaction, instead of hydrogen oxidation. At issue with these "negative" crossovers is what is being reduced, the membrane or some other species? A study was carried out and published ${ }^{18}$ that determined the source of the reduction reaction is trace oxygen. However, this was only present for membranes with extremely low hydrogen crossover values. For example, for NRE 211, the presence of hydrogen at the cathode (due to crossover through the membrane) is sufficient to react with the trace oxygen at the cathode, in essence masking oxygen's presence. For some of the team member membranes, hydrogen crossover was so low that there was less hydrogen at the cathode than the trace oxygen. In the absence of hydrogen at the cathode, the oxygen is manifested by the reduction currents observed in the LSV, as shown in Figure 54. 


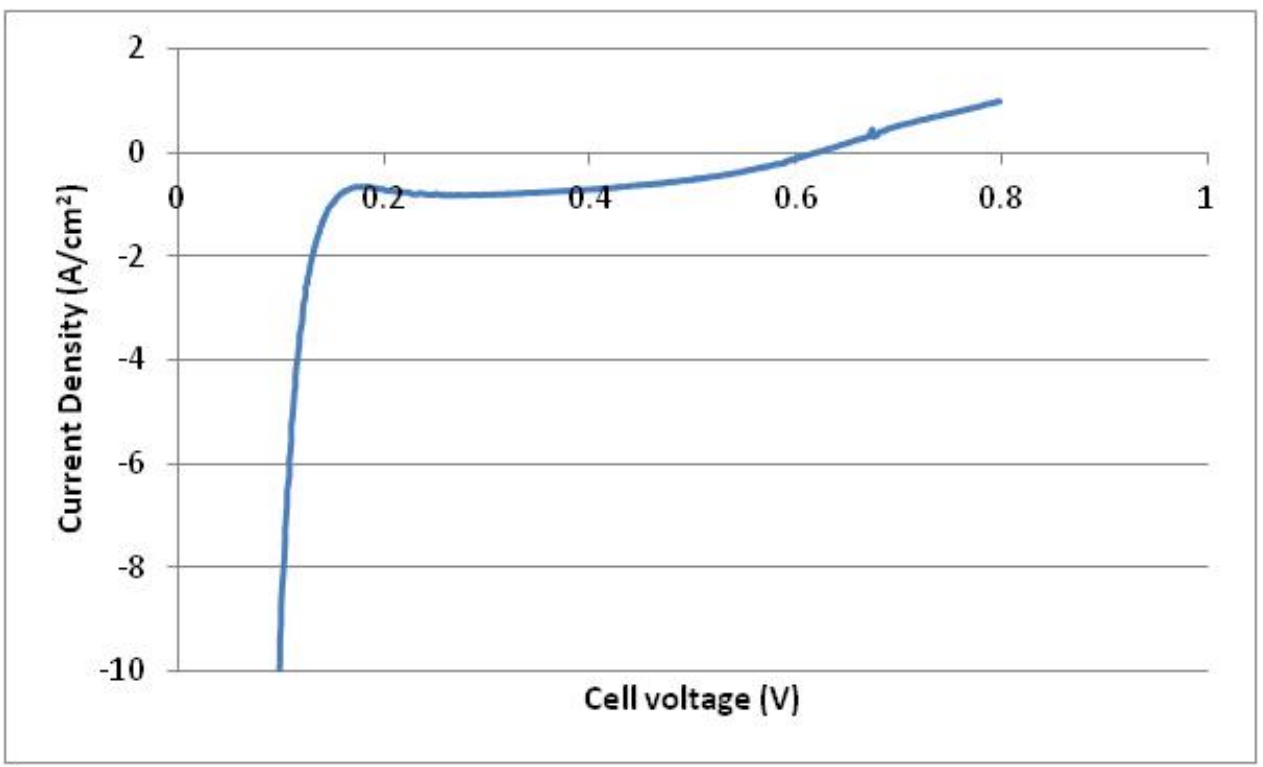

Figure 54. Example of "negative" crossover.

\section{Task 6. Membrane/MEA Durability Evaluation}

In addition to analyzing performance of the membranes as MEAs in a fuel cell, durability was assessed via a 64 hour stability test that was performed during the eleven day test. The stability test was conducted by holding at $400 \mathrm{~mA} / \mathrm{cm}^{2}$ with $\mathrm{H}_{2} /$ air at $95 / 90 / 90$ and 7 psig backpressure. A typical plot of voltage during the stability test is shown in Figure 55 . Because the conditions of this test are relatively mild, the voltage loss is quite low, at $0.3 \mathrm{mV} / \mathrm{h}$. 


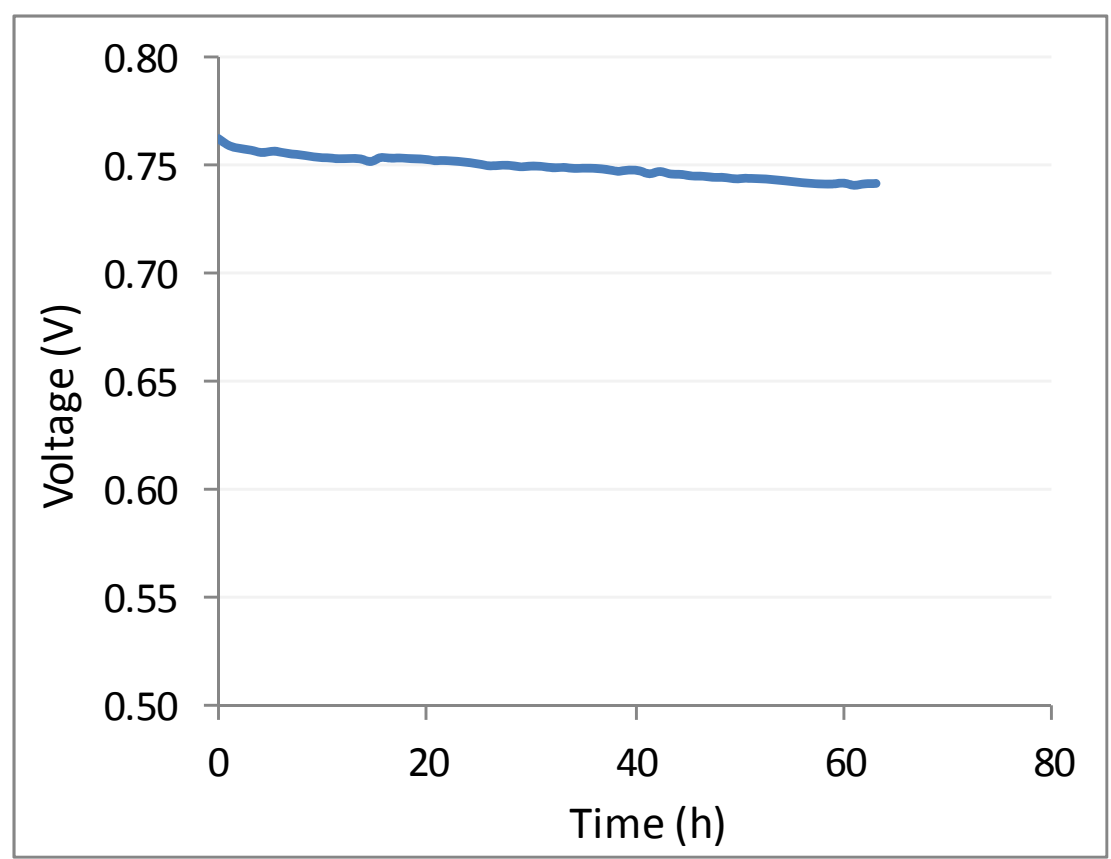

Figure 55. Typical voltage curve during 64 hour stability test at $95{ }^{\circ} \mathrm{C} / 83 \% \mathrm{RH} / 7$ psig and 400 $\mathrm{mA} / \mathrm{cm}^{2}$

In addition to the eleven day protocol, at the request of two teams, accelerated stress tests were performed on their membranes. These tests were OCV hold tests at 90 ${ }^{\circ} \mathrm{C} / 30 \% \mathrm{RH}$ under $\mathrm{H}_{2}$ /air, based on the DOE accelerated stress protocol that was current at the time. One test ran for 100 hours at ambient pressure and the second test ran for 500 hours at 7 psig. A typical plot for a 100 hour OCV test is shown in Figure 56. A typical plot for a 500 hour OCV test is shown in Figure 57. The downward spikes in the 500 hour test are a result of characterization of the cell (water collection, cross-over, electrochemically active surface area, electrical resistance, cell resistance) every 24 hours. Because of the harsher testing conditions, the voltage decay rates for the OCV tests are considerably higher that of the stability tests. 


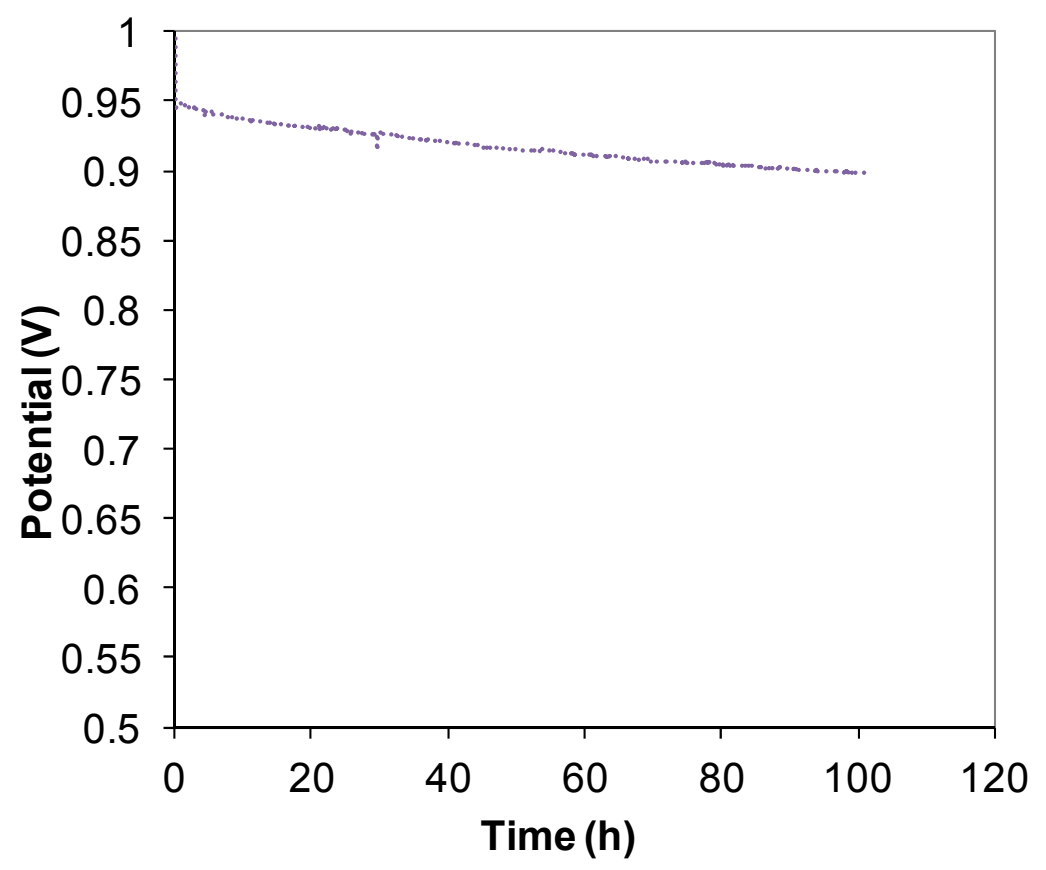

Figure 56. Typical voltage curve during 100 hour OCV test at $90^{\circ} \mathrm{C} / 30 \% \mathrm{RH} / \mathrm{ambient}$ pressure

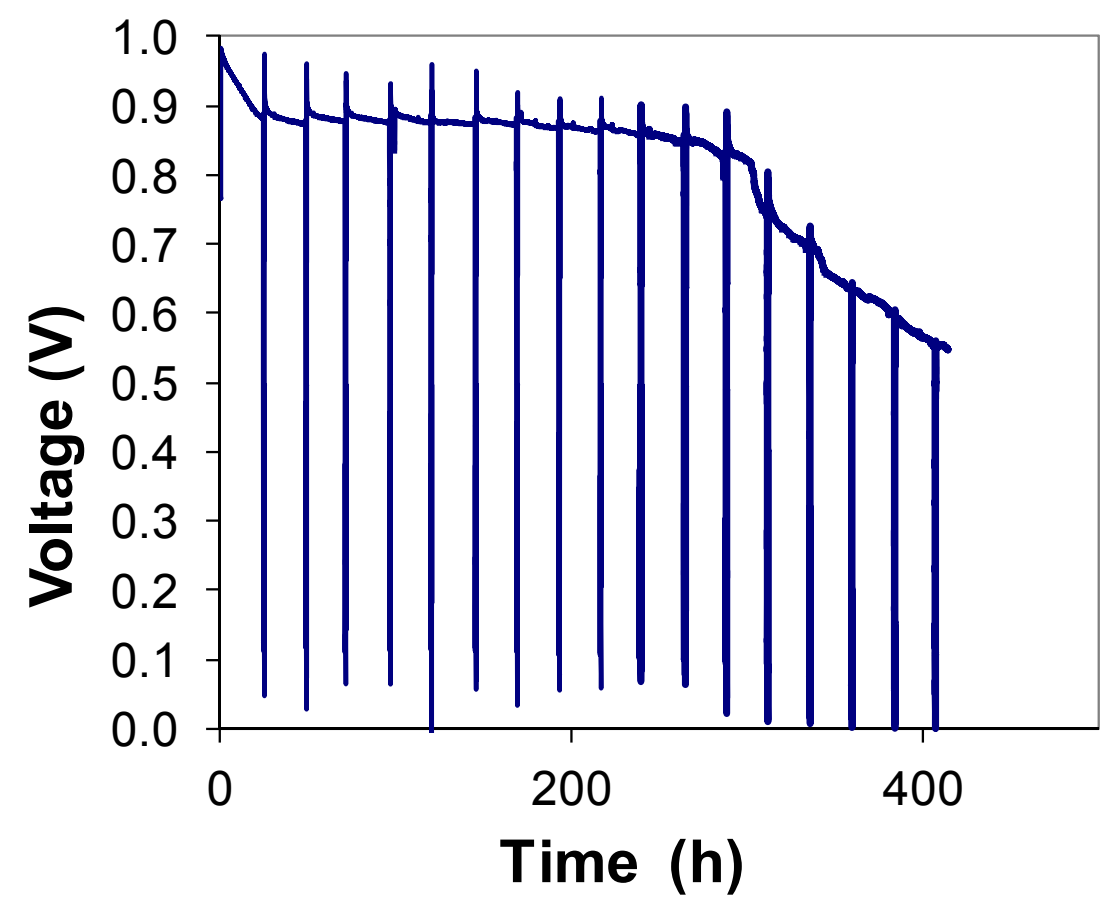

Figure 57. Typical voltage curve during 500 hour OCV test at $90{ }^{\circ} \mathrm{C} / 30 \% \mathrm{RH} / 7 \mathrm{psig}$

Throughout the 64 hour stability tests and the OCV accelerated stress tests, periodic measurements of reactant crossover, electrical resistance, and electrochemically active surface area were made using linear sweep voltammetry, potential hold, and cyclic voltammetry, respectively. During the stability and OCV tests, condensate water was collected twice a day from both the anode and cathode exhausts of the cells containing fluorocarbon membranes for analysis by ion chromatography for the presence of 
fluoride ions, a product of membrane decomposition. A typical plot of the fluoride emission rates during the 100 hour OCV test at $90 \mathrm{C} / 30 \% \mathrm{RH} /$ ambient pressure is shown in Figure 58. The increase in fluoride emission rate with time in this plot indicates that the membrane degradation rate is increasing with time.

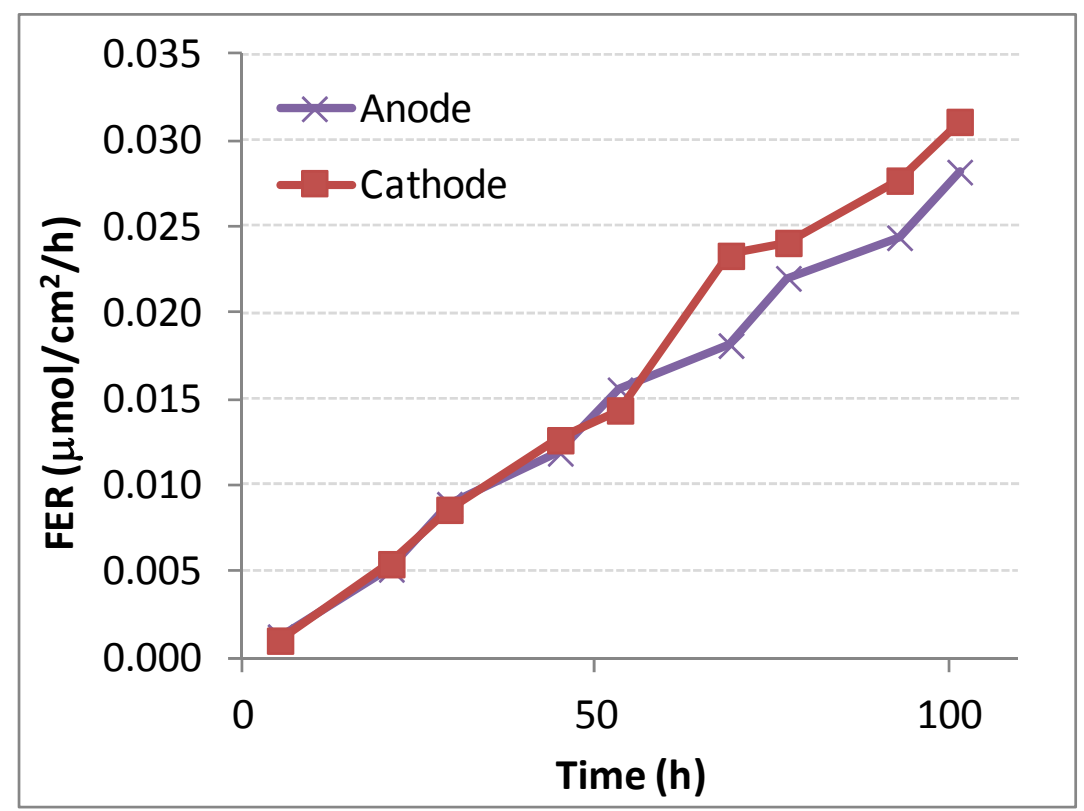

Figure 58. Typical fluoride emission rates during the 100 hour OCV test at $90{ }^{\circ} \mathrm{C} / 30 \% \mathrm{RH} / \mathrm{ambient}$ pressure

After the tests, post test analysis was conducted to further characterize the failure or degradation of the membranes. Areas of localized cross-over in the MEAs were determined by exposing the anode side of the MEA to dilute (4\%) hydrogen and the cathode side to air and imaging the temperature increases that occur at defect locations with an IR camera. IR images of NRE 211 membrane that underwent the 100 hour OCV accelerated stress test ( $a$ and $c$ ) and the eleven day performance test (b and $d)$ are shown in Figure 59. SEM, along with EDAX analysis, was used to determine the extent, location and nature (localized, uniform etc.) of degradation by examining phenomena such as membrane thinning, cracks, and platinum band formation. Mechanical properties of the membranes were also investigated using a mechanical tensile strength apparatus. 


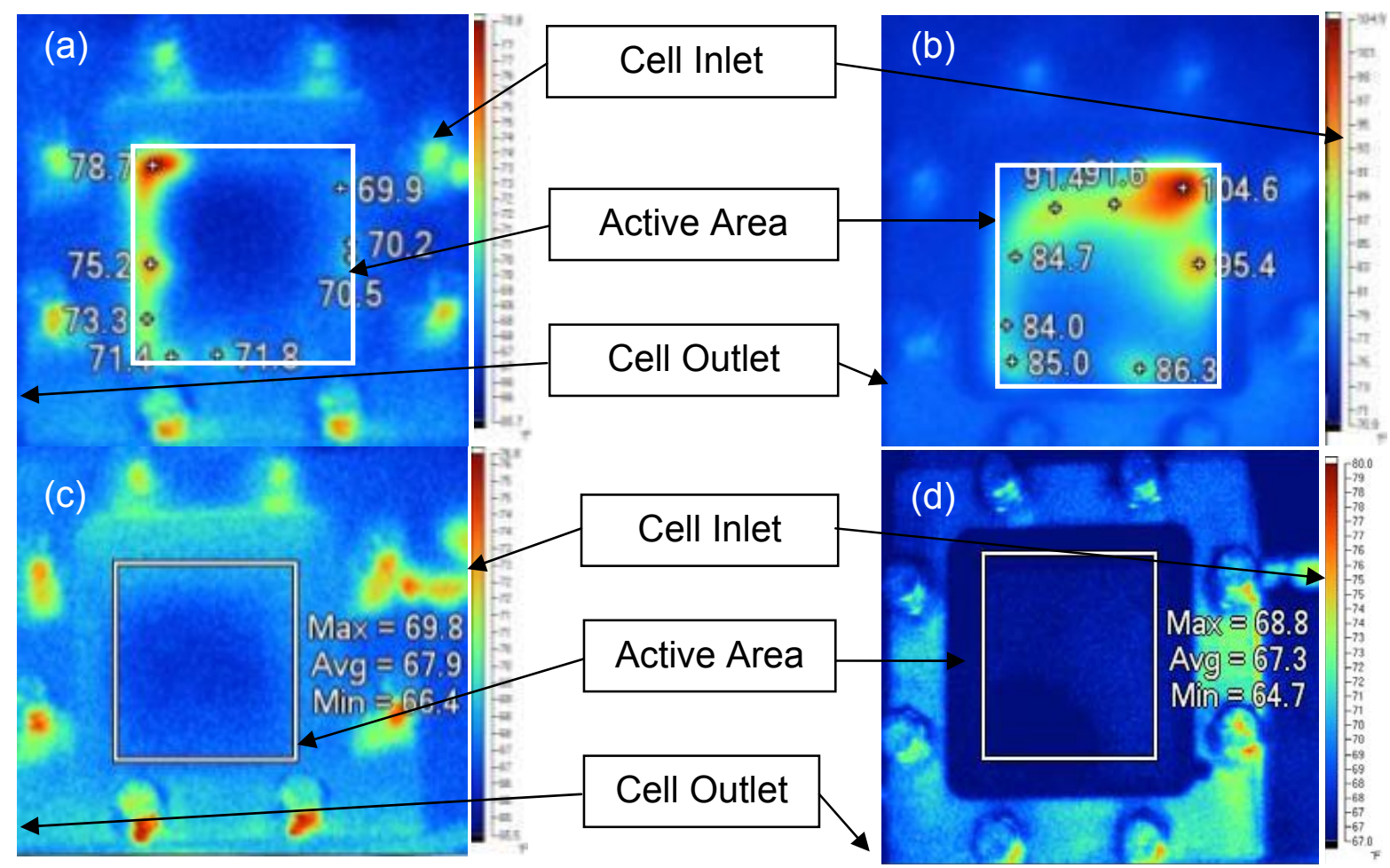

Figure 59. Infrared images of the temperature increases on tested MEAs that were a) OCV accelerated stress tested, and b) eleven day performance tested. Temperature increases are noted with approximate temperatures based on the emissivity of carbon.

\section{Activities as Lead Organization for HTMWG}

\section{Task 7. Meetings of Membrane Working Group}

As the Lead Organization for the High Temperature Membrane program, it was FSEC's responsibility to organize semi-annual meetings of the High Temperature Membrane Working Group. While these meetings were primarily geared to the funded participants, they were open to all individuals having an interest in the topic.

The first meeting of the High Temperature Membrane Working Group was held at the Annual Merit Review Meeting in Washington, DC on May 19, 2006. For this first meeting, all of the newly funded Pls presented an overview of their planned programs. The speakers and their affiliations are shown below in Table 9 
Table 9. HTMWG Speakers

\begin{tabular}{|l|l|}
\hline Project Principal Investigator & Affiliation \\
\hline Peter Pintauro & Case Western University \\
\hline Dominic Gervasio & Arizona State University \\
\hline Andy Herring & Colorado School of Mines \\
\hline Morton Litt & Case Western University \\
\hline Joyce Hung & GE Global \\
\hline Ludwig Lipp & Fuel Cell Energy \\
\hline Serguei Lvov & Pennsylvania State University \\
\hline Jimmy Mays & University of Tennessee \\
\hline James McGrath & Virginia Tech University \\
\hline Corky Mittelsteadt & Giner Electrochemical \\
\hline Darryl DesMarteau & Clemson University \\
\hline Clovis Linkous & FSEC/University of Central Florida \\
\hline
\end{tabular}

The second meeting of the High Temperature Membrane Working group was held in conjunction with the $232^{\text {nd }}$ American Chemical Society National Meeting and Exposition in San Francisco on Thursday, September $14^{\text {th }}, 2006$. FSEC arranged for five speakers to present an overview of the tests to which membranes will be subjected under this program and to address the issue of the most appropriate relative humidity at which conductivity measurements should be made. The presentations were "Membrane Performance and Durability Overview for Automotive Fuel Cell Applications," by Tom Greszler (GM); "Measuring Physical Properties of Polymer Electrolyte Membranes," by Courtney Mittelsteadt (Giner); "In-Plane Conductivity Testing" by Tim Bekkedahl (BekkTech); "Through-thickness Membrane Conductivity Measurement for HTM Program: Issues and Approach," by Kevin Cooper (Scribner); and "Temperature and RH Targets," by Vishal Mittal (UCF/FSEC).

The next meeting was held Wednesday, May 14, 2007, in conjunction with the Annual Merit Review. The agenda for this meeting was developed to provide information on the proposed universal membrane classification scheme, membrane/MEA durability test conditions, membrane conductivity, and possible networking activities with Europe via CARISMA.

John Kopasz, Argonne National Lab, described a variety of possible polymer membranes to investigate, such as hydrocarbon, fluorocarbon, inorganic, branched, comb, hyperbranched, dendritic, with additives, or polymer membranes with structural supports. His presentation focused on the problem of figuring out what avenues should be pursued, which are dead ends, and how such decisions should be made.

The next presentation by Tom Benjamin focused on Membrane and MEA Accelerated Stress Test Protocols. He pointed out that accelerated stress test protocols are needed to reduce new product introduction cycle, and a lifetime estimate is needed now.

The third presentation was given by Tim Bekkedahl of BekkTech. This presentation outlined the procedure being used to develop the in-plane conductivity protocol. A 
number of parameters were being determined and the consequences of each were discussed and preliminary data from Nafion standards was presented.

For the last presentation of the meeting, Anca Faur Ghenciu presented on the Coordination Action for Research on Intermediate and High Temperature Specialized Membrane Electrode Assemblies (CARISMA), a networking project for high temperature polymer electrolytic membrane fuel cell (PEMFC) membrane electrode assembly (MEA) activities in Europe.

The fall meeting was held on Wednesday, October 10, 2007. It was conducted as a joint session of the HTMWG and CARISMA (Coordination Action for Research on Intermediate and high temperature Specialized Membrane electrode Assemblies) and held at the Hilton Hotel, Washington DC, in conjunction with the Electrochemical Society Meeting.

Dr. Jin Wang from Argonne National Lab described opportunities for membrane research with surface sensitive $\mathrm{x}$-ray techniques. Some of the $\mathrm{x}$-ray techniques that can be applied include reflectivity and standing waves, $x$-ray photon correlation spectroscopy and GISAXS using x-ray wave-guides.

The next speaker was Deborah Jones from the National Scientific Research Council. Dr. Jones outlined membrane development in Europe. She said that the European Commission has provided funding under six framework programs for the last 20 years. Funding has increased but so have the requests for the money. Under Framework Program 7, energy is included with other topics and an implementation plan will be initiated under this FP. Current projects are running under FP6 and CARISMA is one of these projects.

Following Dr. Jones, Lorenz Gubler of the Electrochemistry Laboratory, Paul Scherrer Institute in Switzerland, presented "A Strategy for Aging Test of Fuel Cell Membranes." He began with a discussion of the merits of graft co-polymerization, which include the tailoring of the membrane composition to the required application and potential cost effectiveness. He then went on to discuss the membrane "health state" and ways to monitor it.

The next meeting, again held in conjunction with the AMR, was held Monday, June 9, 2008 in Washington, DC. Speakers included Jim Waldecker from Ford Motor who presented an "Automotive Perspective on Membrane Evaluation"; Xinyu Huang of FSEC who covered the "Fundamental Study of the Mechanical Strength Degradation Mechanisms of PFSA Membranes and MEAs"; Vishal Mittal from UTC Power who discussed "Membrane Durability in PEM Fuel Cells: Chemical Degradation"; and Robert B. Moore from Virginia Tech who presented "Processing-Performance Relationships for Perfluorosulfonate lonomer Membranes."

The 2008 Fall Meeting was held in conjunction with the Pacific Rim Meeting on Electrochemical and Solid-State Science (PRIME) in Honolulu, Hawaii. Marianne 
Rodgers of FSEC presented "FSEC's MEA Test Protocol" for discussion with Team members who would be supplying membranes for testing. Her talk was followed by one from Shyam Kocha of Nissan entitled "Performance Measurement of MEAs." The final presentation of the meeting was given by Bryan Pivovar of NREL who gave "A Discussion on Improved MEAs."

Monday, May 18, 2009 was the Spring Meeting of the HTMWG and was again held in conjunction with the Annual Merit Review Meeting. Dr. John Kopasz gave an update on the Membrane Classification Scheme that was developed three years previously. $\mathrm{He}$ then reviewed the DOE membrane targets, emphasizing that they had been updated to use area-specific resistance (ASR) instead of conductivity. He also reviewed the importance of, and metrics for, mechanical and chemical durability of membrane electrode assemblies (MEAs).

Dr. Yu Seung Kim from Los Alamos National Lab, then gave a talk on the Integration of Non-Traditional Membranes into MEAs. The talk was broken down into two major parts: Membrane-Electrode Interface and Non-PFSA lonomers.

The third speaker of the meeting was Dr. James Fenton from the University of Central Florida's Florida Solar Energy Center (FSEC). Dr. Fenton distributed copies of the Procedure for Performing PEM Single Cell Testing that was prepared by FSEC. This document was to be used for the MEA manufacture and testing that was to be done with membranes supplied by the DOE-funded membrane projects.

The final talk of the meeting was presented by Dr. Craig Gittleman from General Motors (GM), who spoke regarding the Automotive Perspective on PEM Evaluation. This included an overview of FC operating conditions from the OEM perspective and various tests that GM uses for testing PEMs, both ex situ and in situ tests. He also stressed the importance of not focusing solely on conductivity. He concluded by saying that failure modes of mechanical degradation, chemical degradation and shorting must all be considered when developing materials for automotive fuel cell systems.

The Fall 2009 Meeting was held Monday, November 16, 2009 in conjunction with the Fuel Cell Seminar in Palm Springs, CA. Dr. Michael Hicks, from IdaTech, gave a presentation regarding Membrane Requirements for Back-up Power Applications, followed by an overview of the U.S. Fuel Cell Council, of which he was the current president. This informative presentation provided an overview of the USFCC, the membership and structure, their priorities and recent successes and their outreach activities.

The next speaker was Ilgaz Cumalioglu from Plug Power. His presentation provided an overview of the GenSys Blue, a fuel cell heating appliance. This was followed by a presentation from Dr. Kevin Colbow of Ballard Power Systems. Dr. Colbow began his presentation with an overview of Ballard, including company statistics and market focus. He then provided an overview of the membrane testing methodologies used at Ballard. 
The Spring 2010 Meeting was held in conjunction with the AMR on Friday, June 11, 2010. At this meeting, two talks were presented: "Low Relative Humidity PEM Fuel Cell Membrane Development at DuPont" given by Biswajit Choudhury of DuPont and "PBI and High Temperature Membrane Development" by Brian $C$. Benicewicz from the University of South Carolina.

The final meeting of the HTMWG was held Thursday, October 14, 2010 during the Electrochemical Society Meeting in Las Vegas, NV. The first speaker of the meeting was Ahmet Kusoglu, who was presenting for Adam Weber of LBL. Kusoglu's talk was entitled "Continuum Modeling of Membrane Properties." This talk was followed by "Some Durability Considerations for Proton Exchange Membranes" presented by Steven Hamrock from 3M. The final talk, given by Kevin Cooper of Scribner Associates, was "Progress and Status on Through-Plane Resistance and Conductivity Measurement of Fuel Cell Membranes."

\section{Education and Training}

As a part of the FSEC commitment to providing training, a Fuel Cell Short Course was held in February 2006, 2007, 2008 and 2009 at the Florida Solar Energy Center. This four day course included lectures in the morning and laboratory sessions in the afternoon. The final day was an optional workshop for making in-plane conductivity measurements. Instructors for the course included Dr. Vijay Ramani, Dr. H. Russell Kunz, Dr. James Fenton, Dr. Kevin Cooper and Mr. Tim Bekkedahl. A sample agenda for the course can be seen below in Table 10.

\section{Table 10. Sample Agenda for Fuel Cell Short Course}

\section{Sunday, Feb. 1}

Reception and Overview

\section{Monday, Feb. 2}

On-site Registration

Continental Breakfast

Fuel Cell Basics + Materials Lecture (Ramani)

Fuel Cell Thermodynamics Lecture (Kunz/Ramani)

Coffee Break

Analytical Electrochemistry Lecture (Fenton)

Lunch

\section{Laboratory Session 1}

Discussion Session

\section{Tuesday, Feb. 3}

Continental Breakfast

Electrode Kinetics Lecture (Ramani/Fenton)

Sources of Overpotential Lecture (Kunz/Ramani)

Coffee Break

Data Analysis Lecture (Kunz)

Lunch

Laboratory Session 2
5:00 - 8:00 PM DoubleTree Hotel

$\begin{array}{ll}\text { 7:30 - 8:00 AM } & \text { Visitors Center } \\ \text { 7:30 - 8:00 AM } & \text { Visitors Center } \\ \text { 8:00 - 9:00 AM } & \text { Auditorium } \\ \text { 9:00 - 10:00 AM } & \text { Auditorium } \\ \text { 10:00 - 10:30 AM } & \\ \text { 10:30 - 11:30 AM } & \text { Auditorium } \\ \text { 11:30 AM - 1:00 PM } & \text { Visitors Center } \\ \text { 1:00 - 5:00 PM } & \text { Lab } \\ \text { 5:00 - 6:00 PM } & \text { Auditorium }\end{array}$

$\begin{array}{ll}\text { 8:00 - 8:30 AM } & \text { Visitors Center } \\ \text { 8:30 - 9:30 AM } & 102 \\ \text { 9:30 - 10:30 AM } & 102 \\ \text { 10:30 - 11:00 AM } & \\ \text { 11:00 - 12 Noon } & 102 \\ \text { 12 Noon - 1:30 PM } & \text { Visitors Center } \\ \text { 1:30 - 5:00 PM } & \text { Lab }\end{array}$


Discussion Session

Wednesday, Feb. 4

Continental Breakfast

Impedance Lecture (Cooper)

CO Tolerance and DMFCs Lecture (Ramani)

Coffee Break

Challenges and Opportunities Lecture (Kunz)

Lunch

Laboratory Session 3

Discussion Session

Thursday, Feb. 5

Continental Breakfast

Optional In-plane Conductivity Workshop

Optional workshop is open to all attendees interested in measuring membrane conductivity. FSEC, as part of its high temperature, low relative humidity membrane DOE contract, must develop conductivity protocols. You will learn how conductivity measurements are made, and make a set of measurements on standards such as Nafion ${ }^{\circledR}$ 112. You're encouraged to bring your own samples for discussion on issues affecting measurements. Attendees will assemble BekkTech conductivity cells, demonstrate the process for making conductivity measurements and discuss in-plane conductivity.

In addition to the basic short course, an additional one day course was offered free to all interested parties during which the fundamentals of making in-plane conductivity measurements were taught

The highly successful course educated 94 participants over the four years that it was held. Attendees included individuals from industry, academia and national labs. The number of attendees by year is shown in Table 11.

Table 11. FC Short Courses and Attendance

\begin{tabular}{|l|l|}
\hline Date & \# of attendees \\
\hline Feb. 5-8, 2006 & 20 \\
\hline Feb. 4-8, 2007 & 34 \\
\hline Feb. 3-7, 2008 & 28 \\
\hline Feb. 1-5, 2009 & 12 \\
\hline
\end{tabular}

\section{Conclusions}

A six year program was conducted for the development and characterization of proton exchange membranes for fuel cells. FSEC was the Lead Organization and, as such, had tasks involving the development of a supported PFSA membrane and a sulfonated hydrocarbon membrane, as well as tasks supporting the other teams in the DOE High Temperature Membrane Program. After the Go/No-Go decision point, the number of teams continuing with membrane development was down-selected to five and FSEC was tasked with fabricating and characterizing MEAs made from membranes provided by these five teams. In addition to developing standardized procedures for testing, FSEC published protocols describing the following procedures: Procedure for 
Performing In-Plane Membrane Conductivity Testing in July 2008 and Procedure for Performing PEM Single Cell Testing in April 2009. Both documents were made available to the HTMWG and are available to the fuel cell community.

As a part of the FSEC commitment to providing training, a Fuel Cell Short Course was held in February 2007, 2008 and 2009. In addition to the basic short course, an additional one day course was offered free to all interested parties during which the fundamentals of making in-plane conductivity measurements were taught.

Another responsibility as Lead Organization was the planning and conducting of semiannual High Temperature Membrane Working Group Meetings. Each year, the spring meeting was held in conjunction with the AMR and, with the exception of the first meeting, two to three speakers were invited to give presentations that were perceived to be of interest to the participants. These meetings were open to all interested parties, not just those currently having DOE funding.

Significant progress toward the DOE goals of conductivity and durability occurred over the course of the program. Additionally, the close interactions between the membrane providers and FSEC allowed the providers to concentrate on improving membranes while FSEC pursued the MEA development and testing and provided detailed reports to guide further membrane development.

\section{References}

\footnotetext{
${ }^{1}$ N. Grassie, J. Gilks, "Thermal analysis of polystyrenes cross-linked by pdi( chloromethyl)benzene," J. Polym. Sci., Part A: Polym. Chem. 11 (1973) 1985-1994.

${ }^{2}$ F.A. Carey, R.J. Sundberg, Advanced Organic Chemistry - Part A: Structure and Mechanisms, Fifth ed., Springer, New York, (2007) 113-121.

${ }^{3}$ A.J. Appleby, "Recent developments and applications of the polymer fuel cell," Phil. Trans. R. Soc. London A 354 (1996) 1681-1693.

${ }^{4}$ O. Savadogo, "Emerging membranes for electrochemical systems: (I) solid polymer electrolyte membranes for fuel cell systems," J. New Mater. Electrochem. Syst. 1 (1998) 47-66.

${ }^{5}$ K.D. Kreuer, "On the development of proton conducting materials for technological applications," Solid State lonics 97 (1997) 1 - 15.

6 J.A. Kerres, "Development of ionomer membranes for fuel cells," J. Membr. Sci. 185 (2001) 3-27.

7 T.A. Zawodzinski Jr., C. Derouin, S. Radzinski, R.J. Sherman, V.T. Smith, T.E. Springer, S. Gottesfield, "Water uptake by and transport through Nafion 117 membranes," J. Electrochem. Soc. 140 (1993) 10411047.

${ }^{8}$ F.N. Büchi, G.G. Scherer, "Investigation of the transversal water profile in Nafion membranes in polymer electrolyte fuel cells," J. Electrochem Soc. 148 (2001) A183-A188.

${ }^{9}$ K.D. Kreuer, "Fast proton conductivity: a phenomenon between the solid and liquid state," Solid State lonics 94 (1997) 55-62.

${ }^{10} \mathrm{~S}$. Sambandam, V. Ramani, "SPEEK/functionalized silica composite membranes for polymer electrolyte fuel cells," J. Power Sources. 170 (2007) 259-267.

${ }^{11}$ S.D. Mikhailenko, F. Celso, S. Kaliaguine, "Properties of SPEEK based membranes modified with a free radical scavenger," J. Membr. Sci. 345 (2009) 315-322.

${ }^{12}$ C.L. Gardner and A.V. Anantaraman, "Studies of ion-exchange membranes. II. Measurement of the anisotropic conductance of Nafion ${ }^{\circledR}$ " Journal of Electroanalytical Chemistry, 449, 209-214 (1998).

${ }^{13} \mathrm{~S}$. Ma, Z. Siroma and H. Tanaka, "Anisotropic Conductivity Over In-Plane and Thickness Directions in Nafion-117," Journal of the Electrochemical Society, 153, A2274-A2281 (2006).
} 
${ }^{14}$ K.M. Nouel and P.S. Fedkiw, "Nafion(R)-based composite polymer electrolyte membranes," Electrochimica Acta, 43, 2381-2387 (1998).

${ }^{15}$ R.F. Silva, M.D. Francesco and A. Pozio, "Tangential and normal conductivities of Nafion® membranes used in polymer electrolyte fuel cells," Journal of Power Sources, 134, 18-26 (2004).

${ }^{16}$ P. Brooker, M. Rodgers, L. Bonville, R. Kunz, D. Slattery, and J. Fenton. "Effect of Spray parameters on Electrode surface and performance," ECS Transactions, 28 (27) 51-59 (2010).

${ }^{17}$ P.Brooker, M. Rodgers, L.J. Bonville, H.R. Kunz, D. Slattery and J. Fenton. "Effect of Spray Parameters on Electrode Surface and Performance," ECS Transactions 28 (27) 51-59 (2010).

${ }^{18}$ R.P. Brooker, M.P. Rodgers, L.J. Bonville, H.R. Kunz, D.K. Slattery, J.M. Fenton. "Influence of trace oxygen in low-crossover proton exchange membrane fuel cells," Journal of Power Sources 218 (2012) 181-186. 
Appendix I

\section{Procedure For Performing In-Plane Membrane Conductivity Testing}



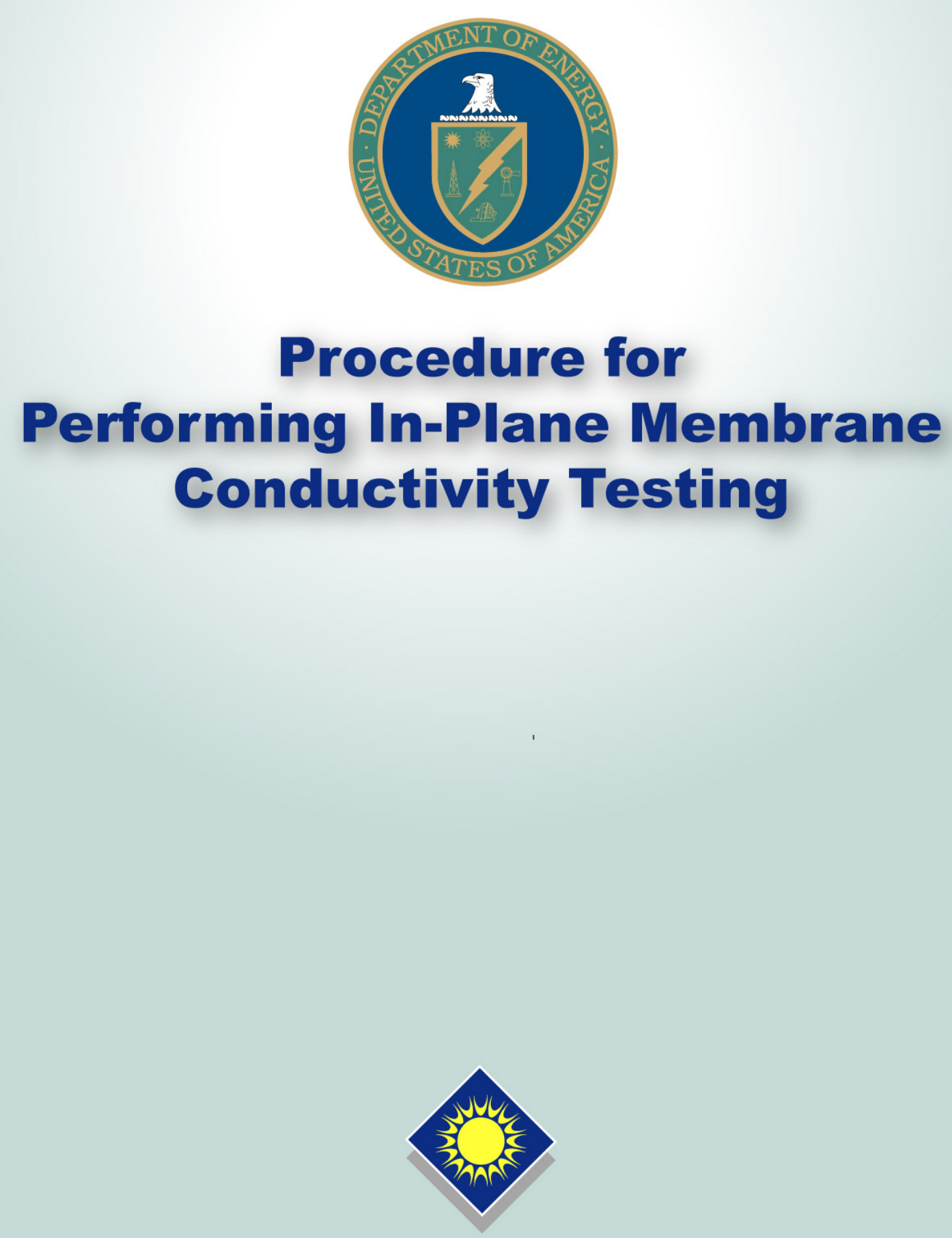

Work Performed by the Florida Solar Energy Center under DOE Contract \# DE-FC36-06G016028

June 9, 2008 


\section{EXECUTIVE SUMMARY}

This document outlines, in detail, a test protocol for performing in-plane conductivity measurements on membranes for PEM fuel cells. Responsibility for developing this test protocol was tasked to the Topic 2 awardee under DOE Contract \#DE-FC36-06G016028. Under this award, FSEC was to work with the fuel cell community to develop standardized methodologies to membrane conductivity as a function of temperature and relative humidity $(\mathrm{RH})$ and to measure membrane mechanical properties.

This conductivity protocol is used at FSEC for all membrane testing. FSEC follows the conductivity protocol established by BekkTech; and while different equipment was used for the samples that have been compared, this test protocol reproduced BekkTech conductivity results. BekkTech performs the DOE protocol using the BekkTech Conductivity Test System, Model BT-552. FSEC has reproduced the BekkTech test results using FSEC's existing test equipment with the only significant modification to the BekkTech procedures being the length of time at each RH. (BekkTech holds for 15 minutes at each RH. FSEC holds for 60 minutes at each RH.)

Researchers following the test protocol will be able to reproduce results that have been obtained by both FSEC and BekkTech. 


\section{Contents}

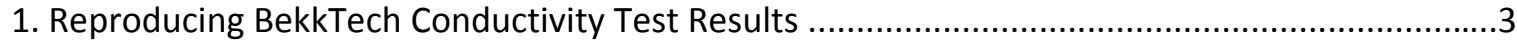

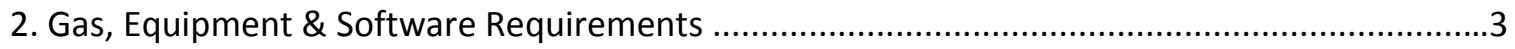

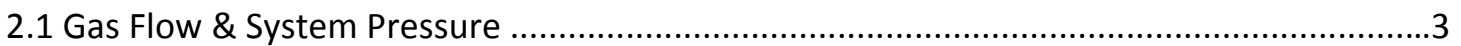

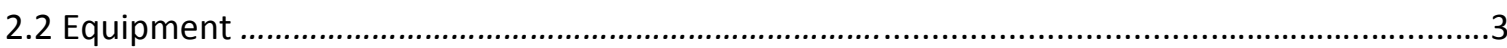

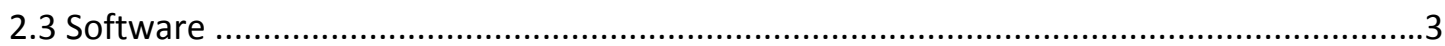

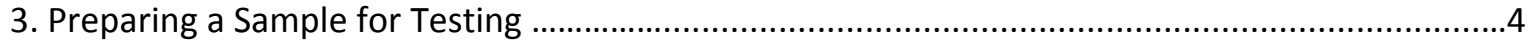

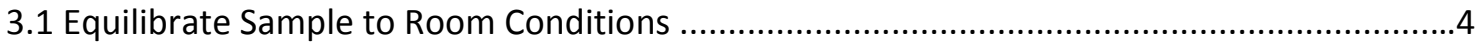

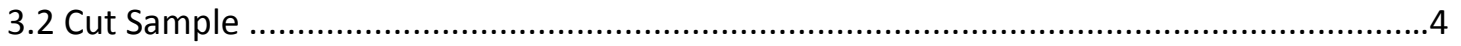

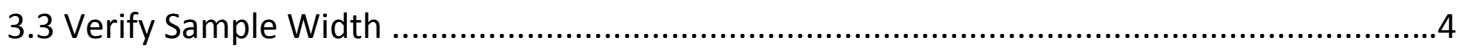

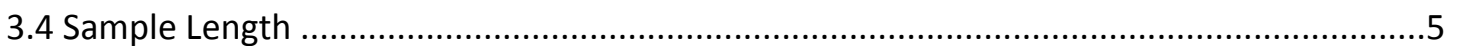

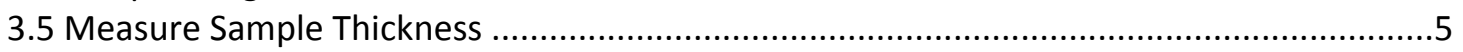

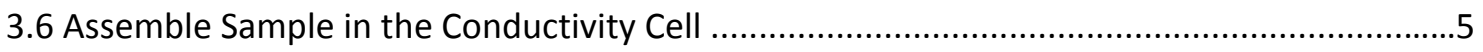

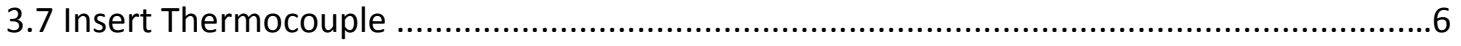

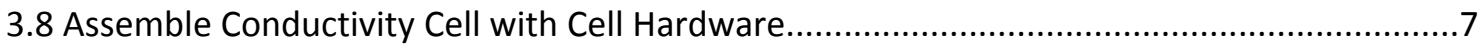

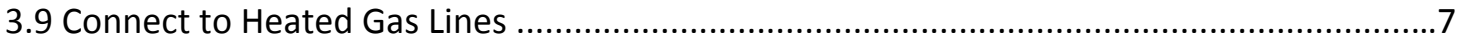

3.10 Electrical Connections to the Conductivity Cell................................................................9

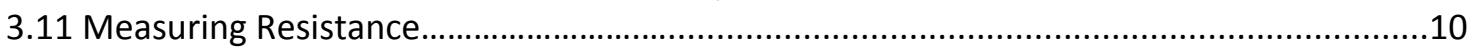

3.12 Connect Cell Hardware to Heater Power and Heater Thermocouple...................................10

4. Test Protocol for Samples Submitted to BekkTech Under the DOE Program ........................... 10

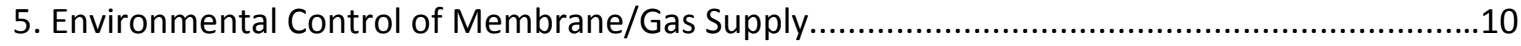

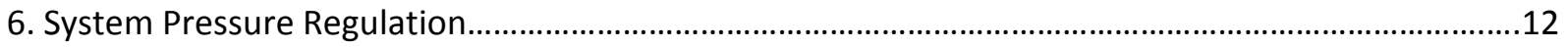

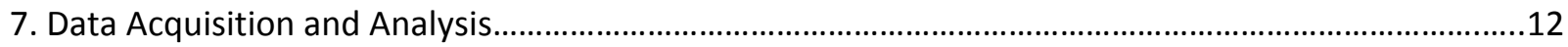

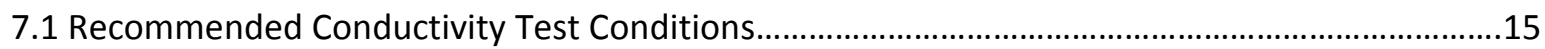

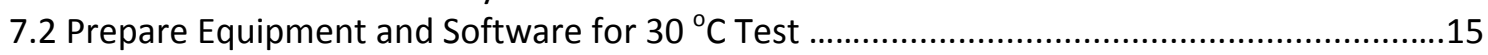

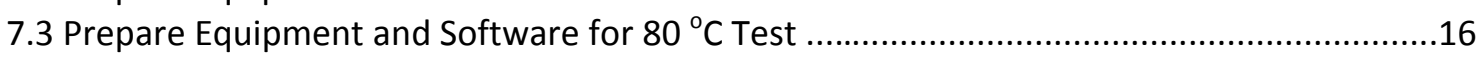

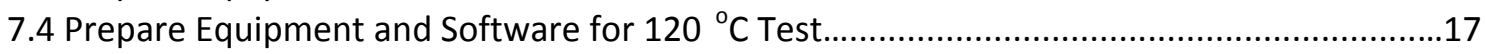

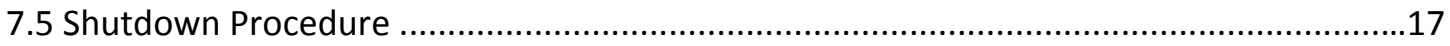

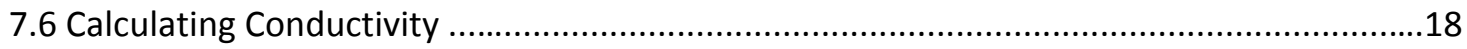

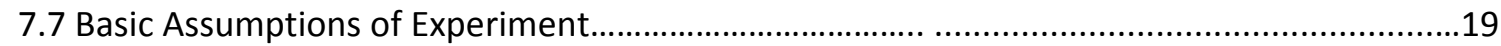




\section{Test Protocol for Membrane Conductivity Screening Test}

Conductivity testing for the DOE program Milestones are conducted by BekkTech Corp. and reported to the individual teams and to FSEC Program Management for presentation and review with DOE. The purpose of this protocol is to provide the individual Task 1 team members with a verified protocol for their screening tests. This document outlines the conductivity test procedures used at FSEC. FSEC follows the conductivity protocol established by BekkTech, and while different equipment was used, for the samples that have been compared, this test protocol reproduced BekkTech conductivity results.

\section{Gas, Equipment \& Software Requirements}

FSEC uses the equipment, and software listed below to perform conductivity measurements.

\subsection{Gas Flow and System Pressure}

- Gas - Hydrogen

- $30^{\circ} \mathrm{C}$ Tests

- Gas Flow Control - Two Mass Flow Controllers from the Fuel Cell Test Station: Model $850 \mathrm{C}$, Scribner Associates, Inc. are used for gas-mixing to achieve dew points for $30^{\circ} \mathrm{C}$ testing.

o System Pressure - $100 \mathrm{kPa}$ absolute. This is approximately atmospheric pressure in Florida.

- $80^{\circ} \mathrm{C}$ Tests

- Gas Flow Control - One Mass Flow Controller from the Fuel Cell Test Station: Model 850C, Scribner Associates.

o System Pressure - $100 \mathrm{kPa}$ absolute. This is approximately atmospheric pressure in Florida.

- $120^{\circ} \mathrm{C}$ Tests

- Gas Flow Control - One Mass Flow Controller from the Fuel Cell Test Station: Model 850C, Scribner Associates.

o System Pressure - $230 \mathrm{kPa}$ absolute. This is approximately $130 \mathrm{kPa}$ gauge in Florida. Pressure is provided by a Scribner and Associates backpressure regulator.

\subsection{Equipment}

- Fuel Cell Technologies $5 \mathrm{~cm}^{2}$ fuel cell test hardware with longer bolts supplied by BekkTech

- BekkTech Conductivity Cell - Part \# BT-112

- BekkTech Saturator - Part \# BT-104

- BekkTech Heated Gas Line - Part \# BT-125

- Princeton Applied Research 263 Potentiostat/Galvanostat

- Temperature Controllers \& Thermocouples

- Omega CSC32 Temperature Controller with a K-type thermocouple in the saturator

o Self-tune Plus Love Controls with a K-type thermocouple in the heated gas line

o Love Controls with T-type thermocouples in the fuel cell

- In-house-made water condensers on the gas exit

- Scribner Associates backpressure regulator

\subsection{Software}

- Conductivity is monitored as a function of time using CorrWare (Scribner Associates)

- Gas flow and cell temperature are controlled using Fuel Cell Software (Scribner Associates) 
- Data is analyzed using Excel (Microsoft)

\section{Preparing a Membrane Sample for Testing}

Clean all work surfaces and test hardware with ethanol and compressed air. Wear properly specified gloves while handling the membrane to prevent contamination.

\subsection{Equilibrate Sample to Room Conditions}

Place membrane sample on a clean counter surface for 24 hours to allow equilibration to room temperature and room humidity.

FSEC Facility Room Conditions: Room temperature of approximately $21^{\circ} \mathrm{C}$ and average room relative humidity of $60 \%$.

\subsection{Cut Sample}

Use the Sample Punch (BekkTech part number ACC-960, Figure 1) to cut a piece from the membrane for testing. Sample to be tested measures approximately $5 \mathrm{~mm} \times 25 \mathrm{~mm}$. Sandwich the membrane between thin sheets of Teflon when cutting the sample.

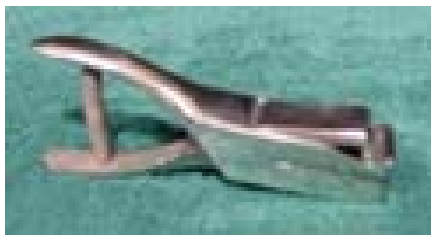

Figure 1. Sample Punch

Alternative Cutting Method: Use an Exacto knife and a straight edge to cut the sample. The sample must be long enough to extend slightly beyond the platinum mesh of the conductivity cell.

\subsection{Verify Sample Width}

Use a Width Measurement Tool (BekkTech part number ACC-940) to verify the width of the sample being tested. The Width Measurement Tool has magnification of $11 \mathrm{x}$ and a reticule with $0.1 \mathrm{~mm}$ gradients.

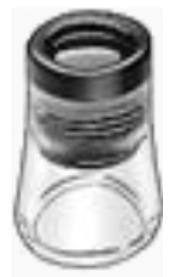

Figure 2: Width Measurement Tool

\subsection{Sample Length}

Sample length is set by the BekkTech Conductivity Cell. We use a length of $4.25 \mathrm{~mm}$ for all conductivity calculations.

\subsection{Measure Sample Thickness}


Use a Mitutoyo Gauge (Figure 3) is to determine sample thickness. Measure the equilibriated (according to section 3.1) thickness of the membrane using an average of at least 10 readings taken over the entire membrane. Sandwich the membrane between thin sheets of Teflon of known thickness when making the caliper readings.

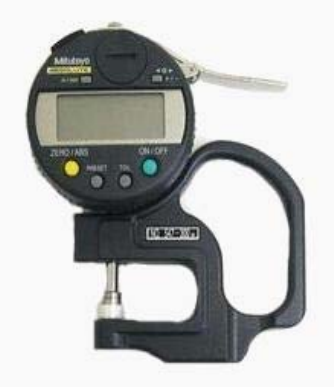

Figure 3. Mitutoyo Gauge

\subsection{Assemble Sample in the Conductivity Cell}

The BekkTech conductivity cell is shown in Figure 4. Place the Teflon support (square Teflon piece) under the clamp of the BekkTech conductivity Cell. This prevents unnecessary bending of platinum wires during assembly.

Remove all four screws holding the top membrane clamp. Then remove the top membrane clamp from the bottom membrane clamp. Use tweezers to gently lift the platinum wires up from the bottom clamp.

Insert the membrane sample under the platinum wires. Place the membrane sample perpendicular to the voltage measurement probes in the main body. Ensure there is adequate overlap between the ends of the membrane and platinum gauze at either end of the sample. A schematic of a side view of the membrane sample assembly is shown in Figure 5. The conductivity cell is designed for a minimum of 3 $\mathrm{mm}$ of overlap with the gauze. For thick samples that will be run at high humidity, place the membrane above the platinum wires. For thin samples or dry operating conditions, place the membrane below the platinum wires.

Use tweezers to place the top membrane clamp onto the top surface of the membrane sample. Use the notches on the top membrane clamp as a guide. Gently secure the membrane clamp using the four fasteners. A picture of the conductivity cell with the top clamp secured is shown in Figure 6. Be careful to apply only light torque (finger tight) when tightening fasteners, as threads in main body are easily stripped-out.

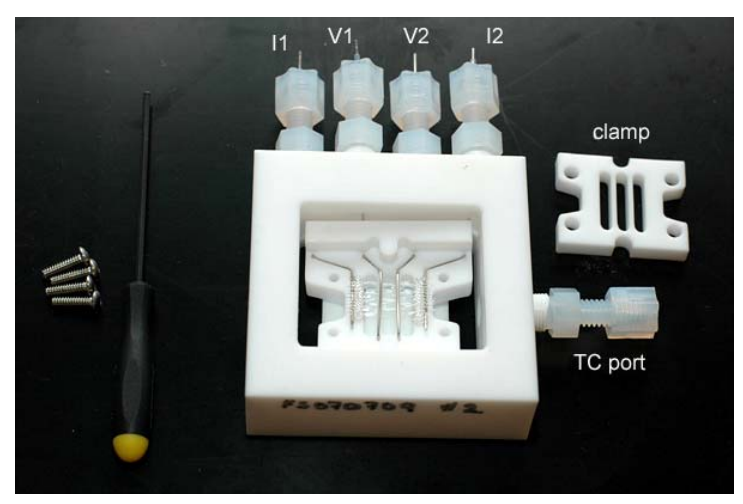


Figure 4. BekkTech Conductivity Cell shown with Teflon support (not labeled) beneath the membrane/platinum wire probe configuration. The membrane has been inserted properly in the Main Body with top clamp off to the side.

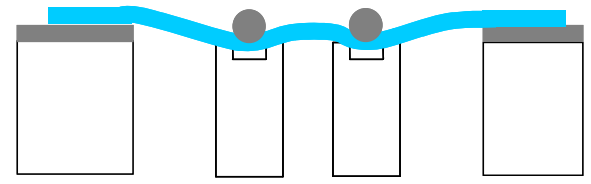

Figure 5: Assemble Sample Under Pt Wires

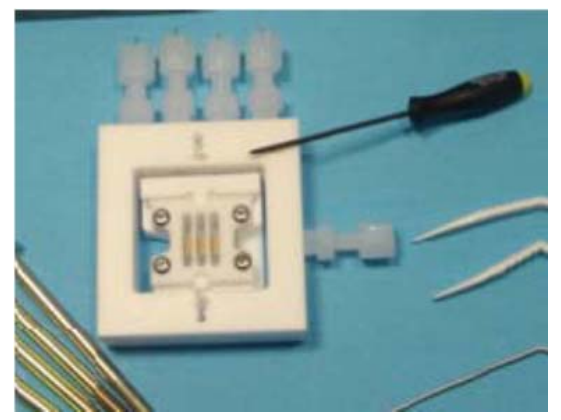

Figure 6. Replace Top Clamp

\subsection{Insert Thermocouple}

Insert Type T internal thermo couple (TC) into the Bottom Membrane Clamp beneath the membrane as shown in Figure 7. The TC should be positioned so that the junction is directly below the membrane. The junction is typically $\sim 0.5 \mathrm{~mm}$ to $1 \mathrm{~mm}$ from the end of the TC. Once placed, snug the fitting around the TC.

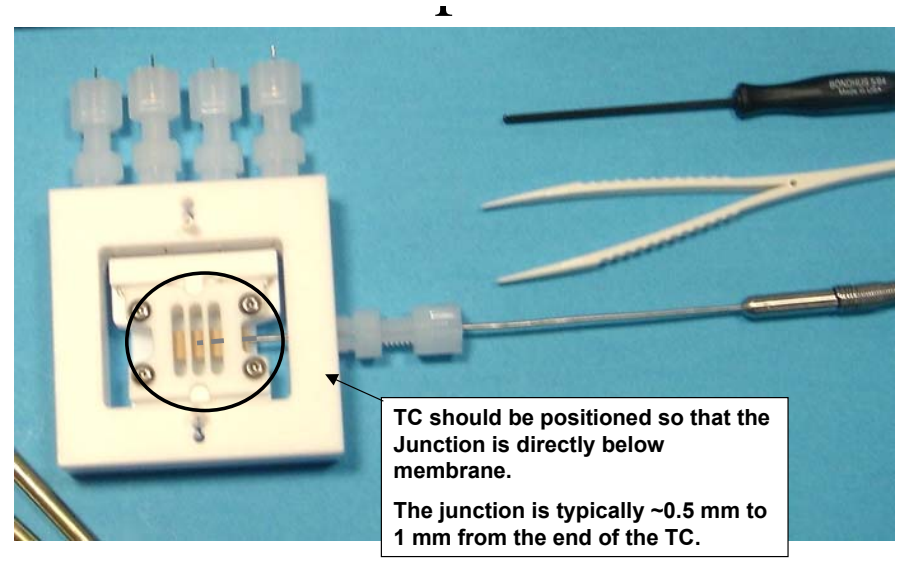

Figure 7. Internal Thermocouple Placement

\subsection{Assemble Conductivity Cell with Cell Hardware}

Place the Bekktech Conductivity Cell onto the graphite end plate of the Fuel Cell Technology test hardware as shown in Figure 8. The current collectors that extend from the ends of the graphite end plates must be aligned in the same direction as the voltage/current external ports of the Conductivity Cell. Place the remaining graphite end plate on top of the Conductivity Cell. Re-assemble the cell hardware. Using the longer bolts provided by BekkTech, secure the graphite/Conductivity Cell/graphite sandwich (Figure 9). You will use only 4 bolts to secure the assembly. The Conductivity Cell makes a 
good seal with the 4 bolts. Install the bolts in a diagonal pattern with a very light torque of about 20 inIbs to make a good seal. The Teflon conductivity cell will expand upon heating, so if the sandwich is bolted too tightly, the Teflon will deform between the plates and begin to "flow out" the sides.

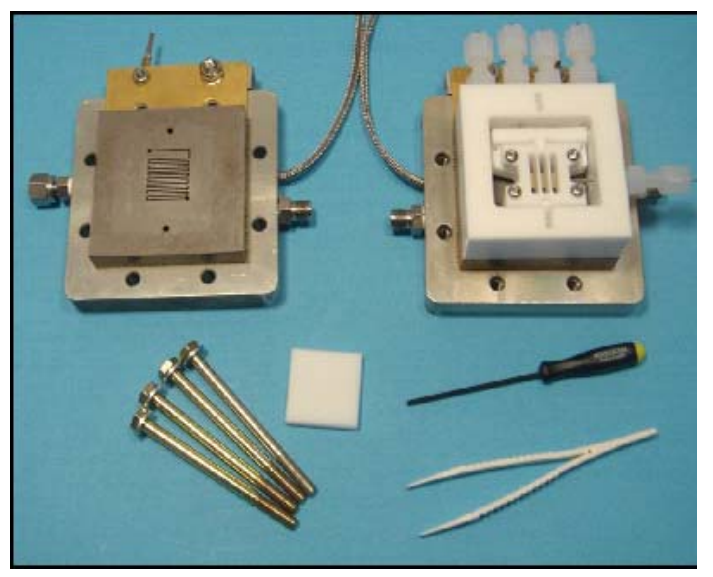

Figure 8: Conductivity cell with cell hardware

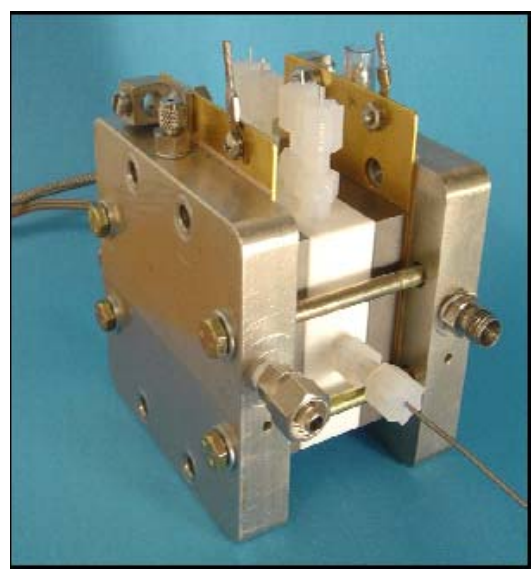

Figure 9: Assembled conductivity cell in cell hardware

\subsection{Connect to Heated Gas Lines}

Serious injury or death can occur if hydrogen and oxygen are combined within the conductivity cell. Therefore, only one source of gas is used in performing conductivity tests regardless of the "environmental system" used.

FSEC uses a combination of BekkTech and Scribner components to conduct membrane conductivity tests. The BekkTech Conductivity Cell hardware and BekkTech Saturator are used in conjunction with the Scribner $850 \mathrm{C}$ and a backpressure regulator located after the condenser on the gas exit line. In this case, FSEC uses the Scribner test stand for flow control and membrane temperature control and the BekkTech saturator for rapid humidity control. The backpressure regulator is used for pressure control. FuelCell ${ }^{\circ}$ SOFTWARE is used control the flowrates and cell temperature.

Connect the gas outlet from the BekkTech saturator to the anode gas inlet of Fuel Cell Technology test hardware. Plug the anode outlet of the fuel cell test hardware with a $1 / 4$ " stainless steel cap. Connect the cathode gas outlet of the cell hardware to the cathode exhaust line (which is connected to a condenser followed by a pressure regulator). Plug both cathode supply at the $850 \mathrm{C}$ station and cathode gas inlet of fuel cell test hardware with $1 / 4$ " stainless steel caps. Doing this, and purging the system with $\mathrm{N}_{2}$ prior to application of hydrogen, will eliminate the chances of accidental gas mixing. The setup described above with the gas lines, condenser and backpressure regulator connected to the fuel cell is shown below in Figures 10 and 11. 


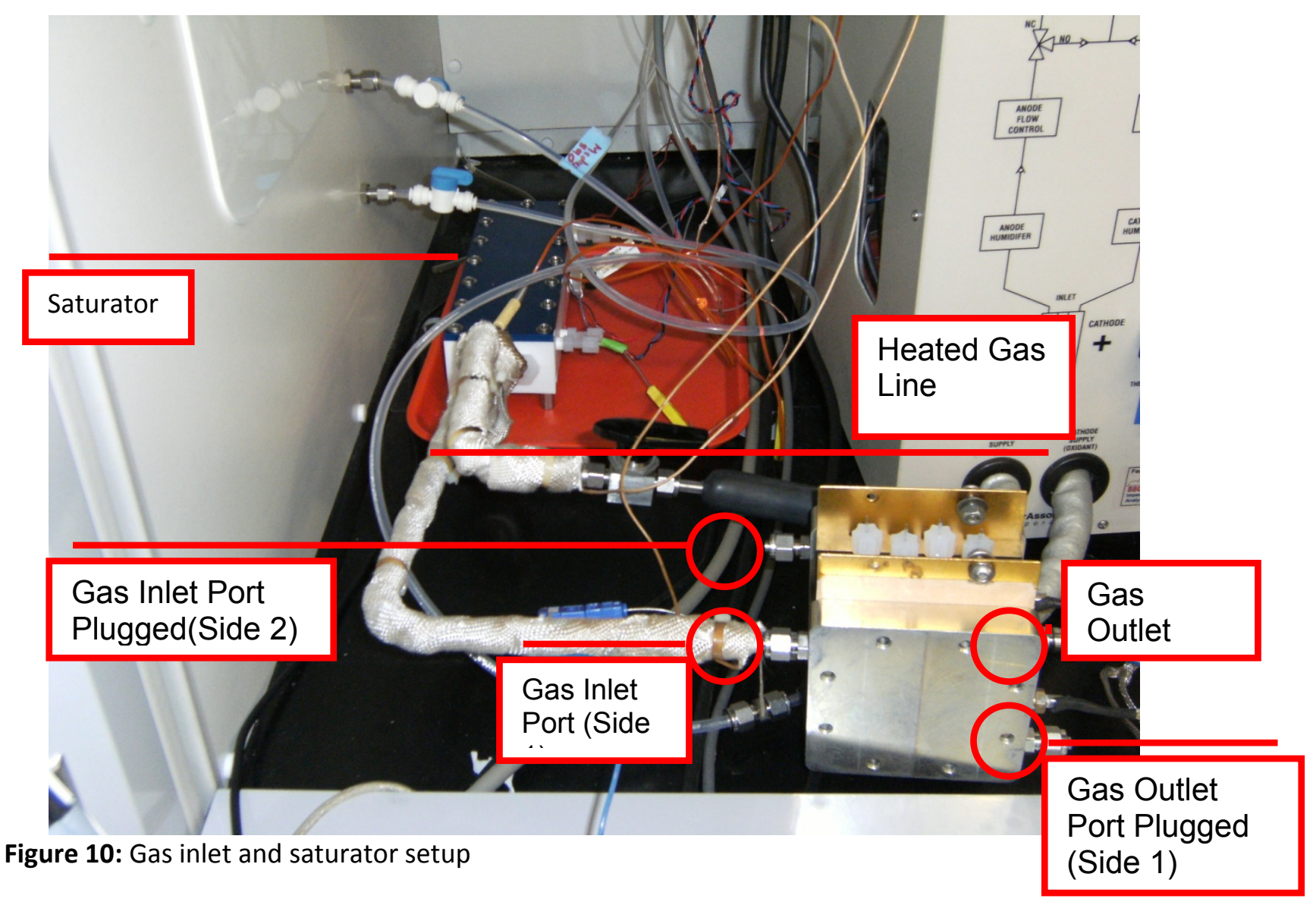




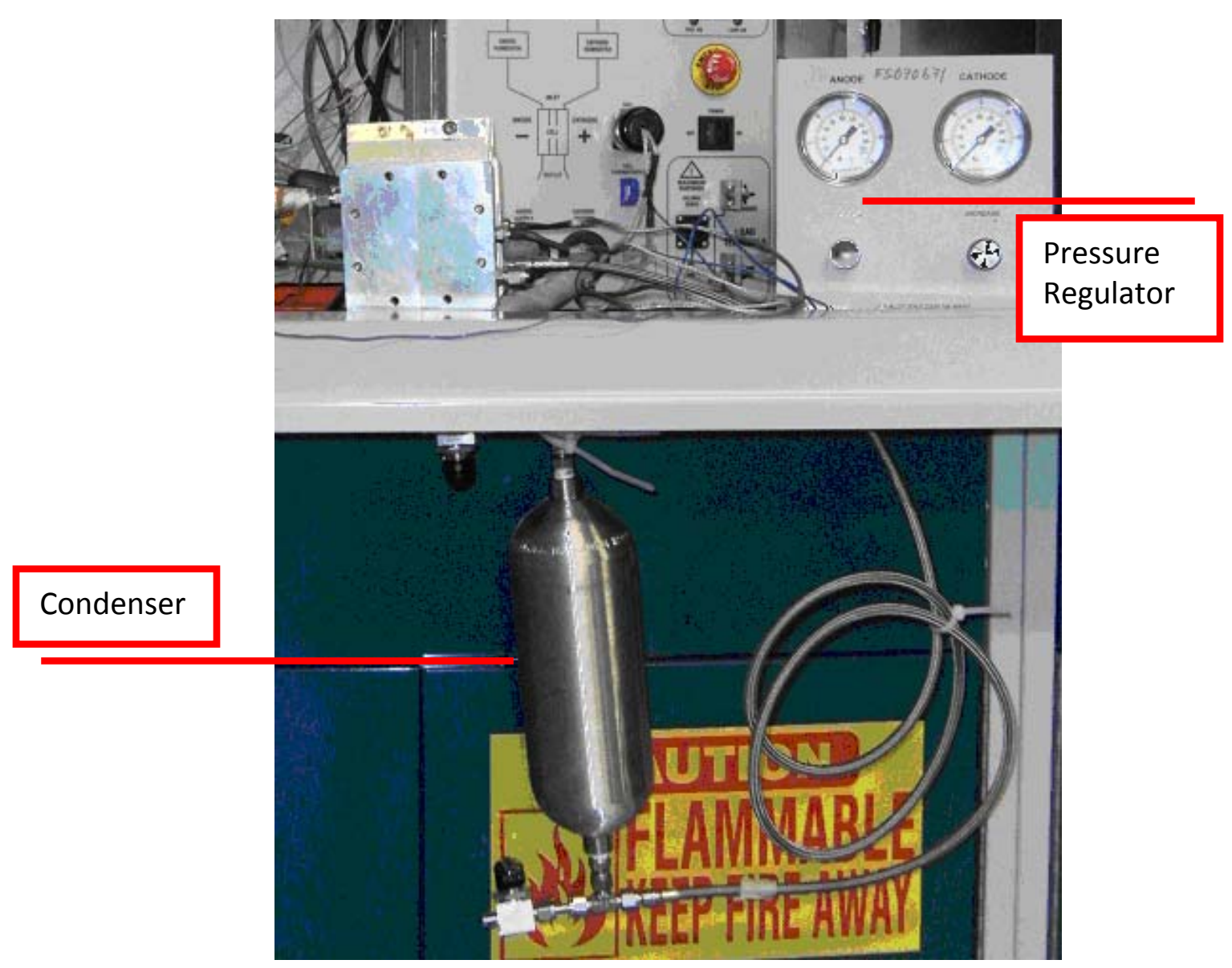

Figure 11: Condenser and pressure regulator setup

\subsection{Electrical Connections to the Conductivity Cell}

Figure 12 shows the Fuel Cell Technologies Cell Hardware with the BekkTech Conductivity Cell in place and the electrical connections attached to perform a 4-probe measurement. The electrical connection is made to a Princeton Applied Research Potentiostat/Galvanostat, Model 263.

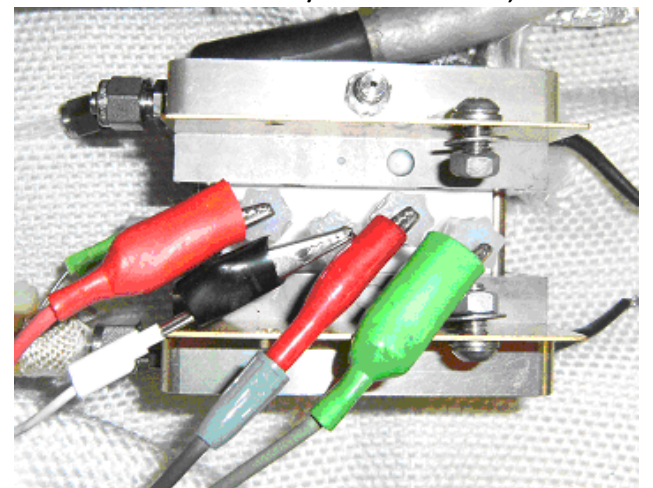

Figure 12: Wiring for a four electrode measurement. Connectivity from Left to Right is: Counter, Reference, Sense, Working 


\subsection{Measuring Resistance}

FSEC uses a Princeton Applied Research Galvanostat/Potentiostat, Model 263 to set a voltage and measures the resulting current for conductivity tests. We perform a Scanning DC Sweep from $0.3 \mathrm{~V}$ to $-0.3 \mathrm{~V}$. The linear Voltage-Current data is fit for resistance.

\subsection{Connect Cell Hardware to Heater Power and Heater Thermocouple}

Plug the internal cell thermocouple (TC) into the thermocouple outlet. Plug the power cable from the cell hardware heaters into the power outlet on the test stand.

CAUTION: We recommend that you always wait to connect the cell hardware heaters to power until after you have verified that the cell hardware internal TC is properly placed in the cell hardware. If this TC is accidentally left out of the cell hardware or improperly installed, the TC will communicate an incorrect temperature to the cell hardware temperature controller. Irreparable damage to the cell hardware and conductivity cell may result.

\section{Test Protocol for Samples under the DOE Program}

Each sample is tested for approximately six days - first at $30^{\circ} \mathrm{C}$, then $80^{\circ} \mathrm{C}$, then $120^{\circ} \mathrm{C}$. A membrane sample is assembled into the conductivity cell/cell hardware fixture and tested at $30^{\circ} \mathrm{C}, 80^{\circ} \mathrm{C}$, and 120 ${ }^{\circ} \mathrm{C}$ without removal from the cell hardware.

This section is intended to give nut \& bolts instruction on how to start up or change gas supply conditions using the Scribner $850 \mathrm{C}$ test stand and Fuel Cell SOFTWARE, adjust system pressure using the backpressure regulator, and take V vs. I data using the PAR potentiostat and Corrware software.

\section{Environmental Control of Membrane/Gas Supply Operation}

Open FuelCell SOFTWARE. Figures $13 \mathrm{a}$ and $\mathrm{b}$ show initial dialog boxes for setup cell and setup fuel with settings for a $30{ }^{\circ} \mathrm{C}$ run. The cell temperature (i.e. membrane temperature) and fuel flow control will change based on the scheduled testing condition (either 30,80 or $120^{\circ} \mathrm{C}$ ). The initial dialog boxes for 80 and $120^{\circ} \mathrm{C}$ runs are shown in Figures 14 and 15, respectively.

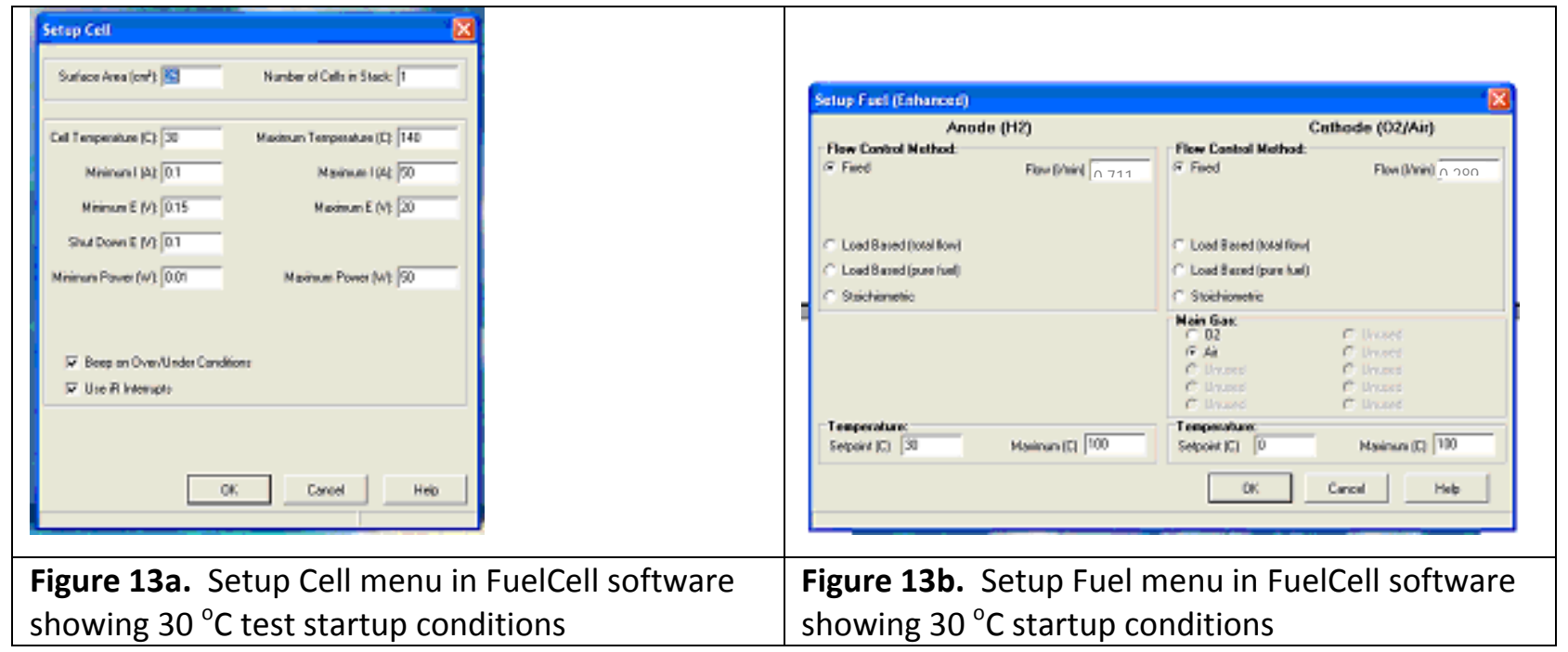




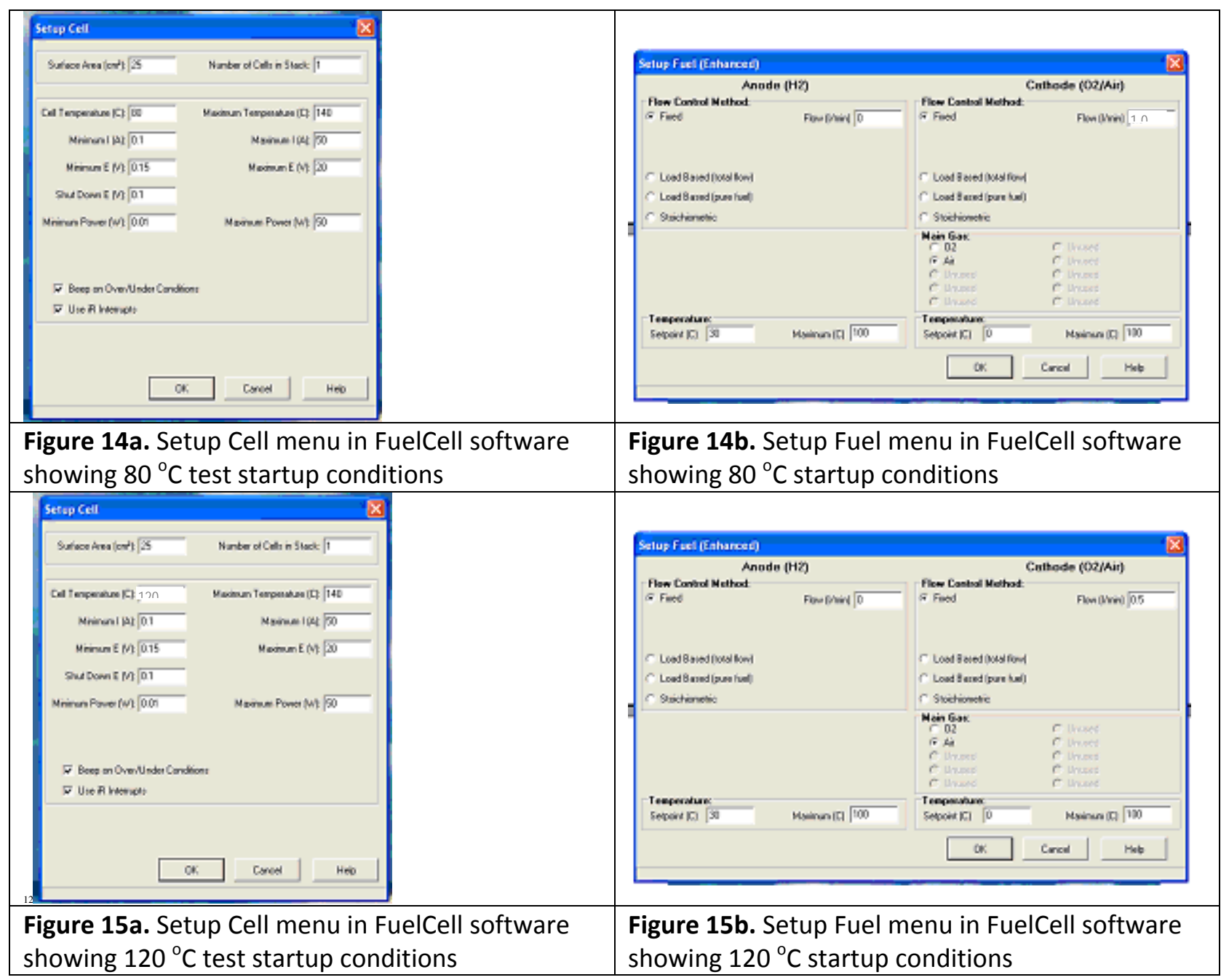

Hydrogen gas is used for all conductivity tests. Only nitrogen and hydrogen are connected to the test station. Fuel flow rates and temperatures are set based on test membrane temperature and test relative humidity (outlined in sections 7.2-7.4). Sections 7.2-7.4 contain more detailed information regarding flowrate settings. The temperature setpoint for the fuels is not critical because these temperatures will actually be controlled using the BekkTech saturator. The temperature of the saturator controls the relative humidity of the membrane. The relative humidity will be changed every 60 minutes based on the protocol for recommended conductivity test conditions, outlined in section 4 .

In the Main Control dialog box of the FuelCell software, as shown in Figure 16, click "Cell" to control the temperature of the cell. Turn on the temperature control for the saturator and line. The temperature of the line should be $10-15^{\circ} \mathrm{C}$ above the temperature of the saturator to prevent condensation. Then click the "Apply Fuel" button once the prescribed temperatures are reached. A click will sound from the $850 \mathrm{C}$; indicating solenoid valves for flow control are in function. 


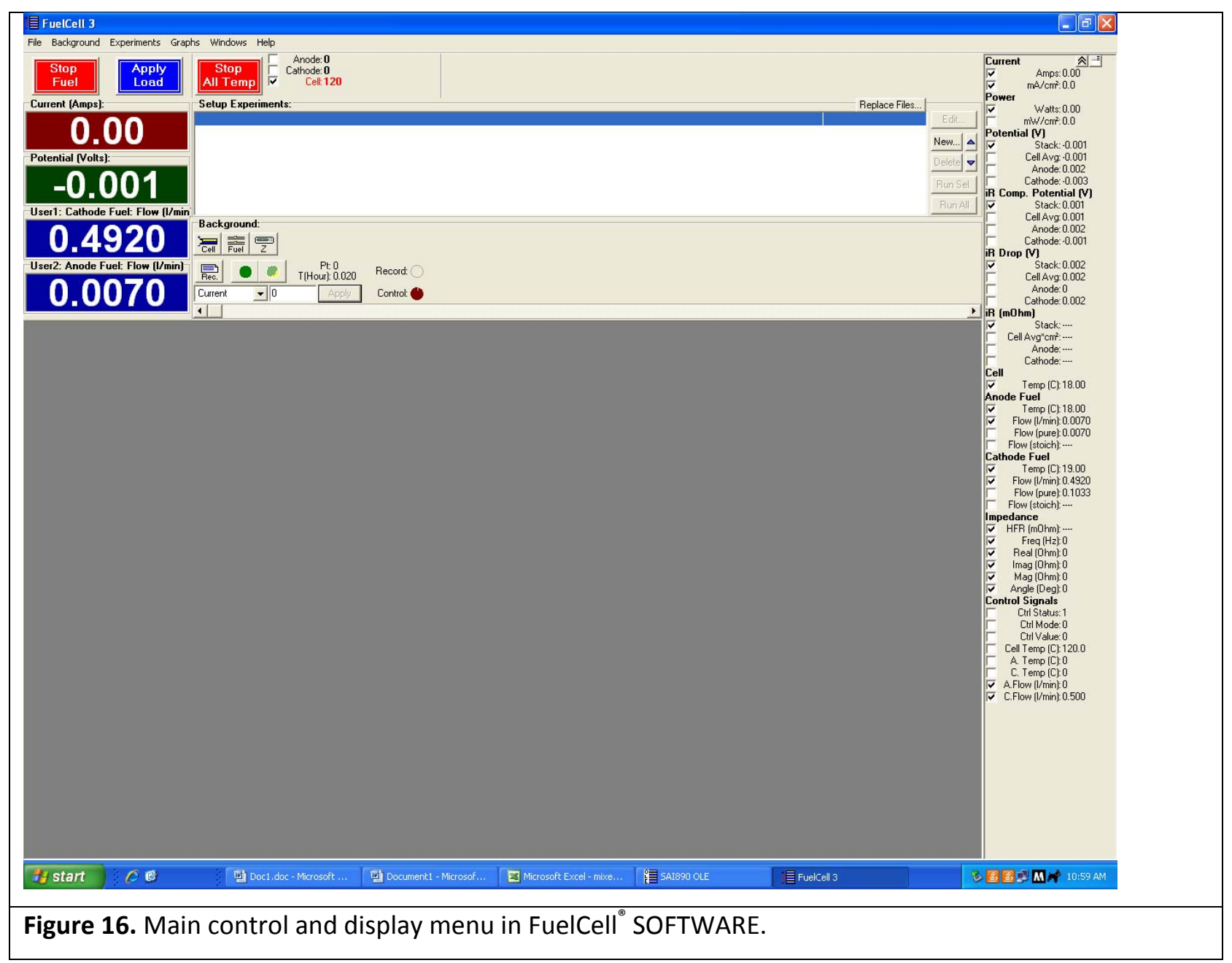

\section{System Pressure Regulation}

When testing at membrane temperatures $>100{ }^{\circ} \mathrm{C}$, the system must be operated at pressures above atmosphere in order to achieve $100 \% \mathrm{RH}$. System pressure is raised by restricting gas flow out of the system via a regulator placed after the exhaust gases pass through a condenser. The pressure is adjusted by dialing the regulator valve until the desired pressure is read off the gauge. A system pressure of $230 \mathrm{kPa}$ is recommended for testing at a membrane temperature of $120^{\circ} \mathrm{C}$.

\section{Data Acquisition and Analysis}

Open Corrware2 data acquisition software to perform conductivity measurement (collect V vs I data) and following the steps shown below.

1. Select the Cyclic Voltammagram experiment (Figures 17 and 18). Choose file name and where it will be saved. Then measure selected lines. In Figure 20, a typical plot is shown. When an appropriate amount of time has passed (one hour for each humidity and two hours for start up) press stop (the red octagon) to stop the experiment. 

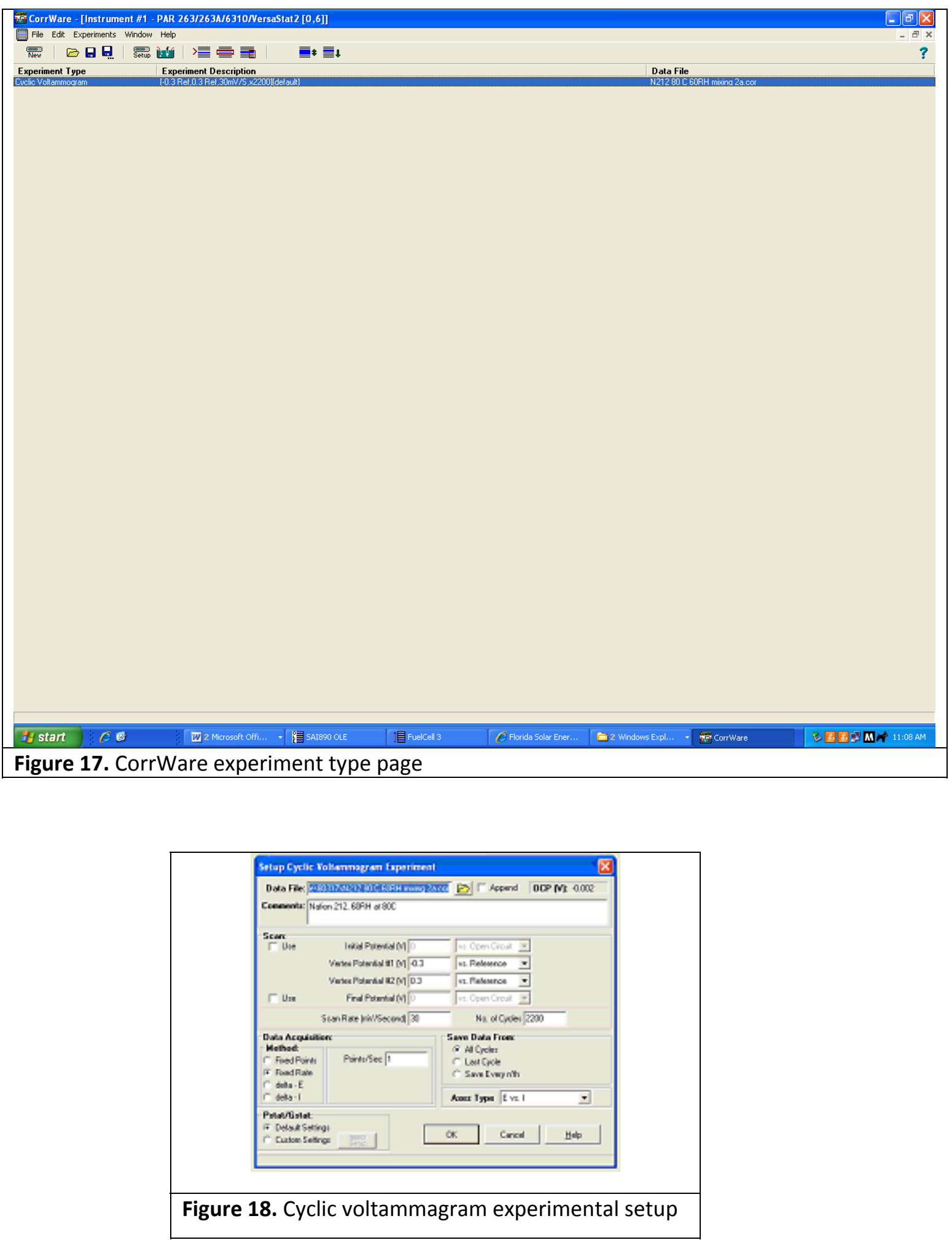


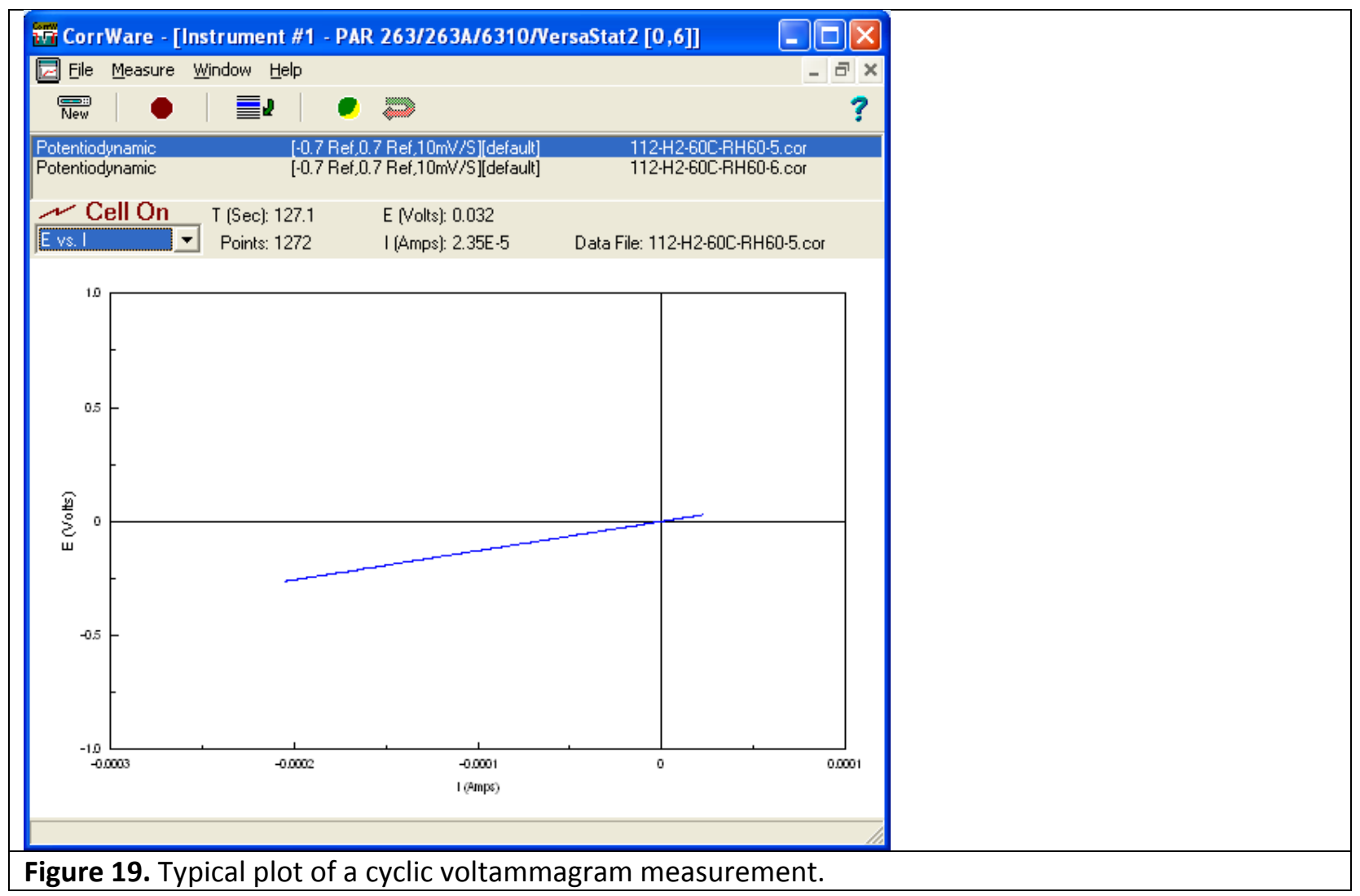

2. To analyze the data, open CorrWare Data \MacroRev5.xls, found on the desktop. Select "enable macros." This program analyzes the CorrWare data by obtaining the slope of the V-I plots (i.e., the resistance) over time. Copy the name of the file that was just saved (.cor) in "Datafile to process". This file must be in the same folder as MacroRev5. Open the template file (.xls) whose name matches that in "Template file name". The output file will be that named in "New Data Analysis Name". Click on "Create New Data Analysis File". In a few seconds a new file is created that is the .xls version of the .cor file that was just obtained.

3. In the new .xls file open the "RH\&4ElecCondVsTime" tab. This gives a plot of conductivity vs time. An example is shown in Figure 20. By examining this plot, it is possible to determine when the membrane's conductivity reached steady-state. In the plot in Figure 20, steady state was reached around 60 minutes. If steady-state is not reached, repeat the measurement using a new file name until a steady-state is reached.

4. Open the "data" tab in the .xls file. The final column (G) is the calculated 4 electrode conductivity. The file time is in column D. Take an average of the conductivity values that have been obtained in steady state. This value is the conductivity of this membrane in the conditions under study.

5. Repeat the test for various operating conditions. 


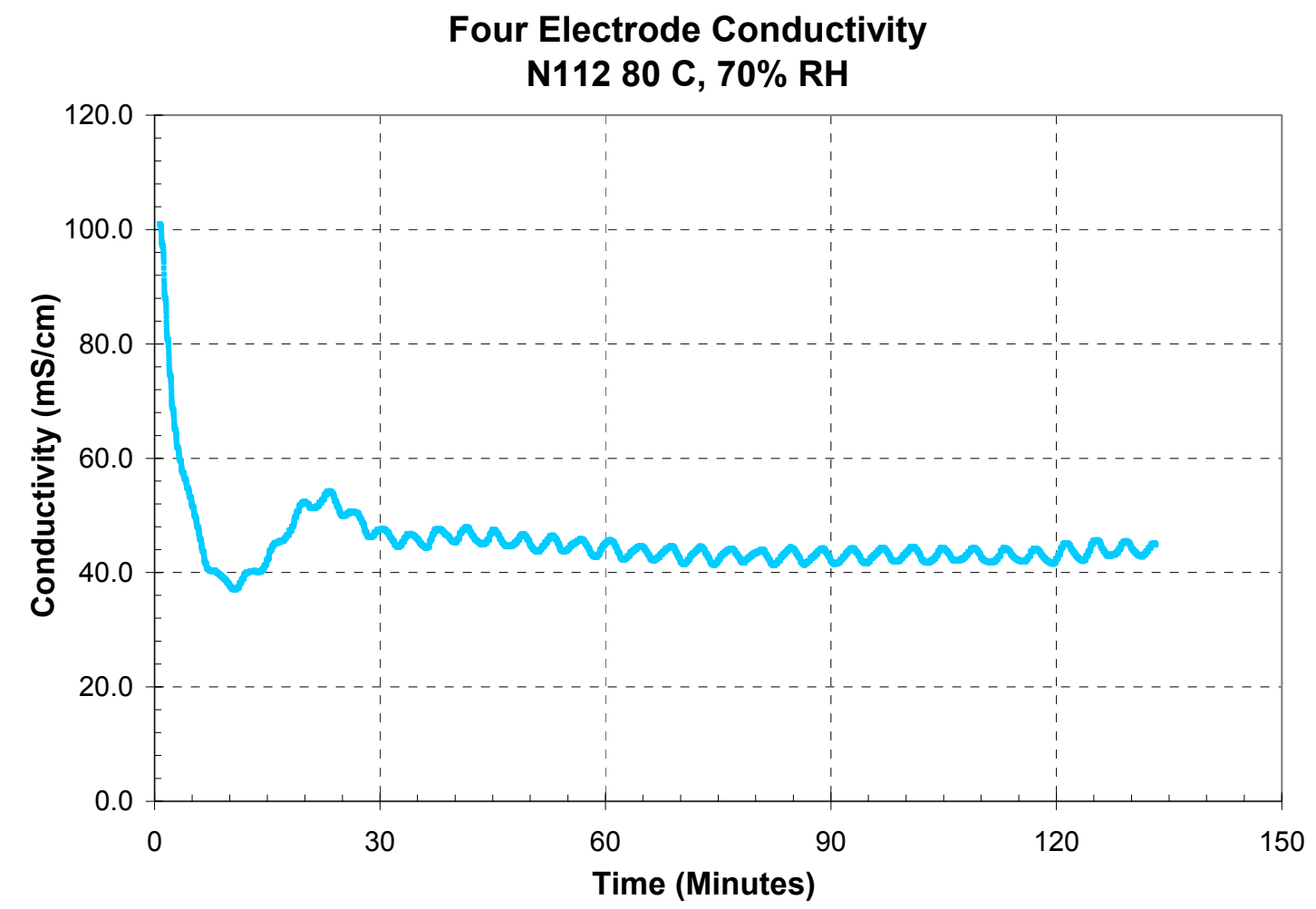

Figure 20. Sample conductivity plot.

\subsection{Recommended Conductivity Test Conditions}

The test includes both decreases and increases to the $\mathrm{RH}$. This provides a more complete picture of the characteristics of the sample since the water content may change slowly with relative humidity and the conductivity may change with time.

- Load membrane into Conductivity Cell.

- Adjust Temperatures, pressures and flowrates to meet "wet-up" specifications

- Wet-up at desired temperature $\left(30,80\right.$, or $\left.120^{\circ} \mathrm{C}\right), 70 \% \mathrm{RH}$ for 2 hours

- Follow RH steps allowing 60 minutes of stabilization for each, as follows:

Dew Point for $70 \% \mathrm{RH}$ ramping down to $20 \%$ in increments of $10 \%$ followed by a ramping up to $100 \%$ in increments of $10 \%$.

\subsection{Prepare Equipment \& Software for $30^{\circ} \mathrm{C}$ Test}

Ensure that the valve on the dry gas line that connects into the wet gas line is open. Gas-mixing is needed for controlling dew points at $30^{\circ} \mathrm{C}$. Hydrogen gas is fed to both the anode and the cathode.

Gas Flow - 1000 SCCM Hydrogen

Gas Mixing - The dew points are set using a mixture of dry gas $\left(-50^{\circ} \mathrm{C}\right.$, anode, water was drained from the test station) with gas saturated to a dew point of $45^{\circ} \mathrm{C}$ (cathode).

System Pressure $-100 \mathrm{kPa}$ absolute. This is atmospheric pressure in Florida

Sample Conditioning - Wet-up at $30{ }^{\circ} \mathrm{C}, 70 \%$ RH for 2 hours.

After 2 Hours of Conditioning - Operating conditions are adjusted every 60 minutes. Note that 2 Mass Flow Controllers are required for this temperature. One flows gas through the Saturator (Wet Gas, 
cathode). The second mixes with the saturated gas after the Saturator (Dry Gas, anode). Wet and dry gas flows are controlled using FuelCell software (Scribner).

The gas flow rates required to reach the desired relative humidities are outlined in Table 1. From 20-40\% RH $2000 \mathrm{sccm}$ of gas is used, while from $50-100 \%$ RH $1000 \mathrm{sccm}$ of gas is used.

\begin{tabular}{|c|c|c|}
\hline $\begin{array}{c}\text { Relative Humidity } \\
\text { (\%RH) }\end{array}$ & $\begin{array}{c}\text { Wet Gas Flow Rate } \\
\left(45{ }^{\circ} \mathrm{C} \text { dew point) }\right. \\
\text { (SCCM) }\end{array}$ & $\begin{array}{c}\text { Dry Gas Flow Rate } \\
\left(-50{ }^{\circ} \mathrm{C} \text { dew point) (SCCM) }\right.\end{array}$ \\
\hline 70 & 289 & 711 \\
\hline 60 & 246 & 754 \\
\hline 50 & 204 & 796 \\
\hline 40 & 326 & 1764 \\
\hline 30 & 243 & 1798 \\
\hline 25 & 202 & 1839 \\
\hline 20 & 161 & 1798 \\
\hline 25 & 202 & 1757 \\
\hline 30 & 243 & 1664 \\
\hline 40 & 326 & 796 \\
\hline 50 & 204 & 754 \\
\hline 60 & 246 & 711 \\
\hline 70 & 289 & 669 \\
\hline 80 & 331 & 625 \\
\hline 90 & 375 & 604 \\
\hline 95 & 396 & 582 \\
\hline 100 & 418 & 6 \\
\hline
\end{tabular}

Table 1. Wet and dry gas flow rates required to reach the desired relative humidities at $30{ }^{\circ} \mathrm{C}$.

\subsection{Prepare Equipment \& Software for $80{ }^{\circ} \mathrm{C}$ Test}

Ensure that the valve on the dry gas line that connects into the wet gas line is closed. Gas-mixing is not needed for controlling dew points at $80{ }^{\circ} \mathrm{C}$.

Gas Flow - 1000 SCCM Hydrogen

Gas Mixing - None

System Pressure $-100 \mathrm{kPa}$ absolute. This is atmospheric pressure in Florida.

Sample Conditioning - Wet-up at $80^{\circ} \mathrm{C}, 70 \% \mathrm{RH}$ for 2 hours.

After 2 Hours of Conditioning - Operating conditions (saturator temperature) are adjusted every 60 minutes, as follows:

- Dew Point of $71.4{ }^{\circ} \mathrm{C}$ for $70 \% \mathrm{RH}$

- Dew Point of $67.9^{\circ} \mathrm{C}$ for $60 \% \mathrm{RH}$

- Dew Point of $63.8^{\circ} \mathrm{C}$ for $50 \% \mathrm{RH}$

- Dew Point of $58.9^{\circ} \mathrm{C}$ for $40 \% \mathrm{RH}$

- Dew Point of $52.9^{\circ} \mathrm{C}$ for $30 \% \mathrm{RH}$

- Dew Point of $49.2{ }^{\circ} \mathrm{C}$ for $25 \% \mathrm{RH}$

- Dew Point of $44.8^{\circ} \mathrm{C}$ for $20 \% \mathrm{RH}$

- Dew Point of $49.2{ }^{\circ} \mathrm{C}$ for $25 \% \mathrm{RH}$ 
- Dew Point of $52.9^{\circ} \mathrm{C}$ for $30 \% \mathrm{RH}$

- Dew Point of $58.9^{\circ} \mathrm{C}$ for $40 \% \mathrm{RH}$

- Dew Point of $63.8^{\circ} \mathrm{C}$ for $50 \% \mathrm{RH}$

- Dew Point of $67.9^{\circ} \mathrm{C}$ for $60 \% \mathrm{RH}$

- Dew Point of $71.4^{\circ} \mathrm{C}$ for $70 \% \mathrm{RH}$

- Dew Point of $74.6{ }^{\circ} \mathrm{C}$ for $80 \% \mathrm{RH}$

- Dew Point of $77.4^{\circ} \mathrm{C}$ for $90 \% \mathrm{RH}$

- Dew Point of $78.7^{\circ} \mathrm{C}$ for $95 \% \mathrm{RH}$

- Dew Point of $80.0{ }^{\circ} \mathrm{C}$ for $100 \% \mathrm{RH}$

\subsection{Prepare Equipment and Software for $120{ }^{\circ} \mathrm{C}$ Test}

Ensure that the valve on the dry gas line that connects into the wet gas line is closed. Gas-mixing is not needed for controlling dew points at $120^{\circ} \mathrm{C}$.

Gas Flow - 500 SCCM Hydrogen

Gas Mixing - None

System Pressure - $230 \mathrm{kPa}$ absolute. This is approximately $130 \mathrm{kPa}$ in Florida.

Sample Conditioning - Wet-up at 80C, 70\% RH for 2 hours.

After 2 Hours of Conditioning - Operating conditions (saturator temperature) are adjusted every 60 minutes, as follows:

- Dew Point of $108.9^{\circ} \mathrm{C}$ for $70 \% \mathrm{RH}$

- Dew Point of $104.4^{\circ} \mathrm{C}$ for $60 \% \mathrm{RH}$

- Dew Point of $99.2{ }^{\circ} \mathrm{C}$ for $50 \% \mathrm{RH}$

- Dew Point of $93.0^{\circ} \mathrm{C}$ for $40 \% \mathrm{RH}$

- Dew Point of $85.4^{\circ} \mathrm{C}$ for $30 \% \mathrm{RH}$

- Dew Point of $81.1^{\circ} \mathrm{C}$ for $25 \% \mathrm{RH}$

- Dew Point of $75.2{ }^{\circ} \mathrm{C}$ for $20 \% \mathrm{RH}$

- Dew Point of $81.1^{\circ} \mathrm{C}$ for $25 \% \mathrm{RH}$

- Dew Point of $85.4^{\circ} \mathrm{C}$ for $30 \% \mathrm{RH}$

- Dew Point of $93.0^{\circ} \mathrm{C}$ for $40 \% \mathrm{RH}$

- Dew Point of $99.2{ }^{\circ} \mathrm{C}$ for $50 \% \mathrm{RH}$

- Dew Point of $104.4{ }^{\circ} \mathrm{C}$ for $60 \% \mathrm{RH}$

- Dew Point of $108.9{ }^{\circ} \mathrm{C}$ for $70 \% \mathrm{RH}$

- Dew Point of $113.0^{\circ} \mathrm{C}$ for $80 \% \mathrm{RH}$

- Dew Point of $116.7{ }^{\circ} \mathrm{C}$ for $90 \% \mathrm{RH}$

- Dew Point of $118.4{ }^{\circ} \mathrm{C}$ for $95 \%$ RH

- Dew Point of $120.0^{\circ} \mathrm{C}$ for $100 \% \mathrm{RH}$

\subsection{Shut Down Procedures}

- When the test has completed, stop fuel using FuelCell software.

- Cool the system by reducing the temperatures on the temperature controllers.

- When the system has cooled to below $100{ }^{\circ} \mathrm{C}$, reduce back pressure to $100 \mathrm{kPa}$ and allow system to depressurize.

- Turn off PAR 263 Potentiostat. 
- When the system has cooled to $\sim 50^{\circ} \mathrm{C}$, close FuelCell program, turn off test station, and turn off Nitrogen and Hydrogen.

\subsection{Calculating Conductivity}

The formula for calculating conductivity is included in the MacroRev5.xls file. To manually calculate conductivity, use the following information. $R$ is calculated using a Least Squares Fit of the voltage-current data.

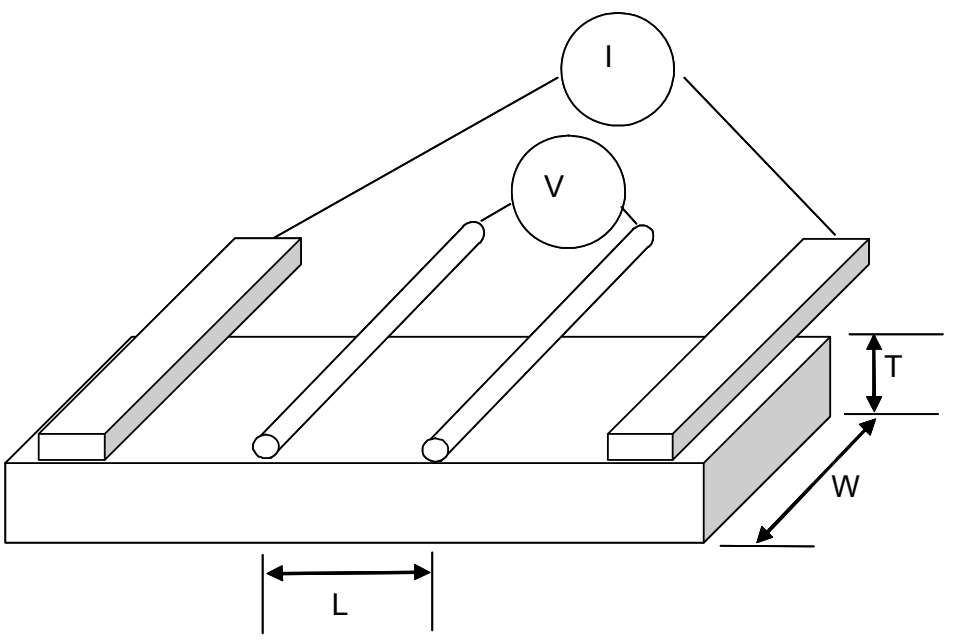

Figure 21. Schematic of conductivity cell.

The distance between V1 and V2 probe points (L) in the conductivity cell is $4.25 \mathrm{~mm}$. The definition of Resistance in terms of bulk resistivity, $\mathbf{R}$, is shown in equation 1.

$$
R=\frac{\rho L}{A}=\frac{\rho L}{W T}
$$

Where, $\mathbf{A}$ is the cross-sectional area perpendicular to the current flow, which in this case, is sample Width * Thickness. $\mathbf{L}$ is the distance in the direction of ion flow, between voltage measurements. Solving this equation for resistivity, $\rho$ results in equation 2 .

$$
\rho=\frac{R W T}{L}
$$

Conductivity, $\sigma$, is the inverse of resistivity, as shown in equation 3.

$$
\sigma=\frac{1}{\rho}=\frac{L}{R W T}
$$

For example,

- Size of Nafion membrane sample: $0.5 \mathrm{~cm}$ wide, $0.005 \mathrm{~cm}$ thick

- Slope of current vs. voltage measurement (resistance): 2,230 Ohms @ 60C, 100\% RH. 


$$
\rho=\frac{R \cdot W \cdot T}{L}=\frac{2,230 \mathrm{ohms} \cdot 0.5 \mathrm{~cm} \cdot 0.005 \mathrm{~cm}}{0.425 \mathrm{~cm}}=13.11 \mathrm{Ohms} \cdot \mathrm{cm}
$$

This yields a conductivity of:

$$
\sigma=\frac{1}{\rho}=0.076 \text { Siemens } / \mathrm{cm}
$$

\subsection{Basic Assumptions of Experiment}

When assessing the accuracy of results, note the following assumptions:

- The length of the membrane between the platinum wire measurement probes connected to V1 and V2 is known to be $0.425 \mathrm{~cm}$ for the Conductivity Cell.

- V1 and V2 are measured using platinum wire $0.75 \mathrm{~mm}$ diameter. The two wires are $5 \mathrm{~mm}$ apart, center-to-center. Thus, for a rigid sample, $5 \mathrm{~mm}$ may be a better distance to use. But, for a pliable sample, $4.25 \mathrm{~mm}$ is a better measurement.

- Be aware that some membrane samples may swell or change dimension, impacting resistivity measurements.

- The interior humidity of the Conductivity Cell is exactly what is set at the humidifier.

- Many humidifiers are inaccurate. Be sure to test the humidification system if results of these tests will be used for more than comparative analysis.

- Low flows and condensing environments can lead to lower than expected humidity levels. 
Appendix II

Through-Plane Conductivity Protocol 


\section{Through-Thickness Conductivity Measurement Procedure}

The following is the test procedure for through-plane resistance and conductivity measurement of proton exchange membranes using the Membrane Test System (MTS) developed by Scribner Associates, Inc.

\section{Background}

The principal objective is to determine the through-thickness conductivity of proton exchange membranes (PEMs). This is done by measuring the through-thickness resistance of a membrane sample. As illustrated in Figure 24, the through-thickness conductivity $\left(\sigma_{\perp}\right.$ in $\left.\mathrm{S} / \mathrm{cm}\right)$ is determined from the resistance $\left(\mathrm{R}_{\perp}\right.$ in $\Omega$ ), the thickness of the membrane ( $\mathrm{L}$ in $\mathrm{cm}$ ) and the crosssectional area through which the current passes $\left(\mathrm{A}\right.$ in $\left.\mathrm{cm}^{2}\right)$,

$$
\sigma_{\perp}=\frac{L}{R_{\perp} \cdot A}=\frac{I}{V} \frac{L}{A}
$$

The requirements of such a membrane test system included the ability to accurately measure this material property over a range of temperature, humidity and absolute pressure conditions,

- $30{ }^{\circ} \mathrm{C}$ to $120{ }^{\circ} \mathrm{C}$

- $20 \%$ to $95 \% \mathrm{RH}$

- $100 \mathrm{kPa}_{\mathrm{a}}$ to $230 \mathrm{kPa}_{\mathrm{a}}$

Furthermore, to be useful as a research and development $(\mathrm{R} \& \mathrm{D})$ tool for membrane analysis, the test system should use bare membranes. That is, accurate measurement of the through-thickness resistance and conductivity should not require the use of a catalyzed membrane. The requirement to use a catalyzed membrane significantly increases the time, cost and complexity of the evaluation process, which is undesirable for developmental membranes for which electrode/bulk membrane interfacial chemistry and processing parameters are unknown. In addition, ideally, the measured resistance would not include

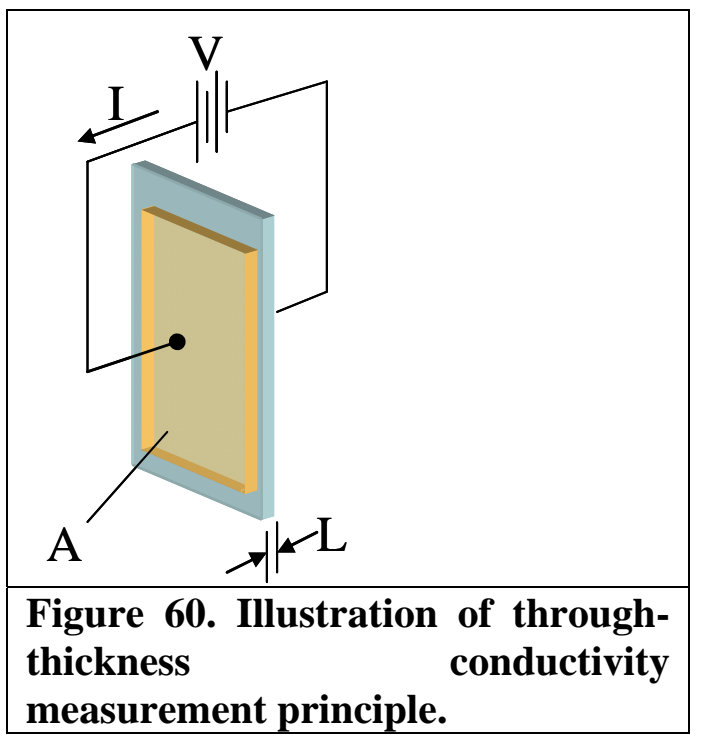
confounding non-membrane resistances, such as those due to contacts and electrical leads. This requirement necessitates a four-electrode technique such as is commonly used for in-plane membrane resistance / conductivity measurement.

The main components of the MTS hardware set-up are shown in Figure 25:

vi. Wet-dry mixed gas handling system - temperature controlled humidifier tank; two 500 sccm full-scale $\mathrm{H}_{2}$ mass flow controllers; heated gas transfer line and gas mixing zone; water and multi-gas $\left(\mathrm{H}_{2}, \mathrm{~N}_{2}\right)$ inlets; and electronics for control and communications with MTS control hardware. A fan-cooled radiator, stainless steel collection tank and 
back pressure regulator are used when operating the humidifier and cell at high temperatures $\left(>100{ }^{\circ} \mathrm{C}\right)$. Selected points within the gas humidification and transfer system are instrumented with thermocouples for temperature profile monitoring.

vii. Test chamber and cell head - insulated, temperature-controlled aluminum housing with gas inlet and outlet; Vaisala gas dew point (DP) and temperature sensors; and cell head with integrated electrodes/specimen holder, specimen clamping mechanism, and thermocouples for in-situ gas and specimen temperature monitoring.

viii. MTS control and DAQ hardware - host computer-controlled electronics for gas flow rate and temperature control and data acquisition (DAQ); four temperature controllers, communications with PC, alarm inputs $\left(\mathrm{H}_{2}\right.$ sensor, low water level, loss of inlet gas pressure).

ix. Frequency Response Analyzer - Solartron Analytical 1260 Impedance Analyzer for 4terminal impedance spectroscopy measurement.

x. Host computer (not shown) - proprietary MTS software for experiment set-up and control (humidifier and cell temperature, gas flow rate and wet-to-dry ratio, etc.); ZPlot ${ }^{\circledR} /$ CorrWare ${ }^{\circledR}$ for impedance/DC electrochemical measurements.
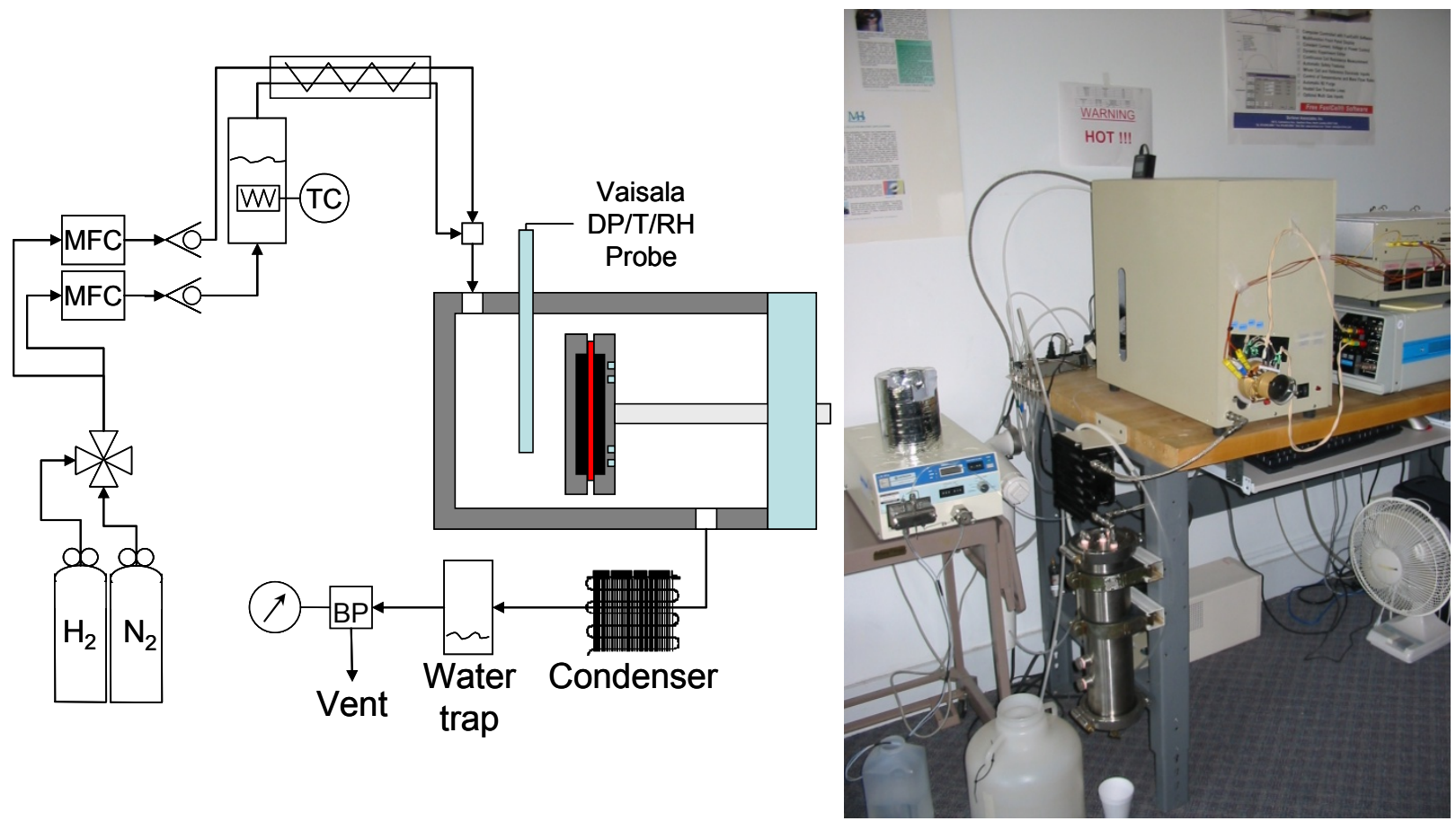

Figure 61. Left: Schematic of the major hardware components of the MTS (excluding the control electronics, DAQ system and analytical instrumentation). Right: Prototype through-thickness membrane resistance measurement system.

Operation at temperatures at or above $100{ }^{\circ} \mathrm{C}$ requires that the system be operated at pressures above ambient, e.g., $230 \mathrm{kPa}_{\mathrm{a}}$ is the current recommended operating pressure for conductivity measurements at $120{ }^{\circ} \mathrm{C}$. Pressurized operation poses significant safety hazards because unintended loss of pressure due to failure of a gas transfer line, fitting or seal results in explosive release of superheated steam. A further hazard is the potential release of hydrogen in the event of a pressure loss. 
Because of the safety issues involved with pressurized operation at elevated temperatures, the MTS gas handling system includes the following features,

- All gas handling components that must operate at elevated temperature are made from stainless steel with the exception of a $0.5 \mathrm{~m}$ section of stainless steel braid reinforced flexible line that connects the exit of the MTS test chamber to a force-air radiator. (The pressure rating of the braid-reinforced plastic line is 1500 psi at $150{ }^{\circ} \mathrm{C}$, which far exceeds the operating condition).

- The back pressure regulator used to control the system pressure has a maximum operating temperature of $\sim 60{ }^{\circ} \mathrm{C}$. Therefore, the gas must be cooled to at least that temperature prior to reaching the regulator. This is achieved with a $1000 \mathrm{~W}$ forced-air radiator. Tests confirm that the temperature of the gas exiting the radiator is near ambient.

- A stainless steel water collection vessel.

- Alarm outputs that when triggered cause the set-points of all temperature controllers to be set to ambient $\left(20^{\circ} \mathrm{C}\right)$. The alarm is triggered in the event of,

o Detection of a combustible gas $\left(\mathrm{H}_{2}\right)$ via an integrated combustion sensor,

o Low water level condition in the humidifier tank via an internal float switch or,

o Loss of inlet gas pressure.

\section{Test Procedure}

The procedure is based on operation of Scribner Associates' MTS hardware and software for control of the membrane and gas temperature and relative humidity.

The membrane resistance measurement is based on a potentiostatic, swept frequency impedance spectroscopy experiment employing a four-electrode design. The four electrode measurement method eliminates non-membrane sourced ohmic resistances, such as lead and electrode electrical and contact resistances, common in two-electrode measurements.

\section{A. Cell Assembly}

1. Cleaning Electrodes

a. Place cell head vertically in a ring-stand clamp connected to a stand. Release compression on electrodes (if any) and separate the two sets of electrodes.

b. While wearing gloves, use cotton swabs and methanol (or other suitable solvent) to thoroughly clean the electrodes and allow to them dry, or use clean compressed air

c. Clean tools with methanol and cotton swabs or lint-free tissues (Kimwipes)

d. Use methanol and tissues to clean thickness gage (Mitutoyo Digimatic Indicator, model ID-C112T), including the face, stem, handle, and base 


\section{Membrane Preparation}

a. Change to new gloves and cut a sample of the membrane approximately $9 \mathrm{~mm} \mathrm{x}$ $31 \mathrm{~mm}$ with a pair of scissors and a clear ruler

b. Use the digital thickness gage to measure the membrane thickness is five different locations. For each location, make 3 replicate measurements checking that each reading is the same

\section{Preparation of Cell Electrodes}

a. Cut two samples of gas diffusion electrode GDE material (E-TEK, High Temperature ELAT, 140E-W), approximately 18 mm x 5 mm.

b. Apply and spread a small amount ( 1 drop) of conductive carbon paint (SPI Supplies, colloidal graphite) to the first (upward-facing) source electrode using a disposable plastic pipette. Ensure that none of the carbon paint gets onto the PEEK around the electrode(s)

c. Using plastic tweezers (fine tipped metal ones for the sense electrodes), place one of the GDE samples on top of the carbon paint, with the large weave (macro porous) side facing the platinum source and in contact with the carbon paint. Use the tweezers to gently align the GDE with the platinum and pat the top of the GDE to make sure the carbon paint is absorbed

d. After waiting a few minutes to allow it to dry, rotate the cell $180^{\circ}$ and repeat the previous two steps for the second source electrode

4. Assembly of Membrane in Cell

a. Screw in the compression head until the two sets of electrodes are about $1 \mathrm{~cm}$ apart. Use clean plastic tweezers to position membrane in between the electrodes making sure the membrane only makes contact with the electrodes (GDE and Pt sense electrode) and supporting PEEK material

b. Continue screwing in the compression head, moving the electrodes together until the compression head dial indicator begins to move, indicating that membrane is in contact with the electrodes on both sides. Zero the dial face. Screw in the compression head to apply 0.35 ” (350 mil) of spring compression $(=2.15 \mathrm{MPa}=$ 312 psi). Note: one revolution of the dial compresses the compression spring = $0.050 ”$. 
5. Final Assembly

a. Twist each pair of source and sense electrode wires (source 1 with source 2 and voltage sense 1 with voltage sense 2), and insert the pin connectors to the cell head feed-throughs

b. Screw the assembled cell head into chamber, attach thermocouple connectors, and place cell head insulating hood on (if operating at temperatures higher than $30^{\circ} \mathrm{C}$ )

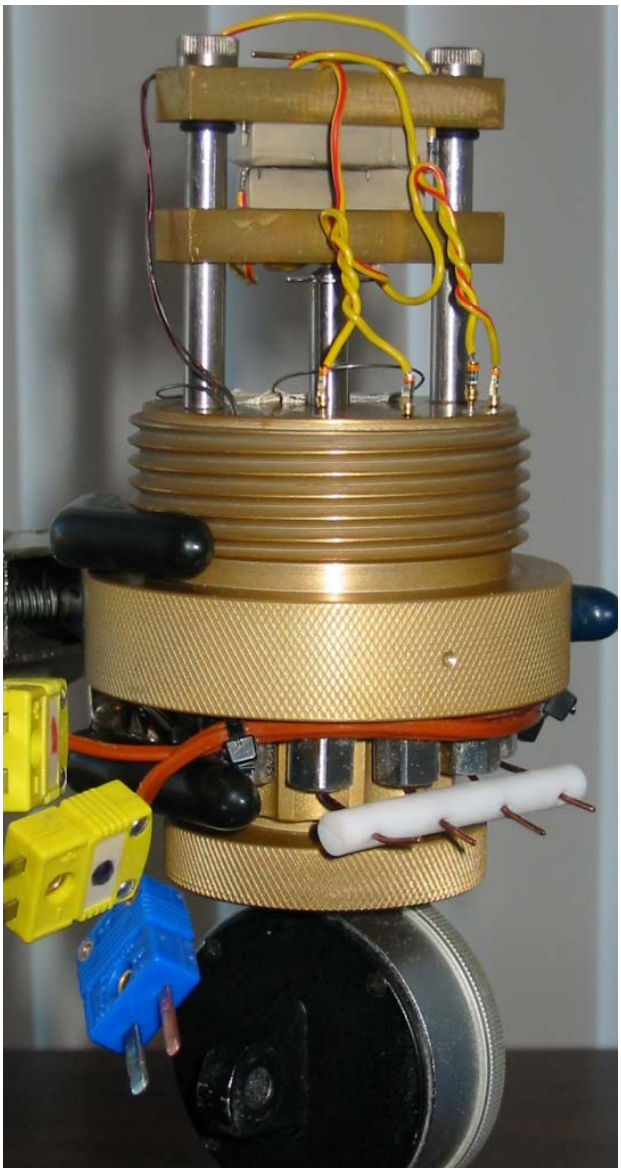

Figure 62. MTS cell head with integrated electrodes, electrode holders, and compressionspring based membrane clamping mechanism. The compression spring dial indicator is at the bottom, co-planar electrodes (not visible) mounted in PEEK (brown) are at the top. Cell components are anodized aluminum (gold) or stainless steel.

B. Test System Start Up and Operating Procedure

1. Hardware and Temperature and Dew Point Data Acquisition Setup 
a. Prepare membrane test sample, load in cell, and place cell in chamber as described above

b. Check $\mathrm{H}_{2} \mathrm{O}$ level in humidifier and fill as necessary with > $16 \mathrm{M} \Omega$ water.

c. Open gases at cylinder $-\mathrm{H}_{2}$ and $\mathrm{N}_{2}$

d. Select $\mathrm{N}_{2}$ as the active gas with the multi-gas selector valve

e. Turn on temperature and dew point data acquisition hardware

i. Temperature data is acquired with Type K thermocouples, Model 8928 8Channel Data Acquisition Unit (Scribner Assoc.), $3^{\text {rd }}$ party communications software (WinWedge) and Excel.

ii. Dew Point data is acquired with a HTM 337 (Vaisala) heated humidity probe, $3^{\text {rd }}$ party communications software (WinWedge) and Excel.

f. Start temperature, dew point, and $\mathrm{RH}$ data acquisition software file (WinWedge and Excel)

g. Turn on MTS chassis power

2. MTS Software Setup

a. Start MTS software

b. Open MTS setup file and select for desired operating condition $\left(30^{\circ} \mathrm{C}, 80^{\circ} \mathrm{C}\right.$ or $120^{\circ} \mathrm{C}$ )

i. General operating conditions during start up

1. Total dry gas flow rate: $500 \mathrm{sccm}$

2. Percent wet: $\quad 0 \%$

3. Measurement type: none

c. Select temporary data file

d. Press START to run setup file experiment and bring system to operating conditions

i. If operating at $30{ }^{\circ} \mathrm{C}$

1. Turn on case fan

2. Slowly increase the humidifier and dome temperatures to avoid thermal overshoot

ii. If operating at $120^{\circ} \mathrm{C}$

1. Bring system to $130 \mathrm{kPa}$ back-pressure (230 kPa absolute) 
2. Turn on radiator-condenser fan

3. Ensure that condenser tank is less than half full (drain as necessary)

3. Purge for at least 10 minutes

4. Switch active gas to $\mathrm{H}_{2}$ using the multi-gas selector

5. When cell and humidifier temperatures have reached desired temperature(s) set the percent wet to required value to get $70 \% \mathrm{RH}$ at the operating temperatures

6. Condition sample membrane for 2 hours at $70 \% \mathrm{RH}$

7. Perform a test impedance measurement using ZPlot ${ }^{\circledR}$

a. Turn on measuring instrument (Solartron Analytical 1260 Impedance Analyzer), and connect cell cables to leads on MTS cell head as shown in Table 12.

b. Make sure that the ZPlot ${ }^{\circledR}$ setup file is the same as that called by the MTS software

Table 12. MTS electrode lead connections to impedance analyzer.

\begin{tabular}{|l|l|}
\hline SA 1260 FRA & MTS Cell Head \\
\hline WE & I1 \\
\hline CE & I2 \\
\hline RE2 & V1 \\
\hline RE1 & V2 \\
\hline
\end{tabular}

c. Verify that the open circuit voltage (OCV) of the cell is $0.000 \mathrm{~V}+/-0.005 \mathrm{~V}$

d. Perform a test controlled potential, swept frequency impedance scan (Figure 63)

i. Frequency range: $10^{7} \mathrm{~Hz}$ to $1 \mathrm{~Hz}$

ii. AC signal: $\quad 10 \mathrm{mV}$

iii. DC bias: $\quad 0$ vs. reference

iv. Interval: logarithmic, 10 steps/decade

e. If the resulting impedance scan shows a 1 or 2 impedance arc on a Nyquist plot (complex plane) with a noticeable high frequency intercept, continue to Step e, otherwise skip to Part $\mathrm{C}$ to begin purge and shut down procedure to allow modification of specimen loading

f. Close ZPlot ${ }^{\circledR}$ before starting experiment list in MTS software 


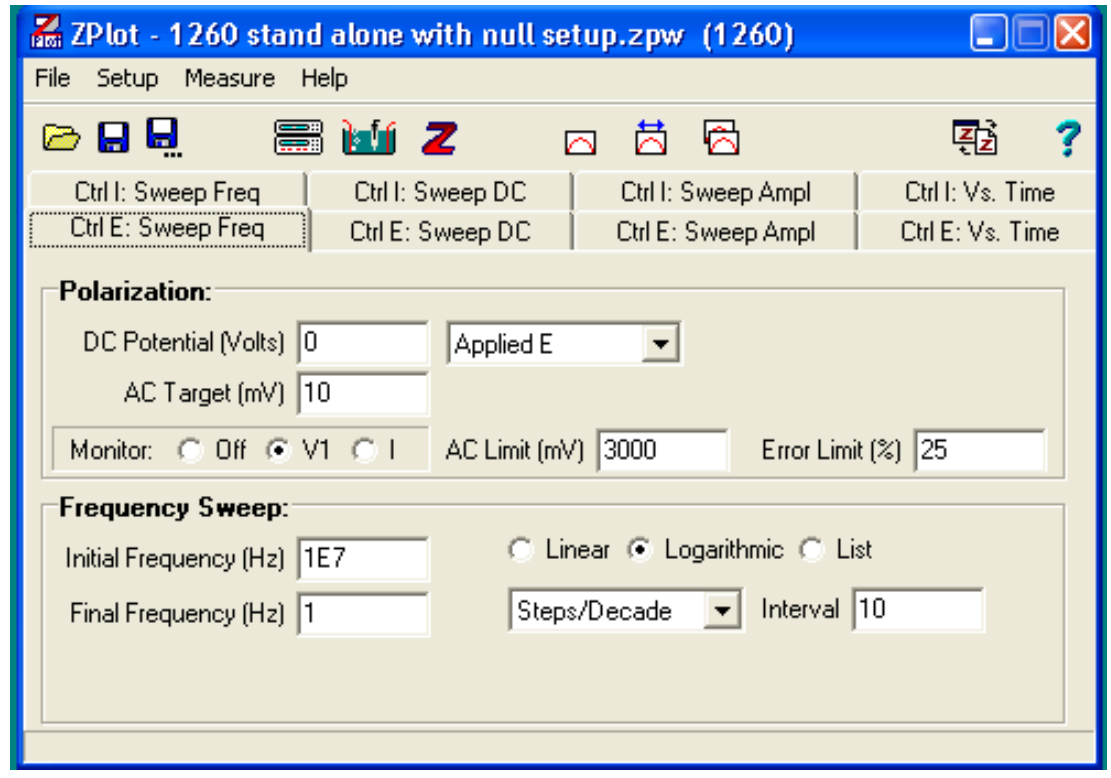

Figure 63. ZPlot ${ }^{\circledR}$ controlled potential, swept frequency impedance measurement using Solartron 1260 Impedance Analyzer in stand-alone mode.

8. Perform Relative Humidity Cycle with Membrane Resistance Measurement

a. Load MTS relative humidity (RH) cycling setup file. When run, the MTS software will execute the sequence of experiments in the setup file, i.e., RH step and call ZPlot ${ }^{\circledR}$ to run the impedance experiment defined in the experiment ( b.

\section{c. Figure 65)}

i. $\mathrm{RH}$ Cycle sequence is from $70 \% \mathrm{RH} \rightarrow 20 \% \mathrm{RH} \rightarrow 95 \% \mathrm{RH}$ in $10 \%$ decrements/increments at 15 minute intervals plus time to perform impedance experiment (see example below)

ii.

iii.

iv. Figure 65 shows the MTS Setup Experiment dialogue.

d. Press START in MTS software to begin experiment sequence 
e. Periodically check humidifier water level (especially at higher temperatures) and fill as necessary

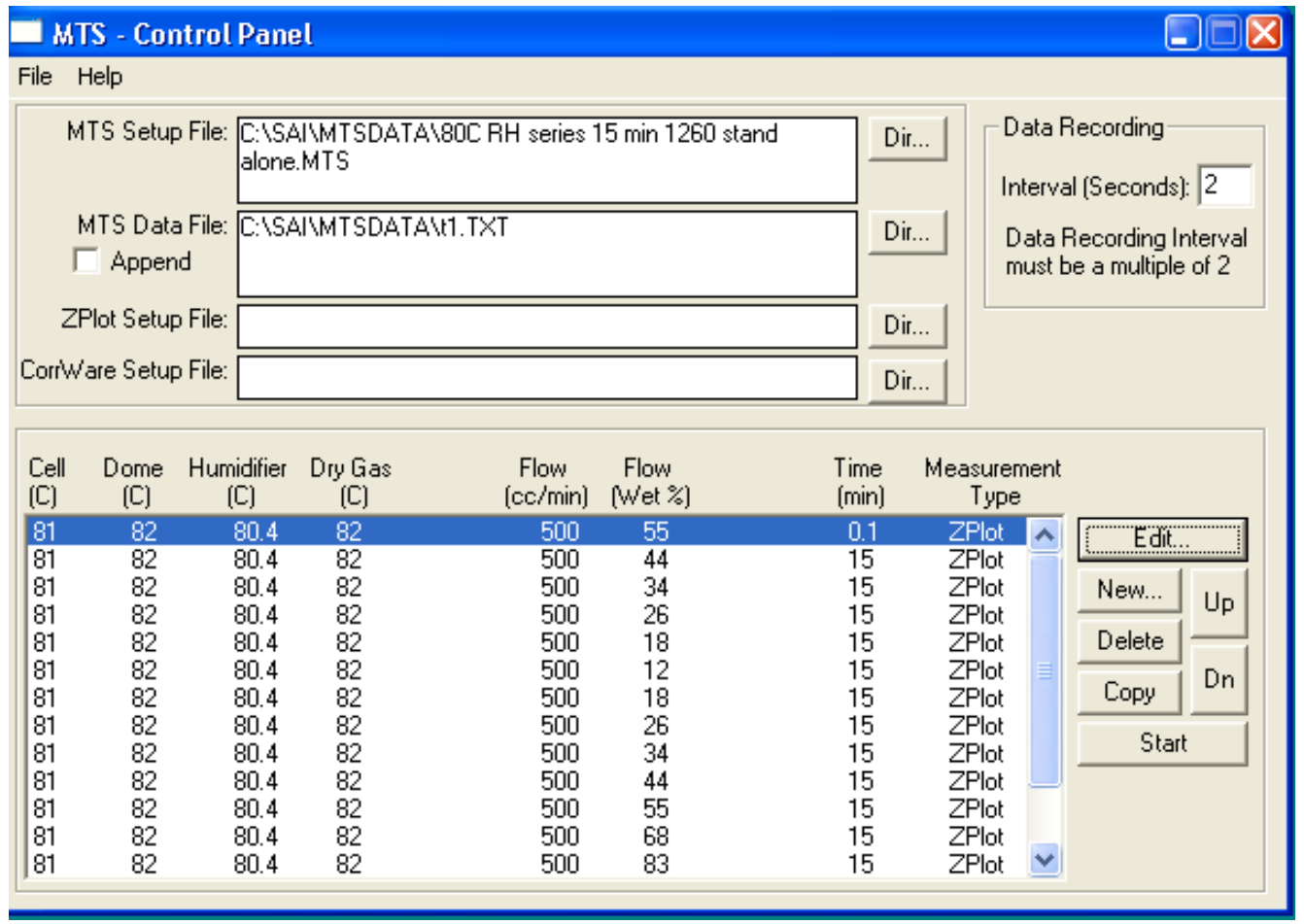

\section{HTS - Setup Experiment}

Settings Cell Temperature (C): 81

Humidifier Temperature (C): 80.4

Dome Temperature (C): 82

Dry Gas Temperature (C): 82

Total Flow (cc/min): 500

Wet \%: 55

Measurement

Pretreatment Time (min): 0.1

Measurement Type: $C$ ZPlot $C$ Cor'Ware $C$ None

ZPlot Options

$\sqrt{\checkmark}$ Save ZPlot Data File

Setup File: C:Documents and

Settings'demolab\DesktoplMTS Electrode Data`1260 stand alone with

Dir...

Corr'Ware Options

Setup File:

:

Figure 64. Example of list of experiments to execute the RH cycle from $70 \% \mathrm{RH} \rightarrow 20 \% \mathrm{RH} \rightarrow 95 \%$ RH in $10 \%$ decrements/increments, 15 minute conditioning time / step. Test condition: $80^{\circ} \mathrm{C}$.

Figure 65. MTS Experiment setup menu is used to set temperatures for the cell chamber, humidifier, and humidifier dome and heated transfer line (currently labeled Dry Gas Temperature). The desired relative humidity is determined by setting the appropriate percent Wet, which is the fraction of the total dry gas flow rate that is humidified, the remaining fraction of total dry gas by-passes the 
humidifier and is effectively water-free. After a pretreatment time, an MTS experiment can call for an impedance test to be performed via a pre-defined ZPlot ${ }^{\circledR}$ setup file or an DC electrochemistry experiment via a predefined CorrWare ${ }^{\circledR}$ setup file.

\section{Test System Shut-Down Procedure}

1. Disconnect SA 1260 impedance analyzer leads from electrode terminals on MTS cell head

2. Turn SA 1260 power OFF

3. Switch multi-gas selector valve to $\mathrm{N}_{2}$

a. Conditions for purge
i. Total dry gas flow rate
$500 \mathrm{sccm}$
ii. Percent wet
$0 \%$
iii. All temperatures
$20{ }^{\circ} \mathrm{C}$

b. Purge for at least 10 minutes

4. Stop and close communications software (WinWedge)

5. Save and close temperature and dew point data acquisition files (Excel)

6. Close MTS software

7. Turn off MTS chasis power

8. Turn off power to temperature and dew point data acquisition hardware (Scribner 892 DAQ system)

9. Unplug cell thermocouples from MTS cell head

10. Remove MTS cell head from chamber

\section{Data Analysis Procedure}

1. Temperature, Dew Point and Relative Humidity Data

a. From the experiment Excel file, use the measured dew point and chamber gas temperature to calculate the actual percent relative humidity (\% RH) for each $\mathrm{RH}$ set point in the experiment sequence

2. Use ZPlot ${ }^{\circledR}$ data files to determine the membrane through-thickness resistance (in Ohms)

a. In ZView ${ }^{\circledR}$, select data files to be analyzed 


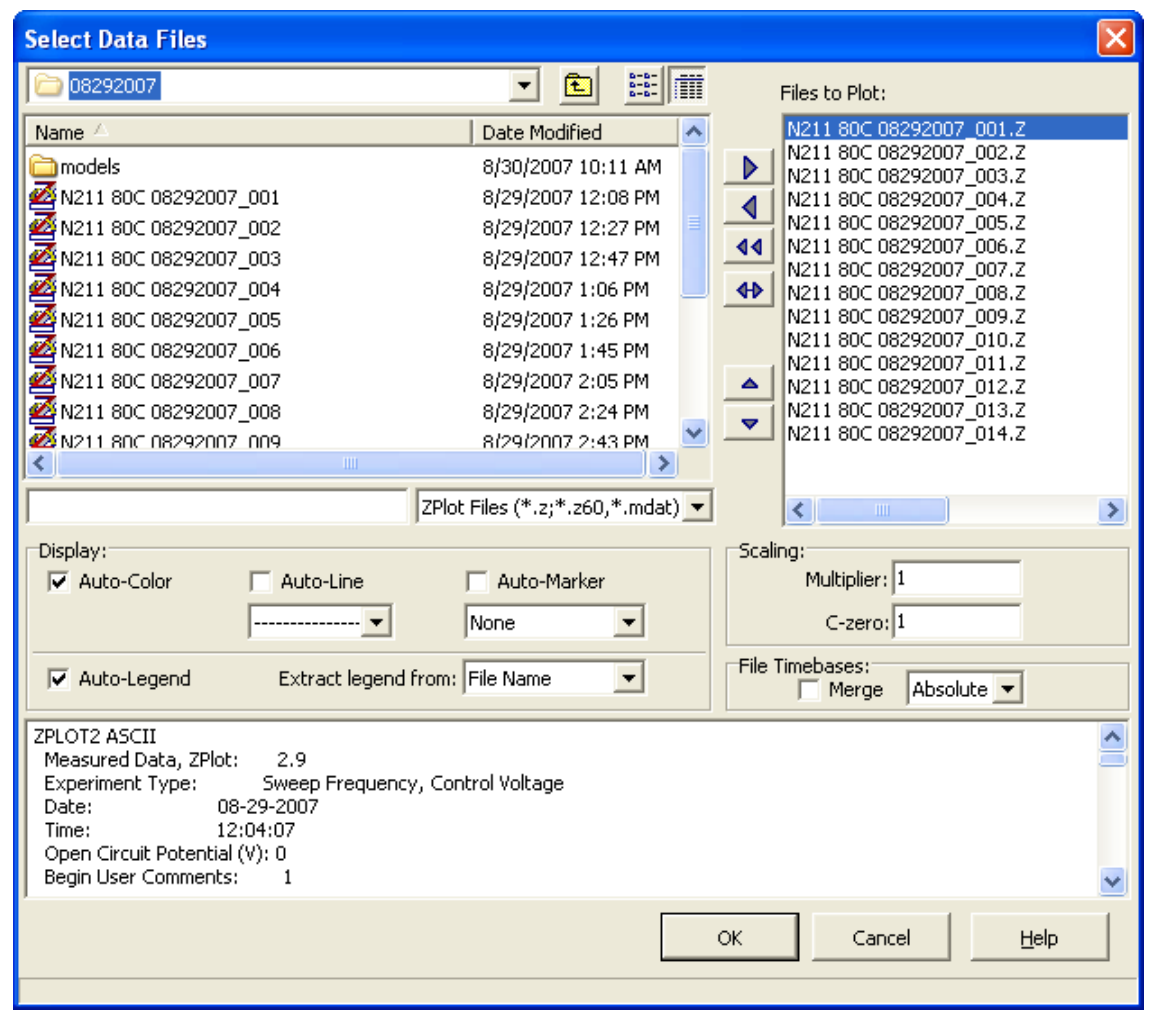

Figure 66. ZPlot ${ }^{\circledR}$ impedance scan data files loaded for analysis.

b. Select the data to be fitted using the two cursors

c. Fit the selected impedance data with a Voigt equivalent circuit model to determine the high frequency intercept, $R_{s}$, which is the membrane throughthickness resistance. A Voigt model is a resistor $\mathrm{R}_{\mathrm{s}}$ in series with a one or more parallel resistor-capacitor elements $(\mathrm{R} \| \mathrm{C})$. Using constant phase elements (CPE) in place of capacitors can improve the fit. In general, 2 or $3 \mathrm{R} \| \mathrm{C}$ (or $\mathrm{R} \| \mathrm{CPE}$ ) elements are suitable.

d. Repeat steps b and c for each RH step.

e. Using the fitted through-thickness resistance value $\left(R_{s}\right)$, calculate the throughthickness area specific resistance $\left(\mathrm{ASR}_{\perp}\right.$ in $\Omega$ - $\mathrm{cm}^{2}$ ) using the effective electrode area $\left(A=0.50 \mathrm{~cm}^{2}\right)$,

$$
A S R_{\perp}\left[\Omega-c m^{2}\right]=R_{s} \cdot A
$$


f. Through-thickness conductivity $\left(\sigma_{\perp}\right.$ in $\left.\mathrm{S} / \mathrm{cm}\right)$ is the quotient of the dry membrane thickness (L) and the ASR,

$$
\sigma[S / \mathrm{cm}]=\frac{L}{A S R}=\frac{L}{A \cdot R_{s}}
$$
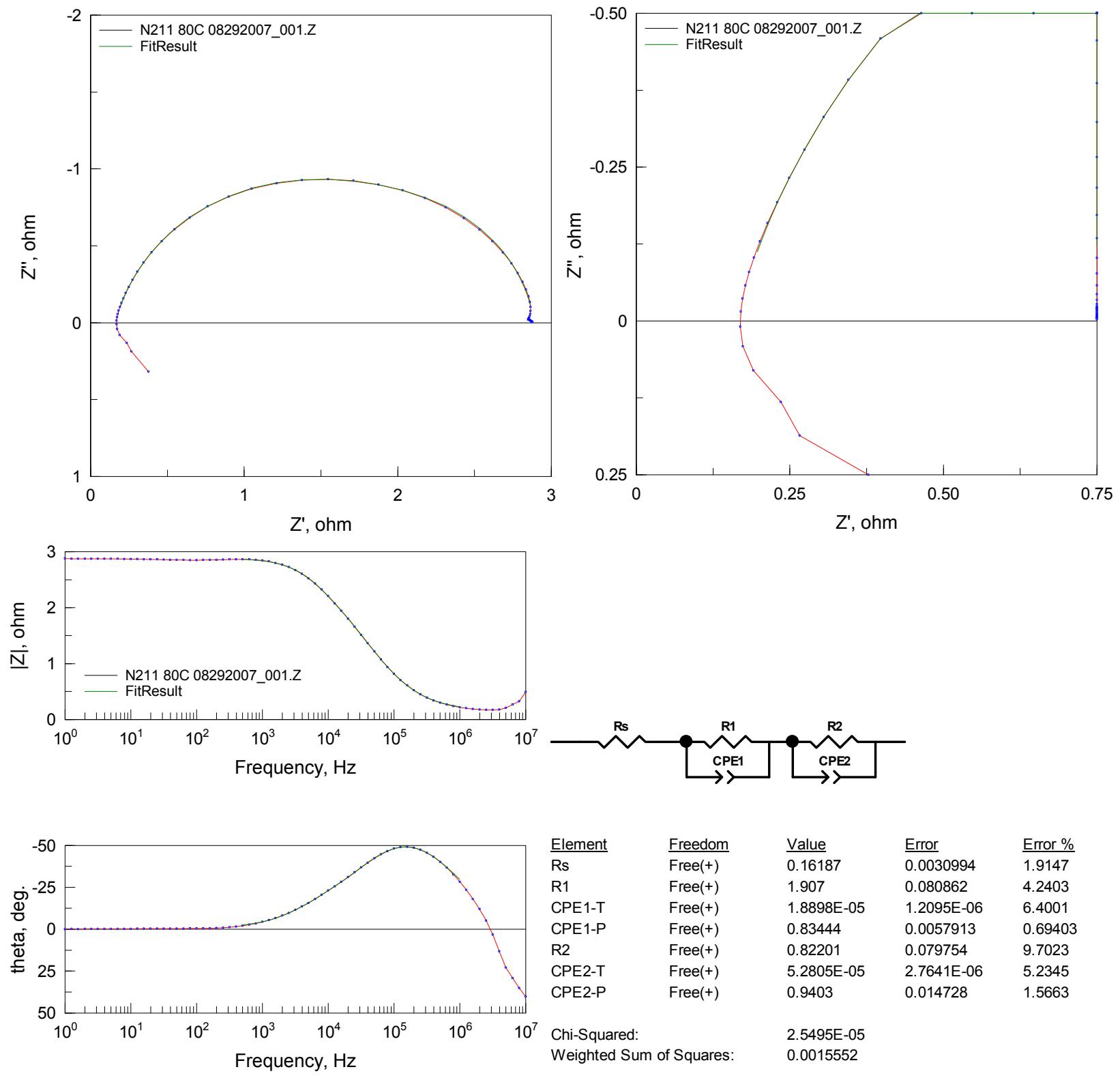

\begin{tabular}{|c|c|c|c|c|}
\hline Element & Freedom & $\underline{\text { Value }}$ & Error & Error \% \\
\hline Rs & $\overline{\text { Free }(+)}$ & $\overline{0.16187}$ & 0.0030994 & $\overline{1.9147}$ \\
\hline R1 & Free(+) & 1.907 & 0.080862 & 4.2403 \\
\hline CPE1-T & Free(+) & $1.8898 \mathrm{E}-05$ & $1.2095 \mathrm{E}-06$ & 6.4001 \\
\hline CPE1-P & Free(+) & 0.83444 & 0.0057913 & 0.69403 \\
\hline $\mathrm{R} 2$ & Free $(+)$ & 0.82201 & 0.079754 & 9.7023 \\
\hline CPE2-T & Free $(+)$ & $5.2805 \mathrm{E}-05$ & $2.7641 \mathrm{E}-06$ & 5.2345 \\
\hline CPE2-P & Free $(+)$ & 0.9403 & 0.014728 & 1.5663 \\
\hline \multicolumn{2}{|c|}{ Chi-Squared: } & \multicolumn{3}{|l|}{ 2.5495E-05 } \\
\hline \multicolumn{2}{|c|}{ Weighted Sum of Squares: } & \multicolumn{3}{|l|}{0.0015552} \\
\hline
\end{tabular}

Figure 67. Example of equivalent circuit fit to impedance scan. Only the high frequency intercept, $R_{s}$, is of interest. Conditions: Nafion NRE-211, $80{ }^{\circ} \mathrm{C}, \quad 70 \% \quad R H$. 


\section{Appendix III}

\section{FSEC's Procedures \\ For Performing PEM Single Cell Testing}

Test protocol for Cell Performance Tests

Work Performed Under

DOE Contract \# DE-FC36-06G016028

April 8, 2009 


\section{EXECUTIVE SUMMARY}

This document defines, in detail, a test protocol for performing proton exchange membrane (PEM) single cell testing. Development of this test protocol is a part of the requirements of FSEC's Task 5, Characterize MEA Performance, under DOE Contract \#DE-FC36-06G016028. This test protocol has been evaluated and is used at FSEC for single-cell testing.

Under this contract, FSEC will perform single-cell tests to assess the relative merits of the candidate membranes that are submitted by the Task 1 team members. These tests will be conducted at operating conditions that are of interest to the DOE and, where appropriate, will be run using identical procedures on all tested cells. Task 1 team members that are continuing beyond the Go - No Go milestone are requested to review this document and identify "conditions that are of concern." FSEC will iterate with these Task 1 team members to resolve these concerns

Researchers following the test protocol will be able to reproduce results that have been obtained by FSEC. 


\section{Contents}

1. Overview of FSEC's Procedures for Performing PEM Single Cell Testing ................................. 6

1.1 Introduction To The Test Protocol for PEM Cell Screening Test......................................... 6

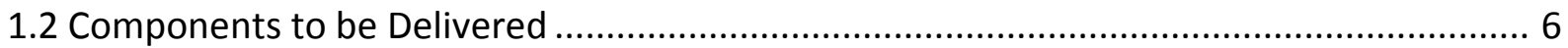

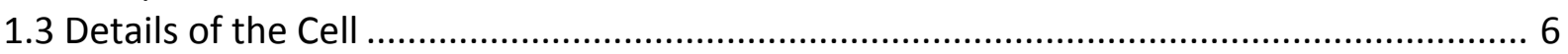

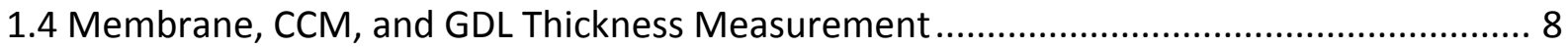

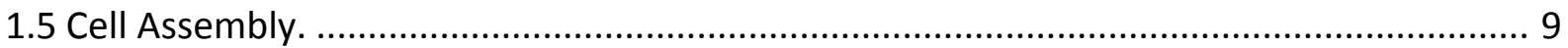

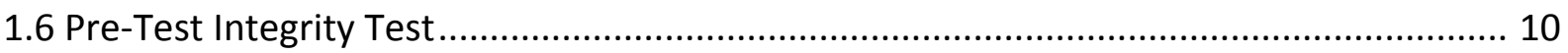

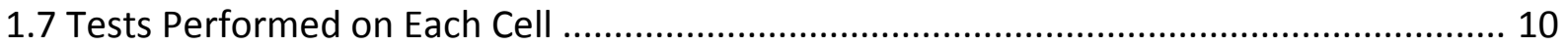

1.7.1 Linear Sweep Voltammetry, Cyclic Voltammetry, And Cell Conditioning ................. 10

1.7.2 Performance Verification Test ........................................................................... 13

1.7.3 Post-test Integrity Test ..................................................................................... 15

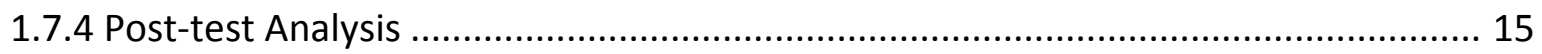

1.7.5 Cell Data Report .............................................................................................. 16

1.8 Fuel Cell Hydrogen Safety Plan .............................................................................. 16

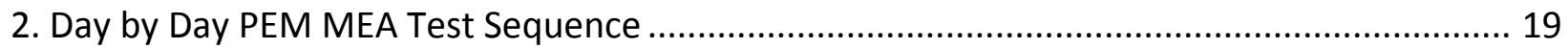

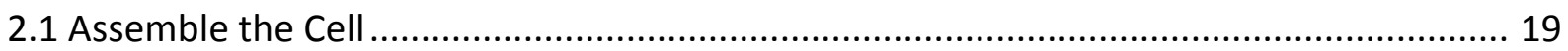

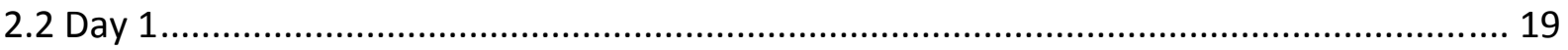

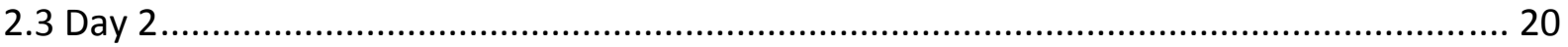

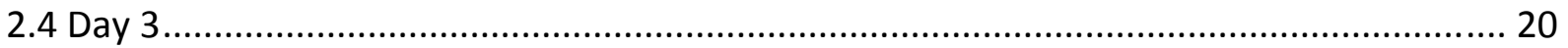

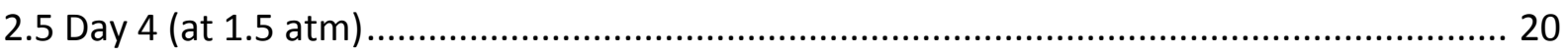

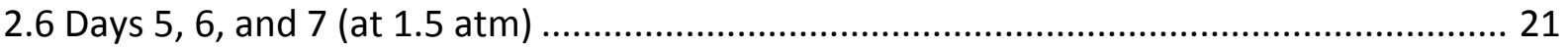

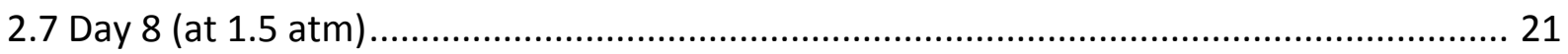

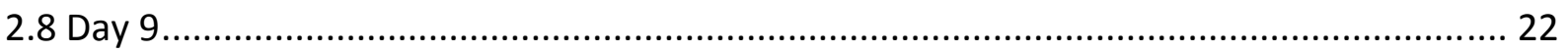

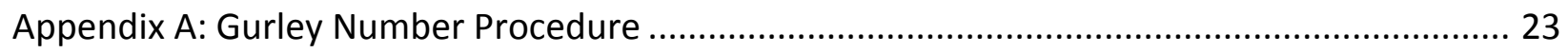

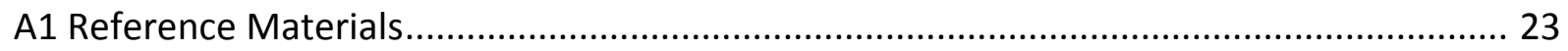

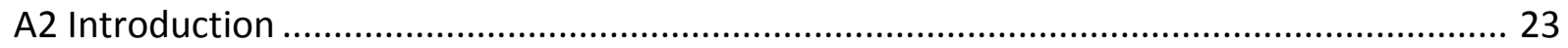

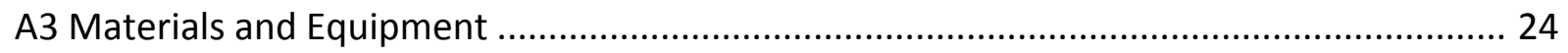

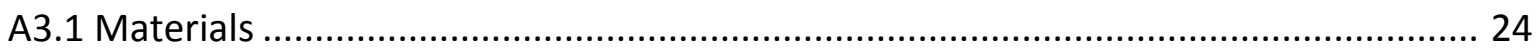

A3.2 Equipment .............................................................................................. 24

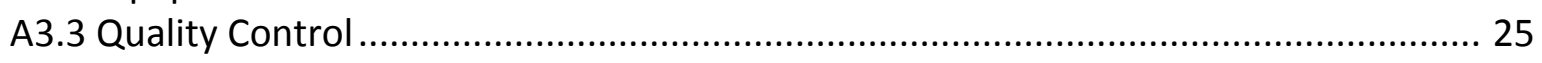

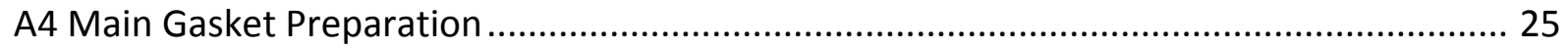

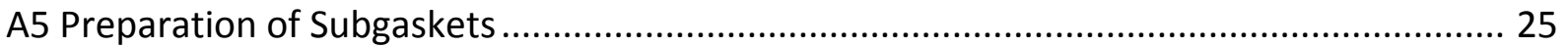

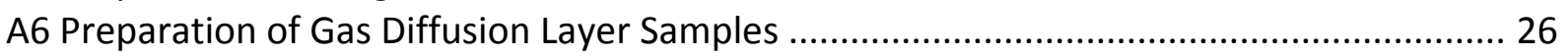

A7 Cleaning of Fuel Cell Components .............................................................................. 26

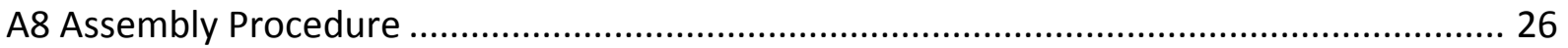

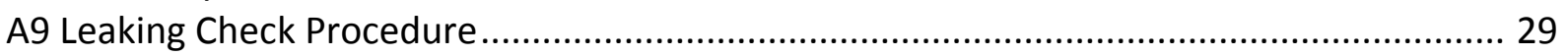

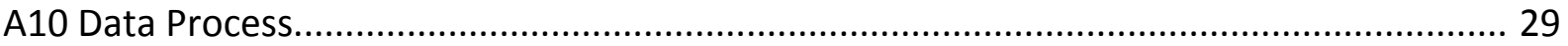

A10.1 Data Sheet Gurley Number Calculations ........................................................... 30

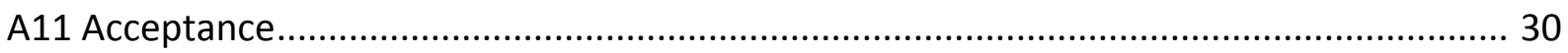




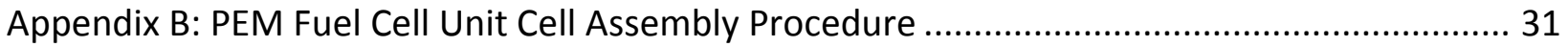

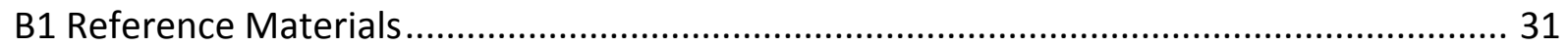

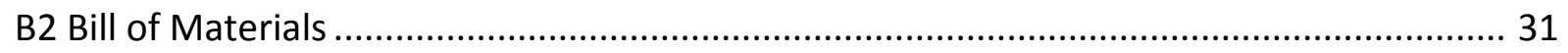

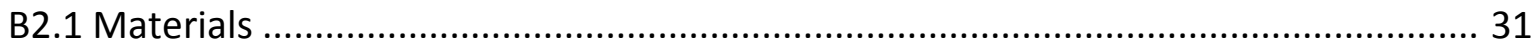

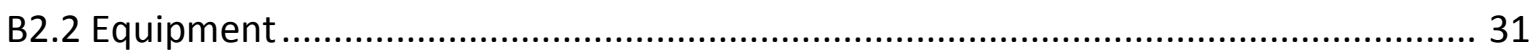

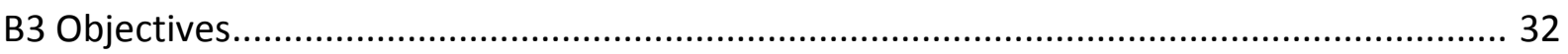

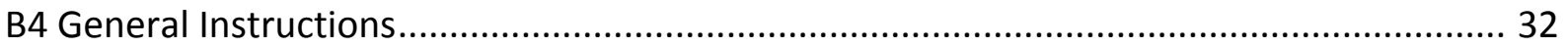

B5 Preparation for Cell Assembly.................................................................................. 32

B6 Assembling the Cell - Fuel Cell Technology (FCT) Hardware Set. .................................. 32

Appendix C Procedure for Leak Testing a Single Cell After Assembly ..................................... 34

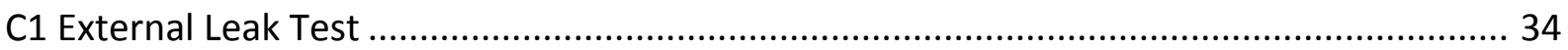

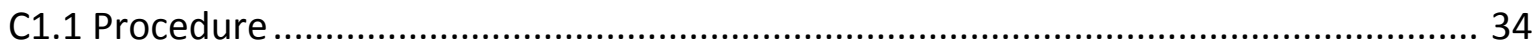

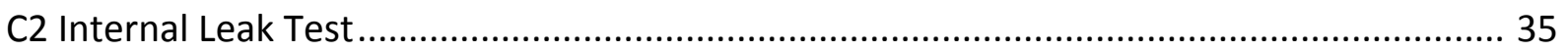

C2.1 Procedure for Internal Leak Test.................................................................. 35

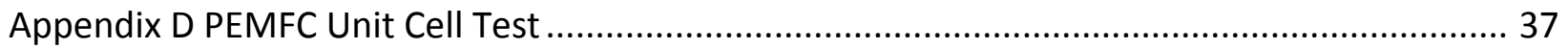

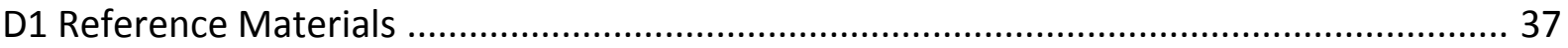

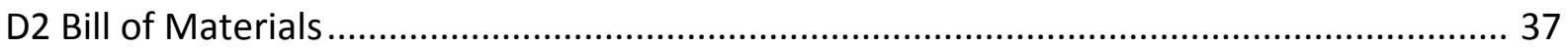

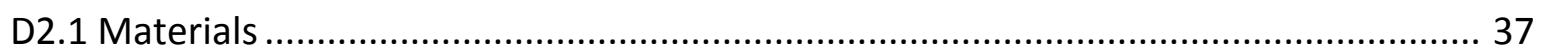

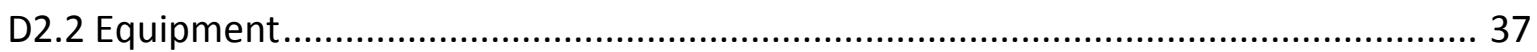

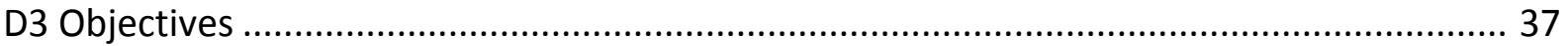

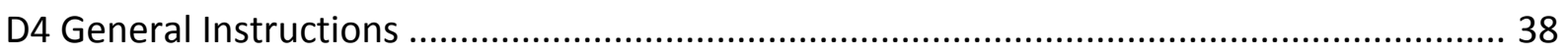

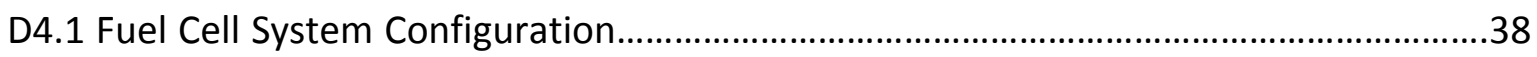

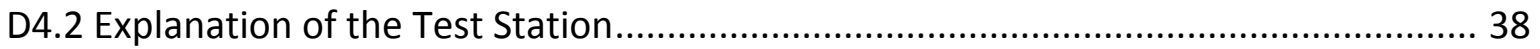

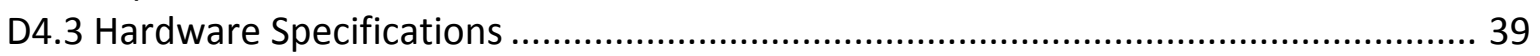

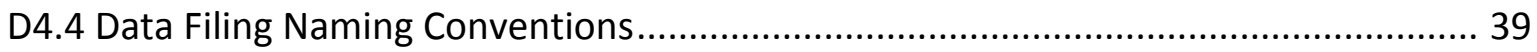

D4.6 Nomenclature of Test Condition Temperatures.................................................. 39

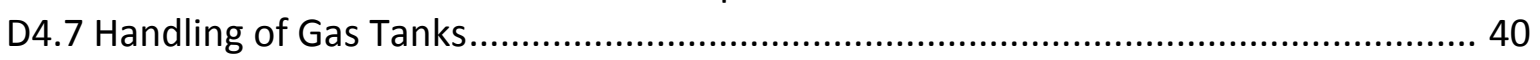

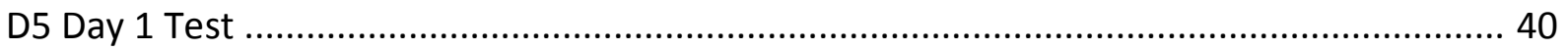

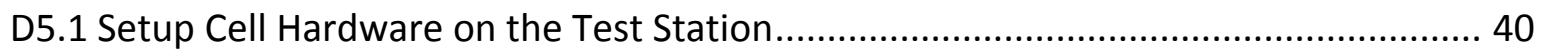

D5.2 Preparation of Cell Test on the Test Station ............................................................ 40

D5.3 Operation of Computer to Start Up Cell ............................................................. 40

D5.4 Crossover and Cyclic Voltammetry Tests at 25/25/25 ...................................... 42

D5.5 Humidification of the Membrane ........................................................................... 44

D5.6 Operation of the Cell in Break-In Mode................................................................. 45

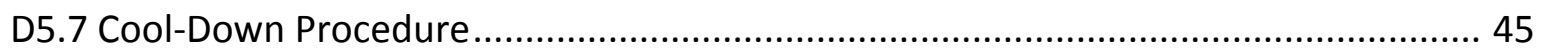

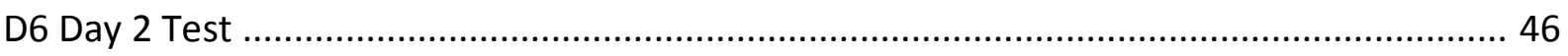

D6.1 Crossover and Cyclic Voltammetry Tests at 25/25/25 ........................................ 46

D6.2 Polarization Curve Measurement at 80/80/73 (Air/O $\mathrm{O}_{2}$ Alternating) ......................... 46

D6.3 Crossover and Cyclic Voltammetry Tests at 80/80/73 .......................................... 48

D6.4 Hold at $400 \mathrm{~mA} / \mathrm{cm}^{2}$ Overnight ................................................................... 49

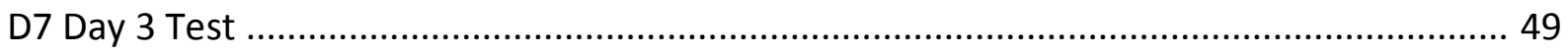

D7.1 Performance Measurement at 80/80/73 (Air/O $\mathrm{O}_{2}$ Alternating, $\left.1.5 \mathrm{~atm}\right)$.................. 49 
D7.2 Performance Measurement at 100/90/90 (Air, $1.5 \mathrm{~atm}$ ) ........................................ 49

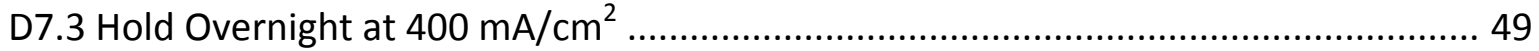

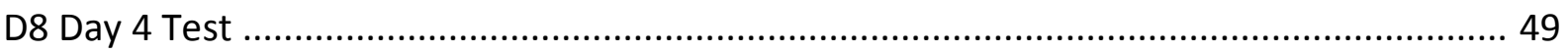

D8.1 Performance Measurement at 100/90/90 ( $\mathrm{O}_{2} /$ Air Alternating, $\left.1.5 \mathrm{~atm}\right) \ldots \ldots \ldots \ldots \ldots \ldots . . . .49$

D8.2 Crossover and Cyclic Voltammetry Tests at 120/90/90 ........................................ 49

D8.3 Performance Measurement at 120/90/90 (Air/ $\mathrm{O}_{2}$ Alternating, $1.5 \mathrm{~atm}$ ) ................. 49

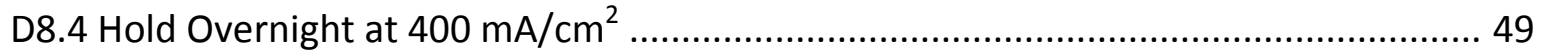

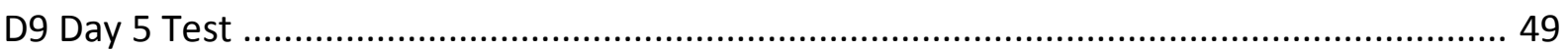

D9.1 Crossover and Cyclic Voltammetry Tests at 100/90/90 …...................................... 49

D9.2 Performance Measurement at 100/90/90 (Air/O ${ }_{2}$ Alternating, $1.5 \mathrm{~atm}$ ).................. 49

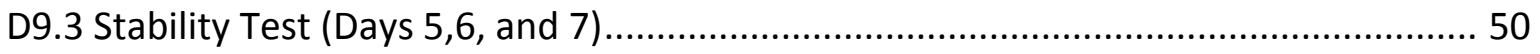

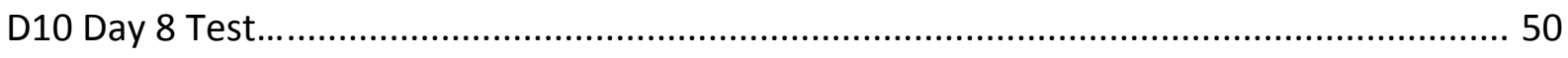

D10.1 Crossover and Cyclic Voltammetry Tests at 100/90/90 ……............................... 50

D10.2 Performance Test at 100/90/90 (Air/ $\mathrm{O}_{2}$ Alternating, $1.5 \mathrm{~atm}$ )................................ 50

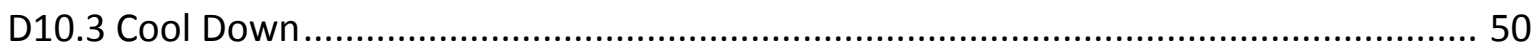

D11 Day 9 Test ......................................................................................................... 51

D11.1 Crossover and Cyclic Voltammetry Tests at 25/25/25 ........................................ 51

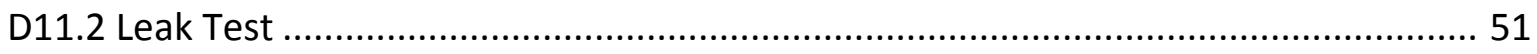

D11.3 Resistance Test ............................................................................................. 51

D11.4 Shut Down and Remove from Test Stand......................................................... 51

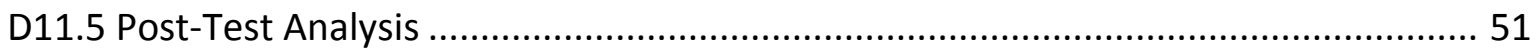

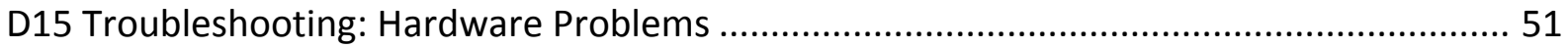

D16 Chart Summarizing Day-to Day Activities ...................................................................... 53

Appendix E Fluoride Concentration Measurements Test Procedure ......................................... 54

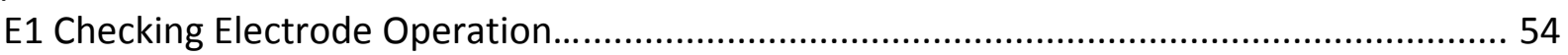

E1.1 Suggested Equipment.................................................................................. 54

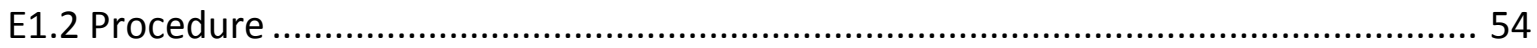

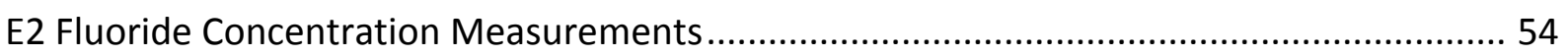

E2.1 Direct Calibration........................................................................................... 54

E2.2 Calibration Curve .......................................................................................... 55

E2.3 Measuring Samples with Concentrations Greater than 1 ppm ................................. 56

E2.4 Measuring Samples with Concentrations Less than 1 ppm ...................................... 57

E3 Electrode Cleaning and Storage ……......................................................................... 58

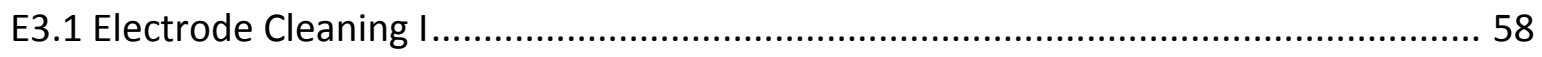

E3.2 Electrode Cleaning II..................................................................................... 58

E3.3 Electrode Storage I ........................................................................................ 58

E3.4 Electrode Storage II ....................................................................................... 58

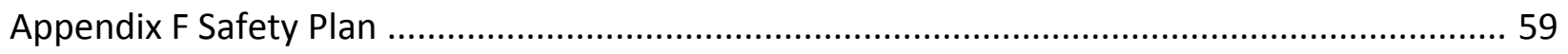

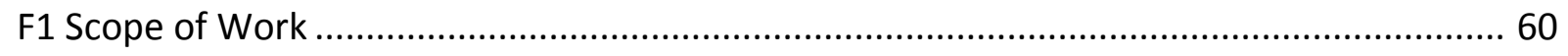

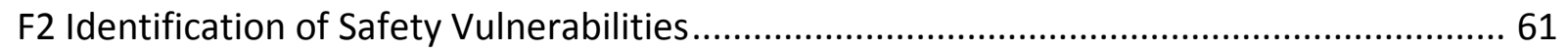

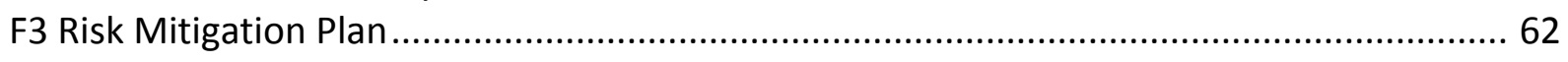

F3.1 Organic Vapor Exposure ................................................................................... 62 


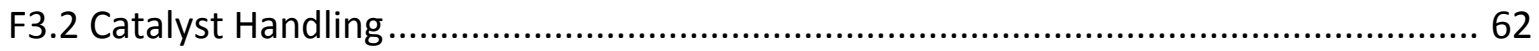

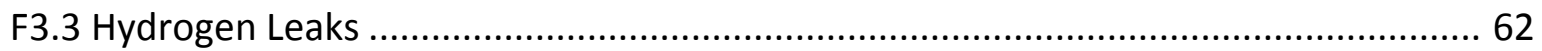

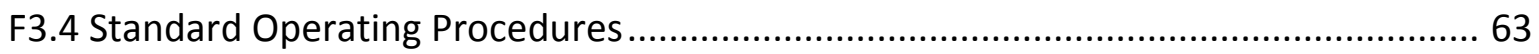

F3.5 Previous Experience With Hydrogen ...................................................................... 64

F3.6 Safety Performance Measurement and Management of Change Reviews ................ 64

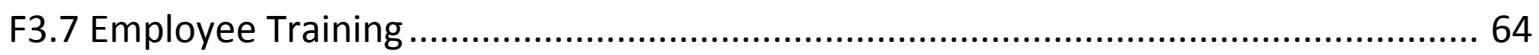

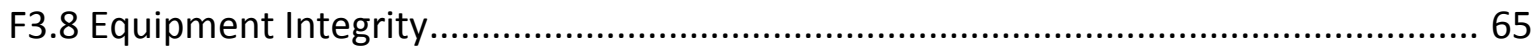

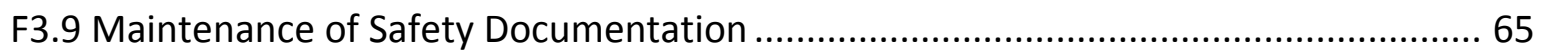

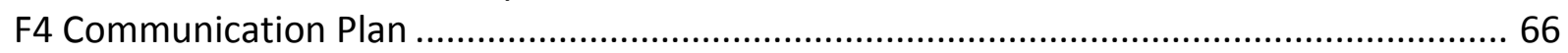

F4.1 Emergency Response Plan.............................................................................66

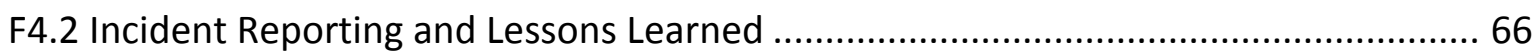

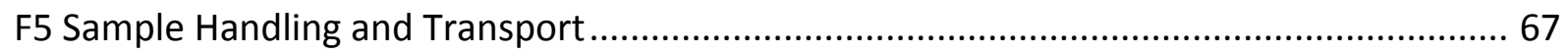

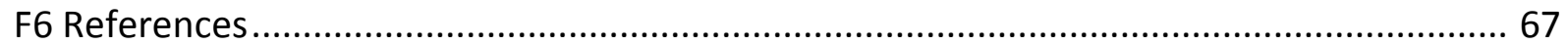

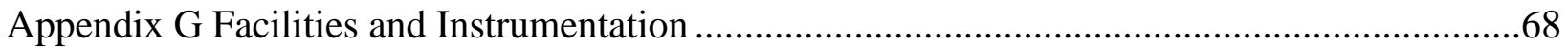

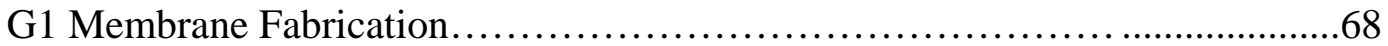

G2 Membrane Electrode Assembly Fabrication.................................................68

G3 Electrochemical Characterization ..........................................................68

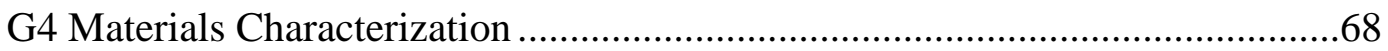




\subsection{Introduction to the Test Protocol for PEM Cell Tests}

PEM single-cell testing for performance, durability and accelerated stress is conducted on a "Fee for Service" basis at a number of government as well as commercial laboratories. These services are available for the individual Task 1 team members with customer-specific protocols to meet their individual testing requirements. This document defines the PEM test procedures that will be used at FSEC for conducting the screening tests that are required under FSEC's Task 5 "Characterize performance of MEA" of the DOE program DE-PS36-6095020. The purpose of this testing is to assess the relative merits of the candidate membranes that are submitted by the Task 1 team members. These tests will be conducted at operating conditions that are of interest to the DOE. The goal is to show the current capability of these membranes rather than simply to provide a Go/No Go rating against the Program Requirements. A further objective of this protocol is to clearly define the operating conditions to which the individual membranes will be subjected. This allows the details to be understood by the DOE; and, with this information, each team member can set limits of processing and operation based on the capabilities of their individual membranes. To the extent that all membranes are tested to the same protocol, the results provide a fair and accurate evaluation of the performance capabilities of each configuration. It is understood that the fabrication history for the membranes, as well as the characteristics of the interfacing cell components, the cell assembly procedures, and the cell operating history can have a significant impact on the cell performance. The impact of these "histories" is normalized in this protocol by using identical procedures on all the cells.

FSEC has followed this protocol on numerous cells and this test protocol produced repeatable results.

\subsection{Components to be Delivered}

Task 1 team members deliver sample membranes developed under this DOE program. A sufficient number of pieces sized $12 \mathrm{~cm}$ by $12 \mathrm{~cm} \mathrm{(4/4} \mathrm{inches} \mathrm{by} 4 \frac{3 / 4}{4}$ inches) will be submitted to enable the tests to be completed. These membranes, along with the fabricators' constraints for further processing, are represented to the DOE as the Task 1 team members' best effort of performance under this program.

\subsection{Details of the Cell}

The test CCM is fabricated using membranes provided by the Task 1 team members. Prior to fabrication of the CCM, membrane samples will be examined for uniformity (no bubbles, debris, fogginess, stretches, cracks, and thickness variations), gas crossover, and flexibility to ensure the membranes are suitable for testing. Sample pieces will be cut from the membrane and sent to Bekktech, LLC and Scribner Associates for conductivity testing and to Material Science at the University of Central Florida for SEM/EDAX characterization. A diagram depicting how each supplied membrane will be used is shown in Figure 1.1. The CCM is fabricated by spraying a catalyst ink (ionomer, $\mathrm{Pt} / \mathrm{C}$, methanol mixture) on a membrane to achieve a nominal loading of $0.4 \mathrm{mg} \mathrm{Pt} / \mathrm{cm}^{2}$ of TEC10E50E -- Pt $50 \mathrm{wt} \%$ catalyst supported on a high surface area carbon (SA $=800 \mathrm{~m}^{2} / \mathrm{g}$ ) supplied by TKK. FSEC has achieved baseline performance by mixing the catalyst 
with 32\% $1100 \mathrm{EW}$ Nafion ${ }^{\circledR}$ using methanol and then spraying using a nitrogen-driven spray gun, which is carried by a numerically-controlled $\mathrm{X} / \mathrm{Z}$ plotter. The $\mathrm{CCM}$ is then dried at $100{ }^{\circ} \mathrm{C}$, heat-treated at $136{ }^{\circ} \mathrm{C}$ and compressively pressed $5.1 \mathrm{~atm}$ (75 psi) compressive pressure for five minutes, and then protonated using a $0.5 \mathrm{M}$ sulfuric acid solution and washed in distilled water. A second CCM and two coupons are made at the same time, with identical processing. This second CCM and one coupon will be returned to the membrane fabricator untested for their evaluation and analysis. FSEC will communicate with the team members about the fabrication constraints for each membrane and an attempt will be made to accommodate the membrane requirements and the supplier wishes, while still achieving comparable results. Depending on the membrane composition and the supplier requirements, it may be necessary to adjust the type of ionomer, ionomer loading, drying temperature, hot press temperatures, and solvent.

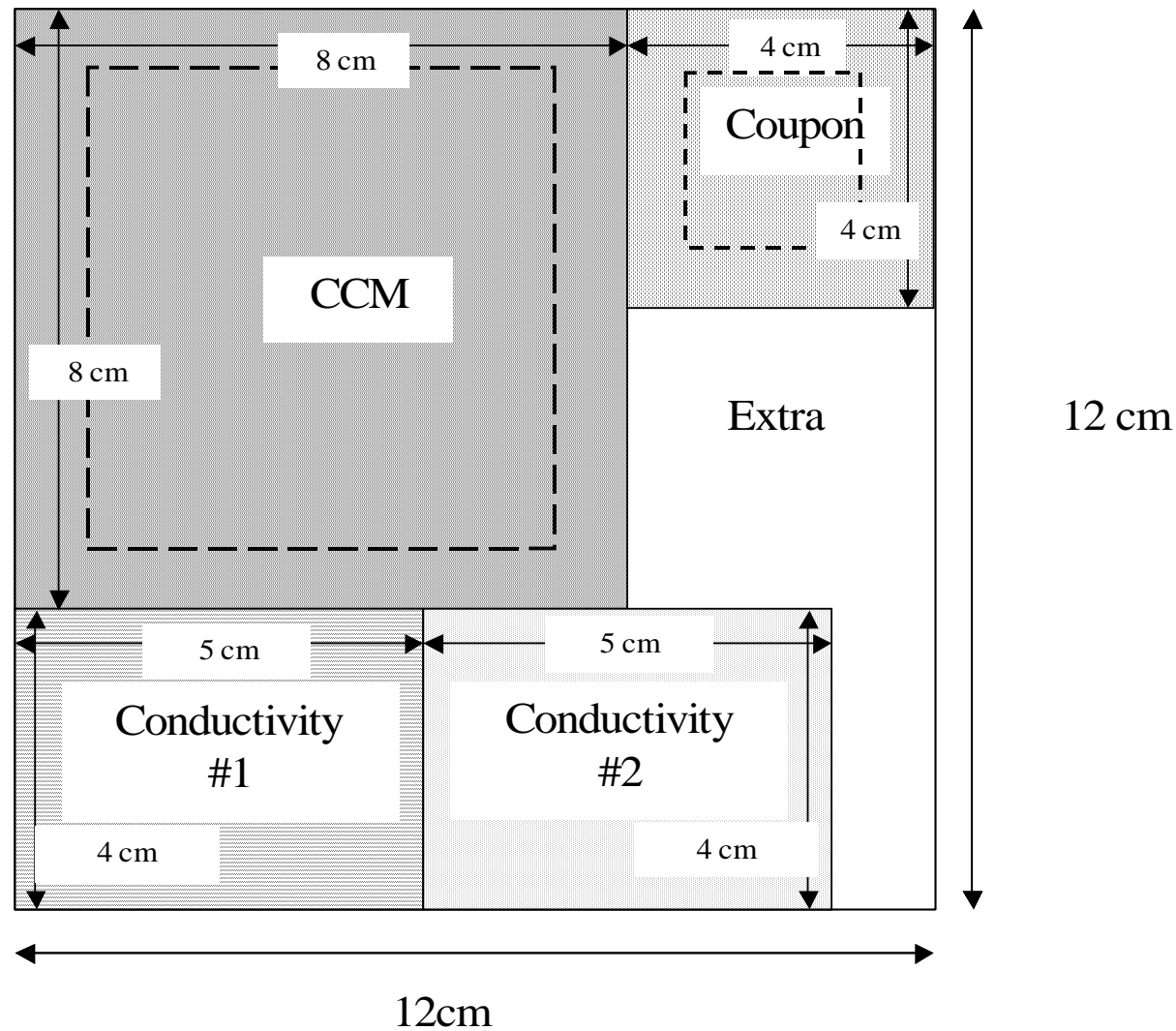

Figure 1.1. Depiction of membrane sample pieces. CCM and coupon pieces will be sprayed at the same time. Conductivity pieces will be sent to Scribner and Associates and Bekktech for testing.

The single-cell hardware $\left(25 \mathrm{~cm}^{2}\right)$ used for this program was manufactured by Fuel Cells Technologies Incorporated (FCT) www.fuelcellstechnologies.com. It consists of a pair of graphite bipolar plates with a serpentine flow pattern, gold-coated current collector plates, and aluminum pressure plates. The design of the anode bipolar plate flow field has been rotated $90^{\circ}$ to give a cross flow pattern and the dimensions of the serpentine flow field for both anode and cathode have been modified (width and depth) to decrease pressure drop. All other aspects of this hardware are as originally designed by FCT. 

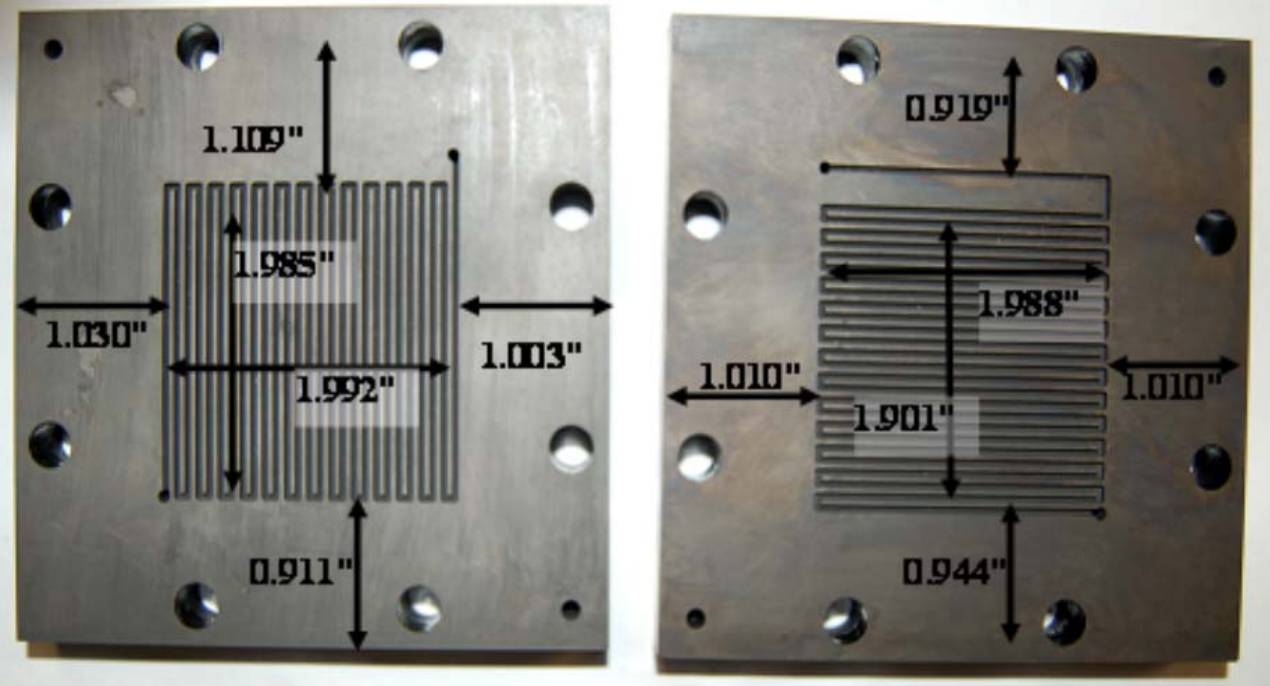

Figure 1.2. Bipolar plates (anode, left and cathode, right) showing single serpentine flow field.

All the MEAs for these cells use type 10BB gas-diffusion layers purchased from SGL Carbon (Sigracet ${ }^{\circledR}$ ) Each of these gas-diffusion layers were tested for through-plane permeability prior to use, following the procedure in Appendix A. The minimum acceptable permeability for the cathode GDL is given by a Gurley Number of $0.024 \mathrm{~L} / \mathrm{min} / \mathrm{cm} \mathrm{H}_{2} \mathrm{O} / \mathrm{cm}^{2}$. The anode GDL permeability is allowed to be much lower. The cell seals are made of a stack-up of Teflon ${ }^{\circledR}$ gaskets with the thickness of the gaskets thinner than the cell assembly giving a "pinch" of 230 to $250 \mu \mathrm{m}$ (9-10 mils).

\subsection{Membrane, CCM, and GDL Thickness Measurement}

The thickness of the membrane, CCM, and GDLs are measured using a Mitutoyo Gauge (Figure 1.2). Component thicknesses are defined using average of at least nine readings evaluated over the entire component at locations shown on the template in Figure 1.3. The membrane, CCM, or GDL is sandwiched between thin sheets of Teflon ${ }^{\circledR}$ of known thickness when making the measurements. The template is used to maintain the consistency of the location of successive measurements. The Teflon ${ }^{\circledR}$ sheets are measured first and then the membrane, CCM, or GDL is inserted between them and a second set of readings is taken. Subtracting the first reading from the second provides the component thickness. 


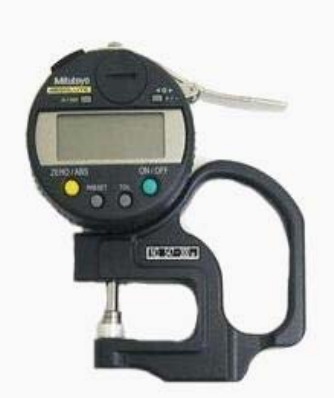

Figure 1.3. Mitutoyo Guage for measuring thickness of membranes, CCMs, MEAs, and GDLs

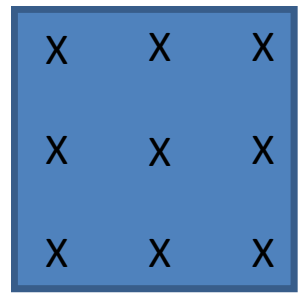

Measure each Membrane in 9 places

Take the average

Figure 1.4. Template for measuring thickness of membrane, CCM, GDL, and MEA

\subsection{Cell Assembly}

Figure 1.4 shows an expanded view of a complete PEM fuel cell hardware. The design of the hardware is for $25 \mathrm{~cm}^{2}$ cells. For this program, cells are assembled by hand using bipolar plates, load plates, and end plates purchased from FCT. Prior to assembly, GDLs are tested for permeability, and cut to the required size. Teflon sheets are also die cut to size, and the membrane is spray-coated with a mixture of TKK platinum on carbon catalyst to form the CCM. CCMs have $0.4 \mathrm{mg} / \mathrm{cm}^{2}$ catalyst on each electrode for the screening tests; however they can be fabricated with catalyst loadings down to $0.05 \mathrm{mg} / \mathrm{cm}^{2}$ by the same processing equipment. After all components have been prepared, cleaned and documented, cells are assembled as defined in the "Assembly Procedure" included as Appendix B. Cell "pinch", which establishes the compressive load on the active area of the MEA is controlled by selecting Teflon sealing gaskets that are thinner than the sum of the component thicknesses in the active area of the cell. This pinch is a critical parameter for cell assembly and is controlled by selecting Teflon ${ }^{\circledR}$ gaskets of appropriate thickness as shown in Figure 1.5. 


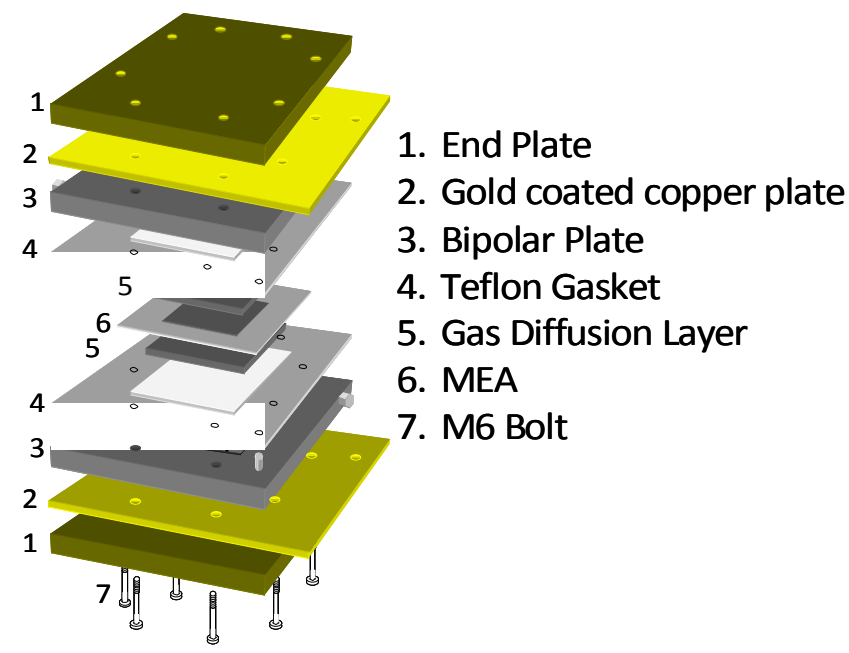

Figure 1.5. Expanded view of PEM fuel cell hardware

\section{GDL Thickness}
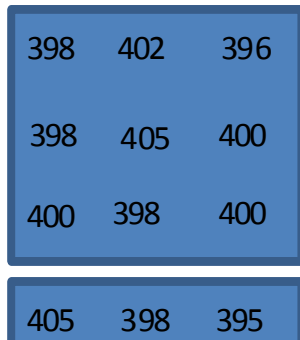

405

$402 \quad 409 \quad 404$

All numbers are in $\mu \mathrm{m}$.

The gaskets were each $310 \mu \mathrm{m}$

Measure each component in 9 places

Build cell with 229-254 $\mu$ m pinch

Pinch $=\mathrm{T}_{\mathrm{GDL} \text { (Anode) }}+\mathrm{T}_{\mathrm{GDL} \text { (Cathode) }}+\mathrm{T}_{\mathrm{CCM}}-\mathrm{T}_{\text {Gaskets }}$

\section{CCM Thickness}
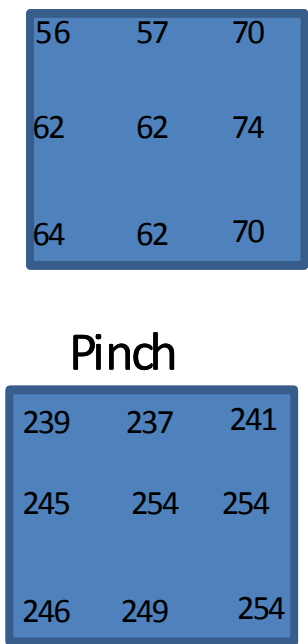

Figure 1.6. Schematic showing sample calculation of pinch by measuring thicknesses of each component using the template.

\subsection{Pre-Test Integrity Test}

After the cell is built and before it is delivered to the test stand, it is externally leak-tested, internally leak-tested, and electrically isolation-tested, each according to the procedures in Appendices $C$ and $D$. These tests are to ensure that the cell integrity is sufficient to warrant the test effort and to establish a pre-test baseline database. After the cell is mounted in the test stand, the external leak-test of the cell and the stand, and the resistance tests of the cell and the stand are repeated to validate test readiness. Allowable limits for these tests have been established by a combination of FSEC's cumulative test experience and an "impact analysis" of 
the worst-case level of leakage and cell resistance on cell performance. These levels were also verified by the current FSEC database.

\subsection{Tests Performed on Each Cell}

\subsubsection{Linear Sweep Voltammetry, Cyclic Voltammetry (CV), and Cell Conditioning} Prior to performance evaluation, electrochemical active area (ECA) and $\mathrm{H}_{2}$ crossover (CO) tests are performed on the cell at ambient pressure at room temperature and $100 \% \mathrm{RH}, 80^{\circ} \mathrm{C}$ and $\sim 100 \% \mathrm{RH}, 100{ }^{\circ} \mathrm{C}$ and $69 \% \mathrm{RH}$, and $120^{\circ} \mathrm{C}$ and $35 \% \mathrm{RH}$. The cathode is the working electrode and the anode, using hydrogen, is the counter as well as the reference electrode. Flows of 0.4 $\mathrm{L} / \mathrm{min}$ of hydrogen and nitrogen are introduced to the anode and cathode side of the cell, respectively. The CV is conducted at a scan rate of $30 \mathrm{mV} / \mathrm{s}$ between zero and $0.8 \mathrm{~V}$ to determine the ECA. Hydrogen crossover is measured by the limiting current density method with $\mathrm{H}_{2}$ flowing on the anode and nitrogen on the cathode. The cell potential is scanned potentiodynamically at $4 \mathrm{mV} / \mathrm{s}$ from zero to $0.8 \mathrm{~V}$. A PAR $263 \mathrm{~A}$ potentiostat and CorrWare software is used to control the potential. The crossover test shows both the level of gas diffusion through the membrane and any electrical short. The level of diffusion is given by the flat portion of the curve and the level of short is calculated from the sloping linear relationship between the applied voltage and the measured current, specifically the measured current between $0.3 \mathrm{~V}$ and $0.8 \mathrm{~V}$. Shorts must be less than the equivalent of $10 \mathrm{~mA}$ to be allowable, and to clarify the CV data, the linear slopes resulting from these electrical shorts are removed from the data. Figure 1.6 shows sample CO data and Figure 1.7 shows sample ECA data as a function of cell temperature. In the CV data, the hydrogen desorption peaks can easily be observed at room temperature. CV and CO tests were repeated before each test condition to provide data in support of the cell analysis.

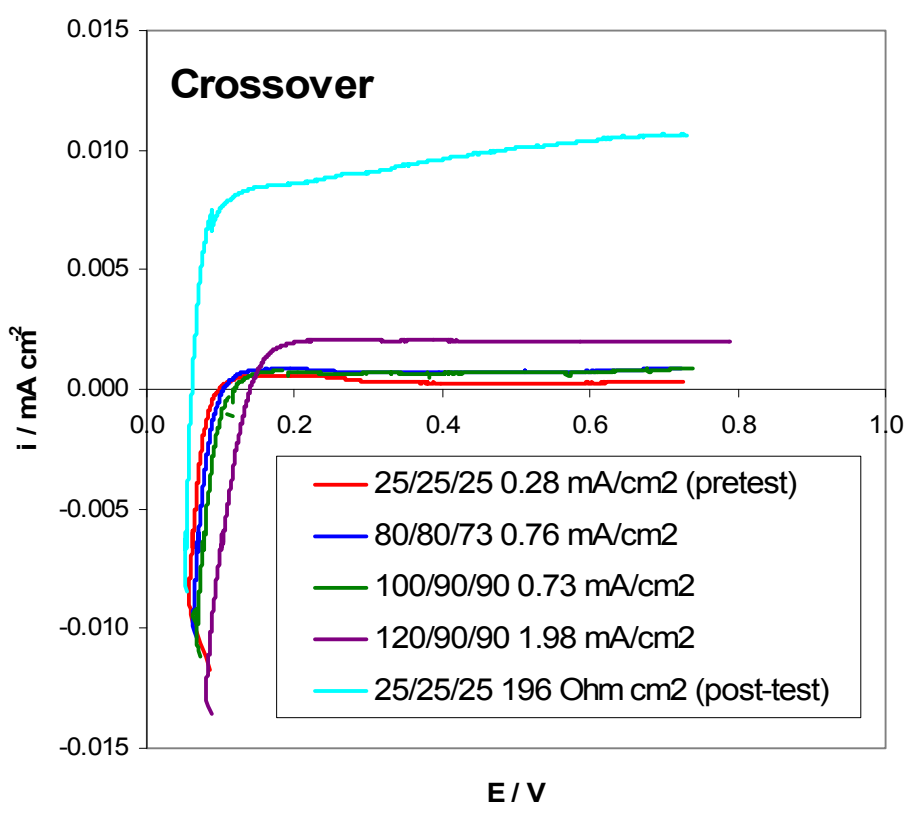

Figure 1.7. CO data at different cell temperatures. Linear sweep voltammogram of FSEC-1; scan rate = $2 \mathrm{mV} / \mathrm{s}, 0.4 \mathrm{~L} / \mathrm{min}\left(\mathrm{H}_{2} / \mathrm{N}_{2}\right), T_{\text {cell }}=25,80,100,120^{\circ} \mathrm{C}$, working electrode = cathode, counter $/$ reference = anode. 


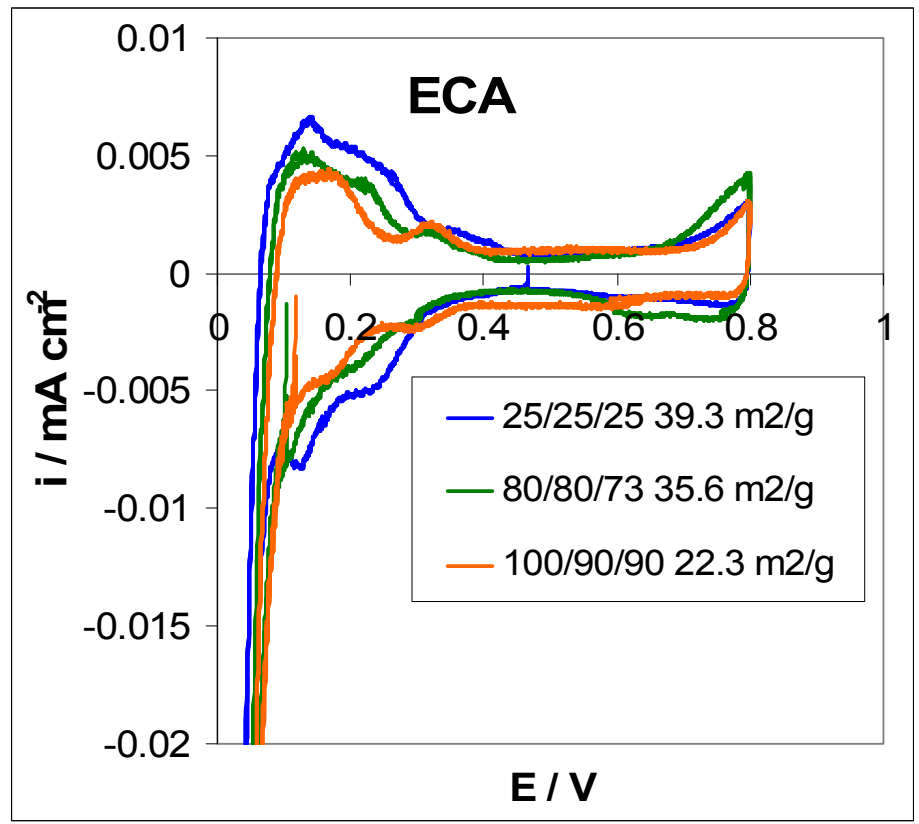

Figure 1.8. ECA data as a function of cell temperature. Cyclic Voltammogram of FSEC1; scan rate = 30 $\mathrm{mV} / \mathrm{s}, 0.4 \mathrm{~L} / \mathrm{min}\left(\mathrm{H}_{2} / \mathrm{N}_{2}\right), T_{\text {cell }}=25,80,100^{\circ} \mathrm{C}$, working electrode = cathode, counter $/$ reference $=$ anode .

Analysis of the cyclic voltammogram provides a measure of the electrochemical surface area (ECA) of the cathode. Periodically repeating this test during the program provides a history of the changes in cathode ECA for sample MEAs as a function of a fixed test history. Analysis of these test results shows comparative merits of the submitted membranes.

It is recognized that the initial testing of $\mathrm{CO} / \mathrm{CV}$ prior to conditioning the $\mathrm{CCM}$ does not represent the full potential of the cell, but these tests provide important data about the initial condition of the cell. In addition, this data is required as input for the analysis of the cell during operation. After the CO/CV test, the cell is heated to $80{ }^{\circ} \mathrm{C}$ and the saturators are heated to 80 ${ }^{\circ} \mathrm{C}$ for the anode and $73{ }^{\circ} \mathrm{C}$ for the cathode, and the cell is conditioned for operation by adding water to the electrolyte. This is a two-step procedure, where water is first added as a vapor from saturated gases (hydrogen on the anode and nitrogen on the cathode), and second by operation of the cell at a fixed voltage of $0.55 \mathrm{~V}$ and run on hydrogen/air. Each step is for three hours, which, for Nafion ", has proven to be sufficient to "wet-up" the electrolyte.

After the electrolyte has been "wet-up", a series of performance curves are run at ambient pressure and high stoichiometry. These tests are run at near $100 \% \mathrm{RH}$ with the cell at $80{ }^{\circ} \mathrm{C}$. The air dew point is a few degrees lower than the cell temperature to avoid flooding the cathode.

Performance sweeps are taken on $\mathrm{H}_{2} /$ Air, $\mathrm{H}_{2} / \mathrm{O}_{2}$, and $\mathrm{H}_{2} /$ Air out to $\mathrm{I}_{\mathrm{Lim}}$. or $\mathrm{I}_{\text {Max. }}$. The limiting current, $\mathrm{I}_{\mathrm{Lim}}$, is the current when the cell voltage becomes $0.3 \mathrm{~V}$. This value is used rather that 0 $V$ to avoid damage to the cell. The maximum current, $I_{M a x}$, is based on the test stand reactant 
flow capability at $2000 \mathrm{~mA} / \mathrm{cm}^{2}$. The repeat of the $\mathrm{H}_{2} /$ Air sweeps allows performance between the two tests to be compared to show that the cell has reached a stable starting performance point, and to indicate that the differences between the air and the oxygen performance is being measured accurately. Test points are held for five minutes during this testing as a compromise between fully stable data and a reasonable amount of total test time.

The cell is then held at these same conditions $\left(80^{\circ} \mathrm{C}, 80^{\circ} \mathrm{C}, 73^{\circ} \mathrm{C}\right)$ while the initial test data is reviewed and the cell integrity is judged to be sufficient to proceed with the remainder of the testing. If the cell performance is not adequate, it is cooled to room temperature, the $\mathrm{CO} / \mathrm{CV}$ is repeated and further data analysis is conducted to determine the next steps.

\subsubsection{Performance Verification Test}

The purpose of the Performance Verification Test is to provide data on cells operating at a series of conditions that are at the DOE goals or that represent significant progress toward those goals and show the relative merits of each of the candidate membranes at those conditions. Having conditioned the cell and verified its integrity, the Performance Verification Test is started without shutting down. The cell is pressurized to 1.5 atmospheres while holding the cell temperature and the anode and cathode saturator temperatures at $80{ }^{\circ} \mathrm{C}, 80^{\circ} \mathrm{C}, 73^{\circ} \mathrm{C}$ respectively; and a series of $\mathrm{H}_{2} / \mathrm{Air}, \mathrm{H}_{2} / \mathrm{O}_{2}, \mathrm{H}_{2} /$ Air performance sweeps are taken at high stoichiometry (above 3 to minimize the effects of reactant utilization). Following these tests, the cell and saturators are heated to $100{ }^{\circ} \mathrm{C}, 90{ }^{\circ} \mathrm{C}, 90^{\circ} \mathrm{C}$, which changes the inlet $\mathrm{RH}$ at the cell to $69 \%$. The three performance sweeps are taken and the temperatures are increased again to $120{ }^{\circ} \mathrm{C}, 90{ }^{\circ} \mathrm{C}, 90{ }^{\circ} \mathrm{C}$ to further reduce the relative humidity to $35 \%$. In all cases, the cell is returned to $100{ }^{\circ} \mathrm{C}, 90{ }^{\circ} \mathrm{C}, 90{ }^{\circ} \mathrm{C}$ and held at $400 \mathrm{~mA} / \mathrm{cm}^{2}$ overnight to evaluate the stability between the different sets of lower relative humidity tests. Cell temperatures are held at 100 ${ }^{\circ} \mathrm{C}, 90{ }^{\circ} \mathrm{C}, 90{ }^{\circ} \mathrm{C}$ in preparation for the stability test.

\subsubsection{Polarization Curve}

Figure 1.8 shows typical performance data, which shows three characteristic regions. The first (low current density region) is dominated by activation overpotential losses, the second (mid current density) is dominated by resistance losses, and the third (high current density region) is dominated by mass transport losses. Analysis of these curves, and the changes to the various regions of the curves, as the testing progresses, provides key insights into the performance and stability of the membrane as well as the catalyst layer and the catalyst-membrane interface.

Fuel Utilization and air Utilization have significant impacts on the shape of these curves. Although utilizations used are higher than the goal values, this data is valuable in comparing performance with lower fuel and air flows. The highest obtainable current density is $I_{\text {Lim }}$, which is an important input to the analysis of the internal resistance of the cathode. 


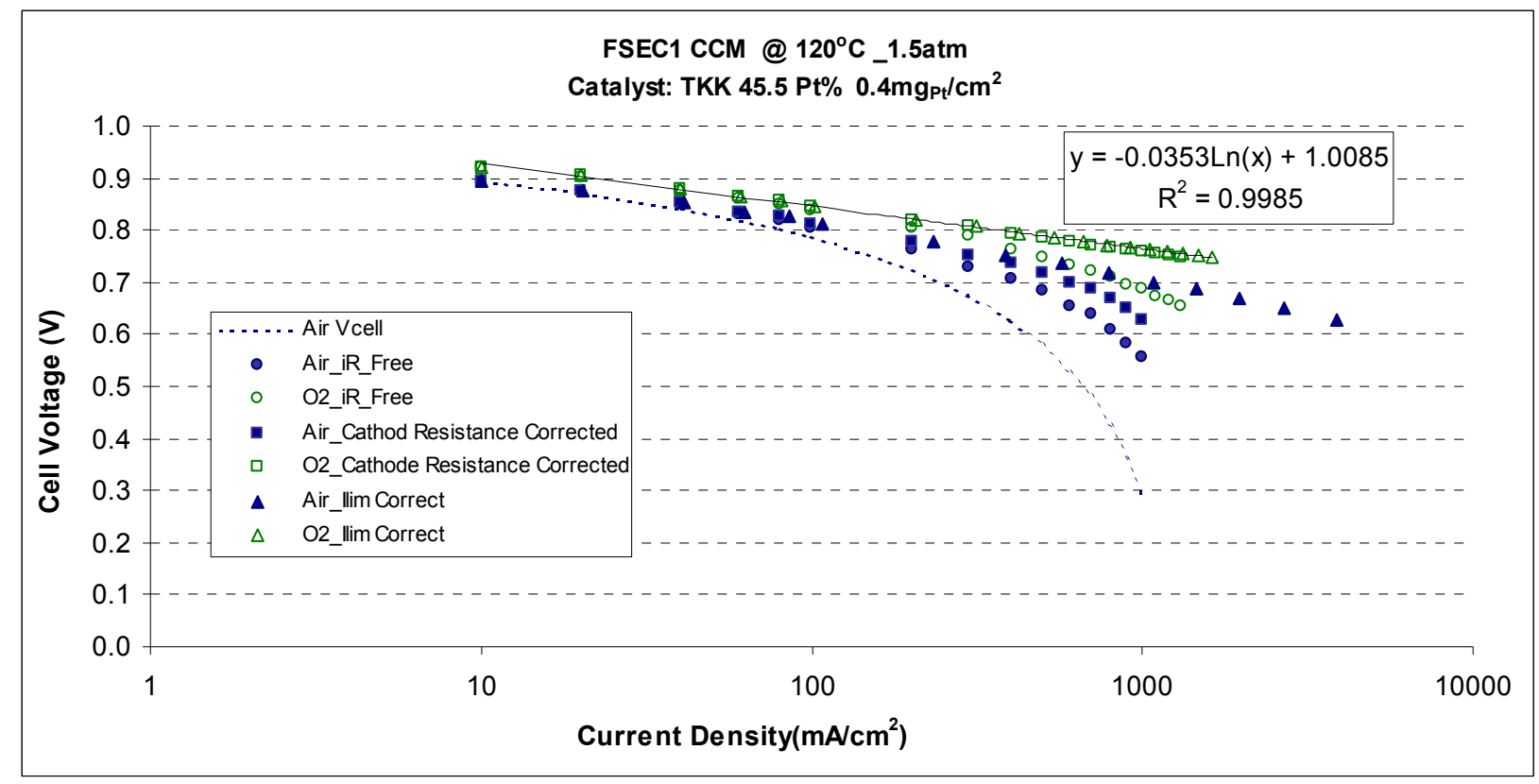

Figure 1.9. Typical performance for a load calibration sweep

\subsubsection{Stability Test}

A 64-hour endurance test is run on the $25-\mathrm{cm}^{2}$ fuel cell under $\mathrm{H}_{2} /$ Air. The operating conditions are $400 \mathrm{~mA} / \mathrm{cm}^{2}, 100{ }^{\circ} \mathrm{C}, 1.5 \mathrm{~atm}$, and $69 \% \mathrm{RH}$ for both the $\mathrm{H}_{2}$ and air reactants. The cell is maintained at a constant current while cell performance and resistance are measured. Initial and final electrochemical active area, fuel crossover, and performance are determined at cell operating temperature. Water from the exit streams is condensed, collected, and analyzed for fluoride ion concentration.

Typical cell voltage and cell resistance stability curves are shown in Figure 1.9. The voltage and resistance are both expected to be stable throughout the stability test. Any change in performance or resistance is a result of MEA degradation due to chemical and mechanical stress. 


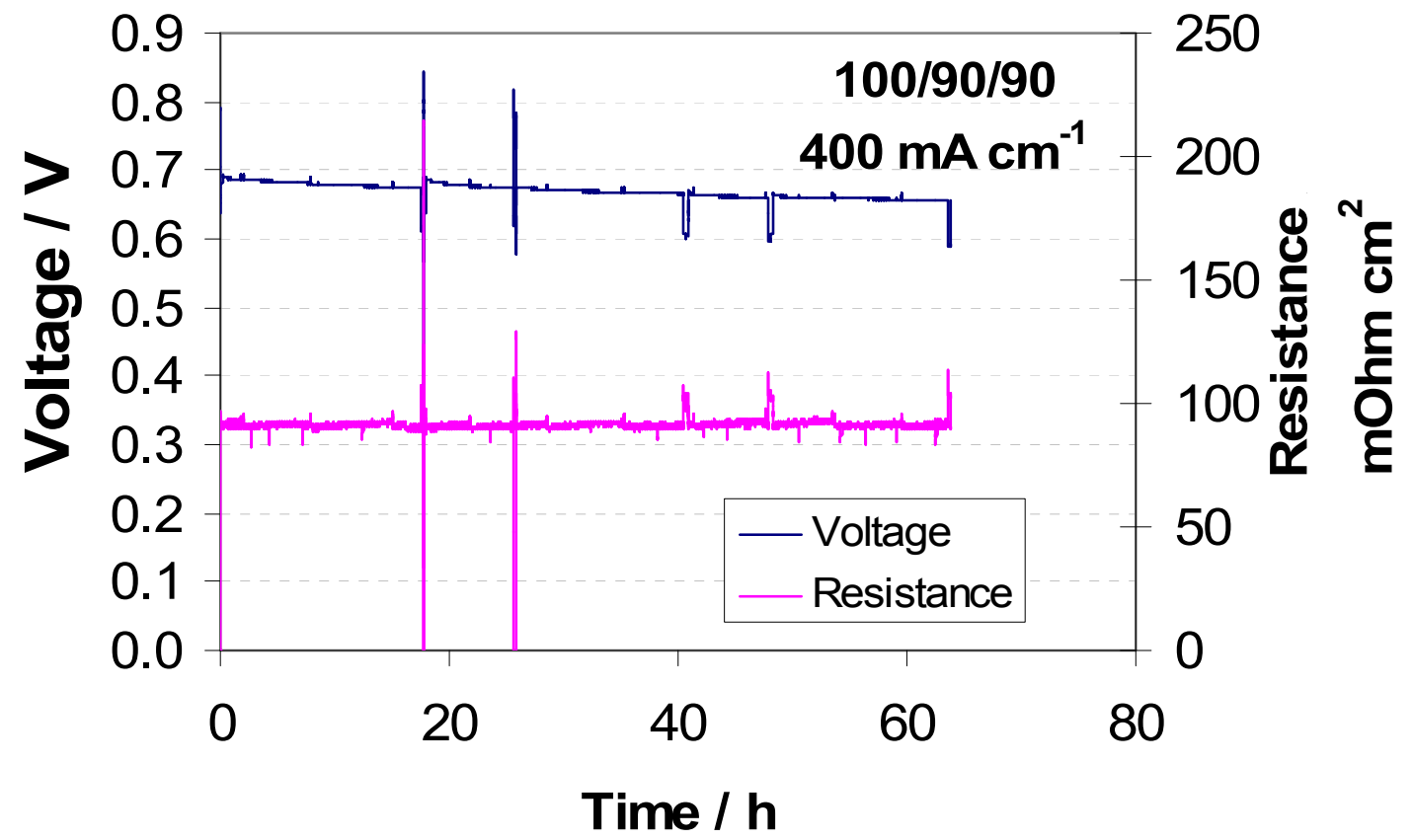

Figure 1.10. Typical performance and cell resistance stability curve. Voltage and resistance of FSEC-3, 0.2 $\mathrm{L} / \mathrm{min}\left(\mathrm{H}_{2} / \mathrm{Air}\right), \mathrm{T}_{\text {cell }}=90^{\circ} \mathrm{C}, \% R H=30, i=400 \mathrm{~mA} / \mathrm{cm}^{2}$.

\subsubsection{Post-Test Integrity Test}

After the cell is tested, and before it is removed from the test stand, the external leak-test of the cell and the stand, and the resistance tests of the cell and the stand are repeated to quantify the end-of-test condition. In addition, before the cell is disassembled, it is externally leak-tested, internally leak-tested, and electrical isolation tested on the bench, each according to the procedures in Appendices $C$ and $D$. Bolt torque is also measured. These tests are to determine the changes in the cell integrity as a result of the protocol testing. These tests provide data on some of the changes to the membrane as well as data external to the MEA that is needed to support the cell analysis.

\subsubsection{Post-test Analysis}

FSEC has developed and verified a process to evaluate sources of polarization, mainly associated with the cathode, in hydrogen/air proton exchange membrane fuel cells and is currently using this process to analyze cell performance and guide development efforts. This process quantifies the six sources of polarization using data from the standardized test program. Non-electrode ohmic overpotential, electrode ohmic overpotential, non-electrode concentration overpotential, electrode concentration overpotential, activation overpotential from the Tafel slope, and activation overpotential from catalyst activity are analytically separated into their distinct elements. The analysis is based on hydrogen/air polarization curves of an in-house membrane electrode assembly (MEA) using hydrogen/oxygen polarization curves as a diagnostic tool. The analysis results compare three cell temperature/relative humidity /oxygen partial pressure ( $\mathrm{p}_{\mathrm{O} 2}$, atm) conditions: $80^{\circ} \mathrm{C} / 100 \% \mathrm{RH}_{\text {anode }} / 75 \% \mathrm{RH}_{\text {cathode }}, 100^{\circ} \mathrm{C} / 69 \% \mathrm{RH}$, and $120^{\circ} \mathrm{C} / 35 \% \mathrm{RH}$, which represent near fully-humidified, moderately humidified, and low humidified conditions, respectively, at $1.5 \mathrm{~atm}$ operating pressure. The technique is useful for 
diagnosing the main sources of loss in MEA development work, especially for high temperature/low relative humidity operation where several sources of loss are present simultaneously. The following verification test data and analysis is reported.

\subsubsection{Cell Data Report}

The experimental testing of a new membrane will result in the following data to enable the evaluation of membrane performance in a cell:

- Cell build verification test data

o Electronic resistance for short determination

o External leakage rate

o Internal leakage rate

- Cell characterization at start-up

o Cyclic voltammetry at $25^{\circ} \mathrm{C}$ to enable electrochemical area determination

0 Linear sweep voltammetry at $25{ }^{\circ} \mathrm{C}$ for crossover and electronic resistance determination

- Performance test data

o Cell voltage and cell resistance (OCV to $0.3 \mathrm{~V}$ ) at the following conditions:

- $\mathrm{H}_{2} / \mathrm{O}_{2}$ and $\mathrm{H}_{2} /$ Air reactants at $1.5 \mathrm{~atm}, 80^{\circ} \mathrm{C} / 80{ }^{\circ} \mathrm{C} / 73^{\circ} \mathrm{C}(100 \% \mathrm{RH})$

- $\mathrm{H}_{2} / \mathrm{O}_{2}$ and $\mathrm{H}_{2} /$ Air reactants at $1.5 \mathrm{~atm}, 100{ }^{\circ} \mathrm{C} / 90{ }^{\circ} \mathrm{C} / 90{ }^{\circ} \mathrm{C}(69 \% \mathrm{RH})$

- $\mathrm{H}_{2} / \mathrm{O}_{2}$ and $\mathrm{H}_{2}$ /Air reactants at $1.5 \mathrm{~atm}, 120{ }^{\circ} \mathrm{C} / 90{ }^{\circ} \mathrm{C} / 90{ }^{\circ} \mathrm{C}(35 \% \mathrm{RH})$

0 A tabulation of cell current density and resistance using $\mathrm{H}_{2} /$ Air reactants at $0.7 \mathrm{~V}$ for the above three conditions (This tabulation is provided to enable rapid membrane comparisons.)

- Stability test data

0 Cell voltage and resistance for 100 hours at the following conditions:

- $\mathrm{H}_{2} /$ Air reactants at $400 \mathrm{~mA} / \mathrm{cm}^{2}, 150 \mathrm{kPa}, 100{ }^{\circ} \mathrm{C}, 69 \% \mathrm{RH}$

0 Cyclic voltammetry to enable post-test electrochemical area determination

o Linear sweep voltammetry for post-test crossover and electronic resistance determination

o Fluoride present in exhaust condensate

\subsection{Fuel Cell Hydrogen Safety Plan}

Florida Solar Energy Center (FSEC) complies with the University of Central Florida (UCF) Chemical Hygiene Plan (CHP), as required by OSHA. This plan and its associated documentation ("Safety Standards for Hydrogen and Hydrogen Systems - SSHHS") provides a written description of safety policies and procedures that all university laboratory personnel must follow. All faculty researchers, student trainees and visiting scientists and engineers working at FSEC's hydrogen research laboratories are provided with training and a copy of SSHHS document. SSHHS document contains guidelines for hydrogen system design, material selection, operation, storage, handling and transportation. Furthermore, FSEC's hydrogen laboratories and field facility meet and/or exceed the design and safety requirements imposed by the Florida State Fire Marshall and all the state and federal codes (NFPA 45 Standard on Fire Protection for Laboratories Using Chemicals, NFPA 50A Standard for Gaseous Hydrogen 
Systems at Consumer Sites, and NFPA 70 National Electric Code) for handling large volumes of hazardous and flammable gases and chemicals including both gaseous and liquid hydrogen. In addition, FSEC's hydrogen field facility has been upgraded with explosion proof electrical systems and meets NFPA 50B Code "Liquefied Hydrogen Systems at Consumer Sites."

Before each new research activity is initiated, the personnel safety at and near the facility is reviewed and emergency procedures implemented at the earliest planning and design stages. Advance planning for a variety of emergencies such as fires and explosions are conducted and proper procedures developed and implemented. All hydrogen systems will be instrumented and checked for:

i. Process monitoring and control.

ii. Collection of performance data.

iii. Providing warnings and/or alarms for out-of-limits conditions.

iv. Early detection of hazardous condition(s).

v. Compatibility with hydrogen service.

vi. Establishment of local and/or remote operation and monitoring of the hydrogen system.

vii. Having appropriate range, accuracy, and response time.

The Safety Assessment Review shall be updated anytime a system or process is changed. An annual facility inspection shall be conducted and documented. A formal Operating and Support Hazard Analysis shall be performed as directed by the UCF Environmental Health and Safety Office. Significant hazards identified shall be eliminated or reduced to acceptable risk levels.

Mr. Randy Fowler is the FSEC's Hydrogen R\&D Laboratories' operational and safety manager. He has attended and completed the following safety related courses and training activities:

i. A full day course on HazMat and received his certification on spill control and respirators.

ii. Has successfully completed "NASA Hydrogen Safety" class.

iii. $\quad$ Attended the "Lab Safety Basics and Beyond" at PITTCON.

iv. Taken and passed UCF's "Chemical Safety and Environmental Management for Laboratories" class.

v. Has post-secondary vocational certificate given by the Brevard Community College on "Chemical Laboratory Specialist," December of 2002.

Mr. Fowler oversees the enforcement of all hydrogen and chemical safety procedures and training of the graduate research students working in FSEC's hydrogen laboratories. In addition, a comprehensive safety plan will be developed and submitted to DOE at the time of contract award. In preparation for this plan, the following steps will also be taken:

- The Chemical Hygiene Plan (CHP) will be re-evaluated, modified as needed and periodically checked for compliance.

- A standard operating procedure (SOP) will be established for all experiments and operations taking into account hazard level of materials to be used. 
- Procedures will be developed for reporting any events or deviations from SOP.

- Failure risk mitigation plan will be developed based on vulnerabilities identified by Modes and Effects Analysis. 


\section{Day by Day PEM MEA Test Sequence}

\subsection{Assemble the Cell}

- The Sample MEA

- From team members two pieces - $12 \mathrm{~cm} \times 12 \mathrm{~cm}\left(4.75^{\prime \prime} \times 4.75^{\prime \prime}\right)$

- Anode and Cathode Catalyst

- TKK 46\% Pt catalyst

- $\quad 0.4 \mathrm{mg} / \mathrm{cm}^{2}$

- $\quad 32$ wt\% Nafion ${ }^{\circledR} 1100$ binder

- Spray

- $136^{\circ} \mathrm{C}$ heat treat

- Protonation

- Two identical: One tested/One returned untested

- GDL

- SGL 10BB

- Pinch $0.25 \mathrm{~mm}+/-0.02 \mathrm{~mm}\left(0.01^{\prime \prime}+/-0.001\right.$ ")

- Teflon Gasket Lay-up

- FCT Cell

- Hardware - Single pass serpentine

- Cross flow cathode horizontal

- FSEC bar and groove dimensions

- Bolt Load

- Star pattern

- $\quad 4.5 \mathrm{~N} \mathrm{~m}$ torque (40 inch pounds)

- Pretest Conductivity

- Tested at BekkTech

\subsection{Day 1}

- Measure mechanical crossover

- $\quad<1$ mA eq. is acceptable

- Measure External Leakage

- $\quad<20$ mA eq. is acceptable

- Cell Resistance acceptable limits

- Anode to Ground > 100 Ohms

- $\quad$ Cathode to Ground > 100 Ohms

- Anode to Cathode $>30 \mathrm{Ohms}$

- Mount in test stand

- Resistance Anode/Cathode to ground > 100 Ohms acceptable

- Room temperature CO and CV

- Wet-Up

- 80/80/73

- $\mathrm{H}_{2} / \mathrm{N}_{2} 3 \mathrm{~h}-\mathrm{No}$ Load

- $\mathrm{H}_{2} /$ Air $\sim 3 \mathrm{~h}-0.55 \mathrm{~V}$ 
- Cool-down to room temperature

- Hold on $\mathrm{N}_{2} / \mathrm{N}_{2}$

\subsection{Day 2}

- Room temperature CO and CV

- Heat up

- $\mathrm{H}_{2} / \mathrm{N}_{2}$

- $80 / 80 / 73^{\circ} \mathrm{C}$

- Ambient pressure

- Measure

- Open circuit voltage (OCV),

- Performance (volts vs. current) curve (VI)

- Cell resistance (by current interrupt)

- Stoichiometry

- Anode 3, Cathode 3.6

- $\mathrm{H}_{2} /$ Air

- $\mathrm{H}_{2} / \mathrm{O}_{2}$

- $\mathrm{H}_{2} /$ Air

- CO and CV at $80 / 80 / 73^{\circ} \mathrm{C}$

- Hold overnight at $400 \mathrm{~mA} / \mathrm{cm}^{2}$

2.4 Day 3

- Pressurize to $1.5 \mathrm{~atm}$

- Measure at $80 / 80 / 73{ }^{\circ} \mathrm{C}$

- OCV, VI curve, cell resistance

- Stoichiometry

- Anode 3, Cathode 3.6

- $\mathrm{H}_{2} /$ Air

- $\mathrm{H}_{2} / \mathrm{O}_{2}$

- $\mathrm{H}_{2} /$ Air

- Heat to $100 / 90 / 90{ }^{\circ} \mathrm{C}$

- CO and CV at $100 / 90 / 90^{\circ} \mathrm{C}$

- Measure

- OCV, VI curve, cell resistance

- Stoichiometry

- Anode 3, Cathode 3.6

- $\mathrm{H}_{2} /$ Air

- Hold overnight at $400 \mathrm{~mA} / \mathrm{cm}^{2}$

2.5 Day 4 (at 1.5 atm)

- Run VI curve at $100 / 90 / 90{ }^{\circ} \mathrm{C}$

- Stoichiometry

- Anode 3, Cathode 3.6

- $\mathrm{H}_{2} /$ Air 
- $\mathrm{H}_{2} / \mathrm{O}_{2}$

- $\mathrm{H}_{2} /$ Air

- Heat to $120 / 90 / 90{ }^{\circ} \mathrm{C}$

- Record CO and CV at $120 / 90 / 90^{\circ} \mathrm{C}$

- Measure

- OCV, VI curve, cell resistance

- Stoichiometry

- Anode 3, Cathode 3.6

- $\mathrm{H}_{2} /$ Air

- $\mathrm{H}_{2} / \mathrm{O}_{2}$

- $\mathrm{H}_{2} /$ Air

- Cool to $100 / 90 / 90^{\circ} \mathrm{C}$

- Hold overnight at $400 \mathrm{~mA} / \mathrm{cm}^{2}$

2.6 Day 5, 6, 7 (at 1.5 atm) - Stability Test

- Record CO and CV at $100 / 90 / 90{ }^{\circ} \mathrm{C}$

- Measure

- OCV, VI curve, cell resistance

- Stoichiometry

- Anode 3, Cathode 3.6

- $\mathrm{H}_{2} /$ Air

- $\mathrm{H}_{2} / \mathrm{O}_{2}$

- $\mathrm{H}_{2} /$ Air

- Start stability test

- $\quad 1.5 \mathrm{~atm}$

- $100 / 90 / 90{ }^{\circ} \mathrm{C}$

- $\mathrm{H}_{2} /$ Air

- $400 \mathrm{~mA} / \mathrm{cm}^{2}$

- Stoichiometry

- $\quad$ Anode 3, Cathode 3.6

- Measure during stability test

- Cell voltage

- Fluoride emission rate (FER) in reactant exhausts

\subsection{Day 8 (at 1.5 atm)}

- Record CO and CV at $100 / 90 / 90^{\circ} \mathrm{C}$

- Measure

- OCV, VI curve, cell resistance

- Stoichiometry

- Anode 3, Cathode 3.6

- $\mathrm{H}_{2} /$ Air

- $\mathrm{H}_{2} / \mathrm{O}_{2}$

- $\mathrm{H}_{2} /$ Air 
- Cool down to room temperature

- $\mathrm{H}_{2} / \mathrm{N}_{2}$

2.8 Day 9

- Room temperature CO and CV

- Resistance test

- Anode to ground

- Cathode to ground

- Remove the cell

- Measure mechanical crossover

- $\quad<1 \mathrm{~mA}$ eq. desired

- Measure external leakage

- $\quad<20$ mA eq. desired

- Measure cell resistance

- Anode to ground-Record Ohms

- Cathode to ground - Record Ohms

- Anode to cathode - Record Ohms

- Post-test

- Measure bolt load

- Disassemble cell

- Conduct visual inspection

- Bag and Seal Components

- Data analysis

- Delta cell resistance

- Delta CO

- Delta CV

- Delta activation loss

- Delta Tafel slope

- Delta diffusion

- Delta I lim

- Delta conductivity

- FER 


\section{Appendix A: Gurley Number Test Procedures Document Number WP0012WPQRS}

\section{A1. Reference materials}

A1.1 Min-Kyu Song, "PEMFC Unit Cell Assembly for NT Membrane and E-TEK Electrode", March 13, 2001, Uconn

A1.2 B.Mueller, E.De Castro etc., "CARBON CLOTH GAS DIFFUSION BACKINGS FOR HIGH PERFORMANCE PEFC CATHODES", Electrochemical Society Proceedings Volume 98-27

\section{A2. Introduction \\ For porous and/or fibrous gas filtration media, resistance to flow is often used as a characteristic measure for quality control and performance. Gurley Number basically measures gas permeation rate through the gas diffusion backing samples.}

The Gurley number represents the gas flow rate (in LPM) for a Gas Diffusion Layer sample at a fixed pressure difference (in $\mathrm{cm}$ of $\mathrm{H}_{2} \mathrm{O}$ ) through a fixed area of sample $\left(\mathrm{cm}^{2}\right)$, and thus indicates the resistance to gas flow.

Samples of gas diffusion layers were cut and fitted into a manifold of main gaskets and subgaskets, such that the uncoated side of the backing is oriented towards the nitrogen inlet and that there is no pinch on the Gas Diffusion Layer. The total gasket thickness has considerable influence on the pressure distribution pattern over the active area on both inlet and outlet sides. Therefore, it is very important to employ enough thickness gaskets to get relatively uniform pressure distribution, resulting in more meaningful Gurley numbers.

Prior to evaluation of a backing sample, the system inherent resistance to gas flow is evaluated by measuring pressure drop across the cell over a range of flow rates. This system resistance to flow is used as a correction in the subsequent measurement of backing gas flow characteristics. The configuration of the system is illustrated as in Figure A1. 


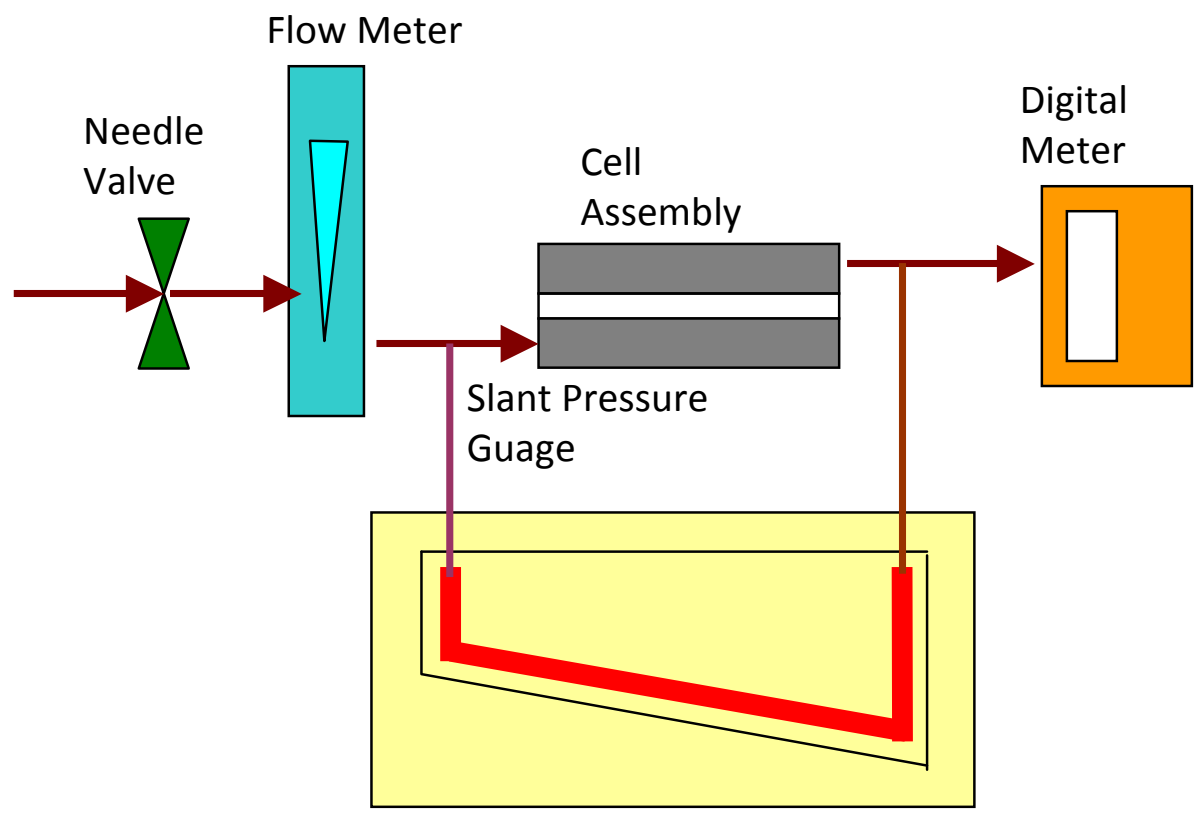

Figure A1. Apparatus for Measuring Gurley Number

\section{A3. Materials and Equipment}

\section{A3.1 Materials}

- Teflon film (0.25 mm (10 mil) thickness)

- Krytox (Dupont performance lubricants, Teflon Grease)

- Gas Diffusion Layers

- Snoop Liquid Leak Detector

- Ethyl Alcohol 200 Proof, Absolute (Dehydrated) USP Grade, Pharmco Products INC

- Deionized Water (From 153 Fuel Cells Laboratory- ERI)

\section{A3.2 Equipment}

- Electronic Digital Micrometer (Mitutoyo)

- CARVER Hydraulic Press (Unit Model \#3912)

- Clicker Dies

- Torque Wrench (0-5.6 N-m, 0 to 50 in-lbs)

- $3 / 8$ inch Nut Driver

- Nut Plate

- Tweezers

- Knife

- Single Cell Parts

- Graphite Flow Channel

- Gold Plated Copper Plates

- Insulator Sleeves

- M6 Bolts / M6 Nuts

- Flat Washers 


\section{A3.3. Quality control (test and criteria)}

- $\quad$ QS 0012 Gas Permeability, Gas Diffusion Layer.

\section{A4. Main Gasket Preparation}

To ensure sealing over the gas diffusion layer edges, the main gasket thickness should be at least $51 \mu \mathrm{m}(2 \mathrm{mil})$ thinner than the gas diffusion layer thickness. In general, the carbon papers and carbon cloths fall in the range between 356 and $457 \mu \mathrm{m}$ (14 and $18 \mathrm{mil}$ ). In this case, a 254 $\mu \mathrm{m}$ (10 mil) thick Teflon main gasket would be appropriate. However, it is important to keep in mind that we should always use a little thinner main gasket than gas diffusion layers.

Using clicker die and hydraulic press, make a normal size gasket, then make it $6.5 \mathrm{~mm}\left(1 / 4^{\prime \prime}\right)$ larger on each side. Using a $25 \mathrm{~cm}^{2}$ cell as an example, a normal gasket would be like in Fig A2a. After made larger, the gasket would look like in Fig A2b.

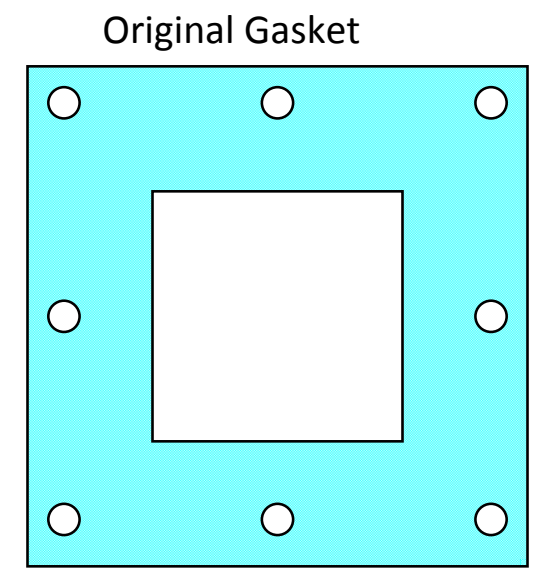

Outside dimension: $9.5 \times 9.5 \mathrm{~cm}^{2}$ Inside dimension: $5.2 \times 5.2 \mathrm{~cm}^{2}$
Enlarged Gasket

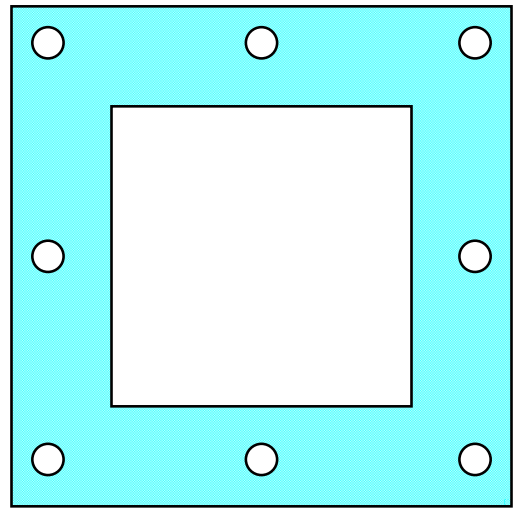

Outside dimension: $9.5 \times 9.5 \mathrm{~cm}^{2}$ Inside dimension: $6.5 \times 6.5 \mathrm{~cm}^{2}$

Figure A2. Preparation of Main Gaskets $\left(5.2 \times 5.2 \mathrm{~cm}^{2}\right.$ cell size)

\section{A5. Preparation of Sub-gaskets}

Sub-gaskets are designed with a $5.8 \mathrm{~cm} \times 5.8 \mathrm{~cm}$ inside dimension and the outside dimension is the same as for normal gaskets. However, it is very important to prepare enough thick gaskets to guarantee that we can have a uniform pressure distribution on the active area, which will lead to a meaningful Gurley Number. The correct total thickness depends on the active area, and on the physical properties of gas diffusion layers.

It is also important to alternate thin and thick gaskets in the final assembly to ensure proper sealing by the gaskets. 
From experience, for $5 \mathrm{~cm}^{2}, 6.25 \mathrm{~cm}^{2}$, and $25 \mathrm{~cm}^{2}$ cells, $3810 \mu \mathrm{m}$ (150 mil) of total gasket thickness is enough to generate a uniform pressure distribution. Suppose the thickness of the main gasket is $254 \mu \mathrm{m}$ (10 mil). We could use seven $254 \mu \mathrm{m}$ (10 mil) gaskets, then one $254 \mu \mathrm{m}$ (10 mil) main gasket. The total gasket thickness would be $1778+1778+254=3810 \mu \mathrm{m}(70+70$ $+10=150 \mathrm{mil})$.

\section{A6. Preparation of Gas Diffusion Layer samples}

Gas Diffusion Layers should be strictly cut according to the size of the main gasket (Figure A2b, $6.5 \times 6.5 \mathrm{~cm}$ ). To ensure proper sealing on the edges of the gas diffusion layer, it is important to make sure that the sample and the main gasket matches nicely.

\section{A7. Cleaning of Fuel Cell Components}

i. Rinse the gold plated copper plate, graphite flow channel block and Teflon gaskets with deionized water by soft brushing.

ii. Wash them with ethanol.

iii. Dry them at room temperature.

\section{A8. Assembly Procedure}

Note. All parts should be oriented as shown in Figure A3.

i. Lubricate the surface of thread of M6 Bolts using Krytox Teflon grease.

Note. Verify nuts turn freely on M6 bolts before placing bolt in the nut plate.

ii. Place M6 bolts head down in the Nut Plate.

iii. Put flat washers on through the Nuts.

iv. Place Insulation Sleeves on through the Nuts.

v. Place Gold Plated Copper Alloy Plate on.

vi. Put Bipolar Plate on.

vii. Put $1778 \mu \mathrm{m}$ (70 mil) Teflon sub-gasket on (7 layers, $254 \mu \mathrm{m}$ or 10 mil for each).

Note. Align notches in each gasket.

viii. Put the main gasket ( $254 \mu \mathrm{m}$ or 10 mil thick) on and align subgaskets and main gasket.

ix. Put the gas diffusion layer on the main gasket. Make sure they fit nicely and the coated side faces up. each).

x. Put another $254 \mu \mathrm{m}$ (70 mil) Teflon ${ }^{\circledR}$ sub-gasket on top (7 layers, $254 \mu \mathrm{m}$ or $10 \mathrm{mil}$ for

Note. Align notches with first seven gasket layers (step 7).

xi. Put the other bipolar plate on.

xii. Put the other gold plated copper-alloy plate on.

xiii. Put insulation sleeves in.

xiv. Put flat washers on.

$x v$. Place Nuts on. Tighten nuts using a Torque Wrench and Nut Driver in the sequence 1 to 8 as shown in Figure A4. Apply $2.8 \mathrm{~N}-\mathrm{m}$ ( $25 \mathrm{in}-\mathrm{lb}$ ) torque for each bolt.

Note. Nuts must turn freely by hand before applying torque. 
Note. Be sure to put the cell onto the nut plate to tighten nuts. After that, it can be hard to take the cell off. In this case, put a screwdriver between the cell and the nuts plate and gently move the screwdriver upward (on both sides), the cell will be easily taken out of the nut plate. Also, use nut plate to loosen the nuts.

xvi. Connect gas tubes as in Figure A3.

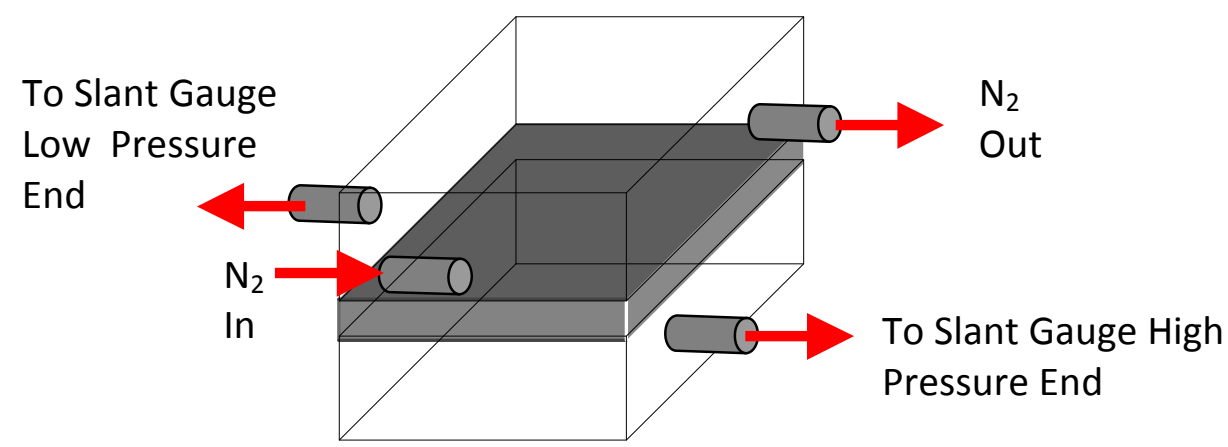

Figure A3. Cell Connections in Gurley Test 


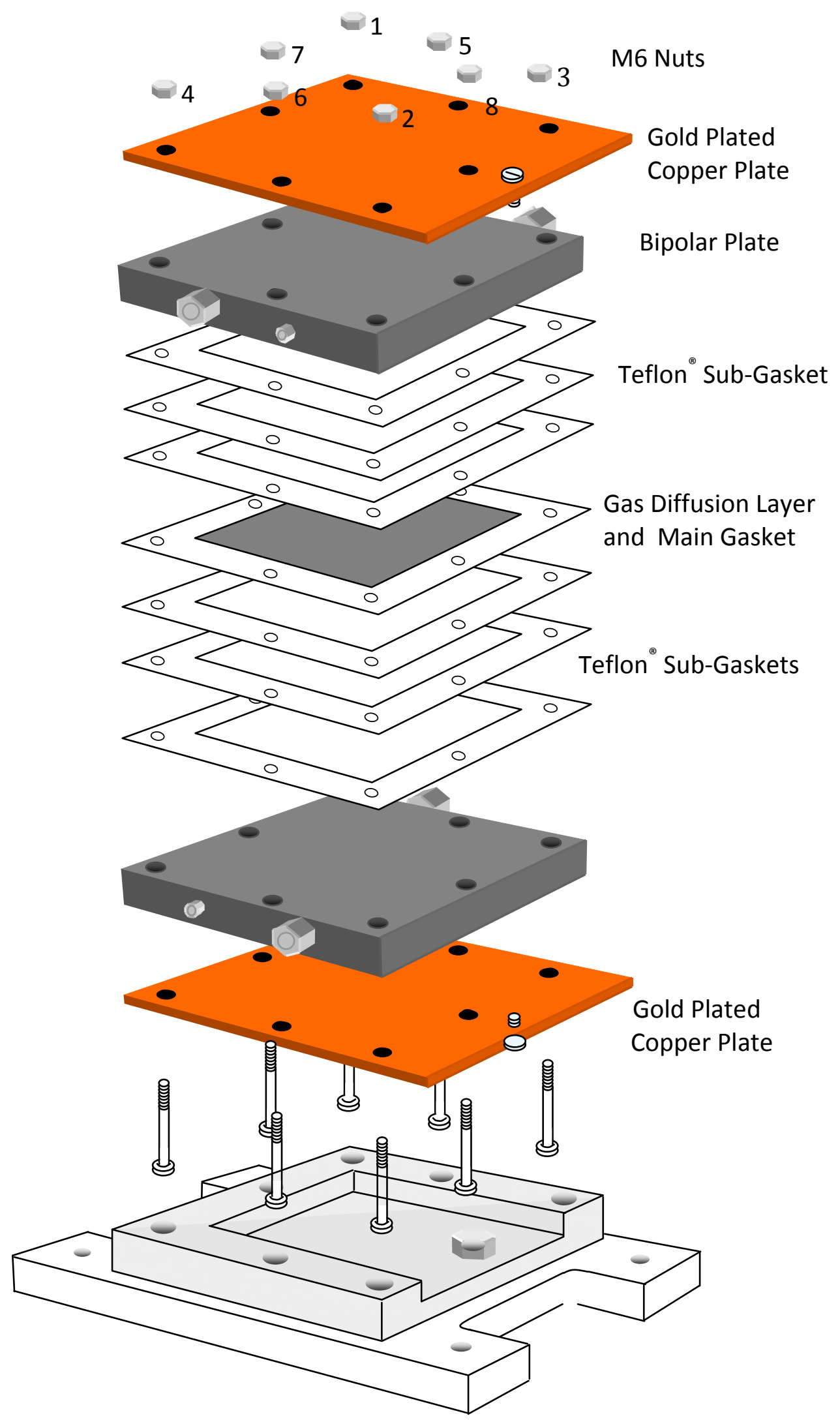

Figure A4. Cell Assembly Explosion View in Gurley Test 


\section{A9. Leaking Check Procedure}

Every connection shown in Figure A3 should be leak tested before taking measurements. For the cell itself, the gasket side should be tested to make sure there is no leak in between the gaskets. The leak test procedure is as follows:

i. $\quad$ Verify that the pressure drop meter is in horizontal position (that should be checked using a level), and the slant liquid level is at 0 position with no pressure applied.

Note. Verify needle valve is closed.

ii. Open $\mathrm{N}_{2}$ gas, keep pressure $\sim 0.68$ atm (10 psi).

iii. Adjust pressure drop at 0.05 inch $\mathrm{H}_{2} \mathrm{O}$. Open valve slowly, make sure that pressure drop can be held at 0.05 inch slant liquid exactly.

iv. Hold Snoop tube end at connection and squeeze upright bottle to apply solid stream of Snoop liquid leak detector. Bubbles form if connection leaks. Bubble size indicates approximate leak size.

Note. For different size gaskets and different gas diffusion layers, pressure drop across the cell may vary tremendously when measuring Gurley Number. Since pressures drop and flow rate have a nearly linear relationship, in general, pressure drop can be used as a control factor to take flow rate measurements.

v. Fill reservoir with Snoop Leak detector Solution if it is not enough.

vi. Turn On Digital Flowmeter, press ball gently, and make sure that one single bubble is generated at one time.

vii. Repeat until the flow rate is relatively constant $( \pm 0.03 \mathrm{~L} / \mathrm{min}$.), and the surface of flowmeter is wet enough. Record the flow rate result on the form (below).

viii. Adjust pressure drop at $0.1,0.15$ and 0.2 inch $\mathrm{H}_{2} \mathrm{O}$, repeat steps (1-2).

\section{A10. Data process}

i. Calculate Gurley Number with the average of flow rate with equation 1.

$$
\text { GurleyNumber }=\frac{\text { FlowRate }(\text { LPM })}{\text { Pr essureDrop } * 2.54 * \text { ActiveArea }}
$$

Active Area is the area of subgasket opening area, for $25 \mathrm{~cm}^{2}$ cell is $5.8 \times 5.8 \mathrm{~cm}^{2}$.

ii. Calculate Average Gurley Number (GN), if the Percent Relative Standard Deviation (\% RSD) of Gurley Number $>10 \%$, at all pressure drop, need REDO it.

$$
\text { RSD }=\frac{\sqrt{\frac{\sum\left(x-x_{i}\right)^{2}}{n-1}}}{x} \cdot 100 \%
$$

where $x$ - GN average, $x_{I}-$ measured GN at adjust pressure drop at $0.05,0.1,0.15$ and 0.2 inch $\mathrm{H}_{2} \mathrm{O}$. 
A10.1 Data sheet Gurley number calculations:

Sample number: GDL-

Date:

\begin{tabular}{|c|c|c|c|c|c|}
\hline & \multicolumn{2}{|r|}{ Pressure } & \multicolumn{2}{|l|}{ Drop } & \\
\hline LPM & 0.05 & 0.1 & 0.15 & 0.2 & \\
\hline \multicolumn{5}{|l|}{ LPM-1 } & \\
\hline \multicolumn{5}{|l|}{ LPM-2 } & \\
\hline \multicolumn{5}{|l|}{ LPM-3 } & \\
\hline \multicolumn{5}{|l|}{ LPM-4 } & \\
\hline \multicolumn{6}{|l|}{ LPM-5 } \\
\hline Avr. LPM & & & & & GN Average \\
\hline \multicolumn{6}{|c|}{$\begin{array}{l}\text { Gurley Number } \\
\text { (GN) }\end{array}$} \\
\hline RSD & & $\%$ & & & \\
\hline RSD Accept & & $<10 \%$ & & & \\
\hline RSD Reject & & $>10 \%$ & & & \\
\hline GDL Accept & & $0.10 \div 0.18$ & & & \\
\hline GDL Reject & & $\begin{array}{c}<0.10 \text { or } \\
>0.18\end{array}$ & & & \\
\hline
\end{tabular}

\section{A11. Acceptance}

Inspect in accordance with QS 0012 Gas Permeability, Gas Diffusion Layer. 


\section{Appendix B: PEM Fuel Cell Unit Cell Assembly Procedure $-25 \mathrm{~cm}^{2}-$}

\section{Document Number WPxyz}

\section{B1 Reference materials}

J. C. Lin, "Preparation and Characterization of Composite Proton Exchange Membranes for Fuel Cell Application", Ph.D. Thesis, UConn (2000).

\section{B2 Bill of Materials}

\section{B2.1 Materials}

i. A catalyst coated membrane (CCM) consisting of

- A piece of membrane (either FSEC1, FSEC3, NRE ${ }^{\circledR} 211, \mathrm{NRE}^{\circledR} 212, \mathrm{Nafion}^{\circledR} 112$, etc.)

- A cathode catalyst layer on one side $\left(\sim 0.4 \mathrm{mg} / \mathrm{cm}^{2}\right)$, active area of $25 \mathrm{~cm}^{2}$.

- An anode catalyst sprayed onto the other side $\left(\sim 0.4 \mathrm{mg} / \mathrm{cm}^{2}\right)$, active area of $25 \mathrm{~cm}^{2}$.

ii. One piece of gas diffusion layer, $5.8 \times 5.8 \mathrm{~cm}^{2}$, with Gurley number of at least 0.024 $\mathrm{L} / \mathrm{min} / \mathrm{cm}-\mathrm{H}_{2} \mathrm{O} / \mathrm{cm}^{2}$ for CATHODE GDL

iii. One piece of gas diffusion layer, $5.8 \times 5.8 \mathrm{~cm}^{2}$, with Gurley number of at least 0.01 $\mathrm{L} / \mathrm{min} / \mathrm{cm}-\mathrm{H}_{2} \mathrm{O} / \mathrm{cm}^{2}$ for ANODE GDL

iv. Teflon ${ }^{\oplus}$ film (25.4 $\mu \mathrm{m}$ (1 mil) thickness)

v. Krytox (Dupont performance lubricants, Teflon Grease)

vi. Deionized Water and ethanol for washing

\section{B2.2 Equipment}

i. A single-cell hardware set

A "Fuel Cell Technology" (FCT) hardware set consists of:

- Two uniquely machined graphite flow fields (with FSEC low delta P serpentine grooves)

- Two aluminum end plates $-1.27 \mathrm{~cm}\left(1 / 2{ }^{\prime \prime}\right)$ thickness

- Two gold-plated current collectors $-0.32 \mathrm{~cm}\left(1 / 8^{\prime \prime}\right)$ thickness

- Four plastic rubber tubes $-0.95 \mathrm{~cm}\left(3 / 8^{\prime \prime}\right)$ long, $0.2 \mathrm{~mm}$ in diameter (called "line-up pins")

- Four black rubber o-rings (to seal all the line-up pins)

- Eight Stainless screws

- Eight black rubber insulating socks (one for each screw)

ii. Digital Balance (METTLER AE240, S/N G56273)

iii. Electronic Digital Micrometer (Mitutoyo)

iv. Torque Wrench (0 to $5.6 \mathrm{~N}$-m or 0 to 50 in-lbs) 


\section{B3 Objectives:}

To describe how to assemble a PEM fuel cell unit cell (called Membrane Electrode Assembly, MEA) using a Nafion '-based membrane and SGL 10 BB GDL's.

\section{B4 General Instructions}

- Lubricate the bolts every two cells to make certain the right amount of torque is applied to the cell (not the friction force)

- Alignment of all components vertically is VERY CRITICAL. Take care to ensure good alignment (even if it means STARTING OVER, if you feel unsure). Misalignment will cause the cell to fail and waste all the effort of the CCM preparation.

\section{B5 Preparation for Cell Assembly}

i. Check that the hardware set contains all the parts. Separate the "cathode" parts and "anode" parts as labeled.

ii. Clean the surface of the two graphite flow fields with ethanol. Take care not to leave excess ethanol in flow fields prior to assembly.

iii. Measure the thickness of the CCM by placing it between two 1-mil Teflon ${ }^{\circledR}$ films (for surface protection) and measure the overall thickness with a Mitutoyo caliper. Then subtract off the Teflon film thickness. Measure AT LEAST 9 VALUES and obtain an average value.

iv. Repeat Step iii for cathode GDL and anode GDL.

v. Set the desired amount of "pinch" - in this case, 229-254 $\mu \mathrm{m}$ (9-10 mils)

vi. Calculate the total thickness of needed Teflon gaskets by:

Total thickness of the gaskets $=\left(T_{\mathrm{ccm}}+T_{G D L, C,}+T_{G D L, A}\right)-$ Pinch

Total thickness of each side (Cathode and Anode) $=$ Total thickness of the gaskets $/ 2$

Note 1. If the total thickness of the gaskets is an ODD number, make total cathode gasket thickness LESS than total anode gasket thickness.

Note 2. Usually $\left(T_{\mathrm{ccm}}+\mathrm{T}_{\mathrm{GDL}, \mathrm{C},}+\mathrm{T}_{\mathrm{GDL}, \mathrm{A}}\right)$ is in the order of $762-889 \mu \mathrm{m}(30-35$ mils)

vii. Prepare different combinations of Teflon gaskets (available as 25, 51, 76, 127, and $254 \mu \mathrm{m}$ or 1, 2, 3, 5 and 10-mil) for the cathode and anode sides.

Note. Cut each gasket using an appropriately designed "die" specific to each hardware design.

viii. Cut both GDLs to the size that will fit PERFECTLY (within $0.3 \mathrm{~mm}$ ) inside the middle opening of the prepared gaskets. The opening is slightly bigger $(1-2 \mathrm{~mm})$ than the cell active area).

\section{B6 Assembling the Cell - Fuel Cell Technology (FCT) hardware set} Refer to Figure B1.

i. $\quad$ Place four bolts through the cathode end plate for alignment of cell parts.

ii. Place the cathode end plate with bolts at the bottom on a sturdy surface.

iii. Place the cathode gold-plated current collector plate on top of the cathode end plate.

iv. $\quad$ Place the two line-up tubes and two o-rings into line-up holes of the cathode end plate to align the end plate with the cathode gold-plated current collector. 
v. Place the cathode graphite flow field on top of the cathode gold-plated current collector (with the grooved side up).

vi. Place the set of cathode gaskets on top. Make SURE it aligns well with all the bolt holes. Use a $1 \mathrm{~cm}$ long piece of scotch tape to attach the gaskets to the flow field plate to ensure alignment in the cell, IF NECESSARY.

vii. Place the cathode GDL in the middle of the set of gaskets (micro-porous layer side UP).

viii. Place the CCM on top (ANODE side UP); align the catalyst active area in the middle of the gasket middle opening.

ix. Place the set of anode gaskets on top. Make SURE it aligns well with all the bolt/nut holes.

x. Place the anode GDL on top, align it with the anode GDL (micro-porous layer side DOWN).

xi. $\quad$ Place the anode flow field plate on top (groove side DOWN).

xii. Place the anode gold-plated current collector plate on top.

xiii. Place the anode end plate on top (with the two plastic line-up tubes and o-rings in place.

xiv. Tighten all the bolts in a cross-wise or star pattern. In six cycles:

A. Tighten loosely by hand (avoid over tightening and applying too much torque)

B. Tighten with a torque-wrench, set to $1.1 \mathrm{~N}-\mathrm{m}$ (10 in-lbs), by feeling the click

C. Tighten with a torque-wrench, set to $2.3 \mathrm{~N}-\mathrm{m}$ (20 in-lbs), by feeling the click

D. Tighten with a torque-wrench, set to $3.4 \mathrm{~N}-\mathrm{m}$ (30 in-lbs), by feeling the click

E. Tighten with a torque-wrench, set to $4.5 \mathrm{~N}-\mathrm{m}$ (40 in-lbs), by feeling the click

F. Recheck all bolts with the torque-wrench set at $4.5 \mathrm{~N}-\mathrm{m}$ (40 in-lbs), by feeling the click

xv. The assembled cell is now ready for a single-cell performance test.

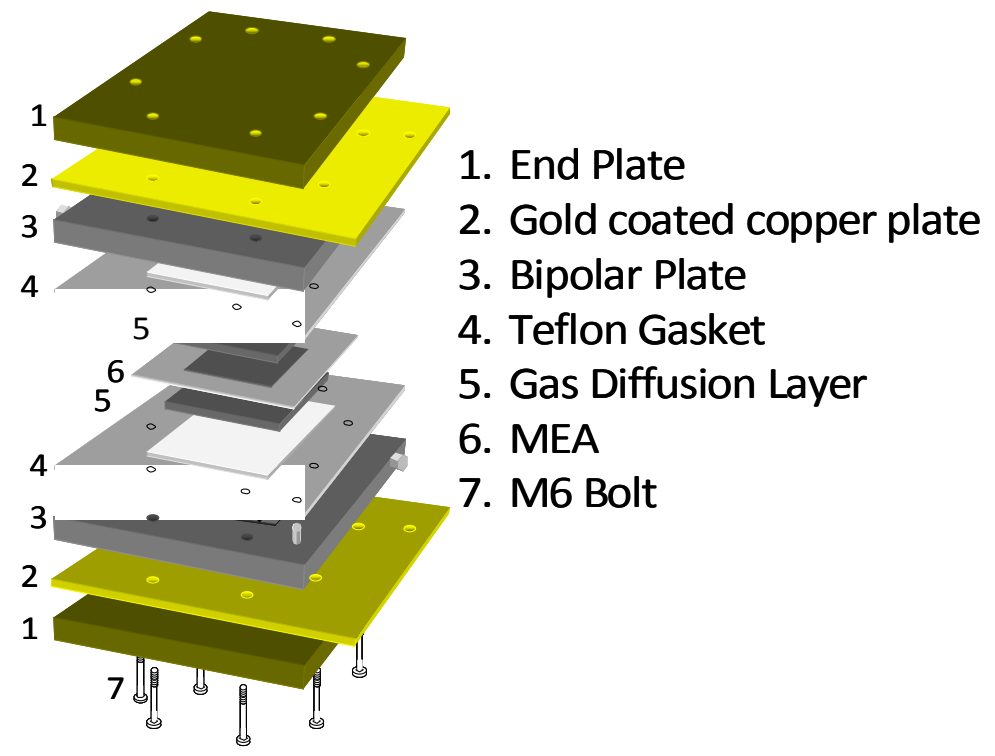

Figure B1. Expanded view of assembled fuel cell 


\section{Appendix C: Procedure for Leak Testing a Single Cell after Assembly Document No. WP0023 and WP0024}

\section{C1 External Leak Test}

\section{C1.1 Procedure}

i. $\quad$ Setup per Figure C1

ii. Connect $\mathrm{N}_{2}$ to hydrogen side with a flow meter followed by an isolation valve.

iii. Connect gas out line to hydrogen side, with an inlet to the air $/ \mathrm{O}_{2}$ side

iv. Connect gas out line to air/ $\mathrm{O}_{2}$ side with a 0 to $0.39 \mathrm{~atm}(0$ to $300 \mathrm{mmHg}$ ) pressure gauge followed by an isolation valve.

v. Pressurize the hydrogen and air/oxygen sides to $0.03,0.07,0.14,0.2 \operatorname{atm}(0.5,1,2$, 3 psi) with nitrogen, respectively.

vi. Record data of the flow meter.

vii. Leak check with DI water, write down where the bubbles come from. Can use "Snoop" on plumbing connection, not on cell.

viii. If no leak can be observed and flow meter remains at zero, close the valve, record pressure drop in 5 min.

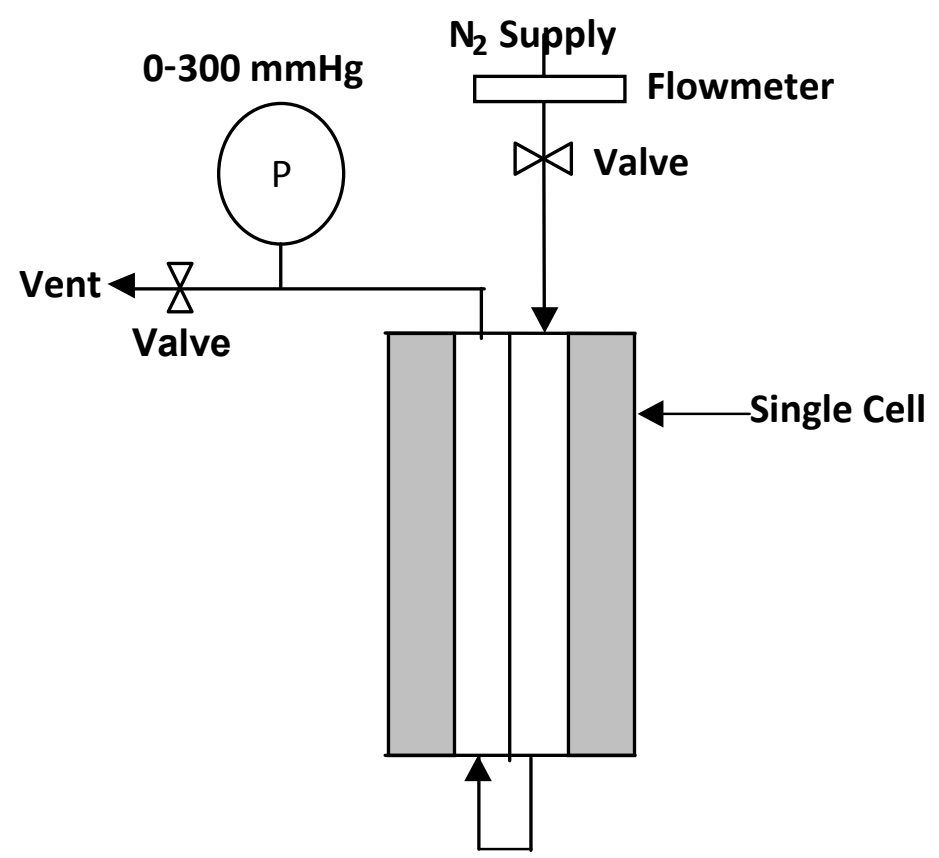

Figure 1. Setup for External Leak Test 


\section{C2 Internal Leak Test}

\section{C2.1 Procedure for Internal Leak}

i. Verify that external cell leakage satisfies the requirements

ii. Set up Figure C2

iii. Connect $\mathrm{N}_{2}$ inlet to the hydrogen side, with a flow meter followed by an isolation valve

iv. Connect gas outlet to the hydrogen side with a 0-0.39 atm $(0-300 \mathrm{mmHg})$ pressure gauge followed by an isolation valve

v. Connect bubble meter to air side

vi. Close the hydrogen vent and pressurize the hydrogen side to $0.03,0.07,0.14,0.2$ atm $\left(0.5,1,2,3\right.$ psig) with $\mathrm{N}_{2}$, respectively

vii. Check the flow rate at the air/oxygen vent with the bubble flowmeter and flow meter, record data on data sheet

viii. If no leak can be found and flow meter remains at zero, close the valve and record pressure drop in 5 min.

\section{C2.2 Procedure for Internal Leak}

i. $\quad$ Set up Figure C2

ii. Connect $\mathrm{N}_{2}$ inlet to the air/oxygen side, with a flow meter followed by an isolation valve

iii. Connect gas outlet to air/oxygen side, with a 0-0.39 atm (0-300 $\mathrm{mmHg}$ ) pressure gauge followed by an isolation valve, other outlet should be closed

iv. Connect bubble meter to hydrogen side

v. Close the air/oxygen vent and pressurize the hydrogen side to $0.03,0.07,0.14,0.2$ atm $\left(0.5,1,2,3\right.$ psig) with $\mathrm{N}_{2}$, respectively

vi. Check the flow rate at the hydrogen vent with the bubble flowmeter and flow meter, record data on data sheet

vii. If no leak can be found and flow meter remains at zero, close the valve and record pressure drop in $5 \mathrm{~min}$. 


\section{Single Cell Assembly}

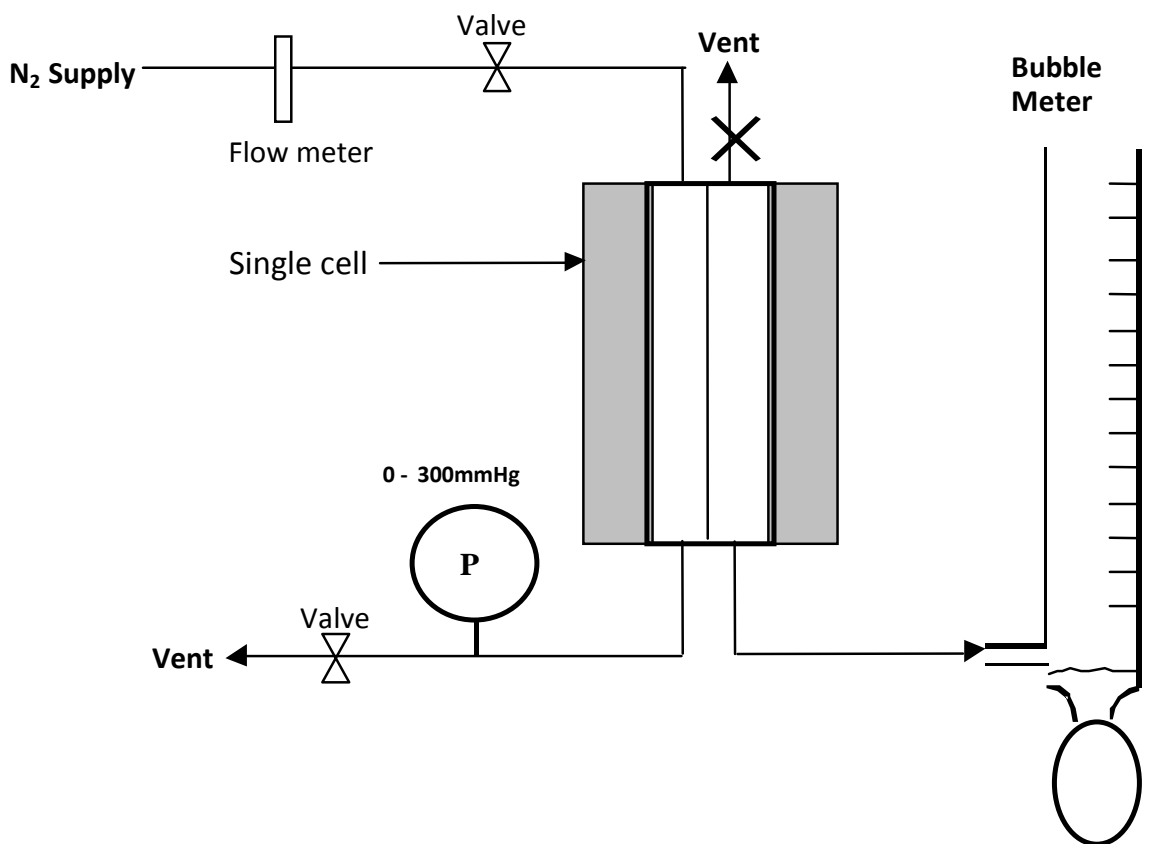

Figure C2: Setup for Internal Leak Test 


\title{
Appendix D: PEMFC Unit Cell Test
}

\section{D1. Reference materials}

i. "Fuel Cell Test System Configuration", Scribner Associates, Inc.

ii. "FuelCell for Windows: Fuel Cell Test Software", Scribner Associate, Inc.

iii. Operating Manual of Fuel Cell for Windows, Fuel cell Test Software, Scribner Associates model 890 load systems, Version 2.0

iv. Scribner Associates Inc. 850C Fuel Cell Test System Operating Manual

v. Configuration and Application Manual of Fuel cell Test System Configuration

vi. Operating Manual of CorrWare for Windows, Electrochemistry/Corrosion Software, Scribner Associates Inc., Version 2.2

vii. The Princeton Applied Research Potentiostat/Galvanostat Model 263A Operating Manual

\section{D2. Bill of Materials \\ D2.1 Materials}

D2.1.1 Gases

i. Nitrogen

ii. Oxygen

iii. Air

iv. Hydrogen

D2.1.2 Deionized water
Ultra high purity (99.999\%), Airgas N.E.

Zero Grade (99.8\%), Airgas N.E.

Zero Grade (90\%), Compressed, Airgas N.E.

Ultra high purity (99.999\%), Airgas N.E.

Facility DI water

\section{D2.2 Equipment}

\author{
i. Fuel Cell Test Station \\ ii. Fuel Cell Test Load Box \\ iii. Scribner Series 890B or 850C Electronic Load and Data Acquisition System \\ iv. Scribner Model 871 Reformate Simulator (optional - not active) \\ v. IBM PC with National Instruments GPIP-PCI Interface and GPIB Cable \\ vi. Cell Cable Sets \\ vii. Potentiostat/ Galvanostat Model 263, Princeton Applied Research \\ viii. Insulation jacket (Cloth) \\ ix. A plastic jack \\ x. Wrench $(13 \mathrm{~mm})$ \\ xi. Multimeter, OMEGA ${ }^{\circledR}$, HHM-25 KIT, OMEGA ENGINEERING INC. STAMFORD CT, \\ U.S.A. \\ xii. Plastic bottle for deionized water
}

\section{D3 Objectives}

To describe the performance test procedure of a PEM fuel cell. 
The overall objective of this test sequence is to determine the performance characteristics of a single, bench-scale, proton exchange membrane fuel cell over a range of temperatures from 80 ${ }^{\circ} \mathrm{C}$ to $120{ }^{\circ} \mathrm{C}$. The cell active area is $25 \mathrm{~cm}^{2}$.

\section{D4 General Instructions}

Before the cell is mounted in the test stand, a review should be performed of the procedures described below and a check made of the availability of all of the materials and facilities to perform the test program.

\section{D4.1 Fuel Cell System Configuration}

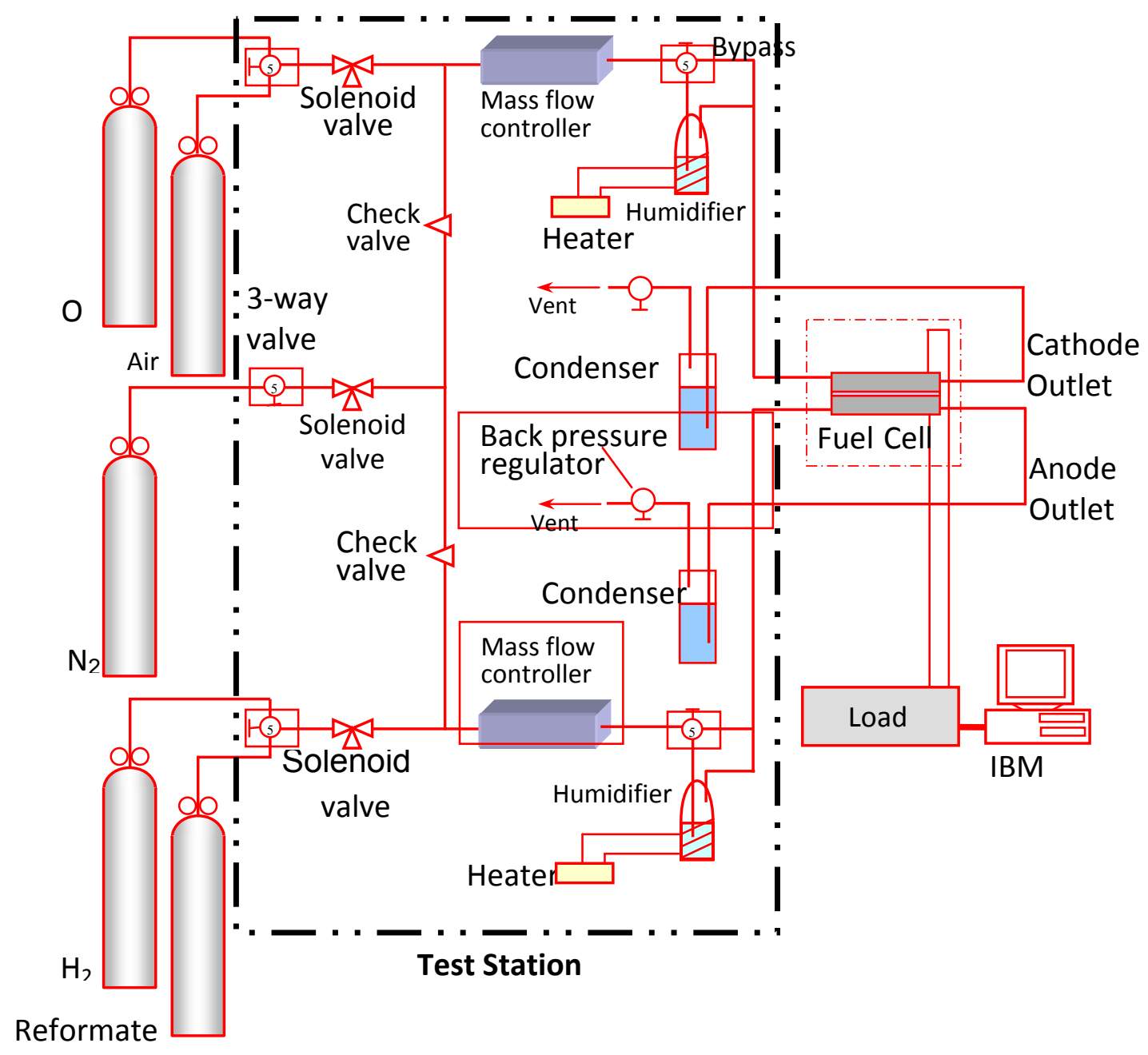

\section{D4.2 Explanation of the test station}

- Gases flow through mass flow controller and humidifier to the fuel cell.

- Gas flow rate is controlled by MKS 1179A mass flow controllers

- Gas temperature and humidity are adjusted by sparging the gases through stainless steel humidifier tanks. 
- The humidified gases are introduced to the fuel cell hard ware.

- The gases diffuse to the electrodes through gas diffusion layer while they are circulating along the gas channel.

- The exhausted gases pass through the back-pressure regulator and then to the vent.

\section{D4.3 Hardware Specifications}

$\begin{array}{ll}\text { D4.3.1 Electronic Load System: } & \\ \text { Load Current Range } & 10,25,100 \mathrm{~A} \text {, full scale } \\ \text { Load Voltage } & 20 \mathrm{~V} \mathrm{max.} \\ \text { Load Power Range } & 100 \mathrm{~W} \\ \text { Min Load Resistance } & 0.5 \text { to } 1 \mathrm{~m} \Omega \\ \text { IR Measurement } & \text { Current Interrupt method } \\ \text { Current Measurement } & \text { Hall Effect Device } \\ \text { Load Cooling } & \text { Forced air, one or three fans }\end{array}$

D4.3.2 Power Requirements and Physical

$\begin{array}{ll}\text { Main Power } & 90-125 \mathrm{VAC}, 50-60 \mathrm{~Hz}, 4 \mathrm{~A} \\ \text { Load and Data Unit } & 17^{\prime \prime} \mathrm{W} \times 10^{\prime \prime} \mathrm{H} \times 21^{\prime \prime} \mathrm{D}(43 \times 25 \times 53 \mathrm{~mm}) \\ \text { Weight } & 35-50 \mathrm{lbs}(16-23 \mathrm{~kg}) \\ \text { System Interface Box } & 8^{\prime \prime} \mathrm{W} \times 3^{\prime \prime} \mathrm{H} \times 10^{\prime \prime} \mathrm{D}\end{array}$

\section{D4.4 Data File Name Convention}

The data file naming convention is "BxxxDyyRzzAA", where

- "B" stands for "BUILD"

- " $x x x^{\prime \prime}$ represents the cell number that is assigned by the database upon entry of the cell assembly record information

- "D" stands for "DAY"

- "yy" represents the number of days that the cell has been "tested"

- (Do not count days elapsed, only the days that the cell has been operated: the first day that you operate the cell $Y Y=1$, if you operate the cell the next day, or any number of days later, then $\mathrm{YY}=2$, the third day the cell is operated, $\mathrm{YY}=3$, and so on.)

- "R" stands for "RUN"

- " $z Z$ " represents the number of the run during day

- "AA" represent the "type of data collected" - Use proper nomenclature as follows:

- CO stands for "cross over" (to estimate hydrogen crossover)

- CV stands for "cyclic voltammetry" (to estimate ECA - electrochemical surface area)

- VI stands for "voltage-current" (performance or polarization curve)

- CC stands for "constant current" (constant current operation)

\section{D4.6 Nomenclature of the test condition (temperatures) is " $B / C / D$ ":}

- "B" refers to $\mathrm{T}_{\text {cell }}$ in ${ }^{\circ} \mathrm{C}$

- " $" \mathrm{C}$ " refers to anode humidifier controller temperatures (both top and bottom) in ${ }^{\circ} \mathrm{C}$

- " $\mathrm{D}$ " refers to cathode humidifier controller temperatures (both top and bottom) in ${ }^{\circ} \mathrm{C}$ 
- When user controls gas lines, they are always $10{ }^{\circ} \mathrm{C}$ higher than $\mathrm{T}_{\text {cell. }}$.

\section{D4.7 Handling of gas tanks}

- At the beginning of EACH day, verify that all gas $\left(\mathrm{N}_{2}, \mathrm{H}_{2}\right.$, Air, and $\left.\mathrm{O}_{2}\right)$ cylinders have enough pressure (Above $13 \mathrm{~atm}$ or $200 \mathrm{psi}$ ).

- At the beginning of Day 1, OPEN gas tanks for $\mathrm{N}_{2}, \mathrm{H}_{2}$, and Air (all gases used that day). Set each gas regulator at $3.4 \mathrm{~atm}$ (50 psi).

\section{D5 Day 1 Test}

\section{D5.1 Setup Cell Hardware on the Test Station}

\section{Time required for this step: 30 minutes}

i. Use a multimeter to measure the resistance between two graphite plates (anode and cathode). Wait until the value is stabilized and record the exact value.

Note. This step is to see that the resistance value is high enough ( $50 \mathrm{ohm}$ ) that there is no indication of short. If the resistance is lower than $10 \mathrm{ohm}$, rebuild the cell.

ii. Connect four gas tubes to the fuel cell hardware

Note 1. Make sure that anode and cathode plates correspond to those of the MEA inside.

Note 2. Make sure there is no leak on the INLET GAS LINES. Check with soapy water.

\section{D5.2 Preparation of cell test on the test station}

\section{Time required for this step: $\sim 5$ minutes}

i. Insert the outside thermocouple into the end of a little hole on the graphite plate of the cell hardware for measuring the cell's temperature.

Caution: Make sure that the thermocouple stays at the end of the hole and use the scotch tape to keep it in place, if needed. If the thermocouple is not in place, the cell will be OVERHEATED to maintain a set point temperature (a cell failure).

ii. Switch both the cathode and anode gas valves on the test station to $\underline{N}_{2}$ gas.

\section{D5.3 Operation of computer to start up cell} Time required for this step: $\sim 5$ minutes

i. Turn on Computer 1 AND Fuel Cell Load Unit 1.

ii. Select the icon for FuelCell software on MS Windows and open it.

iii. A menu box titled "SETUP CELL" (See Figure D1) will pop up. Set cell surface area as APPROPRIATE for the MEA tested (usually $25 \mathrm{~cm}^{2}$ ). Set cell temperature at $25^{\circ} \mathrm{C}$

Note. If the Beep box is checked, FuelCell software program will produce a beep from the computer speaker when the Min or Max limits are exceeded. 


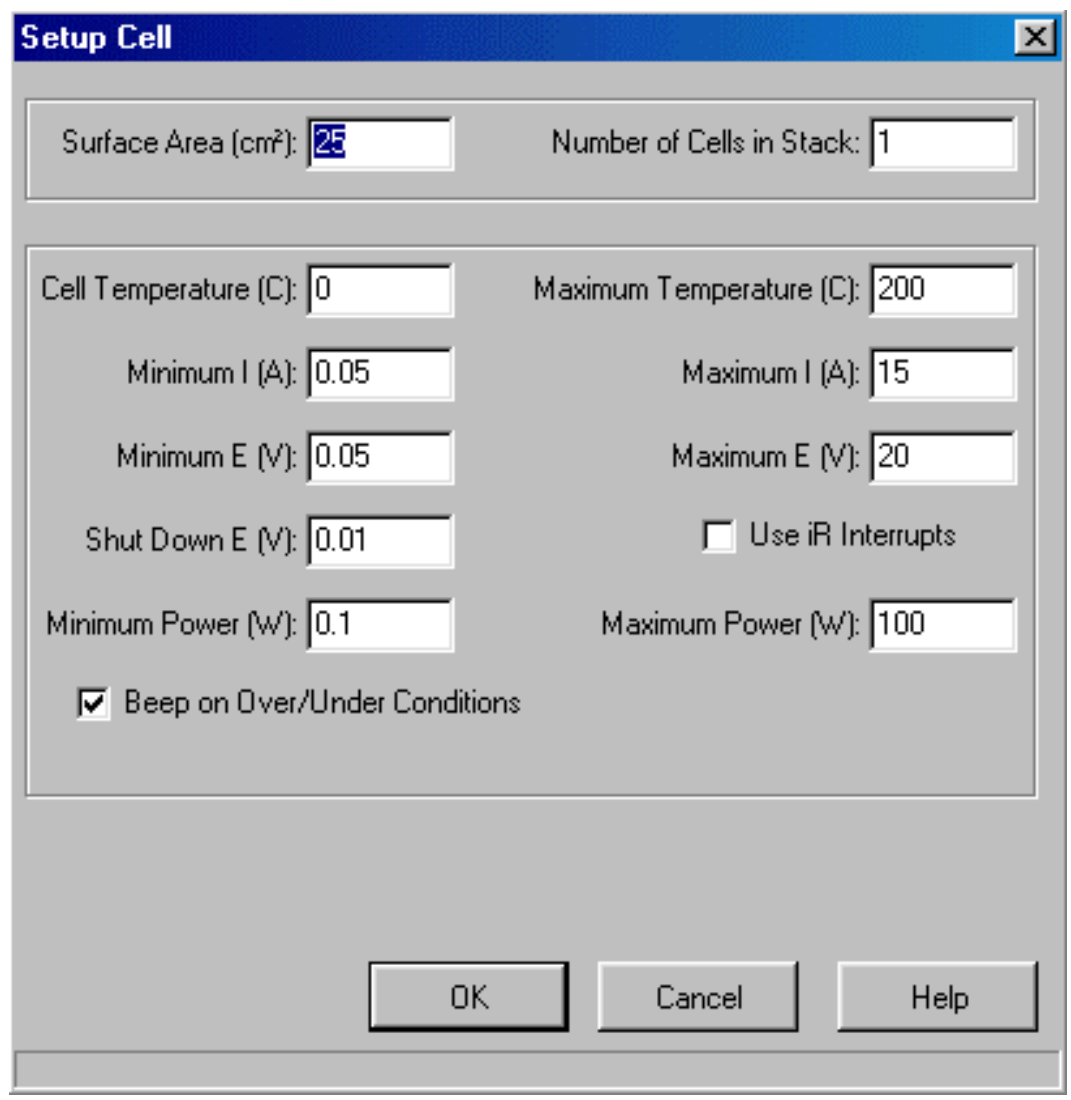

Figure D1. Set up Cell Menu

iv. Another menu box titled "Setup Fuel Flow" (See Figure D2) will pop up.

Set the flow rates at:

- Anode

- Minimum Flow: $\underline{0.4 \mathrm{~L} / \mathrm{min}}$

- Load based flow: $\underline{0 \mathrm{~L} / \mathrm{min} / \mathrm{cell}}+0.023 \mathrm{~L} / \mathrm{min} / \mathrm{Amp} / \mathrm{cell}$ (not used in this case)

- Temperature: $25^{\circ} \mathrm{C}$

- Cathode:

- Minimum Flow: $0.4 \mathrm{~L} / \mathrm{min}$

- Load based flow: $0 \mathrm{~L} / \mathrm{min} /$ cell $+0.066 \mathrm{~L} / \mathrm{min} / \mathrm{Amp} /$ cell (not used in this case)

Temperature: $25^{\circ} \mathrm{C}$ 


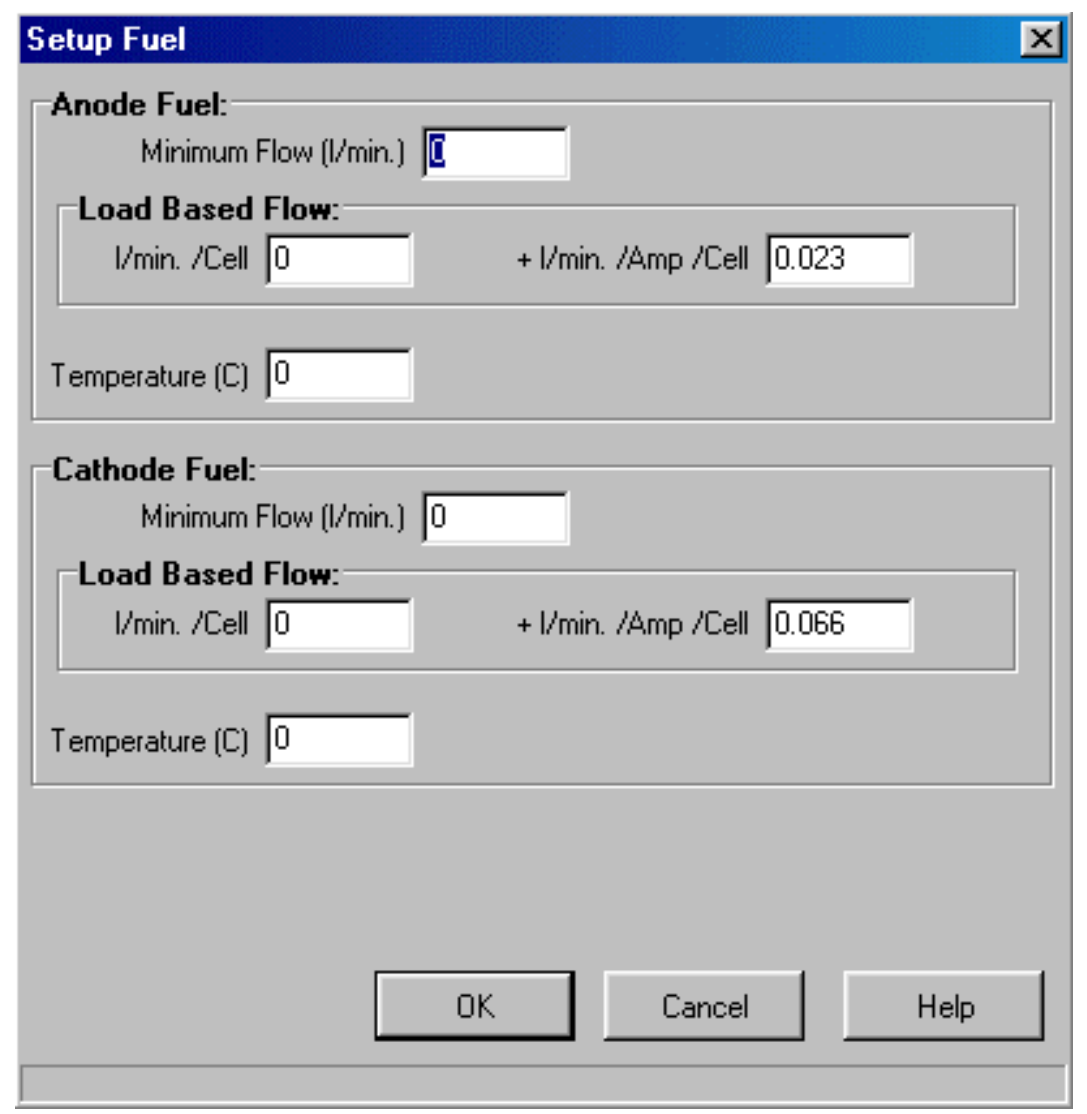

- $\quad$ Figure D2. Setup Fuel Menu

\section{D5.4 Crossover and Cyclic Voltammetry Tests}

\section{Time required for this step: $\sim \mathbf{4 0}$ mins}

Note. This is a series of tests to determine the basic soundness of the cell to see if it meets minimum requirements.

i. On the side of the test station, switch ANODE gas valve to $\mathrm{H}_{2}$ and CATHODE gas valve to $\mathrm{N}_{2}$.

ii. Connect WORKING and SENSE electrodes to the CATHODE and the COUNTER and REFERENCE electrodes to the ANODE. (See Figure D3)

iii. Turn on the Princeton Applied Research 263A (Connected to Computer 3).

iv. Turn on Computer 3 , which is used for measuring short-circuit, crossover current and cyclic voltammetry.

v. Select the icon for CorrWare2 software on the main screen, and double click it to activate the program.

vi. Right click at "Potentiodynamic" and select "Set up cell" option

vii. Set "cell surface area" to $25 \mathrm{~cm}^{2}$ and then click "OK" (see Figure D4)

viii. Right click at "Potentiodynamic" and select "Set up instrument" option. Set "bandwidth" to high stability 
ix. Double click "Potentiodynamic" to wait until the OCP becomes lower than $0.1 \mathrm{~V}$. Name file according to the lonomem Database files (See Section D4.4) and select where it will be saved. Select $4 \mathrm{mV} / \mathrm{s}$ as the scan rate.

Note. This open circuit voltage value would be shown at the upper-right corner of the menu panel

x. Select "Potentiodynamic" from experiment types and click the button for "Measure Selected" in toolbar and begin this measurement

Note. This green label is shown in the toolbar of the menu panel.

xi. Right click at "Cyclic Voltammogram" and select "Set up instrument" option. Set "bandwidth" to high speed.

xii. Double click "Cyclic Voltammogram" and name file according to the lonomem Database files (See Section D4.4) and select where it will be saved. Select $30 \mathrm{mV} / \mathrm{s}$ as the scan rate.

xiii. Select "Cyclic Voltammogram" from experiment types.

xiv. Click at the button for "Measure Selected" in toolbar and begin this measurement;

$x v$. Turn off the PAR263A when finished.

xvi. Disconnect the electrodes (working, counter, sense, and reference) from the cell hardware plates 


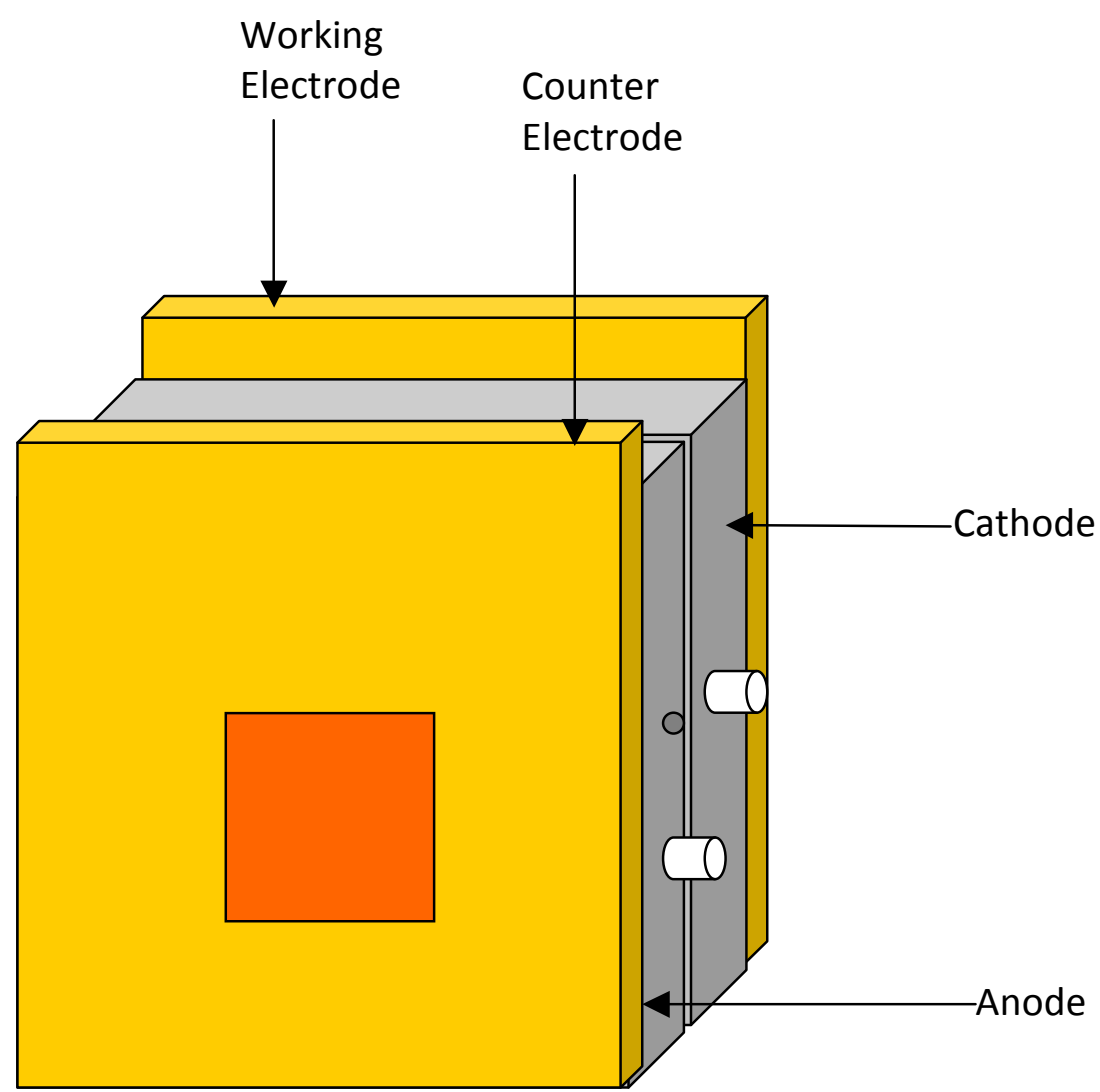

Figure D3. Connection of Electrode with Fuel Cell Hardware for CO/CV Measurements 


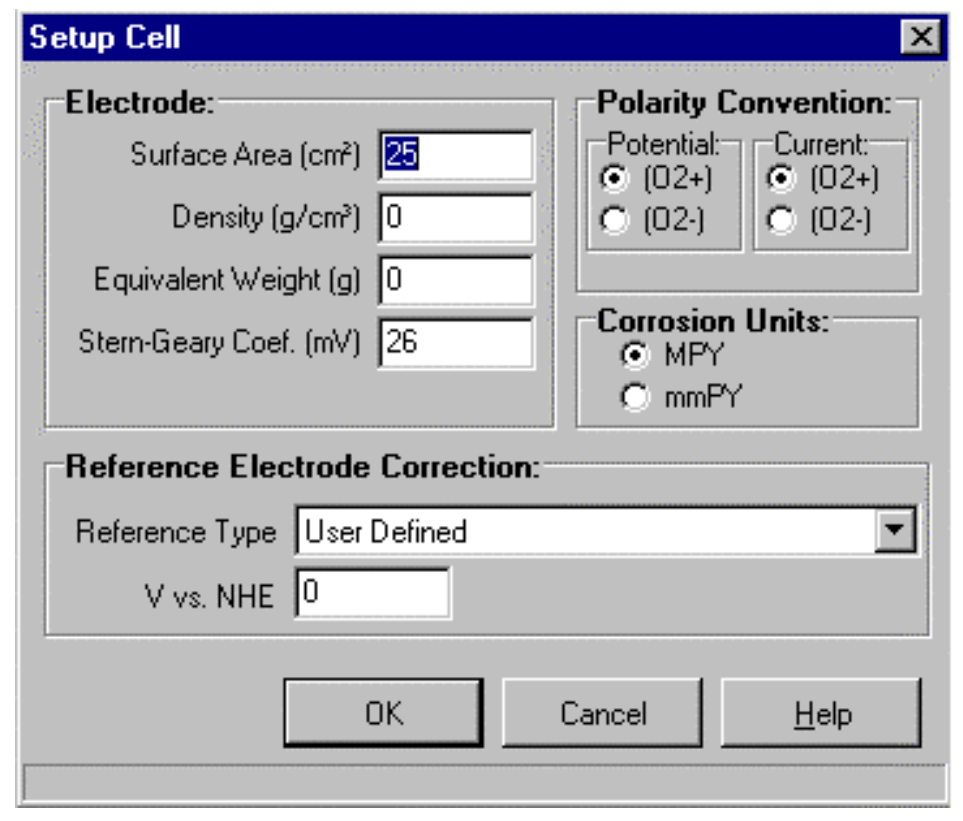

Figure D4. CorrWare Setup Cell Menu

\section{D5.5 Humidification of the Membrane}

Time required for this step: $~ 3.5$ hours

Note. This step is performed to introduce water into the membrane to improve its ionic conductivity and reactant permeability.

i. Switch the ANODE gas valve to $\mathrm{H}_{2}$ and CATHODE gas valve to $\mathrm{N}_{2}$.

ii. Connect the LOAD LINES to the fuel cell hardware:

- Connect the cathode load line (red line) directly with the cathode metal plate of the fuel cell.

- Connect the anode load line (black line) directly with the anode metal plate of the fuel cell.

Caution: Be very certain that the connection is tight!

iii. Insert the SENSE LEADS into the holes of the leads on the fuel cell hardware:

- Insert the cathode sense lead (red line) directly into the hole in the red line attached to the cathode graphite plate

- Insert the anode sense lead (black line) directly into the hole in the black line attached to the anode graphite plate

Caution: Never connect the sense leads to the test fixture without the large LOAD connections being made first. Failure to do this with the load unit active may result in damage to the load.

iv. Change all set points to the "HEAT UP" Step (40/50/50 condition)

- Set cell temperature at $40^{\circ} \mathrm{C}$

- Set anode and cathode gas lines at $50{ }^{\circ} \mathrm{C}$ (If applicable). (Recall $10{ }^{\circ} \mathrm{C}$ higher than cell temperature)

- Set anode and cathode humidifier controllers at $50{ }^{\circ} \mathrm{C}$.

v. After the temperatures reach the set points, hold it there for 5 to $10 \mathrm{~min}$.

vi. Change all set points to the $80 / 80 / 73$ condition:

- Set cell temperature at $80^{\circ} \mathrm{C}$ 
- Set anode and cathode gas lines at $90{ }^{\circ} \mathrm{C}$ (If applicable). Anode and cathode gas line temperatures are $5-10^{\circ} \mathrm{C}$ higher than cell temperature $\left(\mathrm{T}_{\text {cell }}\right)$.

- $\quad$ On the test panel, set anode humidifier controllers at $80^{\circ} \mathrm{C}(100 \% \mathrm{RH})$

- $\quad$ On the test panel, set cathode humidifier controllers at $73{ }^{\circ} \mathrm{C}(75 \% \mathrm{RH})$

vii. Set the flow rates at:

- Anode

- Minimum Flow: $\underline{0.17 \mathrm{~L} / \mathrm{min}}$

- $\quad$ Load based flow: $0 \mathrm{~L} / \mathrm{min} /$ cell $+\underline{0.021 ~ L / m i n} /$ cell (for 3 stoichiometry of $\mathrm{H}_{2}$ )

- Cathode:

- Minimum Flow: $0.17 \mathrm{~L} / \mathrm{min}$

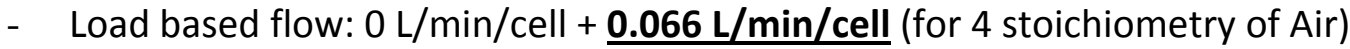

viii. Maintain at this condition $\left(\mathrm{H}_{2} / \mathrm{N}_{2}, 80 / 80 / 73\right)$ to humidify to membrane for $\underline{\mathbf{3}}$ hours.

\section{D5.6 Operation of the Cell in a Break-In Mode Time required for this step: $~ 3$ hours minimum}

Note. This test is performed to let the cell come to a steady state while operating in a benign way as a fuel cell.

i. Set the condition to $\mathrm{H}_{2} / \mathrm{N}_{2}, 80 / 80 / 73{ }^{\circ} \mathrm{C}$ condition (maintain previous step).

ii. On the side of the test station, keep the ANODE gas valve on $\mathrm{H}_{2}$ and switch the CATHODE gas valve to Air.

iii. Wait until the cell voltage (which is the open circuit voltage at this point) stabilizes. ( 3 minutes). Then record the exact open circuit voltage.

Note 1. The value of open circuit voltage will increase with the time. Just wait until it is stable.

Note 2. NEVER leave the cell at the OCV (Open Circuit Voltage) for more than 5 minutes. Platinum and carbon will corrode and cause performance decay. While changing conditions with fuel (hydrogen) and oxidant (air/ $\mathrm{O}_{2}$ ) present, always apply load at $100-400 \mathrm{~mA} / \mathrm{cm}^{2}$. This is to not leave the cell at OCV to avoid cell corrosion.

iv. Click "Apply Fuel" and "Apply Load" buttons.

v. Set the cell voltage at $0.55 \mathrm{~V}$. Record the TOTAL current density to Value \#1 $(\mathrm{t}=0$ hours).

vi. Hold it for one hour, record the TOTAL current to Value \#2 ( $t=1$ hour)

vii. Hold it for another hour, record the TOTAL current to Value \#3 ( $t=2$ hours).

viii. Repeat the recording every hour until the TWO last current values are within $5 \%$ of each other. (Usually takes 3-5 hours)

\section{D5.7 Cool-Down Procedure}

Time required for this step: $\sim 1$ hour

i. Set the cell temperature to $80 / 60 / 60^{\circ} \mathrm{C}$

Note 1. The cell temperature must be about $10-20{ }^{\circ} \mathrm{C}$ above the saturator temperatures during cool down.

Note 2. Water can be added to the saturators, and insulation can be removed from the cell to promote cool down.

ii. While waiting for temperatures to reach the first set points, disconnect the positive load cable, to protect from current leak. 
iii. Set the min flow rate on the anode and the cathode at $0.2 \mathrm{~L} / \mathrm{min}$.

iv. Switch the cathode valve on the side of the station to $\mathrm{N}_{2}$ for purging the cell.

v. Wait until the voltage falls to $0.4 \mathrm{~V}$, then switch the anode valves in the front panel of the station to $\mathrm{N}_{2}$ for purging the cell.

vi. After the temperature reaches $80 / 60 / 60{ }^{\circ} \mathrm{C}$, set it to $60 / 50 / 50$, then $50 / 40 / 40$, then 0/0/0.

vii. Wait until the cell temperature, the humidifier temperatures, and the gas line temperatures are all below $50{ }^{\circ} \mathrm{C}$.

viii. Turn off the power of heater for humidifiers.

ix. Set the anode and cathode flow rate back to zero.

x. Click "Exit" to close the FuelCell software.

xi. Turn off the Fuel Cell Load Unit

xii. Close all valves of the gas cylinders.

xiii. Close anode and cathode valves of the test station.

\section{D6 Day 2 Test}

D6.1 Crossover and Cyclic Voltammetry Tests

Time required for this step: $\sim 0.5$ hour

Repeat the procedure for measuring CO and CV on day 1.

\section{D6.2 Polarization curve measurement at $80{ }^{\circ} \mathrm{C}\left(\mathrm{Air} / \mathrm{O}_{2}\right.$ alternating $)$ Time required for this step: $~ 7$ hours (Air/ $\mathrm{O}_{2} /$ Air)}

Note. This test is performed to determine the cell performance at atmospheric pressure, which is the condition where the electrolyte is near saturation.

i. Set the flow rates as done for the humidification.

ii. Keep the ANODE gas valve on $\mathrm{H}_{2}$ and switch the CATHODE gas valve to Air $\left(\underline{1^{\text {st }} \text { Air }}\right.$ run).

iii. Let the cell reach OCV ( 2-3 min). Record OCV.

iv. Click the "Apply Fuel" button on the main window as shown in Figure D5.

v. Click the "Apply Load" button on the main window as shown in Figure D5.

vi. Apply $400 \mathrm{~mA} / \mathrm{cm}^{2}$ load. Maintain until voltage is constant.

vii. If no experiments are listed under the "Setup Experiments" panel, click on "New..." button on the right of the panel, and select "Arbitrary control". If there are experiments listed in the "Setup Experiments" panel, double click one of them.

viii. The menu box titled "Setup Arbitrary Control Experiment" will pop up

ix. Choose a name and location for the data file (file with the results of the experiment).

x. Select an appropriate control setup file for the experiment, then click "OK"

Note. Control Setup files are text files (i.e. ".txt" files) that are used to control the load. We are currently testing the following loads: $0,10,20,40,60,80,100,200,300,400,500,600,700$, $800,900,1000,1100,1200,1300,1400,1500,1600,1700,1800,1900,2000 \mathrm{~mA} / \mathrm{cm}^{2}$, held at each point for 5 minutes.

xi. Click the "Run Cell" Button on the main window 
xii. Select "Graphs" in menu bar, then click "vs Time" command and click "Voltage" as shown in Figure D6.

xiii. $\quad$ The menu box titled "Graphs \#1" will pop up.

xiv. Change "Background data" to "Experiment data" at the upper-right corner of this menu box

$x v$. Software starts data acquisition for a Cell Voltage vs. Time plot

xvi. Wait until the experiment is finished. While the experiment is in progress, check regularly that the water level in the humidifier is not below the minimum level. Also check that the experiment is progressing without jumping to OCV.

xvii. After the experiment is finished, the load should return to whatever load was being used prior to the experiment, in this case $400 \mathrm{~mA} / \mathrm{cm}^{2}$.

xviii. Switch the cathode valve on the side of station to $\mathrm{O}_{2}$ and wait until voltage stabilizes. Repeat the measurement in $\mathrm{O}_{2}$ (at the same temperature).

xix. After the measurement on $\mathrm{O}_{2}$ is finished, switch the cathode valve back to Air. Repeat the measurement for air ( $\underline{2^{\text {nd }}}$ Air run $)$.

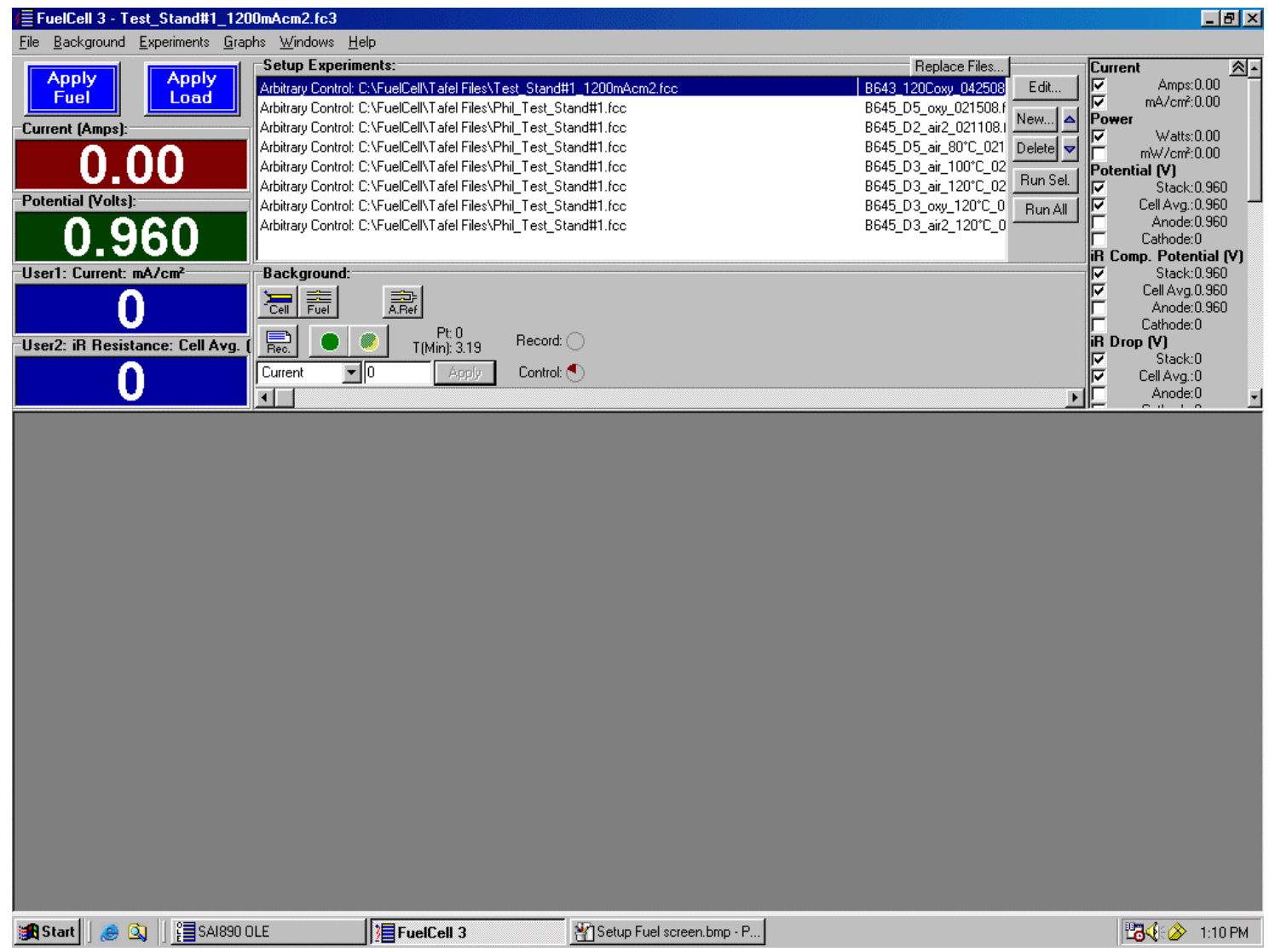

Figure D5. Main Window for FuelCell software 


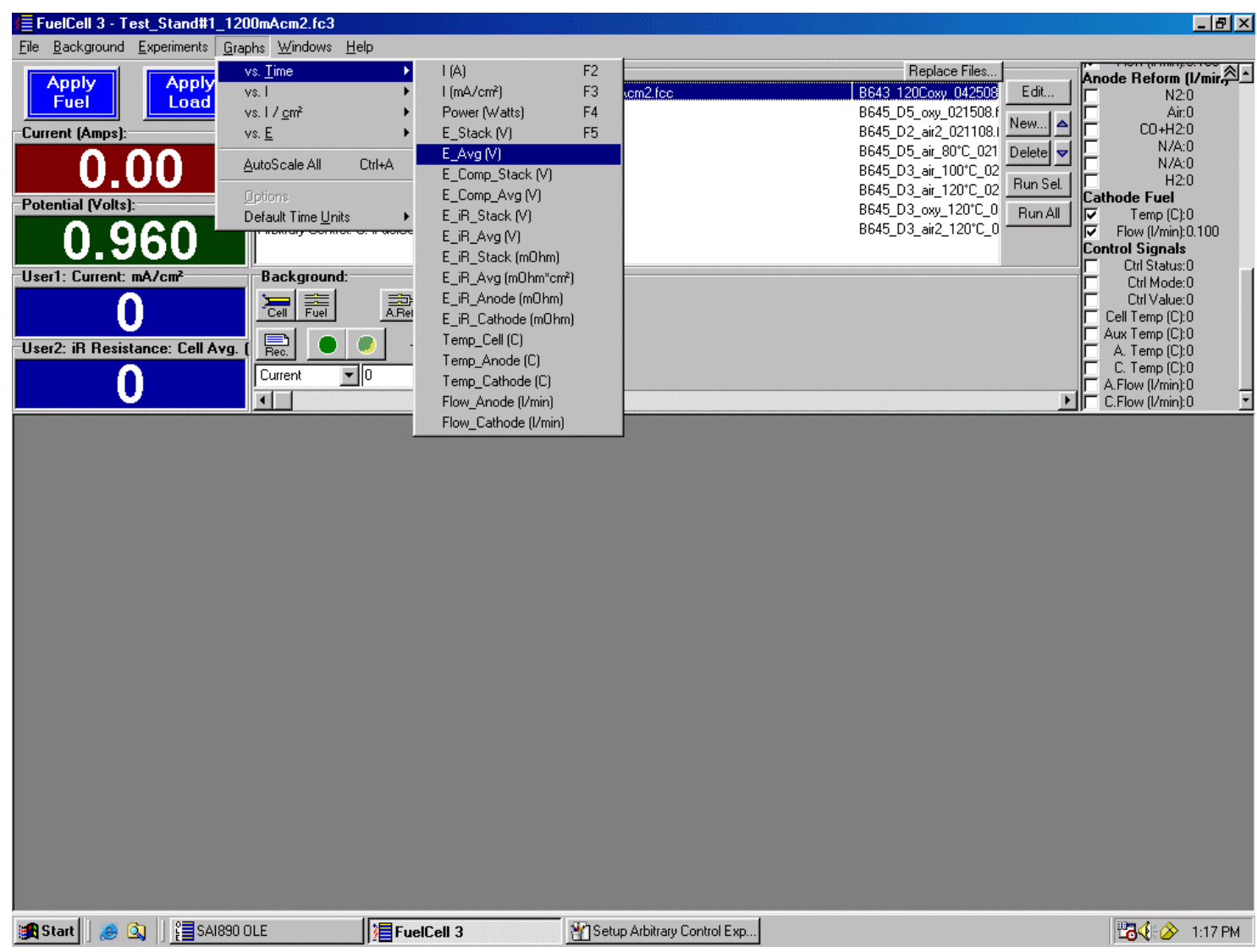

Figure D6. Choose Voltage vs. Time graph

D6.3 Crossover and Cyclic Voltammetry Tests at $80 / 80 / 73$

Time required for this step: $~ 0.5$ hour

Repeat the crossover and cyclic voltammetry procedure from day 1 at 80/80/73.

D6.4 Hold at $400 \mathrm{~mA} / \mathrm{cm}^{2}$ overnight

\section{D7 Day 3 Test}

D7.1 Performance Measurement at 80/80/73 (Air/ $\mathrm{O}_{2}$ Alternating, $\left.1.5 \mathrm{~atm}\right)$

Time required for this step: $\sim 6$ hours

i. Pressurize cell to $1.5 \mathrm{~atm}$.

ii. Run the cell at the $80 / 80 / 73$ condition with $\mathrm{H}_{2} /$ Air.

iii. Wait until the whole sweep measurement is finished then repeat with oxygen and again with air.

D7.2 Performance Measurement at 100/90/90, Air, $1.5 \mathrm{~atm}$

Time required for this step: $\sim 2$ hours

i. Change the temperatures to the $100 / 90 / 90$ condition (using $\mathrm{H}_{2} / \mathrm{Air}$ )

- Set cell temperature at $100^{\circ} \mathrm{C}$ 
- Set anode and cathode gas lines at $110^{\circ} \mathrm{C}$, if applicable

- Set anode humidifier controllers at $100^{\circ} \mathrm{C}$

ii. Apply $400 \mathrm{~mA} / \mathrm{cm}^{2}$ of load, and wait until temperatures and voltage stabilize

iii. Start the measurement of the performance using $\mathrm{H}_{2}$ /air

- Wait until the whole sweep measurement is finished.

\section{D7.3 Hold over night at $400 \mathrm{~mA} / \mathrm{cm}^{2}$}

\section{D8 Day 4 Test}

D8.1 Performance Measurement at 100/90/90 $\left(\mathrm{O}_{2} /\right.$ Air Alternating, $\left.1.5 \mathrm{~atm}\right)$ Time required for this step: $\sim 3$ hours

i. Run the performance test at the $100 / 90 / 90$ condition with $\mathrm{H}_{2} / \mathrm{O}_{2}$

ii. Wait until the whole sweep measurement is finished then repeat with air.

\section{D8.2 Crossover and Cyclic Voltammetry Tests at 120/90/90}

Time required for this step: $\sim 1$ hour

i. Release pressure on cell to ambient

ii. Change the temperatures to the $120 / 90 / 90$ condition

- Set cell temperature at $120^{\circ} \mathrm{C}$

- Set anode and cathode gas lines at $125^{\circ} \mathrm{C}$ (NOT $10{ }^{\circ} \mathrm{C}$ higher than $\mathrm{T}_{\text {cell }}$ as usual)

- On the test panel, set anode humidifier controllers at $90{ }^{\circ} \mathrm{C}$ (same as previous)

iii. Repeat the $\mathrm{CO} / \mathrm{CV}$ procedure of Day 2

\section{D8.3 Performance Measurement at 120/90/90 (Air/ $\mathrm{O}_{2}$ Alternating, $\left.1.5 \mathrm{~atm}\right)$}

Time required for this step: $\sim 3$ hours

i. Pressurize cell to $1.5 \mathrm{~atm}$.

ii. Change cathode gas to air

iii. Apply $400 \mathrm{~mA} / \mathrm{cm}^{2}$ of load and wait until voltage stabilizes

iv. Start the measurement of the performance using $\mathrm{H}_{2} /$ Air

v. Switch to $\mathrm{O}_{2}$, apply $400 \mathrm{~mA} / \mathrm{cm}^{2}$ while waiting

vi. Run the performance test with $\mathrm{H}_{2} / \mathrm{O}_{2}$ then with $\mathrm{H}_{2} /$ Air

D8.4 Reduce Cell temperature to $100^{\circ} \mathrm{C}$ and hold overnight at $400 \mathrm{~mA} / \mathrm{cm}^{2}$

\section{D9 Day 5 Test}

D9.1 Crossover and Cyclic Voltammetry Tests at 100/90/90

Time required for this step: $\sim 1$ hour

i. Release pressure on cell to ambient

ii. Change temperature to $100 / 90 / 90$ condition

iii. Repeat the crossover and cyclic voltammetry procedure of Day 1

D9.2 Performance Measurement at 100/90/90 (Air/ $\mathrm{O}_{2}$ Alternating)

Time required for this step: $\sim 6$ hours minimum $\left(\mathrm{Air} / \mathrm{O}_{2}\right)$

i. Pressurize cell to $1.5 \mathrm{~atm}$ 
ii. Change cathode gas to air

iii. Apply $400 \mathrm{~mA} / \mathrm{cm}^{2}$ of load and wait until voltage stabilizes

iv. Start the measurement of the performance using $\mathrm{H}_{2} /$ Air

v. When measurement is finished, switch to $\mathrm{O}_{2}$ and apply $400 \mathrm{~mA} / \mathrm{cm}^{2}$ while waiting

vi. Run the performance test with $\mathrm{H}_{2} / \mathrm{O}_{2}$.

vii. When measurement is finished, switch to air and apply $400 \mathrm{~mA} / \mathrm{cm}^{2}$ while waiting

viii. Run the performance test with $\mathrm{H}_{2} /$ Air.

\section{D9.3 Stability Test at 100/90/90 $\left(\mathrm{H}_{2} /\right.$ Air, $400 \mathrm{~mA} / \mathrm{cm}^{2}, 1.5 \mathrm{~atm}$, Days 5, 6, and 7)}

- Under "Set-up experiments" click on "New..." button on the right of the panel and select "Constant current"

- Save the file under an appropriate name and input test time ( $\sim 70 \mathrm{~h})$ and current (400 $\mathrm{mA} / \mathrm{cm}^{2}$ )

- Collect condensate water from anode and cathode exhaust each morning and evening, in separate, labeled vials (end up with 12 vials total). Analyze condensate water for fluoride ions according to Appendix $\mathrm{E}$.

\section{D10 Day 8 Test}

\section{D10.1 Crossover and Cyclic Voltammetry Tests at 100/90/90}

Time required for this step: $\sim 0.5$ hour

i. Release pressure on cell to ambient

ii. Repeat the crossover and cyclic voltammetry procedure of Day 2

\section{D10.2 Performance Test at 100/90/90 (Air/O $\mathrm{O}_{2}$ Alternating, $\left.1.5 \mathrm{~atm}\right)$} Time required for this step: $\sim 6$ hours

i. $\quad$ Pressurize cell to $1.5 \mathrm{~atm}$

ii. Repeat Performance measurement at 100/90/90 from day 5

\section{D10.3 Cool-down}

i. Set the cell temperature to $80 / 60 / 60$.

Note 1. The cell temperature must be about $10-20{ }^{\circ} \mathrm{C}$ above the saturator temperatures during cool down.

Note 2. Water can be added to the saturators, and insulation can be removed from the cell to promote cool down.

ii. While waiting for temperatures to reach the first set points, disconnect the positive load cable, to protect from current leak.

iii. Set the min flow rate on the anode $\left(\mathrm{H}_{2}\right)$ and the cathode (air) at $0.2 \mathrm{~L} / \mathrm{min}$.

iv. Switch the cathode valve in the front panel of the station to $\mathrm{N}_{2}$ for purging the cell.

v. Wait until the voltage falls to 0.4 volts, then switch the anode valves in the front panel of the station to $\mathrm{N}_{2}$ for purging the cell.

vi. After the temperature reaches $80 / 60 / 60$, set it to $60 / 50 / 50$, then $50 / 40 / 40$, then $25 / 25 / 25$. 
vii. Wait until the cell temperature, the humidifier temperatures, the saturated gas water, and the gas line temperatures are all below $50{ }^{\circ} \mathrm{C}$.

\section{D11 Day 9 Test \\ D11.1 Repeat the crossover and cyclic voltammetry procedure of Day 2 (at room temperature)}

\section{D11.2 Leak test per Appendix C}

\section{D11.3 Resistance Test per Section D5.1}

\section{D11.4 Shut-down and Remove from the test stand}

i. Turn off the power of heater for humidifiers (if applicable).

ii. Set the anode and cathode flow rate back to zero.

iii. Click "Exit" to close the FuelCell software.

iv. Turn off the Fuel Cell Load Unit

v. Shut down computer.

vi. Close all valves of the gas cylinders.

vii. Close anode and cathode valves of the test station.

viii. Disconnect gas tubing and electrical line from the cell hardware.

\section{D11.5 Post-test}

i. Measure bolt load

ii. Disassemble the Cell

iii. Conduct visual Inspection

iv. Bag and Seal Components With 10 drops of DI Water in each Bag

\section{D12 Troubleshooting: Hardware problems}

\begin{tabular}{|l|l|l|}
\hline \multicolumn{1}{|c|}{ INDICATION } & \multicolumn{1}{|c|}{ CAUSE } & \multicolumn{1}{c|}{ CORRECTION } \\
\hline $\begin{array}{l}\text { - No power when unit is } \\
\text { turned ON } \\
\text { - AC Power not available to } \\
\text { model } 890\end{array}$ & $\begin{array}{l}\bullet \text { Fuse on rear panel of } \\
\text { the control unit may be } \\
\text { blown }\end{array}$ & $\begin{array}{l}\bullet \text { Replace with 4 A, slow blow 3AG } \\
\text { type fuse }\end{array}$ \\
\hline $\begin{array}{l}\text { - No heater power available } \\
\text { for one or more of the } \\
\text { temperature controller }\end{array}$ & & $\begin{array}{l}\bullet \text { Check internal fuses that protect } \\
\text { the temp controller output. }\end{array}$ \\
\hline
\end{tabular}




\begin{tabular}{|c|c|c|}
\hline $\begin{array}{l}\text { - Alarms when FUEL ON } \\
\text { button is pressed in software }\end{array}$ & $\begin{array}{l}\text { - Fuel Gas unit cables } \\
\text { not connected } \\
\text { - Model } 890 \text { Fuel } \\
\text { System } \\
\text { Interface Box not } \\
\text { properly connected }\end{array}$ & $\begin{array}{l}\text { - Check gas pressures and low } \\
\text { pressure safety switch wiring. } \\
\text { - Low gas pressure alarm switches } \\
\text { must be closed for alarms to be off. }\end{array}$ \\
\hline $\begin{array}{l}\text { - No load current when load is } \\
\text { turned ON }\end{array}$ & $\begin{array}{l}\text { - Load cables not } \\
\text { connected } \\
\text { - Sense leads not } \\
\text { connected or reversed } \\
\text { - Sense lead protection } \\
\text { fuse (internal fuse) } \\
\text { blown }\end{array}$ & $\begin{array}{l}\text { - Remove all power to system and } \\
\text { disconnect anode cell lead and } \\
\text { anode sense lead first } \\
\text { - Resistance should measure } \\
\text { between } 10 \text { and } 15 \mathrm{~W} \\
\text { - If incorrect, remove the unit } \\
\text { cover and check the fuse by } \\
\text { removing it from its socket. }\end{array}$ \\
\hline $\begin{array}{l}\text { - Inadequate cooling air flow } \\
\text { causing over-temperature shut } \\
\text { down }\end{array}$ & & $\begin{array}{l}\text { - Check cooling restrictions } \\
\text { - Prolonged over-temperature } \\
\text { operation may damage the load } \\
\text { electronics. }\end{array}$ \\
\hline
\end{tabular}


D13 Chart Summarizing Day-to-Day Activities

\begin{tabular}{|c|c|c|c|c|c|c|}
\hline Day & Time (h) & Temp & Gas A & Gas C & Action & Notes \\
\hline 1 & 0.5 & RT & N/A & N/A & Set-up & Includes leak test, resistance, etc. \\
\hline 1 & 3.5 & $80 / 80 / 73$ & $\mathrm{H}_{2}$ & $\mathrm{~N}_{2}$ & Humidify & \\
\hline 1 & 3 & $80 / 80 / 73$ & $\mathrm{H}_{2}$ & Air & Break-in & At $0.55 \mathrm{~V}$ \\
\hline \multirow[t]{2}{*}{1} & 1 & & $\mathrm{H}_{2}$ & $\mathrm{~N}_{2}$ & Cool down & \\
\hline & $\underline{8 \mathrm{~h}}$ & & & & & \\
\hline 2 & $\overline{0.5}$ & $25 / 25 / 25$ & $\mathrm{H}_{2}$ & $\mathrm{~N}_{2}$ & $\mathrm{CO} / \mathrm{CV}$ & \\
\hline 2 & 2.5 & $80 / 80 / 73$ & $\mathrm{H}_{2}$ & Air & IV & \\
\hline 2 & 2 & $80 / 80 / 73$ & $\mathrm{H}_{2}$ & $\mathrm{O}_{2}$ & IV & \\
\hline 2 & 2 & $80 / 80 / 73$ & $\mathrm{H}_{2}$ & Air & IV & \\
\hline \multirow[t]{2}{*}{2} & 0.5 & $80 / 80 / 73$ & $\mathrm{H}_{2}$ & $\mathrm{~N}_{2}$ & $\mathrm{CO} / \mathrm{CV}$ & \\
\hline & $7.5 \mathrm{~h}$ & & & & & \\
\hline 3 & 2 & $80 / 80 / 73$ & $\mathrm{H}_{2}$ & Air & IV & $1.5 \mathrm{~atm}$ \\
\hline 3 & 2 & $80 / 80 / 73$ & $\mathrm{H}_{2}$ & $\mathrm{O}_{2}$ & IV & $1.5 \mathrm{~atm}$ \\
\hline 3 & 2 & $80 / 80 / 73$ & $\mathrm{H}_{2}$ & Air & IV & $1.5 \mathrm{~atm}$ \\
\hline 3 & 1 & $100 / 90 / 90$ & $\mathrm{H}_{2}$ & $\mathrm{~N}_{2}$ & $\mathrm{CO} / \mathrm{CV}$ & $1.5 \mathrm{~atm}$ \\
\hline \multirow[t]{2}{*}{3} & 2 & $100 / 90 / 90$ & $\mathrm{H}_{2}$ & Air & IV & $1.5 \mathrm{~atm}$ \\
\hline & $\underline{9 h}$ & & & & & \\
\hline 4 & 2 & $100 / 90 / 90$ & $\mathrm{H}_{2}$ & $\mathrm{O}_{2}$ & IV & $1.5 \mathrm{~atm}$ \\
\hline 4 & 2 & $100 / 90 / 90$ & $\mathrm{H}_{2}$ & Air & IV & $1.5 \mathrm{~atm}$ \\
\hline 4 & 1 & $120 / 90 / 90$ & $\mathrm{H}_{2}$ & $\mathrm{~N}_{2}$ & $\mathrm{CO} / \mathrm{CV}$ & \\
\hline 4 & 1 & $120 / 90 / 90$ & $\mathrm{H}_{2}$ & Air & IV & $1.5 \mathrm{~atm}$ \\
\hline 4 & 1.5 & $120 / 90 / 90$ & $\mathrm{H}_{2}$ & $\mathrm{O}_{2}$ & IV & $1.5 \mathrm{~atm}$ \\
\hline \multirow[t]{2}{*}{4} & 1 & $120 / 90 / 90$ & $\mathrm{H}_{2}$ & Air & IV & $1.5 \mathrm{~atm}$ \\
\hline & $8.5 \mathrm{~h}$ & & & & & \\
\hline 5 & 0.5 & $100 / 90 / 90$ & $\mathrm{H}_{2}$ & $\mathrm{~N}_{2}$ & $\mathrm{CO} / \mathrm{CV}$ & \\
\hline 5 & 2 & $100 / 90 / 90$ & $\mathrm{H}_{2}$ & Air & IV & $1.5 \mathrm{~atm}$ \\
\hline 5 & 2 & $100 / 90 / 90$ & $\mathrm{H}_{2}$ & $\mathrm{O}_{2}$ & IV & $1.5 \mathrm{~atm}$ \\
\hline 5 & 2 & $100 / 90 / 90$ & $\mathrm{H}_{2}$ & Air & IV & $1.5 \mathrm{~atm}$ \\
\hline \multirow[t]{2}{*}{5} & .25 & $100 / 90 / 90$ & $\mathrm{H}_{2}$ & Air & Stability & $1.5 \mathrm{~atm}, 400 \mathrm{~mA} / \mathrm{cm} 2$ \\
\hline & $\underline{6.75 h}$ & & & & & \\
\hline 6 & & $100 / 90 / 90$ & $\mathrm{H}_{2}$ & Air & Stability & $1.5 \mathrm{~atm}, 400 \mathrm{~mA} / \mathrm{cm} 2$ \\
\hline \multirow[t]{2}{*}{7} & & $100 / 90 / 90$ & $\mathrm{H}_{2}$ & Air & Stability & $1.5 \mathrm{~atm}, 400 \mathrm{~mA} / \mathrm{cm} 2$ \\
\hline & $60-70 \mathrm{~h}$ & & & & & \\
\hline 8 & 0.5 & $100 / 90 / 90$ & $\mathrm{H}_{2}$ & $\mathrm{~N}_{2}$ & $\mathrm{CO} / \mathrm{CV}$ & \\
\hline 8 & 2 & $100 / 90 / 90$ & $\mathrm{H}_{2}$ & Air & IV & $1.5 \mathrm{~atm}$ \\
\hline 8 & 2 & $100 / 90 / 90$ & $\mathrm{H}_{2}$ & $\mathrm{O}_{2}$ & IV & $1.5 \mathrm{~atm}$ \\
\hline 8 & 2 & $100 / 90 / 90$ & $\mathrm{H}_{2}$ & Air & IV & $1.5 \mathrm{~atm}$ \\
\hline \multirow[t]{2}{*}{8} & 1 & & $\mathrm{H}_{2}$ & $\mathrm{~N}_{2}$ & Cool down & \\
\hline & 7.5h & & & & & \\
\hline 9 & 0.5 & $25 / 25 / 25$ & $\mathrm{H}_{2}$ & $\mathrm{~N}_{2}$ & $\mathrm{CO} / \mathrm{CV}$ & \\
\hline 9 & 1 & & & & Leak and Resistance Tests & \\
\hline 9 & 0.25 & & & & Disassemble Cell & \\
\hline
\end{tabular}




\section{Appendix E: Fluoride Concentration Measurements Test Procedure}

\section{E1 Checking Electrode Operation}

Note 1. Check Electrode Operation every day before beginning measurements Note 2. At all times use a stirring plate and bar.

Note 3. Before and after each measurement rinse electrode in DI water

\section{E1.1 Suggested Equipment}

i. $\quad 2-250 \mathrm{~mL}$ beakers (1 for measurement and 1 to rinse electrode)

ii. $\quad 1-10 \mathrm{~mL}$ measuring cylinder

iii. 2- $50 \mathrm{~mL}$ measuring cylinders (1 for DI water and one for TISAB II)

iv. $\quad 1-2000 \mathrm{~mL}$ beaker (for waste)

v. 1- DI water wash bottle

vi. 1- glass pipette with bulb

\section{E1.2 Procedure}

i. Mix $50 \mathrm{~mL}$ of DI water with $50 \mathrm{ml}$ of TISAB II.

ii. Immerse Electrode into solution

iii. Pipette $1 \mathrm{~mL}$ of either $0.1 \mathrm{M}$ or $100 \mathrm{ppm} \mathrm{F}^{-}$standard into the mixture. Record the equilibrated reading $(\mathrm{mV})$.

iv. Add $10 \mathrm{~mL}$ more of the same standard to them mixture and again record the equilibrated reading $(\mathrm{mV})$.

v. The difference between the two readings should be in the range of 54-60 $\mathrm{mV} /$ decade at $25^{\circ} \mathrm{C}$. If that is not the case refer to TROUBLESHOOTING.

\section{E2 Fluoride Concentration Measurements}

Note 1. At all times use a stirring plate and bar.

Note 2. Before and after each measurement rinse electrode in DI water

\section{E2.1 Direct Calibration}

Note 1. For sample with concentrations greater than $1 \mathrm{ppm}$.

Note 2. Calibrate every day before beginning measurements

Note 3. Use three standards that cover the whole range of the concentrations of the samples that are measured (e.g. 1, 10 and 100 ppm)

\section{E2.1.1 Suggested Equipment}

i. $\quad 4-250 \mathrm{~mL}$ beakers ( 3 for standards and 1 to rinse electrode)

ii. $\quad 2-50 \mathrm{~mL}$ measuring cylinders (1 for TISAB II and one for DI water)

iii. $\quad 1-2000 \mathrm{~mL}$ beaker (for waste) 
iv. $1 \mathrm{DI}$ water wash bottle

\section{E2.1.2 Procedure}

i. Mix $50 \mathrm{~mL}$ of the most dilute standard and $50 \mathrm{~mL}$ of TISAB II (for 1, 2 and $100 \mathrm{ppm}$ the standards are already mixed with TISAB II and are used as given)

ii. Insert electrode into solution and press "Calibrate". Wait for an equilibrated reading (in ppm) and set the value to the value of the standard (e.g. $1 \mathrm{ppm}$ ).

iii. Insert electrode into next standard and press "Calibrate". Wait for an equilibrated reading (in ppm) and set the value to the value of the standard (e.g. 10 ppm).

iv. Repeat with final standard (e.g. 100 ppm)

v. Press "Measure". Record slope that is given (mV)

The electrode is now calibrated for the range of 1 to $100 \mathrm{ppm}$. Checking the electrode against the standards during measurement is recommended.

\section{E2.2 Calibration Curve}

Note 1. For samples with concentrations lesser than $1 \mathrm{ppm}$

Note 2. Make a calibration curve every day before beginning measurements

Note 3. Use low level TISAB (LL-TISAB, made in-house using procedure in E2.2.1) for all measurements

\section{E2.2.1 Making LL-TISAB}

Use very pure reagents - avoid metal ion contamination, especially aluminum and iron as they form complexes with fluoride

$\begin{array}{ll} & \text { E2.2.1.1 Suggested Equipment } \\ \text { i. } & 1-2000 \mathrm{~mL} \text { beaker (for bulk solution) } \\ \text { ii. } & 1-100 \mathrm{~mL} \text { measuring cylinder } \\ \text { iii. } & \text { 1-calibrated pH electrode } \\ \text { iv. } & \text { 1-250 } \mathrm{mL} \text { beaker (for rinsing electrode) } \\ \text { v. } & \text { 1-glass pipette with bulb } \\ \text { vi. } & \text { 1-DI water wash bottle } \\ \text { vii. } & 1-2000 \mathrm{~mL} \text { volumetric flask (for LL-TISAB) } \\ \text { viii. } & 1-500 \mathrm{~mL} \text { volumetric flask (for } \mathrm{NaOH} \text { ) }\end{array}$

E2.2.1.2 Procedure

i. Add ca. $1000 \mathrm{~mL}$ of DI water to the large beaker

ii. Add $114 \mathrm{~mL}$ of pure glacial acetic acid

iii. Add $116 \mathrm{~g}$ of pure sodium chloride and stir

iv. Weigh $100 \mathrm{~g}$ of sodium hydroxide into volumetric flask and make up to $500 \mathrm{ml}$ with water (cool in ice if necessary)

v. Immerse electrode into large beaker and add 5M NaOH until a pH of 5.0-5.5 is achieved (make sure all solutions are at the same temperature) 
vi. $\quad$ Put LL-TISAB into volumetric flask and make up to $200 \mathrm{ml}$

\section{E2.2.2 Making Standard}

This standard is used to make the Calibration Curve

E2.2.2.1 Suggested Equipment:

i. $\quad 1400 \mathrm{~mL}$ beaker

ii. $\quad 15 \mathrm{~mL}$ pipette with pump

iii. $\quad 250 \mathrm{~mL}$ measuring cylinders

E2.2.2.2 Procedure:

i. Measure $5 \mathrm{~mL}$ of $100 \mathrm{ppm} \mathrm{F}^{-}$standard into a measuring cylinder and make up to $50 \mathrm{~mL}$

ii. Measure $50 \mathrm{~mL}$ of LL-TISAB and combine the two solutions in the beaker

\section{E2.2.3 Making Calibration Curve}

The Calibration Curve is needed to convert from $\mathrm{mV}$ to $\mathrm{ppm}$

E2.2.3.1 Suggested Equipment:

i. $\quad 2-250 \mathrm{~mL}$ beakers ( 1 for measurement and 1 to rinse electrode)

ii. $\quad$ 1- $1 \mathrm{~mL}$ pipette with pump

iii. $\quad 2-50 \mathrm{~mL}$ measuring cylinders (1 for LL-TISAB and one for DI water)

E2.2.3.2 Procedure:

i. Measure $50 \mathrm{~mL}$ of DI water and $50 \mathrm{~mL}$ of LL-TISAB into a beaker

ii. Rinse, immerse electrode into solution and record the reading $(\mathrm{mV})$

iii. Add $1 \mathrm{~mL}$ of the standard, leave to equilibrate and record the reading $(\mathrm{mV})$

iv. Repeat 3 until all expected concentrations of $F^{-}$are covered (at least $15 \mathrm{~mL}$ are recommended)

v. Plot a semi-logarithmic graph of $\mathrm{mV}$ against $\mathrm{ppm}$

Note. Addition of $1 \mathrm{~mL}$ of standard is ca. $0.1 \mathrm{ppm}, 5 \mathrm{~mL}$ of standard is ca. $0.47 \mathrm{ppm}$ and $10 \mathrm{~mL}$ of standard is $0.9 \mathrm{ppm}$

\section{E2.3 Measuring Samples with Concentrations Greater than 1 ppm}

Note. For samples with concentrations greater than $1 \mathrm{ppm}$, direct calibration of electrode is required. Use TISAB II for all measurements.

\section{E2.3.1 Suggested Equipment:}

i. $\quad 1-5 \mathrm{~mL}$ pipette with pump (for samples) 
ii. $\quad 2-250 \mathrm{~mL}$ beakers ( 1 for measurement and 1 to rinse electrode)

iii. $\quad 2-50 \mathrm{~mL}$ measuring cylinders (1 for DI water and one for TISAB II)

iv. $\quad 1-2000 \mathrm{~mL}$ beaker (for waste)

v. $\quad 2-1000 \mathrm{~mL}$ beakers (1 for DI water and one for TISAB II)

vi. $\quad 1$ - glass pipette with bulb (for TISAB II)

vii. 1- DI water wash bottle

\section{E2.3.2 Procedure:}

i. Measure $5 \mathrm{~mL}$ of sample into measuring cylinder and make up to $50 \mathrm{~mL}$ with DI water

ii. Measure $50 \mathrm{~mL}$ of TISAB II and combine both cylinders in a beaker

iii. Rinse electrode, immerse in beaker, leave to equilibrate and record the reading $(\mathrm{ppm})$

iv. Repeat with other samples

Input all data into Excel, convert to $\mu$ moles $/\left(\mathrm{cm}^{2} \mathrm{~h}\right)$ (equation: $\left.\mathrm{ppm} \times 2 /(25 \times 19)\right)$ and plot vs hours.

\section{E2.4 Measuring Samples with Concentrations Less than 1 ppm}

For samples with concentrations lesser than 1 ppm, use low level TISAB (LL-TISAB) for all measurements

\section{E2.4.1 Suggested Equipment:}

ii. $1-5 \mathrm{ml}$ pipette with pump (for samples)

iii. 2 - $250 \mathrm{~mL}$ beakers ( 1 for measurement and 1 to rinse electrode)

iv. 2 - $50 \mathrm{~mL}$ measuring cylinders ( 1 for DI water and one for LL-TISAB)

v. $1-2000 \mathrm{~mL}$ beaker (for waste)

vi. 2-1000 $\mathrm{mL}$ beakers (1 for DI water and one for LL-TISAB)

vii. 1 - glass pipette with bulb (for LL-TISAB)

viii. 1 - DI water wash bottle

\section{E2.4.2 Procedure:}

i. Measure $5 \mathrm{~mL}$ of sample into measuring cylinder and make up to $50 \mathrm{~mL}$ with DI water

ii. Measure $50 \mathrm{~mL}$ of LL-TISAB and combine both cylinders in a beaker

iii. Rinse electrode, immerse in beaker, leave to equilibrate and record the reading (mV)

iv. Repeat with other samples

Use Calibration Curve to determine the $\mathrm{ppm}$ values for each $\mathrm{mV}$ reading. Input all data into Excel, convert to $\mu$ moles $/\left(\mathrm{cm}^{2} \mathrm{~h}\right.$ ) (equation: $\left.\mathrm{ppm} \times 2 /(25 \times 19)\right)$ and plot vs hours. 


\section{E3 Electrode Cleaning and Storage \\ E3.1 Electrode Cleaning I}

Note. If electrode is not functioning properly, e.g. wrong slope or drifting of values, then it may help to clean the electrode

i. Hold electrode in one hand and use thumb to press cap down, thereby draining the electrode

ii. Rinse and drain with DI water and then refill to just below the hole with Electrode Filling Solution

\section{E3.2 Electrode Cleaning II}

If the above does not help this is known to help:

i. Using a rubber glove or KimWipe rub the electrode for a minute with some ordinary toothpaste (acts as a slight abrasive)

ii. Rinse thoroughly with DI water and soak in DI water for an hour

iii. If desired, refill the filling solution as above

\section{E3.3 Electrode Storage I}

Note. This is for when the electrode will be used within a week

If the electrode will not be in use for a week or less, store the electrode in the lowest concentration standard (i.e. 1 ppm F')

\section{E3.4 Electrode Storage II}

Note. This is for when the electrode will not be used within a week

i. If the electrode will not be used for a longer period of time, drain and rinse the electrode with DI water as described in A1 and leave to dry.

ii. Put cap on electrode and story dry in a safe place. 


\section{Appendix F: Safety Plan}

Contract Number: DE-FC36-06GO16028

Prepared By: Darlene Slattery

Date: June 30, 2006

Modified: May 1, 2007

\section{Approvals}

James R. Fowler, FSEC CHO

James M. Fenton, FSEC Director
Ali T-Raissi, HRD Division Director

James Uhlir , UCF EH\&S Director 
Project Title: Lead Research and Development Activity for DOE's High Temperature, Low Relative Humidity Membrane Program

Contract Number: DE-FC36-06G016028

Prepared By: Darlene Slattery

Date: June 30, 2006

Project Officer: David Peterson

\section{F1 Scope of Work}

Florida Solar Energy Center (FSEC), a research institute of the University of Central Florida, has been designated as the lead organization for DOE's High Temperature, Low Relative Humidity Membrane Program. As such, FSEC's research and development team will prepare and evaluate new polymeric electrolyte phosphotungstic acid composite membranes. Additionally, FSEC will develop standardized experimental methodologies to 1) measure conductivity (in plane and through-plane) 2) characterize mechanical, mass transport, and surface properties of the membranes and 3) predict durability of the membranes and their membrane electrode assemblies.

Work to stabilize and reduce particle size of the phosphotungstic acid that has lead to the highest conductivity membranes and highest performance membrane electrode assemblies, which surpass Nafion, at $100-120^{\circ} \mathrm{C}$ and low relative humidity will continue. Non-Nafion ${ }^{\circ}$ based poly[perfluorosulfonic acids] (PFSAs) of equivalent weight lower than 1100; sulfonated poly(ether ether ketone)s (SPEEKs) with various sulfonation degrees; sulfonated poly(ether ketone ketone) (SPEKK) as the proton-conducting component in a blend with either poly(ether sulfone) (PES) or SPEKK with different sulfonation levels will be fabricated into new composite membranes containing small particle stabilized phosphotungstic acid. This team, working with the fuel cell community, will develop standardized experimental methodologies to 1) measure conductivity as a function of relative humidity and mechanical properties of membranes, 2) characterize mechanical, mass transport, and surface properties of the membranes, and 3) predict durability of the membranes and their membrane electrode assemblies fabricated by the team for both the in-house research program and for membranes provided by the High Temperature, Low Relative Humidity Membrane Working Group (HTMWG) members. FSEC will provide the HTMWG with standardized tests and methodologies and short course education offerings on these test methodologies along with membrane electrode assembly fabrication techniques so that at the end of three years all research program members will be able to perform this work in their own facility. An easily-implemented protocol and rapid test apparatus for evaluating the through-thickness conductivity (or resistance) of membranes over a broad range of conditions will be developed. FSEC will use its experience in developing accredited standardized test methods for the solar thermal, photovoltaic and building energy efficiency industries to support this activity.

This program will be conducted within the Hydrogen R\&D Division at the Florida Solar Energy Center, located in Cocoa, Florida. The facilities within the division include: 
- Hydrogen Lab I- 2,000 square foot chemical lab

- Hydrogen Lab II - 1,800 square foot chemical lab

- Integrated Fuel Cell Test Bed (IFCT) facility - a 900 square foot fuel cell lab

Research activities in these facilities include:

- Alternative fuels

- Fuel cells

- High-pressure, high-temperature reactions

- Hydrogen energy systems

- Hydrogen membrane separation

- Hydrogen production and storage

- Material failure determination

- Material property determination

- Nano synthesis and materials development

- Photo and thermo-catalytic reaction and reactor engineering

- Photocatalytic and photoelectrochemical processes

- Pollutant detoxification

- Sensors and detectors

- Synthesis of metal hydrides and chemical hydrides

- Thermal imaging

The researchers in the Division are scientists and engineers with extensive backgrounds in all aspects of hydrogen research. Nine of the staff researchers have Ph.D.s and three have M.S. degrees. They are assisted by a number of students, which varies for any given semester.

Ultimate responsibility for meeting deliverables will rest with the project PI. However, he has appointed a Project Manager who will be responsible for oversight of the day to day tasks involved in the project. The Project Manager will work closely with the FSEC Chemical Hygiene Officer $(\mathrm{CHO})$ to ensure that all tasks are carried out in a safe and responsible manner.

\section{F2 Identification of Safety Vulnerabilities}

The University of Central Florida has a "Chemical Hygiene Plan" that the Florida Solar Energy Center follows for all programs. Under that plan, the Department of Environmental Health and Safety Chemical Hygiene Officer $(\mathrm{CHO})$ is tasked with reviewing contract proposals to determine the inclusion of hazardous chemicals or procedures. When they are identified, EH\&S consults with the proposal's Principal Investigator (PI) to ascertain the level of risk. It is the responsibility of the $\mathrm{PI}$ to choose the best method for project analysis. FSEC also has its own $\mathrm{CHO}$ who assists the FSEC PI's with chemical hygiene and compliance, and who maintains FSEC's chemical safety documentation.

To fulfill the requirements of this contract, researchers will prepare polymer solutions and modify them by the addition of phosphotungstic acid and/or via sulfonation. Membranes will be cast and tested. Tests will include in-plane and through-plane conductivity, swelling, 
mechanical strength, chemical strength and glass transition temperature. Membranes deemed worthy of additional analysis will be catalyst coated and developed as a membrane electrode assembly, MEA.

Safety vulnerabilities are identified using a "What if" analysis. A process flow chart for the project was developed and each area was reviewed by the research team. Vulnerabilities thus identified include exposure to organic vapors during membrane fabrication; fire resulting from improper preparation or handling of catalysts; hydrogen leakage from a cylinder, regulator, or system; and loss of ventilation because of power failure in facility.

\section{F3 Risk Mitigation Plan}

\section{F3.1 Organic Vapor Exposure}

A number of solvents will be used in the preparation of the membranes. Because of the impact of humidity on the membranes, it was determined that membrane preparation was best carried out in the controlled environment of a glove box. A glove box dedicated to this process along with the appropriate personal protective equipment, PPE, will protect the membranes while ensuring that the scientist is not exposed to the solvents during the casting process.

\section{F3.2 Catalyst Handling}

The finely divided catalysts on support material are known to be flammable when an alcohol is added to the dry material (SOP). A procedure, that includes the addition of water before the alcoholic solvent is added, which has been verified in earlier programs, will be used. Additionally, catalyst spraying will be carried out in a fume hood to limit worker exposure. Organic materials, such as paper toweling, will not be used in the hood where catalysts are being sprayed.

\section{F3.3 Hydrogen Leaks}

Hydrogen leaks will be determined with both a hand held detector for checking systems and with an area detector in the area most prone to the presence of hydrogen. Hydrogen that flows through a fuel cell unreacted will be vented directly to a fume hood. In the event of a facility power failure that would result in a system shutdown, a valve will automatically shutdown the flow of hydrogen to the system. Gas cylinders not currently in use- hydrogen as well as other gases- will be capped and removed to the storage area that is separate from the laboratory. Before every procedure involving the use of hydrogen, the entire system will be checked for leaks using the hand held leak detector.

Maximum amounts of hydrogen to be used have been calculated on the premise that all test stands are simultaneously in use. In such an instance, there would be less than $8 \mathrm{~L} / \mathrm{min}$ of hydrogen flowing. This was determined based upon the following:

\section{Single Cell:}

Assuming

$25 \mathrm{~cm}^{2}$ MEA 
$80^{\circ} \mathrm{C}$ operation

$\mathrm{H}_{2}$ Stoichiometry $=3$

$1.5 \mathrm{~A} / \mathrm{cm}^{2}-\max$

$\mathrm{H}_{2}$ flow=9.01 mL/min@1A x $25 \times 3 \times 1.5=1014 \mathrm{~mL} / \mathrm{min}$

2). Endurance Test Cell $=1014 \mathrm{~mL} / \mathrm{min}-\max$

3). Diagnostic Test Cell $=1014 \mathrm{~mL} / \mathrm{min}-\max$

4). 4-Cell Stack $=4 \times 1014 \mathrm{~mL} / \mathrm{min}=4056 \mathrm{~mL} / \mathrm{min}-\max$

5). Conductivity Test Cell: $500 \mathrm{~mL} / \mathrm{min}$

Add 1) through 5) gives

$=1014+1014+1014+4056+500=7598 \mathrm{~mL} / \mathrm{min}=7.958$ litre $/ \mathrm{min}$

\section{F3.4 Standard Operating Procedures}

Before initiating any activity, a standard operating procedure (SOP) will be identified. If none has been identified for the particular activity, it will be developed in collaboration with the team member most familiar with the process. Once developed, the SOP will be approved by an internal HR\&D Procedures Committee, headed by the Project Manager, before it is put into practice. Any changes to an SOP must be put in writing, with justifications and possible ramifications and approved by the committee. All SOPs will be signed by the developer, dated and, once approved by the Procedures Committee; a copy will be placed at the point of use. Additional copies will be available in the $\mathrm{CHO}$ s office and on $\mathrm{CD}$ in each laboratory.

Current SOPs include:

- Preparation of membrane solutions

- Manufacture of membranes

- Protonation of membranes

- Heat treatment of MEAs

- Membrane leak test

- PEMFC unit cell test

- Catalyst deposition

Additional SOPs currently under development include

- In-plane conductivity test

- Through-plane conductivity test

- Water uptake measurement

- Glass transition temperature determination

In addition to SOPs for individual tests, under the Chemical Hygiene Plan, all researchers in the laboratory are required to wear safety goggles, lab coats and, when handling chemicals, the 
correct gloves. They are also required to wear closed toed shoes and no food or drink is allowed anywhere in the labs.

\section{F3.5 Previous Experience with Hydrogen}

All researchers in the Hydrogen R\&D Division have extensive experience with hydrogen. While the junior members have as few as $3-5$ years of hydrogen related experience, senior members have as much as 30 years of experience. In addition to experience in assembling and testing of fuel cells and fuel cell components, various researchers within the group are experts in cryogenics, hydrogen storage in metal hydrides, chemical hydrides and complex hydrides, hydrogen production via electrolysis, photocatalytic water splitting, and several reformation processes and separation processes using hydrides and membrane materials. As a result of this experience, all are qualified in the safe handling of hydrogen and systems, which use or produce hydrogen.

In the 17 years that FSEC's hydrogen laboratories have existed, only four incidents have occurred, three of which were very minor and none of which resulted in injuries. Only one was directly related to hydrogen and was the result of a failed O-ring in a system. All incidents were thoroughly reviewed, weaknesses identified and procedures modified. Each incident emphasized that safety precautions in place minimized damage to the surroundings.

\section{F3.6 Safety Performance Measurement and Management of Change Reviews}

Checklists have been developed and will be used to record accomplishment of the steps in a procedure. These checklists will be filed in binders kept at the location of each activity. Periodic monitoring of the checklists will be conducted by the project manager to ensure that procedures are being followed.

The FSEC CHO will make monthly laboratory inspections to determine the presence of any hazard. Identified hazards will be corrected in cooperation with the project PI, the researcher and the $\mathrm{CHO}$ and any necessary changes to procedures will be made. To minimize repeat hazards, remedial training in safe practices will be provided, if necessary.

A checklist of the inspection will be made and filed in a binder in the CHO's office. The checklists will be reviewed periodically to determine the need to make procedure changes to eliminate repeat hazards.

Before changes are made to any equipment or procedures and before any new activities are initiated, a review will be conducted with the researcher(s) involved, the project manager, the $\mathrm{CHO}$ and others as deemed necessary by the project manager.

\section{F3.7 Employee Training}

The University of Central Florida's Environmental Health and Safety Department, EH\&S, requires all laboratory personnel to take a Chemical Safety and Environmental Management course. This course is given at the beginning of each term on the main campus of the university or can be requested at anytime for groups. In addition to the initial course for new employees, all employees are required to take a refresher course yearly. 
In addition to the EH\&S provided training, training videos on a variety of subjects have been obtained and made available to all employees. New employees are required to view the videos and complete the corresponding worksheet, which is filed by the $\mathrm{CHO}$. Topics of these videos include general lab practices such as the use of glassware and balances, and a general safety video that includes use of fire extinguishers and handling of gas cylinders.

The topics of this course include basic lab practices, chemical hygiene, waste management, and fire safety. More specific training is provided by EH\&S for other areas such as Radiation safety and Biohazard Safety. The $\mathrm{CHO}$ or the individual researcher is responsible for training on specific instruments or any specialized apparatus or equipment in the laboratory. The FSEC $\mathrm{CHO}$ and the PI train new personnel on the safe handling of hydrogen and other flammables to be used for a project. Training includes proper handling of gas cylinders, leak checking, proper venting and purging of systems and materials compatibility. Refresher training requirements are determined by the $\mathrm{CHO}$ or $\mathrm{PI}$ based upon employee performance. The $\mathrm{CHO}$ maintains electronic and hard copies of the training history of all laboratory personnel as part of the Chemical Hygiene Plan.

\section{F3.8 Equipment Integrity}

Much of the testing of the membranes will be accomplished using 850C Compact Test Stations from Scribner Associates. These test stations feature automatic shutdown and $\mathrm{N}_{2}$ purge with under voltage, over current, over temperature, loss of supply pressures, low water, communications failure or external alarm. Additionally, there is a manual switch for emergency shutdown. The test stands were installed and qualified by Scribner Associates. Routine inspection of these units will be carried out by the researchers who will be using them. Any maintenance of the units will be done in consultation with Scribner Associates.

New equipment or systems that are installed will be reviewed by the $\mathrm{CHO}$ and Project Manager before being certified for usage. To be certified, a "What if" analysis will be conducted and any safety vulnerabilities identified and procedures developed to mitigate the vulnerabilities.

Routine maintenance of the laboratory safety equipment is conducted by the lab manager/CHO. Eye wash stations and showers are tested monthly and results recorded. The face velocity of fume hoods is verified semi-annually by UCF EH\&S personnel and results indicated on each hood. Fire extinguishers are checked periodically by the State Fire Marshall, while sprinkler systems and fire alarms are checked by FSEC Operations personnel.

\section{F3.9 Maintenance of Safety Documentation}

The Chemical Hygiene Plan in maintained by the FSEC CHO and a copy is available to staff in his office, which is located within Hydrogen Lab I. It is additionally available online via the University EH\&S website. See the reference section for details. 
Material Safety Data Sheets, MSDS, are filed in a set of binders and are available for all substances currently in the inventory or used previously within the labs. The $\mathrm{CHO}$ is responsible for obtaining and filing the MSDS and they are continuously available in his office. Additionally, MSDS may be accessed from a general use computer in the laboratory.

\section{F4 Communication Plan}

\section{F4.1 Emergency Response Plan}

UCF has an Emergency Management Plan, available on the web at http://www.ehs.ucf.edu/Emergency/EMP\%202006-2007.pdf. This plan outlines the procedure for minor emergencies, such as a spill of less than $4 \mathrm{~L}$ of a chemical that is not acutely hazardous or an unknown. In this Plan, employees are advised to notify the laboratory manager or the principal investigator, $\mathrm{PI}$, and use the available spill kits to clean up under the supervision of the PI.

In the event of a major emergency, such as a fire, explosion or a spill of more than $4 \mathrm{~L}$ or one that involves a chemical that is acutely hazardous, FSEC personnel have been instructed to leave the lab and dial 911 immediately from a safe location. In addition, Brevard County (where FSEC is located) has a Special Response Team for hazardous materials that is available 24/7 and is trained to deal with chemical spills or other incidents. Their number is posted by laboratory telephones but they may also be summoned by requests to 911 .

Each laboratory has posted on the door a list of phone numbers of individuals to call in the event of an incident within that laboratory. Non-emergency issues are reported to these contact individuals. Laboratories have spill kits, fire extinguishers, fire alarms, safety showers and eye wash stations. Most FSEC labs also have glass view panels in the walls for quick visual assessment of physical conditions in the lab.

\section{F4.2 Incident Reporting and Lessons Learned}

All incidents are reported to the individual supervisor and FSEC's laboratory manager/CHO. Incidents that result in damage or injury must be written up for submission to the Environmental Health and Safety Department on the main campus. If damage or injury has occurred, the incident is presented to and is discussed at the next FSEC Executive Committee Meeting and a decision is made on further action.

At a minimum, the individual involved and his/her supervisor reviews the activities leading up to the incident, determines a probable cause and modifies procedures and/or the set-up in order to avoid a recurrence

As required in Section 4.3 of the Communications Plan of the DOE "Guidance for Safety Aspects of Proposed Hydrogen Projects," all incidents and near-misses must be reported to DOE. 


\section{F5 Sample Handling and Transport}

The materials that are expected to be transported will be membranes fabricated by other members of the HTMWG and shipped to us for testing. These are not considered hazardous materials and, therefore, their transport is not an issue.

UCF and FSEC have procedures for shipping materials that are considered hazardous. A member of the EH\&S Department is qualified to package such materials for shipment. When the need arises for such shipments, packing materials that meet DOT guidelines are obtained and the EH\&S employee comes to FSEC and prepares the package.

\section{F6 References}

UCF Environmental Health \& Safety Chemical Safety Information, CHP

Emergency Information, UCF

City of Cocoa, Florida (Police \& Fire)

Brevard County, Florida (Hazmat) www.ehs.ucf.edu

www.ehs.ucf.edu/chemical/main.html www.ehs.ucf.edu/emergency/main.html www.cocoafl.org/City\%20Services/ www.brevardcounty.us/fire rescue/ 


\section{Appendix G Facilities and Instrumentation}

Facilities exist at FSEC and the University of Central Florida's Material Characterization Facility Advanced Materials Processing and Analysis Center to allow complete fabrication and characterization of membranes and membrane electrode assemblies.

\section{G1 Membrane Fabrication}

i. Controlled temperature and humidity fabrication stations containing several levelling tables

ii. Oven equipped with a vacuum (Isotemp Vacuum Oven Model 281A)

iii. Balances

\section{G2 Membrane Electrode Assembly Fabrication}

i. Ultrasonic blender (Fisher ${ }^{\circledR}$ Scientific Gen 1000 Homogenizer)

ii. X-Z Spray system

iii. Screen-printing Machine

iv. Hot press (Carver Accustamp)

v. Oven (Fisher Scientific Isotemp Oven)

\section{G3 Electrochemical Characterization}

i. 4 test stations (Scribner Associates Fuel Cell Test Systems $850 \mathrm{C}$ (3) and 890 (1)), with MEADS coming soon (Scribner Associates 8 cell test station)

ii. $\quad 3$ Potentiostats (Princeton Applied Research 263A (2) and 273 (1))

\section{G4 Materials Characterization}

i. X-Ray Diffraction

ii. Transmission Electron Microscopy

iii. Scanning Electron Microscopy (with Energy Dispersive X-ray Analysis)

iv. X-Ray Photoelectric Spectroscopy

v. Auger Spectroscopy

vi. Differential Scanning Calorimetry

vii. Thermal Gravimetric Analysis

viii. Fourier Transform Infrared Spectroscopy with Attenuated Total Reflectance

ix. Mechanical Tensile Strength Testing

x. Fluoride Ion Electrode Analysis

xi. Ion Chromatography

xii. Gas Chromatography with Mass Spectrometry 